\title{
Feeding and extinguishing the flame
}

Citation for published version (APA):

van Teffelen, M. W. (2021). Feeding and extinguishing the flame: the nature, provocation, and treatment of transdiagnostic hostility. [Doctoral Thesis, Maastricht University]. Ridderprint. https://doi.org/10.26481/dis.20210312mt

Document status and date:

Published: 01/01/2021

DOI:

10.26481/dis.20210312mt

Document Version:

Publisher's PDF, also known as Version of record

\section{Please check the document version of this publication:}

- A submitted manuscript is the version of the article upon submission and before peer-review. There can be important differences between the submitted version and the official published version of record.

People interested in the research are advised to contact the author for the final version of the publication, or visit the DOI to the publisher's website.

- The final author version and the galley proof are versions of the publication after peer review.

- The final published version features the final layout of the paper including the volume, issue and page numbers.

Link to publication

\footnotetext{
General rights rights.

- You may freely distribute the URL identifying the publication in the public portal. please follow below link for the End User Agreement:

www.umlib.nl/taverne-license

Take down policy

If you believe that this document breaches copyright please contact us at:

repository@maastrichtuniversity.nl

providing details and we will investigate your claim.
}

Copyright and moral rights for the publications made accessible in the public portal are retained by the authors and/or other copyright owners and it is a condition of accessing publications that users recognise and abide by the legal requirements associated with these

- Users may download and print one copy of any publication from the public portal for the purpose of private study or research.

- You may not further distribute the material or use it for any profit-making activity or commercial gain

If the publication is distributed under the terms of Article $25 \mathrm{fa}$ of the Dutch Copyright Act, indicated by the "Taverne" license above, 


\section{Feeding and Extinguishing the Flame}

The Nature, Provocation, and Treatment

of Transdiagnostic Hostility

Martijn van Teffelen 
Dit proefschrift is mede mogelijk gemaakt door:

\section{met ggz}

de kortste lijn naar herstel

\section{Mondriaan}
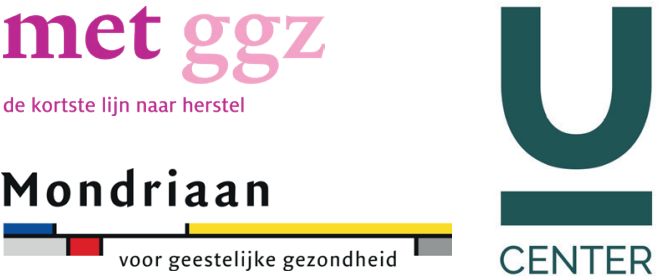

CENTER

Cover design \& layout: (c) evelienjagtman.com

Printing: Ridderprint I www.ridderprint.n|

Copyright: Martijn van Teffelen, Maastricht 2020

\section{ISBN 978-94-6416-426-8}




\title{
Feeding and Extinguishing the Flame
}

The Nature, Provocation, and Treatment

of Transdiagnostic Hostility

\author{
PROEFSCHRIFT \\ ter verkrijging van de graad van doctor aan de Universiteit Maastricht, \\ op gezag van de Rector Magnificus, Prof. dr. Rianne M. Letschert \\ volgens het besluit van het College van Decanen, \\ in het openbaar te verdedigen op \\ 12 maart 2021 om 14:00 uur
}

door

Martijn Willem van Teffelen 


\section{Promotores}

Prof. Dr. F.P.M.L. Peeters

Dr. J. Lobbestael

\section{Co-promotor}

Dr. M.J. Voncken

\section{Beoordelingscommissie}

Prof. Dr. P.E.H.M. Muris (voorzitter)

Prof. Dr. M.M. Rijkeboer

Prof. Dr. H.P. Otgaar

Prof. Dr. B.J. Bushman (Ohio State University, Columbus, Ohio, USA)

Dr. E. Salemink (Universiteit Utrecht) 
Voor Noor

"If you have good thoughts they will shine out of your face like sunbeams and you will always look lovely."

Roald Dahl 



\section{TABLE OF CONTENTS}

Chapter 1 General Introduction 9

Chapter 2 Uncovering the Hierarchical Structure of Self-Reported Hostility

Chapter 3 Provoked Aggression, Psychopathy and Narcissism: Comparing the Impact of Social Exclusion and Insult

Chapter 4 The efficacy of incorporating mental imagery in cognitive restructuring techniques on reducing hostility:

A randomized controlled trial

Chapter 5 Imagery-Enhanced Cognitive Restructuring of Hostile Beliefs: A Narrative Description

Chapter 6 Interpretation Bias Modification Reduces Hostile Bias and Aggression: A Randomized Clinical Trial

Chapter 7 General Discussion

Chapter 8 Summary/Samenvatting

Chapter 9 Scientific and Societal Impact

Appendix Curriculum Vitae 



\section{CHAPTER 1}

General Introduction 



\section{HOSTILITY: AN EXPLOSIVE MATTER}

Many, if not all human beings experience hostile thoughts, angry feelings and yell or curse at some point in their lives. Several may even physically hurt another person. In psychology, human antagonistic behavior and its' related cognitive-affective experiences are often referred to as hostility. Possessing some degree of hostility can be considered healthy. From an evolutionary standpoint it can be argued that the chances of surviving a physical threat (e.g., being attack by a wild animal) increase when the intentions of someone or something in the outside world are correctly identified as threatening. Motivating oneself to behave aggressively in response (e.g., by shouting or launching a physical attack) may scare off or neutralize a threat. Correctly identifying the potential wrongdoing of others and reacting with an angry response may prevent harm. However, hostility becomes more problematic, when a person becomes angry with the wrong person, to the wrong degree, at the wrong time, for the wrong purpose, and in the wrong way. A tragic example of problematic hostility is the case of Shahid B., in the media portrayed as the 'wedding procession whacker' ("Cel en behandeling voor Rotterdamse 'trouwstoetmepper'," 2020). At the age of 26 Shahid B. took part in a wedding procession of his brother. When a police officer stopped the wedding procession due to nuisance, Shahid B. got out of his car and physically assaulted the police officer, who entered unconsciousness for a short period. Shahid B. declared that it was not his intention to act violently. He said: "But that is who I am. I cannot help it. I become too angry. I wanted to stop the situation because my brother-in-law did not do anything wrong. I am sorry about this."

\section{DEFINITION OF HOSTILITY}

In psychological research, hostility is defined as a personality dimension consisting of a tendency to hold a hostile attitudinal style, experience angry affect and behave aggressively (American Psychiatric Association, 2013; Barefoot, 1992; Chaplin, 1982). Profound consequences of hostility are increased risk of interpersonal violence (Henrichs et al., 2014), heart disease (Smith, 1992), increased psychopathological severity (Cassiello-Robbins \& Barlow, 2016), treatment discontinuation (Arntz et al., 2015) and suicidality (Ammerman et al., 2015). Clear prevalence estimates in patients are currently missing. However, one cohort study in $N=$ 3800 psychopathology outpatients indicated that $43.60 \%(n=1657)$ reported moderate to severe anger and $21.20 \%(n=806)$ reported moderate to severe aggressive behavior in the preceding week (Genovese et al., 2017).

Problematic hostility is often a primary reason for people to seek help (Lachmund et al., 2005). Traditional classification instruments, however, do not describe a 'hostility disorder'. The DSM-V (American Psychiatric Association, 2013) for example, captures (aspects of) hostility as 
a symptom, rather than a distinct clinical syndrome. That is, aspects of hostility are included in the definitions of intermittent explosive disorder, posttraumatic stress disorder, borderline personality disorder, paranoid personality disorder, antisocial personality disorder, disruptive mood dysregulation disorder and bipolar disorder. In addition, hostility has been positively associated with many other disorders such as major depressive disorder (Judd et al., 2013), panic disorder (Fracalanza et al., 2014) and generalized anxiety disorder (Deschênes et al., 2012). In line with this, several authors propose that hostility should rather be considered a transdiagnostic construct, or, in other words, a construct that cuts across existing categorical psychiatric classifications (Cassiello-Robbins \& Barlow, 2016; Fernandez \& Johnson, 2016; Vidal-Ribas et al., 2016).

\section{DIMENSIONS OF HOSTILITY}

Perhaps the lack of a 'hostility disorder' reflects the lack of consensus on the definition of hostility throughout the years. The field is therefore not short of jingle (i.e., using the same term for different constructs) and jangle (i.e., using different terms for the same construct) fallacies. Bandura (p. 2, 1973) even referred to it as a "semantic jungle". To clearly define hostility roughly two theoretical perspectives have been put forward. First, the unidimensional perspective conceptualizes hostility as one construct that includes the interrelated elements of cynical beliefs about others and the world, hostile attribution bias (i.e., the tendency to interpret emotionally ambiguous scenarios as hostile), angry emotional states, and aggressive behavior (American Psychiatric Association, 2013; Barefoot, 1992; Chaplin, 1982). Second, the multidimensional perspective conceptualizes hostility in terms of a domain consisting of two or more lower-level facets (Buss, 1961; Smith, 1992; Spielberger et al., 1985). Empirical evidence generally supports the multidimensional perspective. That is, factor analytic studies have reported the presence of two (e.g., expression and experience) to four (e.g., cognitive, affective, physical-behavioral, and verbal-behavioral) factors (Buss \& Durkee, 1957; Buss \& Perry, 1992; Fuqua et al., 1991; Kopper \& Epperson, 1996; Maier et al., 2009; Martin et al., 2000; Musante et al., 1989; Riley \& Treiber, 1989). It seems however, that there is little consensus on the 'optimal' factor structure of the hostility construct.

\section{FEEDING THE FLAME: PROVOKING HOSTILITY}

Wielding the best possible working definition of hostility at hand, scholars have invested a vast number of resources in developing and testing ways to provoke hostility. Understanding the situational factors that provoke hostility is of vital importance to ultimately reduce it. Provocations that reliably predict aggression (i.e., hostile behavior) are, for instance, electric 
shocks (Taylor, 1967), aversive noise blasts (Bushman, 1995) and social exclusion (Twenge et al., 2001). However, knowledge is still limited on potential differences between diverse provocation techniques in eliciting aggression and other outcome measures, as different provocation techniques have not been directly compared to each other.

Moreover, empirical evidence suggests that (among others) two specific personality traits might differentially impact the provocation-aggression relationship: psychopathy and narcissism. On the one hand, psychopathy is characterized by affective deficiency. Studies generally find two psychopathy factors (Harpur et al., 1989); one factor representing a personality dimension (i.e., egocentricity, lack of empathy, lack of guilt and impaired affective processing), and the other factor representing a behavioral dimension (i.e., unstable, and antisocial lifestyle or social deviance). Findings on the psychopathy-provoked aggression relationship indicate that affective deficits in people with psychopathic traits may 'dampen', or negatively mediate the provocation-aggression relationship (Reidy et al., 2011). On the other hand, narcissistic people tend to harbor a cognitive-affective preoccupation with the self, including grandiose self-expectations, superiority, and entitlement (Emmons, 1987; Raskin \& Hall, 1979). Findings on the narcissism-provoked aggression relationship indicate that narcissistic traits attenuate, or positively mediate the provocation-aggression relationship.

\section{EXTINGUISHING THE FLAME: REDUCING HOSTILITY}

To reduce hostility, clinicians have several psychological interventions at their disposal. In the literature, most of these interventions are offered as part of some larger cognitive behavioral therapy (CBT) package. CBT interventions that have shown to successfully reduce hostility include psychoeducation, behavioral skills training, relaxation exercises, exposure, and cognitive restructuring (CR) (DiGuiseppe \& Tafrate, 2003). A meta-analytic review of metaanalyses revealed that CBT programs for hostility show a response rate of $66 \%$. This indicates that $66 \%$ of people receiving CBT report a symptom reduction of $50 \%$ or more (Hofmann et al., 2012). However, treatment effects appear less pronounced compared to those of other psychopathologies (e.g., depression, panic disorder, body dysmorphic disorder) and treatment discontinuation is significant (Arntz et al., 2015; Cassiello-Robbins et al., 2015; Putt et al., 2001). Moreover, patients with increased levels of hostility are often described by therapists as 'challenging' (von der Lippe et al., 2008), and a significant number of patients (34\%) do not profit from treatment (Hofmann et al., 2012). Furthermore, few high-quality treatment effects studies on hostility have been conducted (Del Vecchio \& O'Leary, 2004). This leaves room for improvement. 
A promising target for improving the treatability of hostility is hostile interpretation bias (HIB). $\mathrm{HIB}$ is the tendency to interpret emotionally ambiguous stimuli in a hostile way. For example, consider a person waiting in line with his hands full of groceries. Suddenly, another person bumps into him, making him drop his groceries on the floor. The person who dropped his groceries might interpret the situation in a hostile (e.g., 'the other person did it to provoke me') or in a benign (e.g., 'the other person didn't see me') way. A person with high levels of hostile interpretation bias is more likely to interpret the situation in a hostile way. Cognitive models of hostility state that HIB plays a central role in hostility (Allen et al., 2018; Crick \& Dodge, 1994; Wilkowski \& Robinson, 2008). Evidence shows that HIB increases the likelihood to experience anger and behave aggressively (Crick \& Dodge, 1994; Epps \& Kendall, 1995). Indeed, evidence reveals that interventions that target $\mathrm{HIB}$, such as $\mathrm{CR}$, show favorable outcomes in terms of hostility (DiGuiseppe \& Tafrate, 2003). The current literature suggests that the effectiveness may be enhanced in two ways; first, by optimizing effects of therapist-provided CR, and second, by implementing computerized Cognitive Bias Modification for hostile interpretation.

\section{Optimization of Therapist-Provided CR}

One intervention targeting hostility that could potentially be enhanced is CR. Within CR patients are encouraged to identify and challenge hostile cognitions in past events that triggered anger and/or aggression, for example by gathering evidence for and against a hostile cognition. Findings suggest that enriching $\mathrm{CR}$ with mental imagery is a promising candidate for increasing its efficacy in reducing hostility. For example, two studies with social anxiety disorder patients show that incorporating mental imagery during CR led to greater symptom reduction compared to traditional CR (e.g., McEvoy et al., 2015; McEvoy \& Saulsman, 2014). Additionally, integrating the use of mental imagery into existing treatment protocols for (childhood) trauma increased the effectiveness of several other interventions such as imaginary exposure and imagery rescripting (Arntz \& Weertman, 1999; Ehlers et al., 2005; Smucker et al., 1995).

\section{Implementation of Computerized CBM-I}

Another potential way of reducing hostility is offered by cognitive bias modification for interpretation bias (CBM-I). CBM-I is a computerized procedure that targets HIB by offering patients many (unfamiliar) emotionally ambiguous scenarios on a computer followed by a reinforcement of benign instead of hostile interpretations (Mathews \& Mackintosh, 2000). Meta-analytic evidence demonstrated favorable, moderate to large efficacy of CBM-I on anxiety- and depression-related biases (Hallion \& Ruscio, 2011). Five additional studies demonstrated preliminary support for the efficacy of CBM-I on HIB, with moderate to large degrees (AIMoghrabi et al., 2018; Cougle et al., 2017; Hawkins \& Cougle, 2013; Smith et al., 2018; Vassilopoulos et al., 2014). Moreover, recent evidence suggests that CBM-I may additionally augment the effectiveness of existing therapy protocols in affective disorders (Beard et al., 2019; Butler et al., 2015). 


\section{PURPOSE AND OUTLINE OF THE DISSERTATION}

This dissertation is focused on the examination of the validity of hostility and how to manipulate it. There are three main goals. First, we aimed to investigate the dimensional structure of hostility. Second, we compared laboratory methods that provoke hostility and studied how they interact with the personality traits of psychopathy and narcissism. Third, we attempted to develop new ways to advance treatment options for hostility. With this dissertation we hope to contribute to a better understanding of the hostility construct, and of the differential effects of laboratory provocation methods, and advance treatment options for hostility.

In chapter 2 we examine the dimensions of hostility. More specifically, we examine the hierarchical structure of hostility in a mixed community and highly hostile sample. This is relevant because previous work shows differences in number and content of structural solutions. The main expectation is that a multidimensional hierarchical structure will be uncovered.

Chapter $\mathbf{3}$ focuses on the head-to-head comparison of two laboratory provocation procedures in a male community sample: social exclusion and insult. This is relevant because previous work neglected the differential impact of provocation methods on hostility and their relationship with psychopathic and narcissistic personality traits. We expect that social exclusion and insult were comparable in terms of perceived threat, negative affective change, and aggressive behavior. We also expect that the relationship between psychopathic traits and provoked aggressive responding will be dampened by reduced affective responding. We furthermore hypothesize that narcissistic traits are positively associated with perceived threat, especially after being insult. In turn, we hypothesize that narcissistic traits are positively associated with aggressive responding (i.e., moderated mediation).

New ways to enhance treatment options for hostility are presented in chapter $\mathbf{4}, \mathbf{5}$, and $\mathbf{6}$. In chapter $\mathbf{4}$ we aim to compare the efficacy of one session 'imagery-enhanced CR' (I-CR) for hostility with traditional $\mathrm{CR}$ and an active control $(\mathrm{AC})$ condition at pre- and post-intervention and at one-week follow-up in a sample with increased hostility levels. We hypothesize that $\mathrm{I}-\mathrm{CR}$ is more efficacious than traditional $\mathrm{CR}$ in primarily reducing the believability of hostile cognitions and secondarily reducing aggressive inclinations, state anger and hostility traits, while both interventions are expected to be more efficacious on these variables than an active control condition. These hypothesized condition differences are expected to be maintained when participants are 'provoked' by imaginarily re-exposing them to an idiosyncratic angerprovoking situation at one-week follow-up. Chapter $\mathbf{5}$ provides a narrative description of the I-CR intervention, including case examples to stimulate implementation of this technique in clinical practice. 
In chapter $\mathbf{6}$ we develop and compare the efficacy of an eight-session CBM-I intervention to an active control condition in two studies. The first study serves as a pilot trial to establish the basic working mechanism of CBM-I (i.e., whether our intervention alters biases in the desired direction) followed by a larger trial in people with clinical levels of hostility where the additional impact on hostility outcomes is assessed. It is expected that CBM-I results in a greater increase in benign interpretations and a greater reduction in HIB compared to active control training (AC). It is also expected that CBM-I leads to greater reductions in hostility, including aggressive behavior. Moreover, we pioneer to explore the carry-over effects of CBM-I on subsequent psychotherapy and expect increased quality of working alliance with participant's therapists.

Finally, chapter $\mathbf{7}$ presents an overview and integrative discussion of the performed studies in this thesis, including research and clinical implications, general limitations, and recommendations for future research. 


\section{REFERENCES}

Allen, J. J., Anderson, C. A., \& Bushman, B. J. (2018). The General Aggression Model. Current Opinion in Psychology, 19, 75-80. https://doi.org/10.1016/j.copsyc.2017.03.034

AlMoghrabi, N., Huijding, J., \& Franken, I. H. A. (2018). The effects of a novel hostile interpretation bias modification paradigm on hostile interpretations, mood, and aggressive behavior. Journal of Behavior Therapy and Experimental Psychiatry, 58, 36-42. https://doi.org/10.1016/j.jbtep.2017.08.003

American Psychiatric Association. (2013). Diagnostic and Statistical Manual of Mental Disorders (5th ed.).

Ammerman, B. A., Kleiman, E. M., Uyeji, L. L., Knorr, A. C., \& McCloskey, M. S. (2015). Suicidal and violent behavior: The role of anger, emotion dysregulation, and impulsivity. Personality and Individual Differences, 79, 57-62. https://doi.org/10.1016/j.paid.2015.01.044

Arntz, A., Stupar-Rutenfrans, S., Bloo, J., van Dyck, R., \& Spinhoven, P. (2015). Prediction of treatment discontinuation and recovery from Borderline Personality Disorder: Results from an RCT comparing Schema Therapy and Transference Focused Psychotherapy. Behaviour Research and Therapy, 74, 60-71. https://doi.org/10.1016/j.brat.2015.09.002

Arntz, A., \& Weertman, A. (1999). Treatment of childhood memories: theory and practice. Behaviour Research and Therapy, 37(8), 715-740. https://doi.org/10.1016/S0005-7967(98)00173-9

Bandura, A. (1973). Aggression: A social learning analysis. In (pp. 2). prentice-hall.

Barefoot, J. C. (1992). Developments in the measurement of hostility. In H. S. Friedman (Ed.), Hostility, coping, \& health. (pp. 13-31). American Psychological Association. https://doi.org/10.1037/10105-001

Beard, C., Rifkin, L. S., Silverman, A. L., \& Björgvinsson, T. (2019). Translating CBM-I into real-world settings: Augmenting a CBT-based psychiatric hospital program. Behavior Therapy, 50(3), 515-530. https:// doi.org/10.1016/j.beth.2018.09.002

Bushman, B. J. (1995). Moderating role of trait aggressiveness in the effects of violent media on aggression. Journal of Personality and Social Psychology, 69(5), 950.

Buss, A. H. (1961). The psychology of aggression. John Wiley \& Sons Inc. https://doi.org/10.1037/11160-000

Buss, A. H., \& Durkee, A. (1957). An inventory for assessing different kinds of hostility. Journal of Consulting Psychology, 21(4), 343-349. https://doi.org/10.1037/h0046900

Buss, A. H., \& Perry, M. (1992). The aggression questionnaire. Journal of Personality and Social Psychology, 63(3), 452-459. https://doi.org/10.1037/0022-3514.63.3.452

Butler, E., Mobini, S., Rapee, R. M., Mackintosh, B., \& Reynolds, S. A. (2015). Enhanced effects of combined cognitive bias modification and computerised cognitive behaviour therapy on social anxiety. Cogent Psychology, 2(1). https://doi.org/10.1080/23311908.2015.1011905

Cassiello-Robbins, C., Conklin, L. R., Anakwenze, U., Gorman, J. M., Woods, S. W., Shear, M. K., \& Barlow, D. H. (2015). The effects of aggression on symptom severity and treatment response in a trial of cognitive behavioral therapy for panic disorder. Comprehensive Psychiatry, 60, 1-8. https://doi. org/10.1016/j.comppsych.2015.04.012

Cassiello-Robbins, C., \& Barlow, D. H. (2016). Anger: The unrecognized emotion in emotional disorders. Clinical Psychology: Science and Practice, 23(1), 66-85. https://doi.org/10.1111/cpsp.12139

Cel en behandeling voor Rotterdamse 'trouwstoetmepper'. (2020). [https://www.rijnmond.nl/nieuws/197110/

Cel-en-behandeling-voor-Rotterdamse-trouwstoetmepper]. Rijnmond.nl.

Chaplin, J. P. (1982). Dictionary of psychology. Laurel. 
Cougle, J. R., Summers, B. J., Allan, N. P., Dillon, K. H., Smith, H. L., Okey, S. A., \& Harvey, A. M. (2017). Hostile interpretation training for individuals with alcohol use disorder and elevated trait anger: A controlled trial of a web-based intervention. Behaviour Research and Therapy, 99, 57-66. https:// doi.org/10.1016/j.brat.2017.09.004

Crick, N. R., \& Dodge, K. A. (1994). A review and reformulation of social information-processing mechanisms in children's social adjustment. Psychological Bulletin, 115(1), 74-101. https://doi.org/10.1037/00332909.115.1.74

Del Vecchio, T., \& O'Leary, K. D. (2004). Effectiveness of anger treatments for specific anger problems: A meta-analytic review. Clinical Psychology Review, 24(1), 15-34. https://doi.org/10.1016/j.cpr.2003.09.006

Deschênes, S. S., Dugas, M. J., Fracalanza, K., \& Koerner, N. (2012). The Role of Anger in Generalized Anxiety Disorder. Cognitive Behaviour Therapy, 41(3), 261-271. https://doi.org/10.1080/16506073.20 12.666564

DiGuiseppe, R., \& Tafrate, R. C. (2003). Anger treatment for adults: A meta-analytic review. Clinical Psychology: Science and Practice, 10(1), 70-84. https://doi.org/10.1093/clipsy/10.1.70

Ehlers, A., Clark, D. M., Hackmann, A., McManus, F., \& Fennell, M. (2005). Cognitive therapy for posttraumatic stress disorder: development and evaluation. Behaviour Research and Therapy, 43(4), 413-431. https://doi.org/10.1016/j.brat.2004.03.006

Emmons, R. A. (1987). Narcissism: Theory and measurement. Journal of Personality and Social Psychology, 52(1), 11-17.

Epps, J., \& Kendall, P. C. (1995). Hostile attributional bias in adults. Cognitive Therapy and Research, 19(2), 159-178. https://doi.org/10.1007/BF02229692

Fernandez, E., \& Johnson, S. L. (2016). Anger in psychological disorders: Prevalence, presentation, etiology and prognostic implications. Clinical Psychology Review, 46, 124-135. https://doi.org/10.1016/j. cpr.2016.04.012

Fracalanza, K., Koerner, N., Deschenes, S. S., \& Dugas, M. J. (2014). Intolerance of uncertainty mediates the relation between generalized anxiety disorder symptoms and anger. Cognitive Behaviour Therapy, 43(2), 122-132. https://doi.org/10.1080/16506073.2014.888754

Fuqua, D. R., Leonard, E., Masters, M. A., Smith, R. J., Campbell, J. L., \& Fischer, P. C. (1991). A structural analysis of the State-Trait Anger Expression Inventory. Educational and Psychological Measurement, 51(2), 439-446. https://doi.org/10.1177/0013164491512018

Genovese, T., Dalrymple, K., Chelminski, I., \& Zimmerman, M. (2017). Subjective anger and overt aggression in psychiatric outpatients. Comprehensive Psychiatry, 73, 23-30. https://doi.org/10.1016/j. comppsych.2016.10.008

Hallion, L. S., \& Ruscio, A. M. (2011). A meta-analysis of the effect of cognitive bias modification on anxiety and depression. Psychological Bulletin, 137(6), 940-958. https://doi.org/10.1037/a0024355

Harpur, T. J., Hare, R. D., \& Hakstian, A. R. (1989). Two-factor conceptualization of psychopathy: Construct validity and assessment implications. Psychological Assessment: A Journal of Consulting and Clinical Psychology, 1(1), 6-17. https://doi.org/10.1037/1040-3590.1.1.6

Hawkins, K. A., \& Cougle, J. R. (2013). Effects of interpretation training on hostile attribution bias and reactivity to interpersonal insult. Behavior Therapy, 44(3), 479-488. https://doi.org/10.1016/j.beth.2013.04.005

Henrichs, J., Bogaerts, S., Sijtsema, J., \& Klerx-van Mierlo, F. (2014). Intimate Partner Violence Perpetrators in a Forensic Psychiatric Outpatient Setting: Criminal History, Psychopathology, and Victimization. J Interpers Violence. https://doi.org/10.1177/0886260514552272

Hofmann, S. G., Asnaani, A., Vonk, I. J. J., Sawyer, A. T., \& Fang, A. (2012). The efficacy of cognitive behavioral therapy: A review of meta-analyses. Cognitive Therapy and Research, 36(5), 427-440. https://doi.org/10.1007/s10608-012-9476-1 
Judd, L. L., Schettler, P. J., Coryell, W., Akiskal, H. S., \& Fiedorowicz, J. G. (2013). Overt irritability/anger in unipolar major depressive episodes: past and current characteristics and implications for long-term course. JAMA Psychiatry, 70(11), 1171-1180. https://doi.org/10.1001/jamapsychiatry.2013.1957

Kopper, B. A., \& Epperson, D. L. (1996). The experience and expression of anger: Relationships with gender, gender role socialization, depression, and mental health functioning. Journal of Counseling Psychology, 43(2), 158-165. https://doi.org/10.1037/0022-0167.43.2.158

Lachmund, E., DiGiuseppe, R., \& Fuller, J. R. (2005). Clinicians' diagnosis of a case with anger problems. Journal of Psychiatric Research, 39(4), 439-447. https://doi.org/10.1016/j.jpsychires.2004.10.009

Maier, K. J., Goble, L. A., Neumann, S. A., Giggey, P. P., Suarez, E. C., \& Waldstein, S. R. (2009). Dimensions across measures of dispositional hostility, expressive style, and depression show some variation by race/ethnicity and gender in young adults. Journal of Social and Clinical Psychology, 28(10), 11991225. https://doi.org/10.1521/jscp.2009.28.10.1199

Martin, R., Watson, D., \& Wan, C. K. (2000). A three-factor model of trait anger: Dimensions of affect, behavior, and cognition. Journal of Personality, 68(5), 869-897. https://doi.org/10.1111/1467-6494.00119

Mathews, A., \& Mackintosh, B. (2000). Induced emotional interpretation bias and anxiety. Journal of Abnormal Psychology, 109(4), 602-615. https://doi.org/10.1037/0021-843X.109.4.602

McEvoy, P. M., Erceg-Hurn, D. M., Saulsman, L. M., \& Thibodeau, M. A. (2015). Imagery enhancements increase the effectiveness of cognitive behavioural group therapy for social anxiety disorder: A benchmarking study. Behaviour Research and Therapy, 65, 42-51. https://doi.org/10.1016/j. brat.2014.12.011

McEvoy, P. M., \& Saulsman, L. M. (2014). Imagery-enhanced cognitive behavioural group therapy for social anxiety disorder: A pilot study. Behaviour Research and Therapy, 55, 1-6. https://doi.org/10.1016/j. brat.2014.01.006

Musante, L., MacDougall, J. M., Dembroski, T. M., \& Costa, P. T. (1989). Potential hostility and dimensions of anger. Health Psychology, 8(3), 343-354. https://doi.org/10.1037/0278-6133.8.3.343

Putt, C. A., Dowd, E. T., \& McCormick, R. A. (2001). Impact of pre-existing levels of hostility and aggression on substance abuse treatment outcome. Counselling Psychology Quarterly, 14(2), 139-147. https:// doi.org/10.1080/09515070110058576

Raskin, R. N., \& Hall, C. S. (1979). A narcissistic personality inventory. Psychological Reports, 45(2), 590. https://doi.org/10.2466/pro.1979.45.2.590

Reidy, D. E., Shelley-Tremblay, J. F., \& Lilienfeld, S. O. (2011). Psychopathy, reactive aggression, and precarious proclamations: A review of behavioral, cognitive, and biological research. Aggression and Violent Behavior, 16(6), 512-524. https://doi.org/10.1016/j.avb.2011.06.002

Riley, W. T., \& Treiber, F. A. (1989). The validity of multidimensional self-report anger and hostility measures. Journal of Clinical Psychology, 45(3), 397-404. https://doi.org/10.1002/10974679(198905)45:3<397::AID-JCLP2270450308>3.0.CO;2-4

Smith, H. L., Dillon, K. H., \& Cougle, J. R. (2018). Modification of Hostile Interpretation Bias in Depression: A Randomized Controlled Trial. Behavior Therapy, 49(2), 198-211. https://doi.org/10.1016/j. beth.2017.08.001

Smith, T. W. (1992). Hostility and health: Current status of a psychosomatic hypothesis. Health Psychology, 11(3), 139-150. https://doi.org/10.1037/0278-6133.11.3.139

Smucker, M. R., Dancu, C., Foa, E. B., \& Niederee, J. L. (1995). Imagery rescripting: A new treatment for survivors of childhood sexual abuse suffering from posttraumatic stress. Journal of Cognitive Psychotherapy, 9(1), 3-17. 
Spielberger, C. D., Johnson, E., Russell, S., Crane, R., Jacobs, G., \& Worden, T. (1985). The experience and expression of anger: Construction and validation of an anger and hostility in cardiovascular and behavioral disorders. In M. A. Chesney \& R. H. Rosenman (Eds.), Anger and hostility in cardiovascular and behavioral disorders (pp. 5-30). Hemisphere.

Taylor, S. P. (1967). Aggressive behavior and physiological arousal as a function of provocation and the tendency to inhibit aggression. Journal of Personality, 35(2), 297-310.

Twenge, J. M., Baumeister, R. F., Tice, D. M., \& Stucke, T. S. (2001). If you can't join them, beat them: Effects of social exclusion on aggressive behavior. Journal of Personality and Social Psychology, 81(6), 10581069. https://doi.org/Doi 10.1037//0022-3514.81.6.1058

Vassilopoulos, S. P., Brouzos, A., \& Andreou, E. (2014). A multi-session attribution modification program for children with aggressive behaviour: changes in attributions, emotional reaction estimates, and self-reported aggression. Behavioural and cognitive psychotherapy, 1-11. https://doi.org/10.1017/ S1352465814000149

Vidal-Ribas, P., Brotman, M. A., Valdivieso, I., Leibenluft, E., \& Stringaris, A. (2016). The status of irritability in psychiatry: A conceptual and quantitative review. Journal of the American Academy of Child and Adolescent Psychiatry, 55(7), 556-570. https://doi.org/10.1016/j.jaac.2016.04.014

von der Lippe, A. L., Monsen, J. T., Rønnestad, M. H., \& Eilertsen, D. E. (2008). Treatment failure in psychotherapy: The pull of hostility. Psychotherapy Research, 18(4), 420-432. https://doi. org/10.1080/10503300701810793

Wilkowski, B. M., \& Robinson, M. D. (2008). The cognitive basis of trait anger and reactive aggression: An integrative analysis. Personality and Social Psychology Review, 12(1), 3-21. https://doi. org/10.1177/1088868307309874 



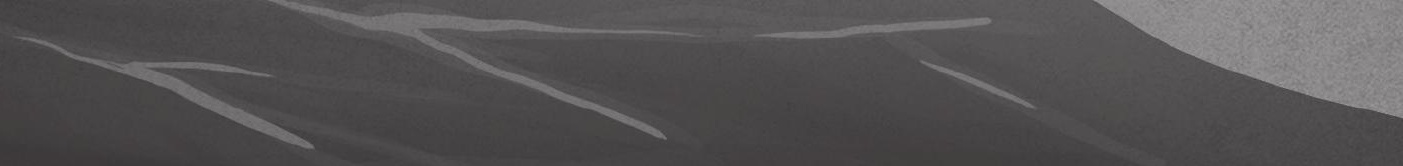

\section{CHAPTER 2}

\section{Uncovering the Hierarchical Structure} of Self-Reported Hostility

This chapter is published as: Van Teffelen, M.W., Lobbestael, J., Voncken, M.J., \& Peeters, F. (2020). Uncovering the Hierarchical Structure of Self-Reported Hostility. PLoS ONE, 15(9), e0239631. https://doi.org/10.1371/journal.pone.0239631 


\section{ABSTRACT}

Hostility and other related terms like anger and aggression are often used interchangeably to describe antagonistic affect, cognition, and behavior. Psychometric studies suggest that hostility consists of multiple separate factors, but consensus is currently lacking. In the present study we examined the hierarchical structure of hostility. The hierarchical structure of hostility was examined in $N=376$ people (i.e., a mixed community and highly hostile sample), using both specific and broad hostility self-report measures. A series of Principal Components Analyses revealed the structure of hostility at five levels of specificity. At intermediate levels, hostility can consistently be expressed in affective, cognitive, and behavioral components. At the most specific level, hostility can be expressed in terms of Angry Affect; Hostile Intent; and Verbal, Relational, and Physical Aggression. The pattern of associations showed significant convergence, and some divergence with broad and more specific hostility measures. The present findings stress the need for novel instruments that capture each hostility facet separately to reduce conceptual confounding. 


\section{INTRODUCTION}

In psychological research, human antagonistic behavior and its' related cognitive-affective experiences are often operationalized by the terms anger, hostility, or aggression. Unfortunately, these and other related terms (e.g., irritability, agitation, and frustration) are often used interchangeably. Some use the same term for different constructs (i.e., the jingle fallacy), while others use different terms for the same construct (i.e., the jangle fallacy) (Anderson \& Bushman, 2002). For example, one may refer to hostility as the 'cognitive component' (Smith, 1992; Spielberger et al., 1985), while others refer to hostility as the interrelated elements of cynical beliefs, angry feelings, and aggressive responding (Chaplin, 1982). Some have referred to anger as the 'affective component' (Ramirez \& Andreu, 2006; Spielberger, 1999), while others refer to anger as a combination of cognitive (i.e., biased information processing) and affective factors (Wilkowski \& Robinson, 2008). There are researchers who refer to anger as 'irritability' (Vidal-Ribas et al., 2016). Also, the behavioral component of hostility is often restricted to observable aggressive behavior (Anderson \& Bushman, 2002), while others refer to aggression as the sum of physical/verbal aggressive behavior, attitudinal hostile beliefs, and angry responsiveness (Buss \& Perry, 1992). Moreover, many self-report measures in the field also use a wide array of terms that even combine two concepts such as 'anger expression', 'hostile aggression', 'affective aggression' and 'angry hostility', adding further confusion.

Adding to this confusion, two theoretical perspectives can be distinguished that conceptualize hostility and its related cognitive-affective experiences. The first, a unidimensional perspective conceptualizes hostility as one construct that includes the interrelated elements of cynical beliefs about others and the world, hostile attribution bias (i.e., the tendency to interpret emotionally ambiguous scenarios as hostile), angry emotional states, and aggressive behavior (American Psychiatric Association, 2013; Barefoot, 1992; Chaplin, 1982). The second, a multidimensional perspective conceptualizes hostility in terms of a broad conceptual domain that consists out of two or more lower-level facets (Buss, 1961; Smith, 1992; Spielberger et al., 1985). Empirical evidence tends to converge with this multidimensional perspective of hostility. That is, exploratory factor analytic (EFA) studies generally find multifactorial solutions (Buss \& Perry, 1992; Maier et al., 2009; Martin et al., 2000; Musante et al., 1989). Typically, these studies include multiple measurements of hostility and apply EFA to identify the optimal number of factors. Part of the confusion surrounding the concept of hostility can be attributed to diverging results from these exploratory studies. Some previous studies demonstrated two factors such as anger expression and anger experience (Buss \& Durkee, 1957; Fuqua et al., 1991; Martin et al., 2000; Musante et al., 1989). Others reported three-factor solutions, distinguishing affect, behavior, and cognition (Kopper \& Epperson, 1996; Martin et al., 2000; Riley \& Treiber, 1989) - also referred to as the ABC-model (Hilgard, 1980), or similarly the AHA-model (i.e., anger, hostility, aggression) (Spielberger et al., 1985). Finally, also a four-factor 
model has been reported with distinctions between hostility, anger, verbal aggression, and physical aggression (Buss \& Perry, 1992; Maier et al., 2009). Taken together, the findings of methodologically heterogeneous factor analytic studies hardly converge in terms of number of produced factors and factor content.

A major caveat in the available evidence is that previous work focused on two levels of analysis: a higher order domain, trait, or latent construct (e.g., hostility) and lower-level facets (e.g., experience and expression). Consequently, the outcomes of EFA's are likely to be a function of the combination of instruments, subscales and items that were fed into the respective models. Theoretically the $\mathrm{ABC}$ - or $\mathrm{AHA}$-model has been influential. However, empirical evidence shows that the optimal factor structure of hostility is debatable. Moreover, it is unclear how different homogenous facets relate to each other and how central they are to the broad-hostility domain. Lack of consensus leads to measurement imprecision. Close inspection of item-content in widely adapted measures of hostility facets for example shows that items often cross-capture hostility facets. For example, how often one shows certain aggressive behaviors when angry (Reactive Proactive Questionnaire) (Raine et al., 2006), or "I have become so mad that I have broken things" (Buss-Perry Aggression Questionnaire) (Buss \& Perry, 1992), or "When I get mad, I say nasty things" (State-Trait Anger Expression Inventory-2) (Spielberger, 1999). Studies in the broad personality psychology field suggest that there is value in investigating model solutions that include more than two conceptual, hierarchical layers (Bacon, 2001). For example, within the construct of narcissism it has been shown that seemingly diverging results of factor analytic studies (i.e., showing different 'optimal' factor solutions) converge into a five-layered hierarchical model in which lower-order facets become more and more specific with each hierarchical layer (Crowe et al., 2019). Other examples of presumed diverging models that converge into a multi-layered hierarchical model have been reported for agreeableness (Crowe et al., 2018), impulsivity (Kirby \& Finch, 2010), emotion expression (Barr et al., 2008), and avoidance behavior (Declercq \& De Houwer, 2009). Along the same lines, hostility could potentially be expressed as a hierarchical structure consisting of one higher order domain that clusters into two to many facets that become more specific in each additional hierarchical layer. To the best of our knowledge, no hierarchical cluster analysis on hostility has been previously performed.

In sum, factor-analytic evidence tends to converge with a multidimensional view of the hostility construct, but previous work shows differences in number and content of factor solutions. The current study, including facet-level and broad-domain measures, therefore builds on earlier work by examining the hierarchical structure of the hostility concept. The main expectation is that a multidimensional hierarchical structure will be uncovered. 


\section{METHODS}

\section{Participants}

Participants were sampled in two ways. First, participants were recruited from the general population in Maastricht, the Netherlands through advertisement. Second, ensuring a representative distribution with enough variation at the extreme end of the hostility dimension (i.e., an estimated $12.4 \%$ of the Dutch population show signs of clinically relevant hostility, given that in the Netherlands an estimated $24.5 \%$ of people suffer from a mental disorder (i.e., anxiety, mood, eating, personality, and somatoform disorders) in one year (Gustavsson et al., 2011). Of these individuals an estimated 51\% report moderate levels of anger (Posternak \& Zimmerman, 2002)), we actively recruited participants with increased and clinically relevant levels of hostility from two mental health facilities in the Maastricht area (i.e., METggz and U-Center). Patients with a score above 1.22 on the hostility subscale of the Personality Inventory for DSM-5 (PID-5H) were eligible to enter the study. This cutoff equals 1 SD above the observed mean in a Danish population (a comparable population to the Netherlands) and approximates the mean in a clinical population (Bach et al., 2016). Exclusion criteria were age younger than 18 and higher than 60, and illiteracy. Patients were excluded from participation by clinical judgement in the mental health facility if they showed signs of current psychosis or mania, alcohol or drug abuse/dependency, and acute suicide risk. For EFA, a minimum sample size of $N=300^{1}$ is suggested (Tabachnick \& Fidell, 2007). In total, we recruited $n=$ 347 people from the general population and $n=30$ patients with clinically relevant levels of hostility. One patient withdrew consent from the study, so the final sample consisted of $N=$ 376. Sample characteristics are shown in Table 1. Statistical analyses showed that, compared to non-patients, patients were less often female, lower educated, student, and were more often using active psychotropic medication.

\section{Materials}

\section{State Trait Anger Expression Inventory-2}

In the 10-item trait anger scale of the State Trait Anger Expression Inventory-2 (STAXI-2T) (Spielberger, 1999) items (e.g., "I am hot-headed") are scored on a 4-point Likert scale ranging from one (not at all) to four (very much). Internal consistency, test-retest reliability (e.g., a = .72 .96) and concurrent validity are good and adequate construct validity has been demonstrated (Lievart et al., 2016; Spielberger, 1999).

1 We calculated the required sample size for correlational analysis at $N=135$, with $a=.01, \beta=.1$, expected $\rho=.3$, and anticipated dropout $=10 \%$. 


\section{Table 1}

\begin{tabular}{|c|c|c|c|c|}
\hline & & Stratum & & Statistical dif. \\
\hline & $\begin{array}{l}\text { Total sample } \\
(N=376)\end{array}$ & $\begin{array}{l}\text { Non-clinical } \\
(n=347)\end{array}$ & $\begin{array}{l}\text { Clinical } \\
(n=29)\end{array}$ & $Z / X^{2} / t(p)$ \\
\hline Age in years, mean (SD) & $35.15(14.72)$ & $34.93(14.97)$ & $37.72(11)$ & $1.47(.141)$ \\
\hline Female, $n(\%)$ & $280(74)$ & $266(77)$ & $14(48)$ & $11.34(.001)$ \\
\hline Male, $n(\%)$ & $96(26)$ & $81(23)$ & $15(52)$ & \\
\hline Nationality, $n$ (\%) & & & & $2.05(.563)$ \\
\hline Dutch & $353(95)$ & $324(93)$ & $29(100)$ & \\
\hline Belgian & $13(3)$ & $13(4)$ & $0(0)$ & \\
\hline German & $4(1)$ & $4(1)$ & $0(0)$ & \\
\hline Other & $6(2)$ & $6(2)$ & $0(0)$ & \\
\hline Education, $n(\%)$ & & & & $27.46(<.001)$ \\
\hline Low & $91(24)$ & $89(26)$ & $2(7)$ & \\
\hline Middle & $141(38)$ & $114(33)$ & $24(83)$ & \\
\hline High & $144(38)$ & $141(41)$ & $3(10)$ & \\
\hline Work situation, $n(\%)$ & & & & $26.14(<.001)$ \\
\hline Employed & $155(41)$ & $141(41)$ & $14(48)$ & \\
\hline Unemployed & $42(11)$ & $36(10)$ & $6(21)$ & \\
\hline Student & $135(36)$ & 135 (39) & $0(0)$ & \\
\hline Social security & $41(11)$ & $32(9)$ & $3(10)$ & \\
\hline Retired & $3(1)$ & $3(2)$ & $0(0)$ & \\
\hline \multicolumn{5}{|l|}{ Medication use, $n$ (\%) } \\
\hline Antidepressant, SSRI & $24(6)$ & $16(5)$ & $8(28)$ & $23.64(<.001)$ \\
\hline Antidepressant, SNRI & $10(3)$ & 5 (1) & $5(17)$ & $25.81(<.001)$ \\
\hline Antidepressant, TCA & 2 (1) & 2 (1) & $0(0)$ & $.17(.682)$ \\
\hline Antidepressant, other & $3(1)$ & 2 (1) & $1(3)$ & $2.79(.095)$ \\
\hline Antipsychotic, atypical & $6(2)$ & $4(1)$ & $2(7)$ & $5.62(.018)$ \\
\hline Anxiolytic & $10(3)$ & 5 (1) & $5(17)$ & $25.81(<.001)$ \\
\hline Mood stabilizer & $3(1)$ & 2 (1) & $1(3)$ & $2.79(.095)$ \\
\hline Stimulant & $7(2)$ & $6(2)$ & $1(3)$ & $.43(.511)$ \\
\hline \multicolumn{5}{|l|}{ Study variables } \\
\hline STAXI-2T, mean (SD) & $16.67(5.21)$ & $16.01(4.53)$ & $24.76(6.03)$ & $-7.63(<.001)$ \\
\hline$A Q H$, mean $(S D)$ & $19.01(7.25)$ & $18.47(7.02)$ & $25.45(7.04)$ & $-5.13(<.001)$ \\
\hline FOA, mean (SD) & $56.72(13.12)$ & 55.57 (11.99) & $70.52(17.78)$ & $4.89(<.001)$ \\
\hline PID-5H, mean (SD) & $.74(.59)$ & $.66(.51)$ & $1.65(.68)$ & $-7.69(<.001)$ \\
\hline
\end{tabular}

Note. SSRI = selective serotonergic reuptake inhibitor; SNRI = selective noradrenergic reuptake inhibitor; TCA = tricyclic antidepressant. 


\section{Aggression Questionnaire}

In the 10-item hostility scale of the Aggression Questionnaire (AQH) (Buss \& Perry, 1992) items (e.g., "Other people always seem to get the breaks") are scored on a 5-point Likert scale ranging from one (extremely uncharacteristic of me) to five (extremely characteristic of me). Internal consistency (e.g., $a=.73-.81$ ) and test-retest reliability are good and adequate/good construct validity has been demonstrated (Hornsveld et al., 2009; McKay et al., 2016).

\section{Forms of Aggression Questionnaire}

The 40-item Forms of Aggression questionnaire (FOA) (Verona et al., 2008) comprises a list of harmful behaviors measured across five subscales including physical (e.g., "I hit, kick, or push them"), verbal (e.g., "I say mean things to them",) property (e.g., "I damage their property"), relational (e.g., "I ruin their friendships with other people") and passive-rational (e.g., "I criticize their work, even if it is good") aggression. In the original version people are asked to indicate how often each behavior occurs when angry. To minimalize overlap with affective features of hostility, participants in the current study were asked to indicate how often each behavior occurs in general instead. Items are scored on a 5-point Likert scale ranging from one ((almost) never) to five ((almost) always). Good internal consistency (e.g., $a=.93-.94$ ) and adequate construct, convergent and discriminant validity have been demonstrated (Verona et al., 2008).

\section{Personality Inventory for DSM-5}

In the 10-item hostility scale of the Personality Inventory for DSM-5 (PID-5H) (Van der Heijden et al., 2014) items (e.g., "I snap at people when they do little things that irritate me") are scored on a 4-point Likert scale ranging from zero (very false or often false) to three (very true or often true). Internal consistency (e.g., $a=.88-.90$ ) is good and adequate construct and convergent validity have been demonstrated (Bach et al., 2016; Krueger et al., 2012; Thomas et al., 2013; Watson et al., 2013).

\section{Procedure}

The Ethical Review Committee Psychology and Neuroscience at Maastricht University provided ethical approval to carry out the study (ERCPN-167_08_05_2016). The study was pre-registered at https://osf.io/gpju6. Some protocol changes were made after the study was preregistered. Specifically, we decided to perform a different analytical approach, we chose to study hostility at trait level (instead of at both state and trait levels) and patients were not screened for instable use of psychotropic medication. The study was performed completely online using Qualtrics software. Beforehand, people were told that the study was about investigating the relationship between thoughts, feelings, and behaviors. After participants provided informed consent, an online link to the study's questionnaires 
was sent by e-mail. Then, information about demographic variables, use of psychotropic medication were obtained and the PID-5H, STAXI-2T, AQH and FOA were administered. After completion, participants were debriefed and received course credit or participated in a raffle with 347 times $€ 7,50$ worth of rewards.

\section{Statistical Analysis}

IBM SPSS and Amos version 24 were used for statistical analysis. First, descriptive statistics were calculated. Second, Spearman's correlation analysis was run to examine baseline correlations between all multidimensional and unidimensional hostility measures. Then, the hierarchical structure of hostility was examined using the so-called 'Bass-Ackwards' method (Goldberg, 2006). Within the context of the examination of personality models, Goldberg (2006) provided a method of examining hierarchical structures in models with more than two levels. The approach allows for the examination of various hierarchical levels of specificity, from a broad construct to more fine-grained, lower-level facets that become more specific at each hierarchical level. Factor solutions were identified using Principal Components Analysis (PCA). First, one unrotated principal component was extracted, followed by the extraction of successively (i.e., two, three, etc.) more Varimax rotated principal components. Varimax rotation was opted following Goldberg (2006) because of optimal parsimony and to encourage factor markers that are maximally unrelated to each other. This was then repeated until one of the factors was either too specific to be interpreted (e.g., containing one item) or was no longer interpretable (e.g., by containing items that show hardly any content similarity). After each extraction, factor loadings were saved and correlated to compare relationships at each level. The identified principal components were then correlated with the raw scores of the questionnaires.

\section{RESULTS}

Means and standard deviations of study variables are shown in Table 1. All study variables were positively skewed (i.e., the value 0 is outside the $+/-2$ * standard error interval of the skewness value). All scores resembled those of other studies using population samples (Ashton et al., 2017; De Fruyt et al., 2013; Hornsveld et al., 2009; Lievaart et al., 2016; Meesters et al., 1996; Verona et al., 2008). Univariate outlier inspection of study variables revealed no bimodality or consistent univariate outliers (following the $3 *$ interquartile range criterion), suggesting that the patients in the present sample did not form a data-cluster.

First, Spearman's correlations and Cronbach's a's are shown in Table 2. These results suggest that the STAXI-2T, AQH, FOA and PID-5H are significantly positively interrelated. All correlations were large according to Cohen (1992) except for the relationship between the $F O A$ and $A Q H$, that was medium. 
Table 2

Spearman's rho correlations between uni- and multidimensional hostility constructs

\begin{tabular}{lllll}
\hline & STAXI-2T & AQH & FOA & $a$ \\
\hline STAXI-2T & & & & .88 \\
AQH & $.54^{*}$ & & & .86 \\
FOA & $.60^{*}$ & $.43^{*}$ & & .93 \\
PID-5H & $.79^{*}$ & $.51^{*}$ & $.65^{*}$ & .88 \\
\hline
\end{tabular}

Note. ${ }^{*} p<.001$. Cronbach's $a$ is reported in the diagonal.

Then, to examine the hierarchical structure of hostility a PCA was run using the 'BassAckwards' method. We evaluated multivariate normality and linearity by inspecting Mahalanobis distance. We observed two multivariate outliers who were removed from the analysis. We observed non-normality on eighteen FOA items (i.e., skewness values smaller or larger than three standard errors) (Curran et al., 1996). Of these eighteen items fifteen extremely violated the normality assumption even after inverse-transformation (i.e., $1 / x)$ and were removed from further analyses to maintain model robustness. The removed items are shown in Appendix A. Factor loadings are presented in Appendix B. Appendix $C$ shows the decision process for principal component extraction. First, one unrotated principal component was extracted, followed by the extraction of successively (i.e., two, three, etc.) more Varimax rotated principal components. This was then repeated until one of the factors was either too specific to be interpreted (e.g., containing one item) or was no longer interpretable (e.g., by containing items that show hardly any content similarity). The first unrotated principal component accounted for $30 \%$ of the total variance. The first ten eigenvalues were: 16.16, 3.90, 2.68, 2.12, 1.61, 1.35, 1.24, 1.20, 1.13, and 1.06. Then, successively larger solutions (i.e., two, three, etc.) were examined. Inspection of the 6-principal component solution showed that the last factor consisted of the two items: "I resent being told what to do, even by people in charge" and "I feel annoyed when not given recognition for doing good work". Thus, the 6-principal component solution was interpreted as not meaningful, resulting in a 5-principal component solution as base of the hierarchical model, accounting for $49 \%$ of the variance.

The hierarchical 5-principal component model is shown in Figure 1. Correlations between the component loadings and the original scales are shown in Table 3. Rotated component loadings and item content are shown in Appendix B. All principal components were labeled according to what was most common to all these items. The first component (P1.1) was labeled Hostility and demonstrated significant positive associations to the original hostility scales ranging from $r=.66(\mathrm{AQ}-\mathrm{H})$ to $r=.88(\mathrm{PID}-5 \mathrm{H})$. The principal components in the two-factor solution were labeled Hostile Cognition (P2.1) and Aggressive Behavior (P2.2). Hostile Cognition related most strongly to the total scores of the STAXI-2T, AQH and PID- 
$5 \mathrm{H}$. Aggressive Behavior most strongly related to the FOA $(r=.92)$. In the three-component solution the Hostile Cognition component split into an Angry Affect (P3.1) and Hostile Intent (P3.3) component. Angry Affect most strongly related to the STAXI-2T and PID-5H. Hostile Intent most strongly related to the AQH $(r=.92)$. In the four-component solution items from the Aggressive Behavior component split into a Social Aggression (P4.2) and Physical Aggression (P4.4, including many inverse-transformed items) components. Social Aggression related most strongly to the FOA ( $r=.87)$, whereas Physical Aggression related most strongly to the STAXI-2T $(r=-.17, p=.001)$ and FOA $(r=.11, p=.029)$. In the fivecomponent solution content from the Social Aggression component split into a Verbal Aggression (P5.2) and Relational Aggression (P5.4) component. Verbal Aggression ( $r=.72$ ) and Relational Aggression ( $r=.35$ ) both most strongly related to the FOA.

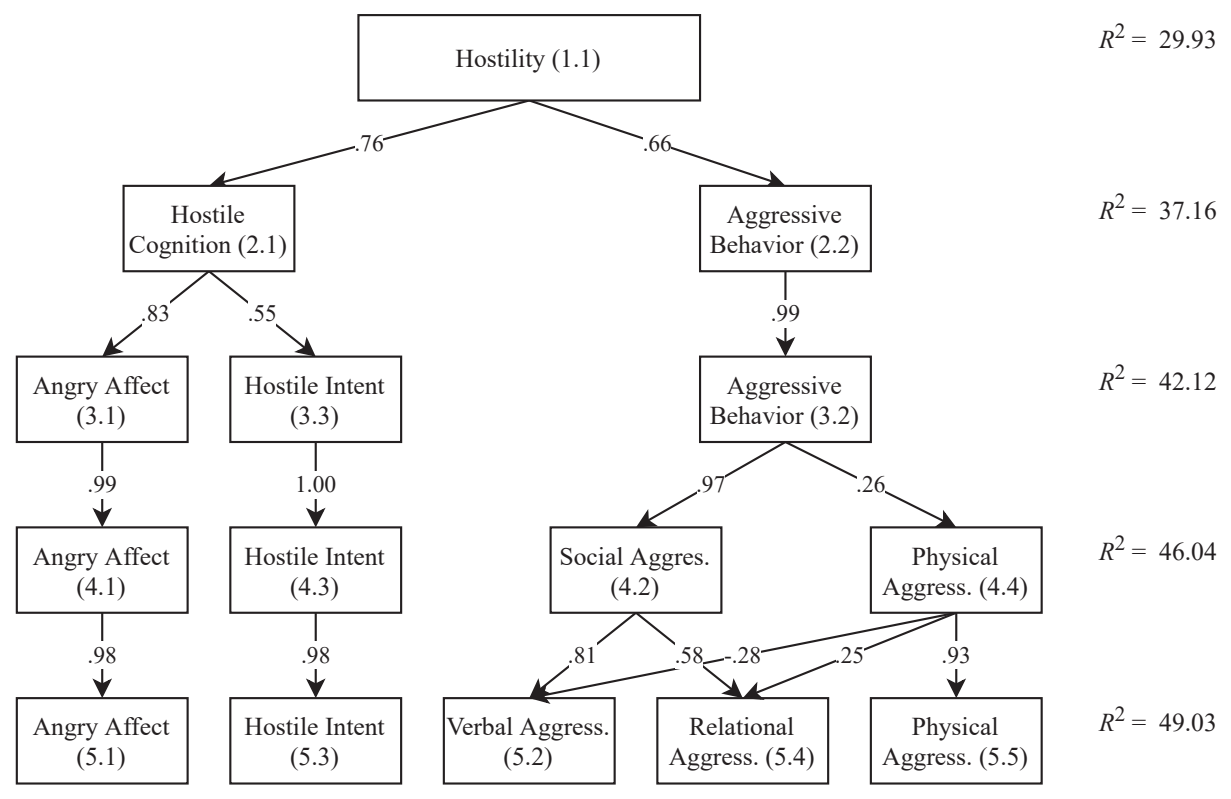

\section{Figure 1}

Hierarchical structure of hostility 
Table 3

Spearman's rho correlations between factor scores and hostility instruments

\begin{tabular}{|c|c|c|c|c|}
\hline & STAXI-2T & AQH & FOA & PID-5H \\
\hline P1.1 & $.84^{\cdots *}$ & $.66^{* *}$ & $.87^{* * *}$ & $.88^{* *}$ \\
\hline P2.1 & $.80^{* * *}$ & $.77^{*+*}$ & $.33^{\cdots *}$ & $.76^{* * *}$ \\
\hline P2.2 & $.35^{\cdots \prime}$ & $.14^{* \prime}$ & $.92^{\cdots *}$ & $.42^{\prime \prime}$ \\
\hline P3.1 & $.74^{\cdots+*}$ & $.18^{* *}$ & $.28^{\cdots \cdots}$ & $.75^{+\cdots}$ \\
\hline P3.2 & $.30^{*-*}$ & $.18^{\cdots *}$ & $.90^{* *}$ & $.36^{* *}$ \\
\hline P3.3 & $.35^{\cdots *}$ & $.92^{\cdots *}$ & $.20 \cdots$ & $.29^{\prime \prime *}$ \\
\hline P4.1 & $.75^{\cdots+\cdots}$ & $.18^{* \cdots}$ & $.28^{\cdots \cdots}$ & $.76^{* *+}$ \\
\hline P4.2 & $.34^{*+*}$ & $.18^{\cdots *}$ & $.87^{* * *}$ & $.38^{\prime \prime \prime}$ \\
\hline P4.3 & $.34^{+*+*}$ & $.92^{\cdots *}$ & $.19^{* * *}$ & $.29^{* * *}$ \\
\hline P4.4 & $-.17^{*}$ & .00 & $.11^{*}$ & -.08 \\
\hline P5.1 & $.71^{\cdots *}$ & $.16^{\prime \prime}$ & $.20^{\cdots}$ & $.72^{\cdots * *}$ \\
\hline P5.2 & $.35^{\prime \prime \prime}$ & $.13^{*}$ & $.72^{\cdots *}$ & $.37^{\prime \prime \prime}$ \\
\hline P5.3 & $.35^{\cdots \prime \prime}$ & $.93^{\cdots *}$ & $.20 \cdots$ & $.30^{\prime \prime \prime}$ \\
\hline P5.4 & .02 & .10 & $.35^{* \cdots}$ & .05 \\
\hline P5.5 & $-.12^{*}$ & .04 & $.23^{\prime \prime \prime}$ & -.03 \\
\hline
\end{tabular}

Note. ${ }^{*}$ significant at $p<.05 ;{ }^{* *}$ significant at $p<.01 ;{ }^{* * *}$ significant at $p<.001 . R^{2}$-values of each level are respectively: $29.93,37.16,42.12,46.04$, and 49.03 .

\section{DISCUSSION}

The present study is, to the best of our knowledge, the first to explore the hierarchical structure of self-reported trait-hostility. We predicted that hostility can be defined as a construct that can be interpreted at different levels of specificity or, in other words, that hostility shows a multidimensional hierarchical structure. We observed that at the highest, most abstract level Hostility is characterized by a low threshold to experience and react harmfully upon angry affect. Findings demonstrate large positive associations between hostility and raw scores on different instruments of hostility. This finding is consistent with different conceptualizations of hostility (American Psychiatric Association, 2013; Barefoot, 1992; Cassiello-Robbins \& Barlow, 2016; Chaplin, 1982; Fernandez \& Johnson, 2016; Vidal-Ribas et al., 2016). At the second level, hostility splits up into an experiential (Hostile Cognition) and expressive component (Aggressive Behavior), converging with factor analytic studies (Buss \& Durkee, 1957; Fuqua et al., 1991; Martin et al., 2000; Musante et al., 1989). Correlations with the original scales show that experiential aspects of hostility are mostly captured by the STAXI-2T, AQH and PID-5H, whereas the expressive aspects are mostly captured by the FOA. At the third level, the experiential factor splits up into an affective (Angry Affect) and cognitive factor (Hostile 
Intent). This is in line with factor analytic studies that demonstrated a cognitive, affective, and behavioral hostility factor (Kopper \& Epperson, 1996; Martin et al., 2000; Riley \& Treiber, 1989). Correlations with the original scales show that the affective component is mostly captured by the STAXI-2T and PID-5H, whereas the cognitive component is mostly captured by the $A Q-H$. At the fourth level, the behavioral component differentiated in an interpersonal (Social Aggression) and physical (Physical Aggression) component. This largely converges with studies showing a four-factor solution consisting of a cognitive, affective and two behavioral factors (Buss \& Perry, 1992; Maier et al., 2009). Associations with the original scales show that Social Aggression is mostly captured by the FOA, whereas Physical Aggression was mostly captured by the STAXI-2T and the FOA. Moreover, we demonstrated that the interpersonal component split up into a verbal and relational aggression component. In short, the present findings show that seemingly diverging factor analytic solutions from previous studies converge into one hierarchically structured model of hostility.

Similar to other models for which hierarchical structures have shown value (e.g., narcissism, agreeableness, impulsivity, avoidance behavior, emotional expression), the current research demonstrates that at the highest, most abstract level $30 \%$ of the variance in hostility is explained by one underlying dimension. Already at the second hierarchical level behavioral characteristics are separated from cognitive characteristics, showing that behavior is a clear distinct characteristic within hostility. Moving down another hierarchical layer, interpretational characteristics are separated from affective characteristics. The affective and interpretational components of hostility remain stable facets in the majority (i.e., three out of five) of hierarchical layers, marking their relative stability. At even more specific hierarchical layers, behavioral characteristics of hostility differentiate in three expressive forms of aggressive behavior: physical, verbal, and relational aggression. Together, these five facets explain $49 \%$ of the variance in hostility items. Surprisingly, the Physical Aggression component at level four and five showed a negative association with the STAXI-2T. A likely explanation is that all inversely transformed items are included in the Physical Aggression component, and that the STAXI-2T includes many items that tap into physical aggressive behavior (e.g., "When I get mad, I say nasty things"). Overall, these findings show that hostility can be perceived as multifaceted construct in which affective, interpretational, and behavioral characteristics are stable components.

Several limitations impact the present findings. First, the present work did not include any predictive measures. Although the present findings show convergent validity, we cannot draw any definite conclusions on the criterion validity of the present findings. A recommendation for future research is hence to include instruments that show differential relationships to different hostility facets, such as agreeableness, shame proneness, empathy, trust, and compassion. Second, the majority of the sample (74\%) was female. Given that women exhibit more indirect 
forms of aggression (e.g., relational, or passive-rational aggression) and men exhibit more direct forms (e.g., physical aggression) (Björkqvist et al., 1992), the results might differ from a sample that includes more men. Third, 30 patients were included in the present sample to ensure enough variation at the extreme end of the hostility dimension. Network models of psychopathology suggest that overall symptom severity is positively related to the strength of correlations between symptom clusters (Robinaugh et al., 2020). Recent work shows that hostility is associated with increase psychopathological severity (Cassiello-Robbins et al., 2015). Theoretically it could be possible that different patterns in the patient subgroup may impact the present findings, for example by artificially driving up correlations. Nonetheless, absence of bimodality and univariate outliers suggests that hostility levels in the present sample reflect a distribution that might be expected in the population and is in line with the dimensional approach to psychopathology (Kotov et al., 2017). Fourth, all self-reports were administered in Dutch. Consequently, the results of present work may be culturally bias and may not generalize to non-Dutch cultures. Fifth, the present work approached hostility from a trait approach. As a result, self-report measures were used. A recommendation for future research is to include measures that capture (state) aspects of hostility on different analytical levels, such as physiologically (e.g., variations in heart-rate variability or skin conductance) or behaviorally (e.g., Competitive Reaction Time Task or Point Subtraction Aggression Paradigm; Cherek et al., 2003; Taylor, 1967). Last, in the present study we worked with a selection of instruments that measure hostility constructs. The STAXI-2 and AQ show excellent psychometric properties (Hornsveld et al., 2009; Lievaart et al., 2016; McKay et al., 2016; Spielberger, 1999) and are extensively used and cited - A Web of Science citation report on 15 November 2019 reveals that the STAXI(-2) and AQ are cited respectively 6160 and 4139 times in scientific articles since 1988. The FOA is less commonly used and cited but does show good psychometric properties in its original form and closely fits modern definitions of aggressive behavior (i.e., any behavior that is intended to cause harm to another person) (Anderson \& Bushman, 2002). Despite this careful questionnaire selection, future research needs to examine whether this hierarchical structure holds when more or other instruments are used.

The current finding that hostility is a construct that can be interpreted at different levels of theoretical generality versus specificity comes with several main implications. One implication is that a person can score high on a measure that captures one aspect of hostility but will not necessarily score high on another. For example, a person with a tendency to be easily angered does not necessarily easily engage in aggressive behavior. Also, a person with the tendency to respond physically aggressive, does not necessarily have the tendency to be verbally aggressive. Hostile affect, cognition and behavior may therefore have different antecedents and consequences, requiring a different approach in clinical context. More importantly, the current study illustrates that the lack of consensus in the current hostility literature is likely the result of conceptual identity confusion (i.e., jingle and jangle fallacies). This, in turn, leads to 
reduced measurement precision and a fragmentation of the research field (i.e., two researchers could study the same construct but name their construct differently). Note that hostility is investigated not only in the field of aggression, but also the fields of social psychology, clinical psychology, and psychiatry. This underlines the need to be both more critical towards the use of language and to be very precise in choice of measurement instruments in these fields. This includes, for instance, the use of items that cross-capture hostility facets, while they pretend to measure only one facet (see Appendix B for examples of items that capture multiple facets). Hopefully, this study will stimulate joint efforts to move towards the standardized use of hostility and its subcomponents. Moreover, we hope to contribute towards moving the field of aggression research to a more valid and standardized assessment level by further stimulating and ameliorate the accurate and standardized assessment and operationalization of hostility. 


\section{REFERENCES}

American Psychiatric Association. (2013). Diagnostic and Statistical Manual of Mental Disorders (5th ed.). Anderson, C. A., \& Bushman, B. J. (2002). Human aggression. Annual Review of Psychology, 53(1), 27-51. https://doi.org/10.1146/annurev.psych.53.100901.135231

Ashton, M. C., de Vries, R. E., \& Lee, K. (2017). Trait variance and response style variance in the scales of the personality inventory for DSM-5 (PID-5). Journal of Personality Assessment, 99(2), 192-203. https://doi.org/10.1080/00223891.2016.1208210

Bach, B., Maples-Keller, J. L., Bo, S., \& Simonsen, E. (2016). The alternative DSM-5 personality disorder traits criterion: A comparative examination of three self-report forms in a Danish population. Personality Disorders: Theory, Research, and Treatment, 7(2), 124-135. https://doi.org/10.1037/per0000162

Bacon, D. R. (2001). An evaluation of cluster analytic approaches to initial model specification. Structural Equation Modeling, 8(3), 397-429. https://doi.org/10.1207/S15328007SEM0803_4

Barefoot, J. C. (1992). Developments in the measurement of hostility. In H. S. Friedman (Ed.), Hostility, coping, \& health. (pp. 13-31). American Psychological Association. https://doi.org/10.1037/10105-001

Barr, L. K., Kahn, J. H., \& Schneider, W. J. (2008). Individual differences in emotion expression: Hierarchical structure and relations with psychological distress. Journal of Social and Clinical Psychology, 27(10), 1045-1077. https://doi.org/10.1521/jscp.2008.27.10.1045

Björkqvist, K., Lagerspetz, K. M., \& Kaukiainen, A. (1992). Do girls manipulate and boys fight? Developmental trends in regard to direct and indirect aggression. Aggressive Behavior, 18(2), 117-127. https://doi. org/10.1002/1098-2337(1992)18:2<117::AID-AB2480180205>3.0.CO;2-3

Buss, A. H. (1961). The psychology of aggression. John Wiley \& Sons Inc. https://doi.org/10.1037/11160-000

Buss, A. H., \& Durkee, A. (1957). An inventory for assessing different kinds of hostility. Journal of Consulting Psychology, 21(4), 343-349. https://doi.org/10.1037/h0046900

Buss, A. H., \& Perry, M. (1992). The aggression questionnaire. Journal of Personality and Social Psychology, 63(3), 452-459. https://doi.org/10.1037/0022-3514.63.3.452

Cassiello-Robbins, C., Conklin, L. R., Anakwenze, U., Gorman, J. M., Woods, S. W., Shear, M. K., \& Barlow, D. H. (2015). The effects of aggression on symptom severity and treatment response in a trial of cognitive behavioral therapy for panic disorder. Comprehensive Psychiatry, 60, 1-8. https://doi. org/10.1016/j.comppsych.2015.04.012

Cassiello-Robbins, C., \& Barlow, D. H. (2016). Anger: The unrecognized emotion in emotional disorders. Clinical Psychology: Science and Practice, 23(1), 66-85. https://doi.org/10.1111/cpsp.12139

Chaplin, J. P. (1982). Dictionary of psychology. Laurel.

Cherek, D. R., Lane, S. D., \& Pietras, C. J. (2003). Laboratory measures: point subtraction aggression paradigm. In Aggression (pp. 231-244). CRC Press.

Cohen, J. (1992). A power primer. Psychological Bulletin, 112(1), 155-159. https://doi.org/10.1037/00332909.112.1.155

Crowe, M. L., Lynam, D. R., Campbell, W. K., \& Miller, J. D. (2019). Exploring the structure of narcissism: Toward an integrated solution. Journal of Personality, 87(6), 1151-1169. https://doi.org/10.1111/jopy.12464

Crowe, M. L., Lynam, D. R., \& Miller, J. D. (2018). Uncovering the structure of agreeableness from self-report measures. Journal of Personality, 86(5), 771-787. https://doi.org/10.1111/jopy.12358

Curran, P. J., West, S. G., \& Finch, J. F. (1996). The robustness of test statistics to nonnormality and specification error in confirmatory factor analysis. Psychological Methods, 1(1), 16-29. https://doi. org/10.1037/1082-989X.1.1.16 
De Fruyt, F., De Clercq, B., De Bolle, M., Wille, B., Markon, K., \& Krueger, R. F. (2013). General and Maladaptive Traits in a Five-Factor Framework for DSM-5 in a University Student Sample. Assessment, 20(3), $295-$ 307. https://doi.org/10.1177/1073191113475808

Declercq, M., \& De Houwer, J. (2009). Evidence for a hierarchical structure underlying avoidance behavior. Journal of Experimental Psychology: Animal Behavior Processes, 35(1), 123-128. https:// doi.org/10.1037/a0012927

Fernandez, E., \& Johnson, S. L. (2016). Anger in psychological disorders: Prevalence, presentation, etiology and prognostic implications. Clinical Psychology Review, 46, 124-135. https://doi.org/10.1016/j. cpr.2016.04.012

Fuqua, D. R., Leonard, E., Masters, M. A., Smith, R. J., Campbell, J. L., \& Fischer, P. C. (1991). A structural analysis of the State-Trait Anger Expression Inventory. Educational and Psychological Measurement, 51(2), 439-446. https://doi.org/10.1177/0013164491512018

Goldberg, L. R. (2006). Doing it all Bass-Ackwards: The development of hierarchical factor structures from the top down. Journal of Research in Personality, 40(4), 347-358. https://doi.org/10.1016/j. jrp.2006.01.001

Gustavsson, A., Svensson, M., Jacobi, F., Allgulander, C., Alonso, J., Beghi, E., Dodel, R., Ekman, M., Faravelli, C., Fratiglioni, L., Gannon, B., Jones, D. H., Jennum, P., Jordanova, A., Jönsson, L., Karampampa, K., Knapp, M., Kobelt, G., Kurth, T., Lieb, R., Linde, M., Ljungcrantz, C., Maercker, A., Melin, B., Moscarelli, M., Musayev, A., Norwood, F., Preisig, M., Pugliatti, M., Rehm, J., Salvador-Carulla, L., Schlehofer, B., Simon, R., Steinhausen, H.-C., Stovner, L. J., Vallat, J.-M., Van den Bergh, P., van Os, J., Vos, P., Xu, W., Wittchen, H.-U., Jönsson, B., \& Olesen, J. (2011). Cost of disorders of the brain in Europe 2010. European Neuropsychopharmacology, 21(10), 718-779. https://doi.org/10.1016/j.euroneuro.2011.08.008

Hilgard, E. R. (1980). The trilogy of mind: Cognition, affection, and conation. Journal of the History of the Behavioral Sciences, 16(2), 107-117.

Hornsveld, R. H., Muris, P., Kraaimaat, F. W., \& Meesters, C. (2009). Psychometric properties of the aggression questionnaire in Dutch violent forensic psychiatric patients and secondary vocational students. Assessment, 16(2), 181-192. https://doi.org/10.1177/1073191108325894

Kirby, K. N., \& Finch, J. C. (2010). The hierarchical structure of self-reported impulsivity. Personality and Individual Differences, 48(6), 704-713. https://doi.org/10.1016/j.paid.2010.01.019

Kopper, B. A., \& Epperson, D. L. (1996). The experience and expression of anger: Relationships with gender, gender role socialization, depression, and mental health functioning. Journal of Counseling Psychology, 43(2), 158-165. https://doi.org/10.1037/0022-0167.43.2.158

Kotov, R., Krueger, R. F., Watson, D., Achenbach, T. M., Althoff, R. R., Bagby, R. M., Brown, T. A., Carpenter, W. T., Caspi, A., Clark, L. A., Eaton, N. R., Forbes, M. K., Forbush, K. T., Goldberg, D., Hasin, D., Hyman, S. E., Ivanova, M. Y., Lynam, D. R., Markon, K., Miller, J. D., Moffitt, T. E., Morey, L. C., Mullins-Sweatt, S. N., Ormel, J., Patrick, C. J., Regier, D. A., Rescorla, L., Ruggero, C. J., Samuel, D. B., Sellbom, M., Simms, L. J., Skodol, A. E., Slade, T., South, S. C., Tackett, J. L., Waldman, I. D., Waszczuk, M. A., Widiger, T. A., Wright, A. G. C., \& Zimmerman, M. (2017). The Hierarchical Taxonomy of Psychopathology (HiTOP): A dimensional alternative to traditional nosologies. Journal of Abnormal Psychology, 126(4), 454-477. https://doi.org/10.1037/abn0000258

Krueger, R. F., Derringer, J., Markon, K. E., Watson, D., \& Skodol, A. E. (2012). Initial construction of a maladaptive personality trait model and inventory for DSM-5. Psychological Medicine, 42(9), 18791890. https://doi.org/10.1017/S0033291711002674

Lievaart, M., Franken, I. H. A., \& Hovens, J. E. (2016). Anger assessment in clinical and nonclinical populations: Further validation of the State-Trait Anger Expression Inventory-2. Journal of Clinical Psychology, 72(3), 263-278. https://doi.org/10.1002/jclp.22253 
Maier, K. J., Goble, L. A., Neumann, S. A., Giggey, P. P., Suarez, E. C., \& Waldstein, S. R. (2009). Dimensions across measures of dispositional hostility, expressive style, and depression show some variation by race/ethnicity and gender in young adults. Journal of Social and Clinical Psychology, 28(10), 11991225. https://doi.org/10.1521/jscp.2009.28.10.1199

Martin, R., Watson, D., \& Wan, C. K. (2000). A three-factor model of trait anger: Dimensions of affect, behavior, and cognition. Journal of Personality, 68(5), 869-897. https://doi.org/10.1111/1467-6494.00119

McKay, M. T., Perry, J. L., \& Harvey, S. A. (2016). The factorial validity and reliability of three versions of the Aggression Questionnaire using Confirmatory Factor Analysis and Exploratory Structural Equation Modelling. Personality and Individual Differences, 90, 12-15. https://doi.org/10.1016/j.paid.2015.10.028

Meesters, C., Muris, P., Bosma, H., \& Schouten, E. (1996). Psychometric evaluation of the Dutch version of the Aggression Questionnaire. Behaviour Research and Therapy, 34(10), 839-843. https://doi. org/10.1016/0005-7967(96)00065-4

Musante, L., MacDougall, J. M., Dembroski, T. M., \& Costa, P. T. (1989). Potential hostility and dimensions of anger. Health Psychology, 8(3), 343-354. https://doi.org/10.1037/0278-6133.8.3.343

Posternak, M. A., \& Zimmerman, M. (2002). Anger and aggression in psychiatric outpatients. The Journal of clinical psychiatry, 63(8), 665-672. https://doi.org/10.4088/JCP.v63n0803

Raine, A., Dodge, K., Loeber, R., Gatzke-Kopp, L., Lynam, D., Reynolds, C., Stouthamer-Loeber, M., \& Liu, J. (2006). The reactive-proactive aggression questionnaire: Differential correlates of reactive and proactive aggression in adolescent boys. Aggressive Behavior, 32(2), 159-171. https://doi.org/10.1002/ ab. 20115

Ramirez, J. M., \& Andreu, J. M. (2006). Aggression, and some related psychological constructs (anger, hostility, and impulsivity); some comments from a research project. Neuroscience and biobehavioral reviews, 30(3), 276-291. https://doi.org/10.1016/j.neubiorev.2005.04.015

Riley, W. T., \& Treiber, F. A. (1989). The validity of multidimensional self-report anger and hostility measures. Journal of Clinical Psychology, 45(3), 397-404. https://doi.org/10.1002/10974679(198905)45:3<397::AID-JCLP2270450308>3.0.CO;2-4

Robinaugh, D. J., Hoekstra, R. H. A., Toner, E. R., \& Borsboom, D. (2020). The network approach to psychopathology: A review of the literature 2008-2018 and an agenda for future research. Psychological Medicine, 50(3), 353-366. https://doi.org/10.1017/S0033291719003404

Smith, T. W. (1992). Hostility and health: Current status of a psychosomatic hypothesis. Health Psychology, 11(3), 139-150. https://doi.org/10.1037/0278-6133.11.3.139

Spielberger, C. D. (1999). State-Trait Anger Expression Inventory-2. Psychological Assessment Resources.

Spielberger, C. D., Johnson, E., Russell, S., Crane, R., Jacobs, G., \& Worden, T. (1985). The experience and expression of anger: Construction and validation of an anger and hostility in cardiovascular and behavioral disorders. In M. A. Chesney \& R. H. Rosenman (Eds.), Anger and hostility in cardiovascular and behavioral disorders (pp. 5-30). Hemisphere.

Tabachnick, B. G., \& Fidell, L. S. (2007). Using multivariate statistics, 5th ed. Allyn \& Bacon/Pearson Education.

Taylor, S. P. (1967). Aggressive behavior and physiological arousal as a function of provocation and the tendency to inhibit aggression. Journal of Personality, 35(2), 297-310.

Thomas, K. M., Yalch, M. M., Krueger, R. F., Wright, A. G. C., Markon, K. E., \& Hopwood, C. J. (2013). The convergent structure of DSM-5 personality trait facets and five-factor model trait domains. Assessment, 20(3), 308-311. https://doi.org/10.1177/1073191112457589 (Special Issue on the Personality Inventory for DSM-5)

Van der Heijden, P., Ingenhoven, T., Berghuis, H., \& Rossi, G. (2014). Nederlandstalige bewerking van The Personality Inventory for DSM-5 ${ }^{\circledR}(P I D-5)$ - Adult, 2011. Uitgeverij Boom. 
Verona, E., Sadeh, N., Case, S. M., Reed, A., 2nd, \& Bhattacharjee, A. (2008). Self-reported use of different forms of aggression in late adolescence and emerging adulthood. Assessment, 15(4), 493-510. https:// doi.org/10.1177/1073191108318250

Vidal-Ribas, P., Brotman, M. A., Valdivieso, I., Leibenluft, E., \& Stringaris, A. (2016). The status of irritability in psychiatry: A conceptual and quantitative review. Journal of the American Academy of Child and Adolescent Psychiatry, 55(7), 556-570. https://doi.org/10.1016/j.jaac.2016.04.014

Watson, D., Stasik, S. M., Ro, E., \& Clark, L. A. (2013). Integrating normal and pathological personality: Relating the DSM-5 trait-dimensional model to general traits of personality. Assessment, 20(3), 312326. https://doi.org/10.1177/1073191113485810 (Special Issue on the Personality Inventory for DSM-5) Wilkowski, B. M., \& Robinson, M. D. (2008). The cognitive basis of trait anger and reactive aggression: An integrative analysis. Personality and Social Psychology Review, 12(1), 3-21. https://doi. org/10.1177/1088868307309874 


\section{APPENDIX A}

FOA items that were removed due to extreme normality violation

Item

Threaten someone physically

Throw something at someone

Hit someone in the face or head

Beat someone up

Hold someone on the ground

Hurt someone physically

Steal someone's things

Start a fire that causes damage

Harm someone's property

Vandalize someone's house or things

Damage someone's property

Mess up someone's work

Tease someone

Ruin someone's friendship with other people

Isolate someone

Become friends with someone else as revenge 


\section{APPENDIX B}

Item content and loading for all rotated principal component solutions

\begin{tabular}{|c|c|c|c|c|}
\hline Item & Instrument & Content & P1.1 & P2.1 \\
\hline 1 & PID-5H & I snap at people when they do little things that irritate me. & 0.66 & 0.58 \\
\hline 2 & PID-5H & I can be mean when I need to be. & 0.59 & 0.47 \\
\hline 3 & PID-5H & I am easily angered. & 0.70 & 0.67 \\
\hline 4 & PID-5H & I resent being told what to do. even by people in charge. & 0.46 & 0.36 \\
\hline 5 & PID-5H & I have a very short temper. & 0.67 & 0.73 \\
\hline 6 & PID-5H & I always make sure I get back at people who wrong me. & 0.58 & 0.61 \\
\hline 7 & PID-5H & I get irritated easily by all sorts of things. & 0.70 & 0.63 \\
\hline 8 & PID-5H & I am usually pretty hostile. & 0.66 & 0.67 \\
\hline 9 & PID-5H & It makes me really angry when people insult me in even a minor way. & 0.65 & 0.63 \\
\hline 10 & PID-5H & I am nasty and short to anybody who deserves it. & 0.63 & 0.57 \\
\hline 11 & STAXI-2T & I am quick tempered. & 0.66 & 0.73 \\
\hline 12 & STAXI-2T & I have a fiery temper. & 0.66 & 0.69 \\
\hline 13 & STAXI-2T & I am a hotheaded person. & 0.66 & 0.67 \\
\hline 14 & STAXI-2T & I get angry when slowed down by others' mistakes. & 0.66 & 0.58 \\
\hline 15 & STAXI-2T & I feel annoyed when not given recognition for doing good work. & 0.51 & 0.44 \\
\hline 16 & STAXI-2T & I fly off the handle. & 0.63 & 0.66 \\
\hline 17 & STAXI-2T & I say nasty things when mad. & 0.67 & 0.56 \\
\hline 18 & STAXI-2T & I feel furious when criticized in front of others. & 0.57 & 0.54 \\
\hline 19 & STAXI-2T & I feel like hitting someone when frustrated. & 0.52 & 0.61 \\
\hline 20 & STAXI-2T & I feel infuriated when do a good job and get poor evaluation. & 0.59 & 0.55 \\
\hline 21 & $\mathrm{AQ}-\mathrm{H}$ & I am suspicious of overly friendly strangers. & 0.34 & 0.42 \\
\hline 22 & $A Q-H$ & I sometimes feel that people are laughing at me behind my back. & 0.52 & 0.53 \\
\hline 23 & $A Q-H$ & I am sometimes eaten up with jealousy. & 0.52 & 0.45 \\
\hline 24 & $\mathrm{AQ}-\mathrm{H}$ & Other people always seem to get the breaks. & 0.48 & 0.61 \\
\hline 25 & $A Q-H$ & I know that "friends" talk about me behind my back. & 0.41 & 0.38 \\
\hline 26 & $\mathrm{AQ}-\mathrm{H}$ & When people are especially nice to me. I wonder what they want. & 0.47 & 0.55 \\
\hline 27 & $\mathrm{AQ}-\mathrm{H}$ & At times I feel I have gotten a raw deal out of life. & 0.41 & 0.62 \\
\hline 28 & $\mathrm{AQ}-\mathrm{H}$ & I wonder why sometimes I feel so bitter about things. & 0.59 & 0.69 \\
\hline 29 & FOA & Start a fight & 0.59 & 0.42 \\
\hline 30 & FOA & Take my time doing things someone wants me to do & 0.41 & 0.15 \\
\hline 31 & FOA & Hit. kick. or push someone & -0.35 & -0.16 \\
\hline 32 & FOA & Put someone down & 0.65 & 0.36 \\
\hline 33 & FOA & Say mean things to someone & 0.70 & 0.45 \\
\hline 34 & FOA & Tell my friends to stop liking someone & -0.30 & -0.03 \\
\hline
\end{tabular}




\begin{tabular}{|c|c|c|c|c|c|c|c|c|c|c|c|c|}
\hline 2.2 & P3.1 & P3.2 & P3.3 & P4.1 & P4.2 & P4.3 & P4.4 & P5.1 & P5.2 & P5.3 & P5.4 & P5.5 \\
\hline 0.35 & 0.52 & 0.32 & 0.30 & 0.51 & 0.30 & 0.30 & 0.13 & 0.50 & 0.25 & 0.30 & 0.18 & 0.16 \\
\hline 0.36 & 0.46 & 0.33 & 0.18 & 0.45 & 0.27 & 0.19 & 0.27 & 0.42 & 0.23 & 0.20 & 0.13 & 0.32 \\
\hline 0.30 & 0.78 & 0.23 & 0.06 & 0.77 & 0.20 & 0.06 & 0.15 & 0.76 & 0.20 & 0.07 & 0.09 & 0.18 \\
\hline 0.29 & 0.38 & 0.26 & 0.11 & 0.40 & 0.35 & 0.10 & -0.27 & 0.34 & 0.48 & 0.14 & -0.03 & -0.14 \\
\hline 0.18 & 0.83 & 0.11 & 0.07 & 0.83 & 0.10 & 0.07 & 0.08 & 0.84 & 0.10 & 0.07 & 0.08 & 0.07 \\
\hline 0.18 & 0.56 & 0.15 & 0.28 & 0.56 & 0.14 & 0.28 & 0.06 & 0.55 & 0.15 & 0.28 & 0.07 & 0.08 \\
\hline 0.33 & 0.59 & 0.30 & 0.29 & 0.59 & 0.33 & 0.29 & -0.05 & 0.57 & 0.33 & 0.29 & 0.15 & 0.00 \\
\hline 0.23 & 0.67 & 0.18 & 0.23 & 0.66 & 0.16 & 0.23 & 0.15 & 0.67 & 0.09 & 0.21 & 0.17 & 0.13 \\
\hline 0.26 & 0.58 & 0.22 & 0.29 & 0.59 & 0.25 & 0.29 & -0.09 & 0.60 & 0.21 & 0.27 & 0.21 & -0.09 \\
\hline 0.31 & 0.50 & 0.28 & 0.30 & 0.49 & 0.24 & 0.30 & 0.18 & 0.49 & 0.16 & 0.29 & 0.20 & 0.19 \\
\hline 16 & 0.82 & 0.09 & 0.10 & 0.81 & 0.08 & 10 & 0.09 & 0.82 & 0.10 & 0.10 & 0.04 & 0.09 \\
\hline 0.21 & 0.79 & 0.14 & 0.07 & 0.79 & 0.13 & 0.07 & 0.09 & 0.81 & 0.09 & 0.05 & 0.14 & 0.07 \\
\hline 0.23 & 0.76 & 0.16 & 0.10 & 0.76 & 0.15 & 0.09 & 0.07 & 0.76 & 0.15 & 0.09 & 0.09 & 0.08 \\
\hline 0.34 & 0.56 & 0.31 & 0.23 & 0.57 & 0.34 & 0.23 & -0.08 & 0.54 & 0.37 & 0.24 & 0.11 & -0.01 \\
\hline 0.27 & 0.32 & 0.26 & 0.35 & 0.34 & 0.33 & 0.34 & -0.22 & 0.33 & 0.31 & 0.33 & 0.20 & -0.20 \\
\hline 0.20 & 0.73 & 0.14 & 0.12 & 0.72 & 0.10 & 0.12 & 0.17 & 0.72 & 0.08 & 0.11 & 0.09 & 0.17 \\
\hline 0.37 & 0.54 & 0.34 & 0.24 & 0.53 & 0.30 & 0.24 & 0.21 & 0.49 & 0.29 & 0.26 & 0.10 & 0.28 \\
\hline 25 & 0.46 & 0.22 & 0.30 & 0.48 & 0.28 & 0.29 & -0.17 & 0.47 & 0.30 & 0.30 & 0.13 & -0.14 \\
\hline 0.08 & 0.52 & 0.05 & 0.32 & 0.50 & -0.02 & 0.33 & 0.28 & 0.50 & -0.03 & 0.34 & 0.01 & 0.29 \\
\hline 0.27 & 0.45 & 0.25 & 0.33 & 0.47 & 0.31 & 0.33 & -0.17 & 0.43 & 0.38 & 0.35 & 0.05 & -0.08 \\
\hline 0.03 & 0.09 & 0.06 & 0.63 & 0.09 & 0.09 & 0.63 & -0.09 & 0.07 & 0.12 & 0.65 & 0.00 & -0.04 \\
\hline 0.18 & 0.18 & 0.20 & 0.70 & 0 & 0.18 & 0.70 & 0.15 & 0.17 & 0.08 & 0.69 & 0.20 & 0.14 \\
\hline 0.27 & 0.20 & 0.29 & 0.53 & 0.19 & 0.25 & 0.54 & 0.21 & 0.20 & 0.08 & 0.50 & 0.32 & 0.17 \\
\hline 0.03 & 0.24 & 0.05 & 0.75 & 0.24 & 0.05 & 0.75 & 0.03 & 0.22 & 0.04 & 0.76 & 0.05 & 0.05 \\
\hline 0.19 & 0.09 & 0.22 & 0.58 & 0.08 & 0.19 & 0.58 & 0.14 & 0.08 & 0.08 & 0.57 & 0.22 & 0.14 \\
\hline 0.08 & 0.18 & 0.10 & 0.73 & 0 & 0.13 & 0.73 & -0.08 & 0.17 & 0.14 & 0.74 & 0.07 & -0.04 \\
\hline-0.08 & 0.28 & -0.07 & 0.69 & 0.27 & -0.07 & 0.69 & 0.03 & 0.26 & -0.04 & 0.71 & -0.05 & 0.05 \\
\hline 0.11 & 0.45 & 0.10 & 0.58 & 0.44 & 0.07 & 0.59 & 0.16 & 0.42 & 0.05 & 0.59 & 0.06 & 0.18 \\
\hline 0.42 & 0.47 & 0.39 & 0.08 & 0.47 & 0.35 & 0.08 & 0.19 & 0.43 & 0.35 & 0.10 & 0.11 & 0.27 \\
\hline 0.45 & 0.06 & 0.46 & 0.23 & 0.05 & 0.43 & 0.23 & 0.18 & 0.08 & 0.18 & 0.17 & 0.48 & 0.13 \\
\hline-0.34 & -0.20 & -0.32 & -0.03 & -0.15 & -0.16 & -0.04 & -0.65 & -0.12 & -0.07 & -0.06 & -0.09 & -0.70 \\
\hline 0.57 & 0.40 & 0.54 & 0.10 & 0.39 & 0.49 & 0.10 & 0.28 & 0.38 & 0.35 & 0.08 & 0.33 & 1 \\
\hline 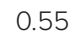 & 0.49 & 0.51 & 0.12 & 0.47 & 0.43 & 0.12 & 0.40 & 0.43 & 0.34 & 0.13 & 0.22 & 0.47 \\
\hline 42 & 0.05 & -0.44 & -0.17 & 0.06 & -0.39 & -0.17 & -0.26 & -0.04 & 0.06 & -0.05 & -0.74 & -0.06 \\
\hline
\end{tabular}


Item content and loading for all rotated principal component solutions (Continued)

\begin{tabular}{|c|c|c|c|c|}
\hline Item & Instrument & Content & P1.1 & P2.1 \\
\hline 35 & FOA & Keep someone from being in my group of friends & 0.46 & 0.15 \\
\hline 36 & FOA & Tell someone that I will not be their friend anymore & 0.44 & 0.16 \\
\hline 37 & FOA & Gossip or spread rumors about someone & 0.50 & 0.11 \\
\hline 38 & FOA & Curse someone out & 0.65 & 0.33 \\
\hline 39 & FOA & Make sure someone gets left out & 0.43 & 0.18 \\
\hline 40 & FOA & Argue with someone & 0.57 & 0.19 \\
\hline 41 & FOA & Do not let someone express their opinion & 0.51 & 0.22 \\
\hline 42 & FOA & Criticize someone's work, even if it is good & 0.43 & 0.09 \\
\hline 43 & FOA & Try to get the last word & 0.61 & 0.27 \\
\hline 44 & FOA & Get sarcastic with someone & 0.56 & 0.22 \\
\hline 45 & FOA & Do not help someone when they need my help & 0.41 & 0.12 \\
\hline 46 & FOA & Throw something at someone & -0.35 & -0.12 \\
\hline 47 & FOA & Tell someone's secrets & 0.37 & 0.01 \\
\hline 48 & FOA & Interrupt someone on purpose & 0.52 & 0.17 \\
\hline 49 & FOA & Refuse to listen to someone & 0.61 & 0.29 \\
\hline 50 & FOA & Insinuate someone has "problems" & 0.56 & 0.23 \\
\hline 51 & FOA & Criticize someone's judgements or decisions & 0.48 & 0.08 \\
\hline 52 & FOA & Openly dismiss someone's opinion & 0.50 & 0.10 \\
\hline 53 & FOA & Blame someone unfairly & 0.53 & 0.17 \\
\hline 54 & FOA & Physically hurt someone & 0.31 & 0.15 \\
\hline
\end{tabular}




\begin{tabular}{ccccccccccccc} 
P2.2 & P3.1 & P3.2 & P3.3 & P4.1 & P4.2 & P4.3 & P4.4 & P5.1 & P5.2 & P5.3 & P5.4 & P5.5 \\
\hline 0.52 & 0.06 & 0.53 & 0.23 & 0.06 & 0.52 & 0.22 & 0.15 & 0.11 & 0.22 & 0.15 & 0.59 & 0.07 \\
0.49 & 0.09 & 0.49 & 0.19 & 0.09 & 0.47 & 0.19 & 0.14 & 0.13 & 0.20 & 0.12 & 0.55 & 0.06 \\
0.64 & 0.04 & 0.65 & 0.18 & 0.03 & 0.61 & 0.18 & 0.24 & 0.05 & 0.34 & 0.14 & 0.55 & 0.21 \\
0.61 & 0.40 & 0.58 & 0.05 & 0.38 & 0.49 & 0.05 & 0.40 & 0.33 & 0.41 & 0.07 & 0.24 & 0.48 \\
0.45 & 0.19 & 0.44 & 0.08 & 0.19 & 0.43 & 0.08 & 0.07 & 0.26 & 0.13 & -0.01 & 0.60 & -0.06 \\
0.65 & 0.25 & 0.63 & 0.03 & 0.26 & 0.65 & 0.02 & 0.01 & 0.18 & 0.68 & 0.06 & 0.16 & 0.17 \\
0.52 & 0.27 & 0.50 & 0.04 & 0.28 & 0.53 & 0.04 & -0.04 & 0.26 & 0.46 & 0.03 & 0.29 & 0.01 \\
0.54 & 0.12 & 0.54 & 0.03 & 0.12 & 0.53 & 0.02 & 0.10 & 0.10 & 0.44 & 0.02 & 0.29 & 0.16 \\
0.62 & 0.33 & 0.59 & 0.04 & 0.35 & 0.63 & 0.03 & -0.06 & 0.27 & 0.69 & 0.07 & 0.13 & 0.11 \\
0.60 & 0.22 & 0.59 & 0.11 & 0.22 & 0.56 & 0.11 & 0.20 & 0.15 & 0.54 & 0.14 & 0.17 & 0.33 \\
0.50 & 0.11 & 0.49 & 0.09 & 0.11 & 0.48 & 0.08 & 0.13 & 0.11 & 0.31 & 0.06 & 0.38 & 0.14 \\
-0.39 & -0.16 & -0.37 & -0.01 & -0.13 & -0.25 & -0.01 & -0.53 & -0.08 & -0.19 & -0.04 & -0.07 & -0.61 \\
0.55 & -0.02 & 0.56 & 0.10 & -0.02 & 0.56 & 0.09 & 0.11 & 0.01 & 0.29 & 0.04 & 0.54 & 0.06 \\
0.60 & 0.20 & 0.58 & 0.05 & 0.22 & 0.64 & 0.04 & -0.13 & 0.16 & 0.65 & 0.06 & 0.21 & 0.00 \\
0.60 & 0.33 & 0.57 & 0.09 & 0.33 & 0.57 & 0.08 & 0.10 & 0.30 & 0.49 & 0.08 & 0.29 & 0.17 \\
0.59 & 0.22 & 0.58 & 0.15 & 0.21 & 0.54 & 0.14 & 0.23 & 0.21 & 0.35 & 0.11 & 0.43 & 0.23 \\
0.64 & 0.10 & 0.64 & 0.06 & 0.11 & 0.68 & 0.05 & -0.09 & 0.03 & 0.73 & 0.09 & 0.15 & 0.08 \\
0.64 & 0.14 & 0.63 & 0.03 & 0.15 & 0.67 & 0.03 & -0.05 & 0.08 & 0.68 & 0.06 & 0.20 & 0.09 \\
0.61 & 0.23 & 0.59 & 0.02 & 0.22 & 0.53 & 0.01 & 0.30 & 0.21 & 0.37 & 0.00 & 0.37 & 0.33 \\
0.31 & 0.14 & 0.30 & 0.07 & 0.10 & 0.14 & 0.08 & 0.68 & 0.08 & 0.00 & 0.09 & 0.14 & 0.69 \\
\hline
\end{tabular}




\section{APPENDIX C}

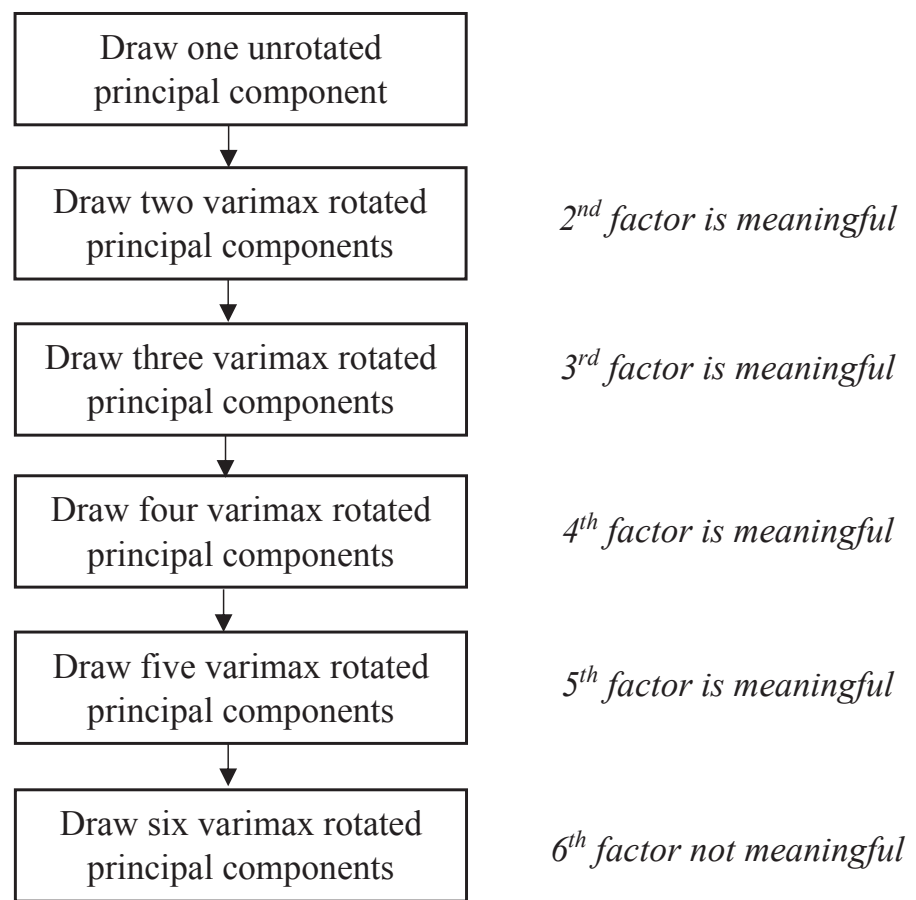

Decision flow chart Bass-Ackwards approach 




\section{CHAPTER 3}

Provoked Aggression, Psychopathy and Narcissism: Comparing the Impact of Social Exclusion and Insult

This chapter is published as: Van Teffelen, M.W., Vancleef, L.M.G., \& Lobbestael, J. (2021). Provoked Aggression, Psychopathy and Narcissism: Comparing the Impact of Social Exclusion and Insult. Psychology of Violence, 11(1), 82-91. https://doi.org/10.1037/vio0000340 
Numerous provocations cause aggressive behavior. However, different provocation procedures are rarely directly compared. This study examined whether two different provocations (i.e., social exclusion and insult) were equally effective in terms of producing aggressive behavior, negative affective change, and threat perception. As psychopathic and narcissistic personality traits may moderate provoked aggression, the current study also explored the differential impact of psychopathic and narcissistic traits on these variables. A male $(N=94)$ community sample was randomly allocated to receive negative social belonging feedback (i.e., social exclusion) or negative intelligence feedback (i.e., insult) by a confederate. Aggressive behavior was measured using a competitive reaction time task (CRTT) after provocation. Here, aggressive behavior before first provocation (i.e., noise blast) by the opponent reflected unprovoked aggression, while aggressive behavior after first provocation reflected provoked aggression. Negative affect was measured pre- and post-provocation and threat perception was measured post-provocation. Results showed that both provocations were equally effective in producing aggressive behavior, negative affective change, and threat perception. An explorative analysis revealed that increased threat perception suppresses initial aggressive responding under condition of agentic threat in narcissistic people. Also, decreased negative affective change during provocation suppressed aggressive responding in people with psychopathic traits. The findings suggest that both provocations can interchangeably be implemented to study provoked aggression. Emotional blunting may protect against detrimental provocation effects in people with psychopathic traits. Under conditions of agentic threat narcissistic traits related to withholding aggressive responding after first provocation, lashing out when a new threat emerges. 


\section{INTRODUCTION}

To prevent aggressive behavior and its destructive consequences it is vitally important to identify and comprehend the effects of its' situational antecedents. Provocations that predict aggressive behavior are, for example, electric shocks (Taylor, 1967), aversive noise blasts (Bushman, 1995), social exclusion (Twenge et al., 2001) and poor evaluation (Bushman \& Baumeister, 1998). Although these provocations predict aggression, knowledge on potential differences between diverse provocation techniques in eliciting aggression and other outcome measures is still limited. Two available studies found that guided imagination of a fictive angerevoking event resulted in increased self-reported anger, compared to autobiographical recall of an anger-evoking event (Jallais \& Gilet, 2010; Zhang et al., 2014). Another study compared the impact of four provocation methods (i.e., an anger-evoking film clip, autobiographical recall of an anger-evoking event, punishment, and harassment) and observed increased physiological responding after autobiographical recall and harassment, but no significant difference in self-reported anger across the four methods (Lobbestael et al., 2008). Yet, between-domain (e.g., physical versus psychological provocation), or even within-domain (e.g., experiencing shocks versus loud noises) head-to-head comparisons of provocations on a behavioral level are sparse. Consequently, the relative strength of previously observed provocation effects on aggressive behavior is unclear, limiting (meta-analytical) comparability. Also, provocation methods may operate through different (e.g., emotional, or cognitive) pathways. In the present work we will directly compare provocation methods on a behavioral, emotional, and cognitive level.

The effects of provocation on aggressive behavior are often studied in the context of personality factors such as psychopathy and narcissism because these factors predispose to behave aggressively (Hyatt et al., 2019; Rasmussen, 2016; Reidy et al., 2011). On the one hand, psychopathy is characterized by affective deficiency. Studies generally find two psychopathy factors (Harpur et al., 1989); one factor representing a personality dimension (i.e., egocentricity, lack of empathy, lack of guilt and impaired affective processing), and the other factor representing a behavioral dimension (i.e., unstable, and antisocial lifestyle or social deviance). On the other hand, narcissistic people tend to harbor a cognitive-affective preoccupation with the self, including grandiose self-expectations, superiority, and entitlement (Emmons, 1987; Raskin \& Hall, 1979).

Evidence of the impact of psychopathic traits on provoked aggression is mixed. Studies in forensic populations (e.g., Williamson et al., 1987) roughly observed no or negative relationships between psychopathy on provoked aggression, while studies in non-forensic populations (e.g., Lotze et al., 2007) demonstrated a stronger positive relationship between psychopathic traits and provoked aggression. For example, one study showed that psychopathic traits and 
aggression were positively related, but only after participants were provoked twice in a row (Jones \& Paulhus, 2010). This has led some authors to propose that dysregulated affect in people with psychopathic traits, or 'emotional blunting', may negatively attenuate the relationship between psychopathic traits and provoked aggression (i.e., mediation) (Reidy et al., 2011).

In contrast, narcissistic traits were consistently found predictive of provoked aggression, for example after receiving poor evaluation (Bushman \& Baumeister, 1998), social exclusion (Twenge \& Campbell, 2003), or noise blasts (Reidy et al., 2008). One theory that can account for the narcissism-aggression relationship is the threatened egotism theory. This states that people with an inflated sense of self respond with retaliation after provocation to restore self-esteem (Baumeister et al., 1996; Rasmussen, 2016). Moreover, there is reason to believe that narcissistic people may respond more aggressively to threats in the agentic domain (i.e., personal achievements and power) compared to threats in the communal domain (i.e., social acceptance) (Konrath et al., 2006). For example, narcissistic people have been shown to be less concerned about social relationships (Raskin et al., 1991) and are willing to sacrifice social acceptance to gain power (Park et al., 2013). Hence, narcissistic traits may predispose to perceiving a provocation as threatening, and especially so under conditions of agentic threat when compared to a communal threat. Following the threatened egotism theory increased threat perception would then lead to aggressive responding (i.e., moderated mediation).

Taken together, studies sparsely investigated the differential impact of provocation methods on aggressive behavior and their relationship with psychopathic and narcissistic personality traits. The primary goal of current study therefore is to extend on earlier findings by comparing two provocation procedures. To enable comparability, we selected a social exclusion and an insult procedure from the literature that were matched on procedural similarity. As we expected the two provocations to have comparable outcomes, we opted to use a Bayesian statistical approach. A Bayesian approach has the advantage that both a null-hypothesis and an alternative hypothesis can be tested. The secondary goal was to explore relationships between psychopathic traits, narcissistic traits, and aggression. Because previous studies investigated psychopathic and narcissistic traits in relative isolation of each other both traits were statistically residualized to assure personality-trait specific conclusions. Specifically, we hypothesized that:

1. Social exclusion and insult will be equal in terms of our primary outcome, i.e., aggressive behavior, and secondary outcomes, i.e., change in negative affect and perceived threat.

2. Psychopathic traits are negatively associated with negative affective responding in response to threat and, in turn are negatively associated with aggressive responding.

3. Narcissistic traits are positively associated with perceived threat, especially under conditions of agentic threat and, in turn, are positively associated with aggressive responding (i.e., moderated mediation). 


\section{METHODS}

\section{Participants}

Participants were recruited through the use of flyers on university campus. Inclusion criteria were age between 18 and 60 and male gender. Advanced level psychology students were excluded due to expected familiarity with the study's procedures and knowledge of the study's topic. Women were excluded to prevent floor effects because psychopathic and narcissistic traits are more prevalent in men (Coid \& Yang, 2011; Grijalva et al., 2015). The main hypothesis was tested using Bayesian statistical analysis. Therefore, traditional power analysis was not possible. In Bayesian statistical analysis, "one uses an entire distribution of parameters instead of a single point value for the effect size" (Kruschke, 2013). Specifically, precision planning in Bayesian statistical analysis uses posterior distributions of previous data. As such distribution is absent at present, a default prior distribution was chosen. For more information on this, see Kruschke and Liddell (2018). In total, 94 people entered the study. To give an indication of the relative precision of the present data set in frequentist statistical terms, a group size of $N_{1}=N_{2}=47$ would have enabled the detection of a between subjects difference in CRTT response of .36 with $80 \%$ power, using a standard deviation of $S D=.63$ (Bobadilla et al., 2013) and $a=.05$. Prior to conducting data analysis, we excluded people who did not believe the provocation procedures $(n=8)$. The final sample thus consisted of $N=86$ people with a mean age of 28 years, of who the majority was student (76\%). Sample characteristics are shown in Table 1. Analyses showed that the groups did not significantly differ in age, nationality, education level and current work situation.

\section{Experimental Provocations}

\section{Social Exclusion: Negative Social Belonging Feedback}

In this condition, participants were told that we were interested in testing different aspects of social interaction and that they were to interact with a second participant, who was in fact a female confederate. In this interaction task, the participant and the confederate were set in separate rooms and received the instruction that they were to engage in interaction by speaking to each other through a microphone. During the task one of them would take on the role of 'speaker' while the other would take on the role of 'evaluator'. We told the participants that these roles were assigned to them randomly, whereas in reality participants always received the role of speaker. When the task started, the evaluator (i.e., the confederate) read aloud questions from the Relationship Closeness Induction Task (Sedikides et al., 1999). The sequence of questions started out with general questions (e.g., "What is your first name?" and "How old are you?") and gradually became more personal (e.g., "Describe the last time you felt lonely" and "If you could change one thing about yourself, what would that be?"). The speaker (i.e., the participant) answered these questions. Each minute the evaluator then supposedly rated on a scale from one to seven 
to what degree she would like to get to know the speaker (one = "not at all" to seven = "very much"). This rating was then projected as bogus feedback on the participant's computer screen with seven colored squares. Squares lit up red or green (i.e., deeper red for lower ratings and brighter green for higher ratings) when the evaluator provided a rating. To induce social exclusion, participants were presented with five ratings, one rating per minute in the sequence: seven-five-three-three-two. Thus, by the end of the task the participants were under the impression that the confederate did not want to get to know them. This procedure lasted six minutes and is similar to other studies that were designed to elicit social exclusion (Buckley et al., 2004). This procedure has been shown to increase negative affect with a standardized effect size of $Z=.60$ (as reported in Blackhart et al., 2009).

\section{Table 1}

Sample characteristics

\begin{tabular}{lccc}
\hline & \multicolumn{2}{c}{ Condition } & Statistical group difference \\
& $\begin{array}{c}\text { Social exclusion } \\
(n=42)\end{array}$ & $\begin{array}{c}\text { Insult } \\
(n=44)\end{array}$ & \\
\hline Age in years, mean (SD) & $26.21(11.31)$ & $29.68(13.00)$ & $Z=1.34, p=.182$ \\
Nationality, $n$ (\%) & $25(29)$ & $25(29)$ & \\
Dutch & $10(12)$ & $16(19)$ & \\
German & $4(5)$ & $2(2)$ & \\
Other European & $3(3)$ & $1(1)$ & \\
Non-European & & & \\
Education, $n$ (\%) & $0(0)$ & $0(0)$ & \\
Low & $27(31)$ & $29(34)$ & \\
Middle & $10(12)$ & $11(13)$ & \\
High & & $10(12)$ & \\
Work situation, $n$ (\%) & $5(6)$ & $29(34)$ & \\
Employed & $31(36)$ & $5(6)$ & \\
Student & $6(7)$ & & \\
Unemployed & &
\end{tabular}

\section{Insult: Negative Intelligence Feedback}

In this condition, participants were asked to freely estimate their IQ prior to engaging in a frustrating "Trivial Pursuit" task, where participants were asked to answer forced choice questions of general knowledge (Lobbestael et al., 2008). The participants were informed that research shows that these general knowledge questions form an estimation of the participants' IQ. The task took about 20 minutes and at four predefined time-points a 
female lab-assistant provided the participant with negative verbal comments such as "You should try harder" or "This way you will not get a good estimation". During the task, the experimenter left the room to provide the student-assistant the opportunity to practice her skills in guiding the task. After the questionnaire, participants received standardized bogus feedback indicating that they had only achieved an average score on the test, and that such a score is unusual and unacceptable for a college student. If participants were non-students, the bogus feedback indicated that they had only achieved an average score on the test, and that this score was lower than they predicted. Research showed that that this procedure significantly increases anger (Gilbert \& Thompson, 1999; Jäncke, 1996; Lobbestael et al., 2008).

\section{Aggression}

Aggressive behavior was measured using a competitive reaction time task (CRTT) (Warburton \& Bushman, 2019). In this task, participants engaged in a game against a computer of whom they thought it was another participant. The goal was to click the mouse button as fast as possible on a rectangle when it changed from yellow to red. The time it took to turn from yellow to red randomly varied between 1000 and 2000 ms. The player that supposedly reacted fastest won the trial. In reality, the game was programmed to let the player win in approximately $50 \%$ of trials, in a total of 25 trials (see Appendix A for the pre-set trial specifications of intensity, duration and win/lose). The participant that lost received the unpleasant tone. The duration and loudness of this tone was determined by the other player prior to each trial, with a maximum of $100 \mathrm{~dB}$. The registered loudness and duration of tones served as a quantitative index of physical aggression (Giancola \& Parrott, 2008). At present, there is no consensus on how to score the CRTT. To avoid 'cherry picking', we followed the scoring procedure described by Brugman et al. (2015). First, principal components analysis (PCA) with orthogonal rotation was run to determine the underlying data structure. As the number CRTT trials variables high (i.e., 2 times 25) and sample size was rather small we decided to cluster CRTT trials based on three characteristics: response type (intensity/duration), preceding experience (win/loss) and phase (before/after receiving a first noise blast by the opponent). This resulted in eight items (e.g., trials won before first provocation - intensity) who were entered in the PCA. Based on Scree-plot and Kaiser-criterion (i.e., eigen values greater than one) inspection the PCA resulted in 2 factors: unprovoked aggression (i.e., intensity/duration on trials before receiving a first noise blast from the opponent), and provoked aggression (i.e., intensity/duration on trials after receiving a first noise blast from the opponent). This factor structure converges with earlier findings (Brugman et al., 2015). The unprovoked and provoked aggression factor scores were used in the analysis. 


\section{Self-Report Measurements}

\section{Psychopathic Traits}

Self-reported psychopathic traits were assessed with the Dutch version of the 154-item Psychopathy Personality Inventory Revised (PPI-R) (Lilienfeld \& Widows, 2005). Items are scored on a four-point Likert scale ranging from one (not true) to four (true). Internal consistency of the scale is good -in our sample, $a=$.84- (Kimonis et al., 2013; Sörman et al., 2016). Convergent, discriminant, concurrent and construct validity have been demonstrated (Edens \& McDermott, 2010; Hughes et al., 2013; Sörman et al., 2016; Uzieblo et al., 2010).

\section{Narcissistic traits}

Self-reported narcissistic traits were measured with the Dutch version of the Narcissistic Personality Inventory (Raskin \& Hall, 1979), an index of grandiose narcissism. We used a 37-item multiple choice version (Emmons, 1987). Items were scored on a seven-point Likert scale ranging from one (I do not at all agree) to seven (I entirely agree). Although high internal consistency levels are generally found, -in our sample, $a=.87$-, evidence of its' construct validity is mixed (Ackerman et al., 2010; Miller et al., 2016). Nonetheless, strong criterion validity has been demonstrated (Miller et al., 2014).

\section{Negative Affect}

Self-reported negative affect was measured using the Dutch version of the negative affect (NA) scale of the Positive and Negative Affect Schedule (PANAS) (Watson et al., 1988). The 10-item (i.e., scared, afraid, upset, distressed, jittery, nervous, ashamed, guilty, irritable, hostile) NA-scale of the PANAS is scored on a five-point Likert scale ranging from one (not at all) to five (very much). Good internal consistency -in our sample, $a=$.83- (Leue \& Lange, 2011; Ostir et al., 2005; Watson et al., 1988) and construct, convergent and discriminant validity (Crawford \& Henry, 2004; Watson et al., 1988) have been demonstrated.

\section{Threat Perception}

Self-reported threat perception was assessed using the Dutch version of the Perceived EgoThreat Questionnaire (PETQ) (Bushman \& Baumeister, 1998). This questionnaire assesses whether the participants found the negative intelligence or negative social belonging feedback they received from the confederate during the provocation procedures malicious, threatening, and unfair. Questions were assessed on a 100-millimeter visual analogue scale (VAS), anchored by word descriptors at each end. The three items ranged from malicious to harmless, threatening to safe and unfair to fair. All items were reverse-scored and summed to indicate the level of threat perception. The total scale was found to be internally consistent $-a=.78$ - in the present sample. 


\section{Procedure}

The Ethical Review Committee Psychology and Neuroscience at Maastricht University provided ethical approval to carry out the study (ECP-145 07_10_2014). At sign-up, people were randomly assigned to either social exclusion or insult. When participants arrived at the lab, the experimental procedure was explained, followed by agreement of informed consent. The procedural explanation depended on the relevant condition. After agreeing upon participation, demographic variables and negative affect were assessed. Next, participants engaged in one of the two provocation procedures, followed by measurement of NA and threat perception. Then, participants played the noise blasting game (CRTT) to measure aggression. The participants were told that the current study was being run in several labs spread across universities. In addition, they were told that they would play the game against an unknown player on our network. To support the believability of our manipulation, we told the participants that every experimenter at the different labs was tracking their participants' progress on a mobile phone application, so that every experimenter had an online overview of available participants. This (bogus) application was shown to the participants. Lastly, psychopathic, and narcissistic personality traits were assessed (in random order). Afterwards, participants were extensively debriefed about the nature of the experiment. In addition, an exit-interview was performed. Using open-ended questions, the participants were asked what they thought the experiment was about, what they thought of the student-assistant/other participant (i.e., played by the same confederate), and what they thought of their opponent during the reaction time game (i.e., CRTT). Responses were scored by the interviewer on a three-point scale (i.e., whether participants believed, doubted, or did not believe the manipulations). People were excluded from data analysis when they indicated that they totally did not believe the manipulations (e.g., by indicating that the CRTT opponent was a computer, or by indicating that the assistant/confederate was playing a role). Lastly, participants were thanked for their participation, and received a gift voucher or course credit if they were students. One experimental session lasted 75 minutes on average.

\section{Statistical Analysis}

SPSS version 23 was used for inferential statistical analysis. JASP (JASP Team, 2018) was used for Bayesian statistical analysis, as we had no a priori expectations on group differences between our social exclusion and insult conditions. By using Bayesian statistics for this part of the analysis we wanted to examine whether the data fit to a null-hypothesis (i.e., no group difference) or to an alternative hypothesis (i.e., a group difference). First, a Wilcoxon signedrank test was run to examine change in negative affect from pre- to post-provocation. Second, Bayes' factors were calculated to examine group means in terms of the primary outcomes, i.e., unprovoked, and provoked aggression, and the secondary outcomes, i.e., change in negative affect and threat perception. The use of Bayes factors provides an alternative way to hypothesis testing. In Bayesian statistical reasoning, one starts with a prior degree of belief 
in the possibility that (for example) there is a relationship between provoked aggression and psychopathic/narcissistic traits. Then, we collect data and adjust this prior degree of belief to the posterior degree of belief. A Bayes factor $\left(\mathrm{BF}_{10}\right)$ is an index for the degree that the prior belief is re-allocated to the posterior belief (Kruschke \& Liddell, 2018). Bayes' factors were interpreted using interpretation categories (i.e., to determine the strength of a Bayes' factor) according to Jeffreys (1961). ${ }^{1}$ Third, relationships between the outcome variables (i.e., unprovoked aggression, provoked aggression, change in negative affect, and threat perception) and the independent variables (i.e., psychopathic, and narcissistic traits) were explored. Pearson's correlation analysis was applied to test the bivariate relationships between unprovoked and provoked aggression, change in negative affect, threat perception, psychopathic traits, and narcissistic traits. Multiple linear regression analysis was run to explore the unique predictive value of independent variables psychopathic and narcissistic traits (i.e., residualized) on dependent variables unprovoked and provoked aggression, change in negative affect, and threat perception. All predictors were simultaneously entered in the model. Last, (moderated)-mediation models were tested using the PROCESS Macro version 3.4 for SPSS (Hayes, 2013). In the psychopathy mediation model psychopathic traits were entered as independent variable, change in negative affect as mediator variable and provoked aggression as independent variable. In the narcissism moderated-mediation model narcissistic traits were entered as independent variable, perceived threat as mediator, condition as moderator (between narcissistic traits and perceived threat) and unprovoked aggression as dependent variable.

\section{RESULTS}

For means and standard deviations of study variables, see Table 2. All variables were normally distributed, except for the positively skewed negative affect indices (i.e., the value 0 is outside the $+/-2{ }^{*}$ standard error interval of the skewness value). Psychopathic and narcissistic trait scores resembled those of other studies using non-clinical male samples (Lobbestael et al., 2014; Uzieblo et al., 2010). Table 2 shows that there were no group differences at baseline regarding psychopathy, narcissism, and NA scores, indicating successful random group allocation.

1 Bayes' Factor $\left(\mathrm{BF}_{10}\right)$ categories, where $\mathrm{H}_{1}=$ the alternative hypothesis and $\mathrm{H}_{0}=$ the null hypothesis are as follows. $\mathrm{BF}_{10}>100$ : extreme evidence for $\mathrm{H}_{1} . \mathrm{BF}_{10}=30-100$ : very strong evidence for $\mathrm{H}_{1}$. $\mathrm{BF}_{10}=10-30$ : strong evidence for $\mathrm{H}_{1}$. $\mathrm{BF} 10=3-10$ : moderate evidence for $\mathrm{H}_{1}$. $B F_{10}=1-3$ : anecdotal evidence for $\mathrm{H}_{1} \cdot \mathrm{BF}_{10}=1$ : no evidence. $\mathrm{BF}_{10}>1 / 3-1$ anecdotal evidence for $\mathrm{H}_{0} . \mathrm{BF}_{10}=1 / 3-$ 1/10: moderate evidence for $H_{0}$. $B F_{10}=1 / 10-1 / 30$ : strong evidence for $H_{0}$. $B F_{10}=1 / 30-1 / 100$ : very strong evidence for $H_{0}$. BF $F_{10}<1 / 100$ : extreme evidence for $H_{0}$. 
Table 2

Study means and standard deviations and difference testing

\begin{tabular}{|c|c|c|c|c|}
\hline & $\begin{array}{l}\text { Social exclusion } \\
\qquad \begin{array}{c}(\boldsymbol{n}=\mathbf{4 2}) \\
\text { Mean }(S D)\end{array}\end{array}$ & $\begin{array}{c}\text { Insult } \\
(\boldsymbol{n}=\mathbf{4 4 )} \\
\text { Mean (SD) }\end{array}$ & $\begin{array}{c}\text { Diff. } \\
\text { test } \\
t(p) / Z(p) \\
\end{array}$ & $\begin{array}{c}\text { Bayes' } \\
\text { factor } \\
B F_{10}\end{array}$ \\
\hline Unprovoked aggression & $-.02(1.11)$ & $.04(.92)$ & $-.38(.702)$ & .24 \\
\hline Provoked aggression ${ }^{a}$ & $.02(1.02)$ & $.08(1.07)$ & $-.27(.787)$ & .24 \\
\hline \multicolumn{5}{|l|}{ Negative affect } \\
\hline Baseline $^{b}$ & $14.43(5.59)$ & $12.57(2.65)$ & $-1.54(.124)$ & 1.24 \\
\hline Post-manipulation ${ }^{b}$ & $15.45(6.54)$ & $13.64(4.14)$ & $-1.01(.311)$ & .64 \\
\hline Change $^{b}$ & $1.02(3.74)$ & $1.07(3.32)$ & $.336(.737)$ & .23 \\
\hline Threat perception & $39.92(18.84)$ & $46.67(24.54)$ & $-1.43(.157)$ & .55 \\
\hline Psychopathy & $297.86(28.60)$ & 298.59 (31.58) & $-.11(.910)$ & .23 \\
\hline Narcissism & $148.31(22.32)$ & $151.53(23.62)$ & $-.65(.519)$ & .27 \\
\hline
\end{tabular}

Note. $B F_{10}=$ Bayes factor. ${ }^{a} \mathrm{n}=7$ cases were excluded who did not believe the aggression manipulation. bThese variables were not normally distributed.

First, a Wilcoxon signed-rank test was run to test the prediction that negative affect increases after provocation. The test was run on baseline and post-provocation scores averaged across condition and showed that negative affect increased from pre- $(M=13.48, S D=4.42)$ to post$(M=14.52, S D=5.49)$ provocation, $Z=2.09, p=.037, d=.46$. These results suggest that our provocation procedures increased negative affect.

Then, Bayesian statistical analysis was performed to examine differences or equality between social exclusion and insult, in terms of (un)provoked aggression, change in negative affect, and threat perception (Hypothesis 1). The null hypothesis (i.e., no difference) was tested against the alternative hypothesis that there was a difference in terms of these variables. In the analyses with provoked aggression as (dependent) variable, seven people were suspicious after they first received a noise blast from the opponent and thus removed from all further analyses. Bayes' factors (see Table 2) indicate moderate evidence in favor of the null hypothesis. More precisely, these findings indicate that for unprovoked aggression, provoked aggression, negative affective change, and threat perception, the data was respectively $1 / B F_{10}=4.16$, $4.15,4.35$, and 1.81 times more likely to have occurred under the null-hypothesis than under the alternative hypothesis. In other words, there was no difference between social exclusion and insult in terms of unprovoked and provoked aggression, negative affective change, and threat perception. 
Next, Pearson's correlation analyses were run on all study variables (Table 3). These bivariate analyses were explorative in nature. The results showed a positive association between provoked aggression and negative affective change $(p=.015)$ only, while all other correlations between the diverse outcome variables were non-significant ( $p$ 's $>.056$ ). The data further revealed a positive relationship between psychopathy and narcissism $(p<.001)$. The results also showed that narcissism was linked with increased threat perception $(p=.020)$. All other relations were found to be non-significant ( $p$ 's $>.060)$.

\section{Table 3}

Pearson's correlations aggression, negative affect change, ego-threat, and psychopathic and narcissistic traits

\begin{tabular}{|c|c|c|c|c|c|c|}
\hline & UA & $\mathrm{PA}^{\mathrm{a}}$ & NA change ${ }^{b}$ & Threat perception & Psychopathy & Narcissism \\
\hline UA & 1 & & & & & \\
\hline $\mathrm{PA}^{\mathrm{a}}$ & .02 & 1 & & & & \\
\hline NA change ${ }^{b}$ & -.09 & $.29^{* *}$ & 1 & & & \\
\hline Threat perception & -.20 & -.01 & .17 & 1 & & \\
\hline Psychopathy & .08 & -.04 & -.20 & .19 & 1 & \\
\hline Narcissism & .03 & .18 & -.07 & $.25^{*}$ & $.53^{* * *}$ & 1 \\
\hline
\end{tabular}

Note. ${ }^{a} 7$ cases excluded as they did not believe the aggression manipulation. 'bpearman's ranked correlations were calculated due to non-normality. ${ }^{*}$ significant at $p<.05$; ${ }^{* *}$ significant at $p<.01$; ${ }^{* * *}$ significant at $p<.001$. NA = negative affect; $U A=$ unprovoked aggression; $P A=$ provoked aggression .

Then, multiple linear regression analyses were run to closer inspect the unique (i.e., residualized) multivariate relationships between residualized psychopathic and narcissistic traits and unprovoked aggression, provoked aggression, change in negative affect, and threat perception. Results are shown in Table 4. The findings suggest that residualized psychopathic traits were unrelated to aggression, change in negative affect, and threat perception. ${ }^{2}$ The results also show that residualized narcissistic personality traits were positively related to provoked aggression, but unrelated to unprovoked aggression, change in negative affect, and threat perception. Closer inspection of multicollinearity diagnostics reveals a variance inflation factor of 1.47, not exceeding a critical threshold of 10 (Hair et al., 1995). In short, residualized narcissistic traits were positively related to aggressive responding after provocation.

2 For completeness, when people who were suspicious of the CRTT manipulation were retained in the model psychopathic traits did negatively predict provoked aggression at $\beta=-.27, p=.033$. 


\section{Table 4}

Multiple linear regression of aggression, negative affect change and threat perception on psychopathic and narcissistic traits

\begin{tabular}{|c|c|c|c|c|}
\hline & $\mathrm{B}$ & SE & $\beta$ & $p$ \\
\hline \multicolumn{5}{|c|}{ DV: unprovoked aggression $R^{2}=.01, F(2,83), p=.748$} \\
\hline Psychopathic traits & .00 & .00 & .09 & .478 \\
\hline Narcissistic traits & -.00 & .01 & -.02 & .885 \\
\hline \multicolumn{5}{|c|}{ DV: provoked aggressiona $R^{2}=.07, F(2,76), p=.078$} \\
\hline Psychopathic traits & -.01 & .01 & -.21 & .116 \\
\hline Narcissistic traits & .01 & .01 & $.31^{*}$ & .026 \\
\hline \multicolumn{5}{|c|}{ DV: negative affect change $R^{2}=.04, F(2,83), p=.158$} \\
\hline Psychopathic traits & -.03 & .02 & -.23 & .070 \\
\hline Narcissistic traits & .01 & .02 & .05 & .671 \\
\hline \multicolumn{5}{|c|}{ DV: threat perception $R^{2}=.07, F(2,83), p=.057$} \\
\hline Psychopathic traits & .06 & .09 & .07 & .553 \\
\hline Narcissistic traits & .20 & .12 & .21 & .095 \\
\hline
\end{tabular}

Note. ${ }^{*}$ significant at $p<.05 ;{ }^{* *}$ significant at $p<.01 .{ }^{a} 7$ extra case excluded as they did not believe the aggression manipulation; when cases are included psychopathic traits significantly predict provoked aggression. DV = dependent variable.

Following this, a multiple regression model was run to test the hypothesis that psychopathic traits are negatively associated with negative affective responding in response to threat and, in turn are negatively associated with aggressive responding (i.e., mediation model) (Hypothesis 2). The results showed that psychopathic traits negatively related to negative affective change from pre- to post-provocation (i.e., $t=-2.37, p=.020$ ) and that negative affective change positively related to provoked aggression (i.e., $t=2.68, p=.009$ ). The direct relationship between psychopathic traits and provoked aggression was not significant $(p=$ .738). The results suggest that decreased negative affective change suppressed aggressive responding in people with psychopathic traits.

Last, a multiple regression model was run to test the hypothesis that narcissistic traits are positively associated with perceived threat, especially under conditions of agentic threat and, in turn, are positively associated with aggressive responding (i.e., moderated mediation). (Hypothesis 3). The results showed that there was no meaningful interaction between narcissistic traits and condition in terms of perceived threat $(p=.092)$. Closer inspection of simple effects revealed a positive relationship between narcissistic traits and perceived threat in the insult condition (i.e., $t=2.86, p=.005$ ), whereas there was no significant relationship between narcissistic traits and perceived threat in the social exclusion condition (i.e., $t=.31$, $p=.756$ ). In turn, perceived threat related negatively to unprovoked aggression (i.e., $t=-2.07$, 
$p=.042)$. The direct relationship between narcissistic traits and unprovoked aggression was not significant $(p=.433)$. The findings suggest that perceived threat in the insult condition suppresses provoked aggressive responding before being provoked during CRTT in individuals with narcissistic traits.

\section{DISCUSSION}

This study compared social exclusion and insult provocations in terms of aggressive behavior, change in negative affect, and threat perception in a male community sample. We predicted comparable effects on all variables for both provocations. Moreover, we explored the impact of psychopathic and narcissistic traits on these variables.

The main findings are in line with our prediction that social exclusion and insult are equal in terms of producing aggression (Hypothesis 1). This converges with earlier observations (Berkowitz, 1960; Bushman \& Baumeister, 1998; Twenge et al., 2001; Twenge \& Campbell, 2003). Interestingly, the findings also show that social exclusion and insult produce negative affect and threat perception - our secondary outcome measures. This converges with earlier findings showing that social exclusion and insult predict negative affect (Blackhart et al., 2009; Buckley et al., 2004; Gilbert \& Thompson, 1999; Jäncke, 1996; Lobbestael et al., 2008) and threat perception (Bushman \& Baumeister, 1998). One explanation for social exclusion and insult to equally produce aggressive behavior therefore is that they impact on similar mediators: the levels of negative affective state and perceived threat. Indeed, the present findings show that social exclusion and insult are equal in producing negative affect and threat perception. This is in line with the social information processing model of aggression, that predicts aggressive behavior when other people's intentions are attributed as hostile (Crick \& Dodge, 1994; Epps \& Kendall, 1995) or when people are in a negative affective state (Lemerise \& Arsenio, 2000). Despite the distinctive nature of both provocation methods (i.e., negative social belonging versus negative intelligence feedback) they thus appear to equally produce aggression, negative affect, and perceived threat. This implies that future research may interchangeably implement any of the two methods to study psychologically provoked aggression.

The findings further reveal no bivariate or multivariate associations between psychopathic traits and aggression, negative affect, and threat perception. Moreover, it was observed that negative affective change during social inclusion and insult suppressed aggressive responding curing CRTT (Hypothesis 2). The findings on the relationship between psychopathic traits and aggressive behavior converge with other studies (Bobadilla et al., 2013; Jones \& Paulhus, 2010 , provocation 1). The present findings diverge with two other studies. A first study reported 
a positive relationship between psychopathy and provoked aggressive behavior after experiencing a combination of negative essay feedback and noise blasts (Jones \& Paulhus, 2010, provocation 2). A second study reported a positive relationship between psychopathic traits and aggressive behavior after insult (Denson et al., 2009). One possible explanation for the current pattern of findings is that psychopathic traits predispose to emotional blunting for provocation. A first notion that supports this is that psychopathy theoretically relates to emotional blunting, because deficient affective responding is one of the core criteria of psychopathy (Harpur et al., 1989). Emotional blunting is therefore inherent to psychopathy. A second notion that supports this is that psychopathic patients demonstrate impairments in physiological responding (e.g., P300 amplitude and P300 latency) to aversive stimuli (Gao \& Raine, 2009). When we calculated the bivariate correlation between the fearless dominance factor (i.e., a factor indicative of emotional blunting) and negative affective change we found that fearless dominance was negatively correlated to negative affective change $(r=-.30, p=$ .004). Importantly, the relationship between overall psychopathic traits and negative affective change in the present study just failed to reach significance, potentially indicating a power problem.

Results on the impact of narcissistic traits reveal a unique predisposition to respond with aggressive behavior, but only when provoked twice (e.g., after social exclusion and receiving a noise blast during CRTT) and when psychopathic traits were controlled for. Our findings further indicate that narcissistic traits predispose to perceive both provocations as threatening, although this effect became (marginally) non-significant when psychopathic traits were controlled for. In line with our predictions, we showed that narcissistic traits related positively to perceiving an insult (i.e., an agentic threat) as more threatening than social exclusion (i.e., a communal threat) (Hypothesis 3). In contrast, we observed that threat perception suppressed aggressive responding prior to being provoked during CRTT. We hereby partly replicated previous work observing that narcissism positively predicted aggressive responding after social exclusion or insult (Bushman \& Baumeister, 1998; Ferriday et al., 2011; Martinez et al., 2008; Twenge \& Campbell, 2003), or when psychopathic traits were controlled for (Jones \& Paulhus, 2010). Also, we replicated that narcissistic traits positively related to threat perception under agentic than under communal threat (Konrath et al., 2006). Specifically, we demonstrated a positive relationship between narcissistic traits and aggressive behavior, but solely after participants obtained noise blasts during the CRTT. This finding may indicate that narcissistic traits may predispose to enter a preparatory, or 'ready-to-attack' state after psychological provocation, focusing their attack on someone (i.e., in our case the CRTT opponent) only after the opponent behaves aggressively (i.e., through blasting noise). Although this reasoning seemingly contradicts the finding that narcissistic traits predispose to displayed aggression (i.e., aggression to an unknown third person) after provocation (Bushman \& Baumeister, 1998; Twenge \& Campbell, 2003), such an interpretation converges with a study observing a 
dampened narcissism-displayed aggression relationship in case people judge a threat 'not ambiguous' (Martinez et al., 2008). Hence, narcissistic traits may predispose to enter a 'readyto-attack' or brooding state when confronted with a perceived unambiguous threat, lashing out when a new threat emerges. Importantly, it has been debated that it is problematic to 'statistically correct' psychopathic and narcissistic traits for each other given the high linear inter-relationship. For example, it was shown that narcissism no longer correlated to selfreported aggressiveness after statistically correcting for psychopathy (Vize et al., 2018). The present findings show the opposite. That is, the data revealed a positive association between aggression and narcissism, but only when psychopathic traits were controlled for. Closer inspection of multicollinearity diagnostics revealed that psychopathic traits did not inflate the effect of narcissism on aggression in the present dataset.

\section{LIMITATIONS}

Several limitations impacted the present findings. First, the sample consisted of (healthy) male, predominantly student participants recruited in the general population, troubling the generalization of these findings across gender and to the clinical range of psychopathy and narcissism. Second, our explorative analysis on the relationship between our personality measures and negative affect, threat perception, and aggressive behavior was statistically underpowered. Therefore, these findings require replication. Third, the main aim of the present study was to determine the relative impact of two established provocation procedures. The design therefore did not include a control condition. Although each experimental procedure reliably invoked anger and aggression inclinations in previous work (Buckley et al., 2004; Bushman \& Baumeister, 1998; Gilbert \& Thompson, 1999; Lobbestael et al., 2008), from this work alone we cannot demonstrate that social exclusion and insult produce more aggression than a control condition. Lastly, the present study examined aggressive responding to an unknown person (i.e., displaced aggression). It would be interesting to observe whether the provoked aggression effect changes or differentiates when people are allowed to respond aggressively to their insulter/rejecter.

\section{RESEARCH IMPLICATIONS}

The present study was primarily designed to directly compare two provocation procedures. Consequently, the present study did not include enough participants to extensively examine trait by condition interaction effects as testing these effects would greatly inflate the chance of type I and II errors. This leaves a number of important questions open to be answered. First, future studies that compare provocation conditions should ideally include a control condition, 
strengthening the conclusion that the tested conditions lead to more aggression than a control condition. Second, given that narcissistic and psychopathic women have shown to respond to provocations in similar ways as males we highly recommend future research to include both genders (Fossati et al., 2010; Wallace et al., 2012). Related to this, there is evidence that men display more dominance than women (Colarelli et al., 2006) and male-male dominance may be expressed differently than male-female dominance (Hayduk, 1983). For this reason, we decided to include a female confederate. As dominance challenges have been shown to be a function of psychopathy levels (Lobbestael et al., 2018), it would be interesting for future research to investigate aggressive responding by same-sex provocateurs.

\section{PREVENTION AND CLINICAL IMPLICATIONS}

The present findings stress that threat perception and affect reactivity may be important targets in prevention and intervention efforts. For example, hostile interpretation bias, a construct related to threat perception, has been shown to be successfully reduced by cognitive bias modification training in students (Hawkins \& Cougle, 2013). The current findings further indicate that threat perception may be an especially important prevention and intervention target in people with narcissistic traits, who show increased threat perception under conditions of agentic threat. With regard to people with psychopathic traits the present findings indicate that emotional blunting may be an important clinical implication. Also, the provocations operationalized in this study apparently do not push the emotional buttons of people with psychopathic traits. Perhaps this may be different when these provocations are executed by people that they feel attached to.

\section{CONCLUSIONS}

In sum, this study showed that social exclusion and insult were comparable in producing aggressive behavior, negative affective change, and threat perception. We also observed a positive relationship between aggressive behavior after "double" provocation and narcissistic traits. This pattern of findings provides novel evidence on the equal impact of social exclusion and insult and fits with current theoretical models evidencing emotional blunting in psychopathic people and increased provoked aggression in narcissistic people. Last, although the findings suggest that while both provocations can interchangeably be implemented to study provoked aggression, the procedures may differentially impact narcissistic people. 


\section{REFERENCES}

Ackerman, R. A., Witt, E. A., Donnellan, M. B., Trzesniewski, K. H., Robins, R. W., \& Kashy, D. A. (2010). What does the narcissistic personality inventory really measure? Assessment, 1073191110382845.

Baumeister, R. F., Smart, L., \& Boden, J. M. (1996). Relation of threatened egotism to violence and aggression: The dark side of high self-esteem. Psychological Review, 103(1), 5.

Berkowitz, L. (1960). Repeated frustrations and expectations in hostility arousal. Journal of Abnormal and Social Psychology, 60(3), 422-429. https://doi.org/10.1037/h0044601

Blackhart, G. C., Nelson, B. C., Knowles, M. L., \& Baumeister, R. F. (2009). Rejection elicits emotional reactions but neither causes immediate distress nor lowers self-esteem: a meta-analytic review of 192 studies on social exclusion. Personality and Social Psychology Review, 13(4), 269-309. https:// doi.org/10.1177/1088868309346065

Bobadilla, L., Metze, A. V., \& Taylor, J. (2013). Physical attractiveness and its relation to unprovoked and reactive aggression. Journal of Research in Personality, 47(1), 70-77. https://doi.org/10.1016/j. jrp.2012.09.004

Brugman, S., Lobbestael, J., Arntz, A., Cima, M., Schuhmann, T., Dambacher, F., \& Sack, A. T. (2015). Identifying cognitive predictors of reactive and proactive aggression. Aggressive Behavior, 41(1), 51-64. https://doi.org/10.1002/ab.21573

Buckley, K. E., Winkel, R. E., \& Leary, M. R. (2004). Reactions to acceptance and rejection: Effects of level and sequence of relational evaluation. Journal of Experimental Social Psychology, 40(1), 14-28. https://doi.org/10.1016/S0022-1031(03)00064-7

Bushman, B. J. (1995). Moderating role of trait aggressiveness in the effects of violent media on aggression. Journal of Personality and Social Psychology, 69(5), 950.

Bushman, B. J., \& Baumeister, R. F. (1998). Threatened egotism, narcissism, self-esteem, and direct and displaced aggression: Does self-love or self-hate lead to violence? Journal of Personality and Social Psychology, 75(1), 219-229. https://doi.org/10.1037/0022-3514.75.1.219

Coid, J., \& Yang, M. (2011). The impact of psychopathy on violence among the household population of Great Britain. Social Psychiatry and Psychiatric Epidemiology, 46(6), 473-480. https://doi.org/10.1007/ s00127-010-0212-4

Colarelli, S. M., Spranger, J. L., \& Hechanova, M. R. (2006). Women, power, and sex composition in small groups: an evolutionary perspective. Journal of Organizational Behavior, 27(2), 163-184. https://doi. org/10.1002/job.350

Crawford, J. R., \& Henry, J. D. (2004). The positive and negative affect schedule (PANAS): Construct validity, measurement properties and normative data in a large non-clinical sample. British Journal of Clinical Psychology, 43(Pt 3), 245-265. https://doi.org/10.1348/0144665031752934

Crick, N. R., \& Dodge, K. A. (1994). A review and reformulation of social information-processing mechanisms in children's social adjustment. Psychological Bulletin, 115(1), 74-101. https://doi.org/10.1037/00332909.115.1.74

Denson, T. F., White, A. J., \& Warburton, W. A. (2009). Trait displaced aggression and psychopathy differentially moderate the effects of acute alcohol intoxication and rumination on triggered displaced aggression. Journal of Research in Personality, 43(4), 673-681. https://doi.org/10.1016/j. jrp.2009.04.003

Edens, J. F., \& McDermott, B. E. (2010). Examining the construct validity of the Psychopathic Personality Inventory-Revised: Preferential correlates of fearless dominance and self-centered impulsivity. Psychological Assessment, 22(1), 32-42. https://doi.org/10.1037/a0018220 
Emmons, R. A. (1987). Narcissism: Theory and measurement. Journal of Personality and Social Psychology, 52(1), 11-17.

Epps, J., \& Kendall, P. C. (1995). Hostile attributional bias in adults. Cognitive Therapy and Research, 19(2), 159-178. https://doi.org/10.1007/BF02229692

Ferriday, C., Vartanian, O., \& Mandel, D. R. (2011). Public but not private ego threat triggers aggression in narcissists. European Journal of Social Psychology, 41(5), 564-568. https://doi.org/10.1002/ejsp.801

Fossati, A., Borroni, S., Eisenberg, N., \& Maffei, C. (2010). Relations of proactive and reactive dimensions of aggression to overt and covert narcissism in nonclinical adolescents. Aggressive Behavior, 36(1), 21-27. https://doi.org/10.1002/ab.20332

Gao, Y., \& Raine, A. (2009). P3 event-related potential impairments in antisocial and psychopathic individuals: A meta-analysis. Biological Psychology, 82(3), 199-210. https://doi.org/10.1016/j. biopsycho.2009.06.006

Giancola, P. R., \& Parrott, D. J. (2008). Further evidence for the validity of the Taylor aggression paradigm. Aggressive Behavior, 34(2), 214-229. https://doi.org/10.1002/ab.20235

Gilbert, S., \& Thompson, J. K. (1999). Winning or losing against an opposite-sex peer on a gender-based competitive task. Sex Roles, 41(11-12), 875-899. https://doi.org/10.1023/A:1018884513692

Grijalva, E., Newman, D. A., Tay, L., Donnellan, M. B., Harms, P. D., Robins, R. W., \& Yan, T. (2015). Gender differences in narcissism: A meta-analytic review. Psychological Bulletin, 141(2), 261-310. https://doi. org/10.1037/a0038231

Hair, J. F., Anderson, R. E., Tatham, R. L., \& Black, W. C. (1995). Multivariate data analysis New York. NY: Macmillan.

Harpur, T. J., Hare, R. D., \& Hakstian, A. R. (1989). Two-factor conceptualization of psychopathy: Construct validity and assessment implications. Psychological Assessment: A Journal of Consulting and Clinical Psychology, 1(1), 6-17. https://doi.org/10.1037/1040-3590.11.6

Hawkins, K. A., \& Cougle, J. R. (2013). Effects of interpretation training on hostile attribution bias and reactivity to interpersonal insult. Behavior Therapy, 44(3), 479-488. https://doi.org/10.1016/j.beth.2013.04.005

Hayduk, L. A. (1983). Personal space: Where we now stand. Psychological Bulletin, 94(2), 293-335. https:// doi.org/10.1037/0033-2909.94.2.293

Hayes, A. (2013). The PROCESS macro for SPSS and SAS (version 2.13)[Software].

Hughes, M. A., Stout, J. C., \& Dolan, M. C. (2013). Concurrent validity of the Psychopathic Personality Inventory-Revised and the Psychopathy Checklist: Screening Version in an Australian offender sample. Criminal Justice and Behavior, 40(7), 802-813. https://doi.org/10.1177/0093854812475135

Hyatt, C., Zeichner, A., \& Miller, J. (2019). Laboratory aggression and personality traits: A meta-analytic review. Psychology of Violence, 9(6), 675-689.

Jallais, C., \& Gilet, A.-L. (2010). Inducing changes in arousal and valence: Comparison of two mood induction procedures. Behavior Research Methods, 42(1), 318-325. https://doi.org/10.3758/BRM.42.1.318

Jäncke, L. (1996). Facial EMG in an anger-provoking situation: Individual differences in directing anger outwards or inwards. International Journal of Psychophysiology, 23(3), 207-214. https://doi.org/10.1016/ S0167-8760(96)00062-1

JASP Team. (2018). JASP(Version 0.8.4)[Computer software].

Jeffreys, H. (1961). Theory of probability (3rd ed.).

Jones, D. N., \& Paulhus, D. L. (2010). Different provocations trigger aggression in narcissists and psychopaths. Social Psychological and Personality Science, 1(1), 12-18.

Kimonis, E. R., Branch, J., Hagman, B., Graham, N., \& Miller, C. (2013). The psychometric properties of the inventory of callous-unemotional traits in an undergraduate sample. Psychological Assessment, 25(1), 84-93. https://doi.org/10.1037/a0029024 
Konrath, S., Bushman, B. J., \& Campbell, W. K. (2006). Attenuating the Link Between Threatened Egotism and Aggression. Psychological science, 17(11), 995-1001. https://doi.org/10.1111/j.1467-9280.2006.01818.x

Kruschke, J. K. (2013). Bayesian estimation supersedes the $t$ test. Journal of Experimental Psychology: General, 142(2), 573-603. https://doi.org/10.1037/a0029146

Kruschke, J. K., \& Liddell, T. M. (2018). The Bayesian New Statistics: Hypothesis testing, estimation, metaanalysis, and power analysis from a Bayesian perspective. Psychon Bull Rev, 25(1), 178-206.

Lemerise, E. A., \& Arsenio, W. F. (2000). An integrated model of emotion processes and cognition in social information processing. Child Development, 71(1), 107-118. https://doi.org/10.1111/1467-8624.00124

Leue, A., \& Lange, S. (2011). Reliability generalization: An examination of the positive affect and negative affect schedule. Assessment, 18(4), 487-501. https://doi.org/10.1177/1073191110374917

Lilienfeld, S. O., \& Widows, M. R. (2005). PPI-R: Psychopathic Personality Inventory Revised: Professional Manual. Psychological Assessment Resources, Incorporated.

Lobbestael, J., Arntz, A., Voncken, M., \& Potegal, M. (2018). Responses to dominance challenge are a function of psychopathy level: A multimethod study. Personality Disorders: Theory, Research, and Treatment, 9(4), 305-314. https://doi.org/10.1037/per0000252

Lobbestael, J., Arntz, A., \& Wiers, R. W. (2008). How to push someone's buttons: A comparison of four angerinduction methods. Cognition \& Emotion, 22(2), 353-373. https://doi.org/10.1080/02699930701438285

Lobbestael, J., Baumeister, R. F., Fiebig, T., \& Eckel, L. A. (2014). The role of grandiose and vulnerable narcissism in self-reported and laboratory aggression and testosterone reactivity. Personality and Individual Differences, 69, 22-27. https://doi.org/10.1016/j.paid.2014.05.007

Lotze, M., Veit, R., Anders, S., \& Birbaumer, N. (2007). Evidence for a different role of the ventral and dorsal medial prefrontal cortex for social reactive aggression: An interactive fMRI study. Neuroimage, 34(1), 470-478.

Martinez, M. A., Zeichner, A., Reidy, D. E., \& Miller, J. D. (2008). Narcissism and displaced aggression: Effects of positive, negative, and delayed feedback. Personality and Individual Differences, 44(1), 140-149. https://doi.org/10.1016/j.paid.2007.07.012

Miller, J. D., Lynam, D. R., \& Campbell, W. K. (2016). Measures of narcissism and their relations to DSM-5 pathological traits: A critical reappraisal. Assessment, 23(1), 3-9. https://doi.org/10.1177/1073191114522909

Miller, J. D., McCain, J., Lynam, D. R., Few, L. R., Gentile, B., MacKillop, J., \& Campbell, W. K. (2014). A comparison of the criterion validity of popular measures of narcissism and narcissistic personality disorder via the use of expert ratings. Psychological Assessment, 26(3), 958-969. https://doi. org/10.1037/a0036613

Ostir, G. V., Smith, P. M., Smith, D., \& Ottenbacher, K. J. (2005). Reliability of the Positive and Negative Affect Schedule (PANAS) in medical rehabilitation. Clinical Rehabilitation, 19(7), 767-769. https://doi. org/10.1191/0269215505cr894oa

Park, S. W., Ferrero, J., Colvin, C. R., \& Carney, D. R. (2013). Narcissism and Negotiation: Economic Gain and Interpersonal Loss. Basic and Applied Social Psychology, 35, 569-574.

Raskin, R. N., \& Hall, C. S. (1979). A narcissistic personality inventory. Psychological Reports, 45(2), 590. https://doi.org/10.2466/pr0.1979.45.2.590

Raskin, R. N., Novacek, J., \& Hogan, R. (1991). Narcissistic self-esteem management. Journal of Personality and Social Psychology, 60(6), 911-918. https://doi.org/10.1037/0022-3514.60.6.911

Rasmussen, K. (2016). Entitled vengeance: A meta-analysis relating narcissism to provoked aggression. Aggressive Behavior, 42(4), 362-379. https://doi.org/10.1002/ab.21632

Reidy, D. E., Shelley-Tremblay, J. F., \& Lilienfeld, S. O. (2011). Psychopathy, reactive aggression, and precarious proclamations: A review of behavioral, cognitive, and biological research. Aggression and Violent Behavior, 16(6), 512-524. https://doi.org/10.1016/j.avb.2011.06.002 
Reidy, D. E., Zeichner, A., Foster, J. D., \& Martinez, M. A. (2008). Effects of narcissistic entitlement and exploitativeness on human physical aggression. Personality and Individual Differences, 44(4), 865875. https://doi.org/10.1016/j.paid.2007.10.015

Sedikides, C., Campbell, W. K., Reader, G., \& Elliot, A. J. (1999). The relationship closeness induction task. Representative Research in Social Psychology, 23, 1-4.

Sörman, K., Nilsonne, G., Howner, K., Tamm, S., Caman, S., Wang, H.-X., Ingvar, M., Edens, J. F., Gustavsson, P., Lilienfeld, S. O., Petrovic, P., Fischer, H., \& Kristiansson, M. (2016). Reliability and construct validity of the Psychopathic Personality Inventory-Revised in a Swedish non-criminal sample-A multimethod approach including psychophysiological correlates of empathy for pain. PloS One, 11(6).

Taylor, S. P. (1967). Aggressive behavior and physiological arousal as a function of provocation and the tendency to inhibit aggression. Journal of Personality, 35(2), 297-310.

Twenge, J. M., Baumeister, R. F., Tice, D. M., \& Stucke, T. S. (2001). If you can't join them, beat them: Effects of social exclusion on aggressive behavior. Journal of Personality and Social Psychology, 81(6), 10581069. https://doi.org/Doi 10.1037//0022-3514.81.6.1058

Twenge, J. M., \& Campbell, W. K. (2003). "Isn't it fun to get the respect that we're going to deserve?" Narcissism, social rejection, and aggression. Personality and Social Psychology Bulletin, 29(2), 261272.

Uzieblo, K., Verschuere, B., Van den Bussche, E., \& Crombez, G. (2010). The validity of the psychopathic personality inventory-revised in a community sample. Assessment, 17(3), 334-346. https://doi. org/10.1177/1073191109356544

Vize, C. E., Lynam, D. R., Collison, K. L., \& Miller, J. D. (2018). Differences among dark triad components: A meta-analytic investigation. Personality Disorders: Theory, Research, and Treatment, 9(2), 101-111. https://doi.org/10.1037/per0000222

Wallace, M. T., Barry, C. T., Zeigler-Hill, V., \& Green, B. A. (2012). Locus of Control as a Contributing Factor in the Relation Between Self-Perception and Adolescent Aggression. Aggressive Behavior, 38(3), 213-221. https://doi.org/10.1002/ab.21419

Warburton, W. A., \& Bushman, B. J. (2019). The competitive reaction time task: The development and scientific utility of a flexible laboratory aggression paradigm. Aggressive Behavior, 45(4), 389-396. https://doi.org/10.1002/ab.21829

Watson, D., Clark, L. A., \& Tellegen, A. (1988). Development and validation of brief measures of positive and negative affect: The PANAS scales. Journal of Personality and Social Psychology, 54(6), 1063-1070.

Williamson, S., Hare, R. D., \& Wong, S. (1987). Violence: Criminal psychopaths and their victims. Canadian Journal of Behavioural Science/Revue canadienne des sciences du comportement, 19(4), 454.

Zhang, X., Yu, H. W., \& Barrett, L. F. (2014). How does this make you feel? A comparison of four affect induction procedures. Frontiers in Psychology, 5. 


\section{APPENDIX A}

Preprogramming setup of CRTT trials

\begin{tabular}{|c|c|c|c|}
\hline Trial number & Intensity & Duration & Win/lose \\
\hline 1 & 0 & 0 & Win \\
\hline 2 & 6 & 7 & Lose \\
\hline 3 & 1 & 1 & Win \\
\hline 4 & 6 & 5 & Lose \\
\hline 5 & 3 & 7 & Lose \\
\hline 6 & 5 & 2 & Lose \\
\hline 7 & 5 & 9 & Win \\
\hline 8 & 2 & 6 & Lose \\
\hline 9 & 1 & 3 & Win \\
\hline 10 & 3 & 3 & Win \\
\hline 11 & 6 & 5 & Lose \\
\hline 12 & 10 & 2 & Win \\
\hline 13 & 4 & 6 & Win \\
\hline 14 & 7 & 9 & Lose \\
\hline 15 & 3 & 10 & Lose \\
\hline 16 & 6 & 5 & Win \\
\hline 17 & 1 & 10 & Lose \\
\hline 18 & 10 & 6 & Lose \\
\hline 19 & 4 & 10 & Win \\
\hline 20 & 9 & 10 & Lose \\
\hline 21 & 6 & 4 & Win \\
\hline 22 & 2 & 3 & Lose \\
\hline 23 & 9 & 7 & Lose \\
\hline 24 & 10 & 3 & Win \\
\hline 25 & 2 & 6 & Lose \\
\hline
\end{tabular}






\section{CHAPTER 4}

The Efficacy of Incorporating Mental Imagery in Cognitive Restructuring Techniques on Reducing Hostility: A Randomized Controlled Trial

This chapter is under revision for publication as: Van Teffelen, M.W., Voncken, M.J., Peeters, F., Mollema, E.D., \& Lobbestael, J. The Efficacy of Incorporating Mental Imagery in Cognitive Restructuring Techniques on Reducing Hostility: A Randomized Controlled Trial. 


\section{ABSTRACT}

Cognitive restructuring (CR) is an effective intervention for hostility. However, the number of patients who fail to benefit suggest that the efficacy of CR can be further improved. The present study investigated whether enhancing CR with mental imagery techniques can increase its effectivity. A high hostility sample (28\% male, and $72 \%$ female) was randomized over one session of imagery enhanced CR (I-CR) $(n=34)$, traditional CR $(n=32)$ or an active control session (AC) $(n=21)$. Changes in hostile beliefs, aggressive tendencies, state anger and hostility traits were assessed pre- and post-treatment, and at 1-week follow-up. Results showed that both I-CR and CR efficaciously reduced hostile beliefs, aggressive tendencies and anger, to a stronger degree than AC. I-CR was more efficacious and sustainable over time than both $C R$ and $A C$ in reducing hostile beliefs and aggressive tendencies. The most important limitations are that this work was conducted in a non-treatment seeking sample and that the sample was rather small. In conclusion, findings suggest that implementing imagery techniques in CR for hostile beliefs enhances its' efficacy. 


\section{INTRODUCTION}

Hostility, a trait dimension that consists of a tendency to (I) behave aggressively, (II) experience angry affect and (III) hold cynical cognitions (e.g., hostile beliefs), can be considered a transdiagnostic (i.e., cross-diagnostic) phenomenon in mental disorders (Cassiello-Robbins \& Barlow, 2016). Cognitive behavioral therapy (CBT) programs have been developed for hostility and show favorable outcomes (Hofmann et al., 2012). One CBT intervention, cognitive restructuring (CR), focuses on changing hostile cognitions. Within $\mathrm{CR}$, patients are encouraged to identify and challenge hostile cognitions in past events that triggered anger and/or aggression, for example by gathering evidence for and against a hostile cognition. A meta-analysis across 23 studies showed that CR is effective in reducing hostility with moderate to large effects ( $d=0.51$ to 1.87 ) (DiGiuseppe \& Tafrate, 2003). However, this meta-analysis did not systematically assess risk of bias. Also, the overall $66 \%$ response rate (i.e., a symptom reduction of at least $50 \%$ ) of CBT for hostility suggests that there remains a significant number of patients who fail to benefit from CBT (Hofmann et al., 2012). Moreover, hostile beliefs may concentrate more on fairness, blaming, justification and cathartic expression rather than the interpretation of facts (DiGiuseppe et al., 1994). For this reason, CR for hostility may more challenging than for instance CR for anxiety-related problems. In the present work, we aim to investigate whether the efficacy of $\mathrm{CR}$ for reducing hostility can be further improved by additional other treatment components.

Previous work suggests that enhancing CR with mental imagery is a promising candidate for increasing its efficacy in reducing hostility. Indeed, the idea of integrating mental imagery in CR is not new (Edwards, 1990) and has been empirically validated for anxietyand trauma-related disorders. That is, incorporating mental imagery during CR for social anxiety disorder patients led to greater symptom reduction compared to traditional CR (e.g., McEvoy et al., 2015; McEvoy \& Saulsman, 2014), but see McEvoy et al. (2020) for contradictory evidence. Additionally, integrating the use of mental imagery into existing treatment protocols for childhood trauma related syndromes or disorders increased the effectiveness of several other interventions such as imaginary exposure and imagery rescripting (Arntz \& Weertman, 1999; Ehlers et al., 2005; Smucker et al., 1995). Furthermore, evidence suggests that imagery plays an important role in angry affect and hostility. For example, a qualitative analysis of emotions and thoughts reported during the recall of intrusive mental images demonstrated that recalling intrusive mental images positively relates to experiencing a variety of affect, including anger (Holmes et al., 2005). Also, a literature review suggests that mental images of autobiographical memories generate a stronger emotional response than its' verbal-linguistic representations (Holmes \& Mathews, 2010). Previous work suggesting that mental imagery is a promising candidate 
for increasing the efficacy of CR is in line with the ideas of Beck (1985) that "hot" (i.e., affectively valenced) cognitions should be more modifiable than "cold" (i.e., affectively unvalenced) cognitions (Beck, 1985). In sum, enhancing CR for transdiagnostic hostility with mental imagery, may potentially lead to an increase of its 'efficacy.

The primary aim of the present study is to compare the efficacy of one session 'imageryenhanced CR' (I-CR) for hostility with traditional CR and an active control (AC) condition in a sample of participants with increased hostility levels at pre- and post-intervention and at one-week follow-up. The main hypothesis is that I-CR is more efficacious than both traditional $\mathrm{CR}$ and the $\mathrm{AC}$ condition in primarily $(\mathrm{H} 1)$ reducing the believability of hostile cognitions and secondarily $(\mathrm{H} 2)$ reducing aggressive tendencies; $(\mathrm{H} 3)$ state anger and $(\mathrm{H} 4)$ hostility traits. Moreover, both interventions, I-CR and CR, are hypothesized to be more efficacious in reducing these variables than an $\mathrm{AC}$ condition. We differentiated between (T1) immediate intervention efficacy and sustained intervention efficacy at one-week follow-up (T2a) before and (T2b) after being 'provoked' by imaginarily re-exposing the participants to an idiosyncratic anger-provoking situation.

\section{METHODS}

\section{Participants}

Participants were recruited using flyers on the campus of Maastricht University, the Netherlands, and from the university's online participant database. We included participants between 18-60 years and with a raw score above .67 on the hostility scale of the Personality Inventory for DSM-5 (PID-5) (Van der Heijden et al., 2014). This cut-off equals the observed PID-5 mean in a Danish population (a comparable population to the Netherlands) (Bach et al., 2016). Sample size was determined a priori using the formula $N_{1}=N_{2}=N_{3}=\left(Z_{1^{-} b}+Z_{1-a / 2}\right)^{2} \times\left(2 / d^{2}\right) / .90$ with $a=.05$ and $b=.20$, anticipating a drop-out of $10 \%$. We reasoned that we would need less participants in the AC condition, because the expected difference would be larger between the active conditions (I-CR and CR) and the control conditions. Based on the current literature, $\mathrm{CR}$ and I-CR were compared with an expected difference of $d=.72$ (McEvoy et al., 2015). CR and I-CR were compared with an AC condition with a minimally expected difference of $d=.98$ (Norton \& Abbott, 2016). Hence, sample size was $N_{1}=N_{2} 34$ in the CR and I-CR conditions and $N_{3}=19$ in the $A C$ condition. The total final sample consisted of $N=87$ participants. The CONSORT Flow diagram is presented in Figure 1. Sample characteristics are shown in Table 1. The groups did not significantly differ in age, gender, nationality, education level and work situation. 


\section{Materials}

\section{Interventions}

Traditional Cognitive Restructuring. In this condition therapists followed parts of the $\mathrm{CR}$ protocol developed by Beck (2011). See Appendix A for a flow-chart. After psycho-education, participants were asked to describe an autobiographical memory of a (preferably) recent anger-evoking event (e.g., "On the street a person bumped into me and made me drop the stuff that I was holding in my hand"). Using Socratic questioning, hostile cognitions (e.g., "He bumped into me on purpose") and accompanying affects (e.g., "Annoyed, frustrated, angry") were identified and filled out in a thought diary on a whiteboard. Then, participants were asked to engage in evidence gathering for (e.g., "He kept looking at me and didn't immediately help to pick up my stuff") and against (e.g., "It looked like he was rushing, he was sweating, he mumbled something that sounded like 'sorry") their hostile cognition. Finally, they were asked what they would conclude about their original hostile cognition given the available gathered evidence and if they could summarize this in a more helpful, realistic or alternative thought (e.g., "He didn't see me because he was in a hurry").

\section{Table 1}

Sample characteristics

\begin{tabular}{|c|c|c|c|c|c|}
\hline & & Condition & & & Statistical dif. \\
\hline & $\begin{array}{l}\text { Total sample } \\
(N=87)\end{array}$ & $\begin{array}{l}\text { I-CR } \\
(n=34)\end{array}$ & $\begin{array}{l}\mathrm{CR} \\
(n=32)\end{array}$ & $\begin{array}{l}\mathrm{AC} \\
(n=21)\end{array}$ & $X^{2} / F(p)$ \\
\hline Age in years, $M(S D)$ & $31.90(14.80)$ & $33.82(15.25)$ & $29.88(14.04)$ & 31.86 (15.47) & $.58(.561)$ \\
\hline \multicolumn{6}{|l|}{ Gender, n (\%) } \\
\hline Male & $24(28)$ & $10(12)$ & $8(9)$ & $6(7)$ & $.17(.917)$ \\
\hline Female & $63(72)$ & $24(28)$ & $24(28)$ & $15(17)$ & \\
\hline \multicolumn{6}{|l|}{ Nationality, n (\%) } \\
\hline Dutch & $83(95)$ & $31(36)$ & $31(36)$ & $21(24)$ & $2.55(.279)$ \\
\hline Belgian & $3(3)$ & $2(2)$ & $1(1)$ & $0(0)$ & \\
\hline German & $1(1)$ & $1(1)$ & $0(0)$ & $0(0)$ & \\
\hline Education, $n$ (\%) & & & & & $9.36(.053)$ \\
\hline Low & 2 & 0 & 1 & 1 & \\
\hline Middle & 53 & 16 & 25 & 12 & \\
\hline High & 32 & 18 & 6 & 8 & \\
\hline Work situation, n (\%) & & & & & $8.25(.083)$ \\
\hline Employed & 29 & 17 & 6 & 6 & \\
\hline Unemployed & 15 & 4 & 8 & 3 & \\
\hline Student & 43 & 18 & 12 & 43 & \\
\hline
\end{tabular}

Note. $\mathrm{I}-\mathrm{CR}=$ imagery enhanced cognitive restricting; $\mathrm{CR}=$ traditional cognitive restructuring; $\mathrm{AC}=$ active control condition. 
Imagery Cognitive Restructuring. The I-CR condition was overall identical to the CR condition with a few notable differences. First, psychoeducation focused on the role of mental images in hostility instead of cognitions. Second, instead of filling in a thought diary, an imagery interview was conducted in which participants were asked to form a mental image from the autobiographical event with their eyes closed as if it was happening now, following Hackmann et al. (2000). Then, participants were asked to translate their hostile cognition (e.g., "He bumped in to me on purpose") into a mental image that represented the affective value of this cognition as good as possible (e.g., "A cartoonish image of a man with an angry red face who is towering high above me, pointing and spitting when he shouts at me"). Finally, the helpful thought (e.g., "He didn't see me because he was in a hurry") and accompanying feelings were then again transformed/represented into another -more helpful- mental image (e.g., "A picture of a smelly running man, with sweat pearls on his forehead, stains below his armpits with an anxious expression").

Active Control Condition. The AC condition was as identical to the I-CR and CR conditions as possible with several important differences aimed to elicit as little therapeutic effect as possible. First, during psychoeducation, participants received a general description of psychotherapy. Second, during the bogus intervention therapists asked as many questions about the situation as possible, actively refraining from insightevoking questions (e.g., "What day was it? Was it warm? Were there many people?").

\section{Measurement}

\section{Hostile belief rating}

To measure the believability of idiosyncratic hostile cognitions, participants were asked to estimate a hostile belief rating (i.e., the likelihood of their thought being true) on a visual analogue scale (VAS) ranging from $0 \%$ to $100 \%$.

\section{Aggressive tendencies}

Aggressive tendencies were assessed by asking participants to indicate how likely they would be to respond with aggression (i.e., by attacking, shouting, or throwing with objects) if the event in the autobiographical memory were to happen right now on a VAS ranging from 0 (not at all) to 100 (very likely).

\section{State anger}

State anger was measured using the anger subscale of the 32-item profile of mood states (POMS) (McNair et al., 1992). Participants are asked to indicate the extent to which each item reflected their current affective state on a 5-point Likert scale ranging from 0 (not at all) to 4 (very much) (i.e., "bad-tempered", "annoyed", "rebellious", "furious", "grouchy", "angry", and "on edge"). Internal consistency of the POMS is good -in the present study 
$a=.87$ of the anger subscale- and construct validity is adequate (Wicherts \& Vorst, 2004). To measure anger levels during the interventions participants were asked to indicate how angry they felt on a VAS (anger VAS) ranging from 0 (not at all) to 100 (very much).

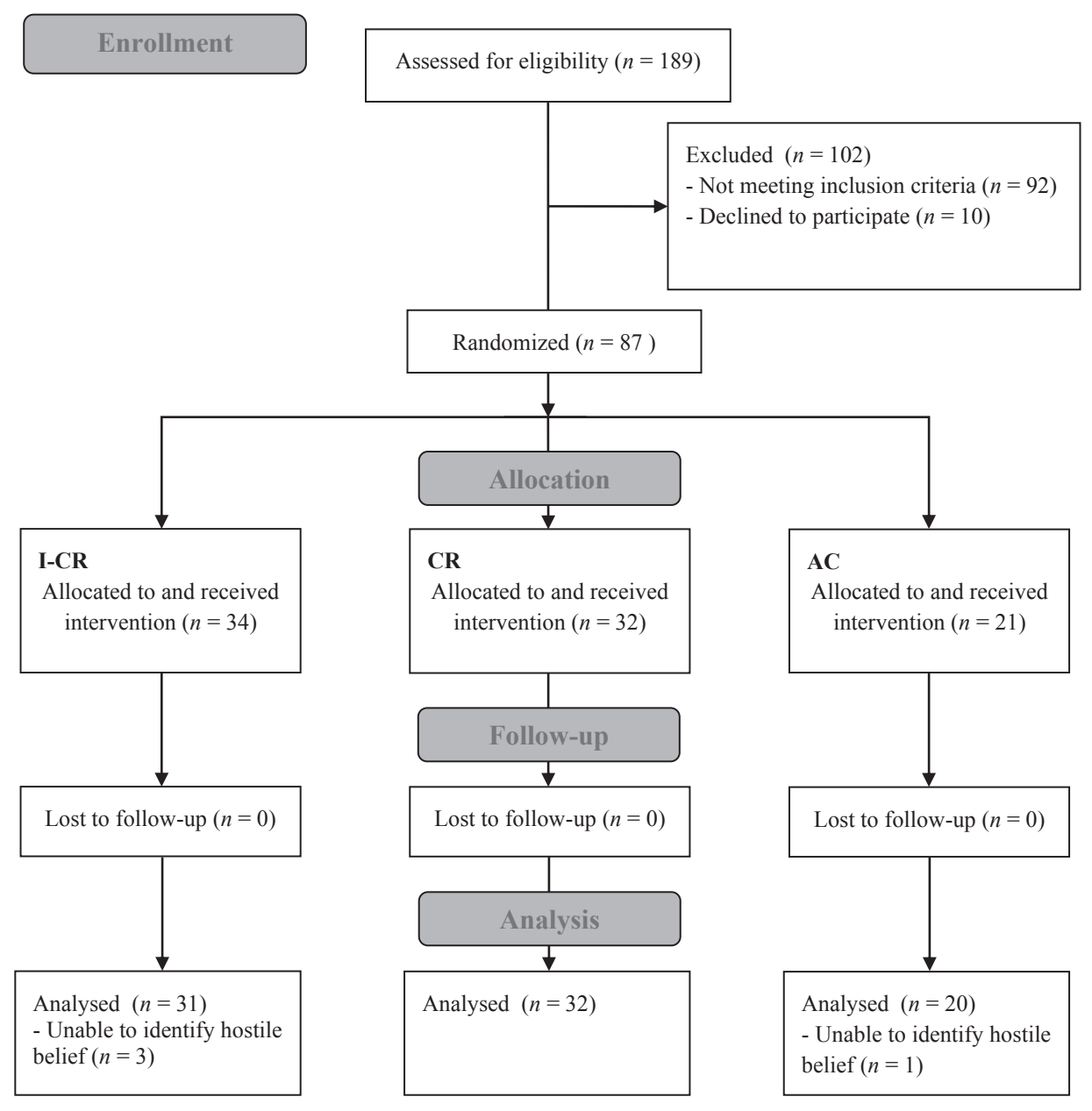

Figure 1

CONSORT flow diagram 


\section{Imagery ability}

Imagery ability was assessed with the 35-item Questionnaire upon Mental Imagery (QMI) (Sheehan, 1967). Participants are, for example, asked to think of seeing 'the sun sinking below the horizon'. Then participants rate how vividly they can see the image on a 7-point Likert scale ranging from 1 (perfectly clear and vivid) to 7 (no image present at all). The QMI possesses good internal consistency (Evans \& Kamemoto, 1973) -in the present study $a=.96$ - and adequate convergent validity (Sheehan, 1967).

\section{Hostility}

Different aspects of hostility were measured with the following five scales. First, the Social Information Processing-Attribution and Emotional response Questionnaire (SIP-AEQ) (Coccaro et al., 2009) measures hostile interpretation bias (i.e., the tendency to interpret emotionally ambiguous stimuli in a hostile way) and is scored on a 4-point Likert scale ranging from 0 (not likely at all) to 3 (very likely). Second, the voodoo doll task (VDT) measures behavioral aggression by counting the number of pins inserted in a doll (DeWall et al., 2013). Third, the 10-item State Trait Anger Expression Inventory-2 trait anger subscale (STAXI-2T) (Spielberger, 1999) measures affective aspects of hostility and is scored on a 4-point Likert scale ranging from 1 (not at all) to 4 (very much). Fourth, the 8-item Aggression Questionnaire (AQ) hostility subscale (Buss \& Perry, 1992) measures cognitive aspects of hostility and is scored on a 5-point Likert scale ranging from 1 (extremely uncharacteristic of me) to 5 (extremely characteristic of me). Last, the Forms of Aggression questionnaire (FOA) (Verona et al., 2008) measures behavioral aspects of hostility and is scored on a 5-point Likert scale ranging from 1 ((almost) never) to 5 ((almost) always). Note that in the current study participants were asked to indicate how often each behavior occurs in general instead of 'when angry', as is the case in the original FOA. All scales have shown good reliability - in the present study a's range from .73 to .88- and adequate validity (Coccaro et al., 2009; DeWall et al., 2013; Hornsveld et al., 2009; Lievaart et al., 2016; Verona et al., 2008).

\section{Emotional stressor}

In the second session all participants engaged in an imagery-interview, following Hackmann et al. (2000). In this interview, participants were asked to form a mental image from the autobiographical event discussed in session one with their eyes closed as if it was happening now. The imagery-interview served as an emotional stressor to examine the sustainability of obtained effects at measurement 6 (M6).

\section{Therapists and Treatment Integrity}

To ensure treatment integrity three master-level clinical psychology students with clinical experience were extensively trained in the treatment protocol by the fourth author, a licensed clinical psychologist (E.M.) who is an expert in applying both imagery and 
cognitive behavioral therapeutic techniques in clinical practice. After training, the students' performance with a pilot-participant was assessed by the study's authors (M.T. and J.L.) and the clinical psychologist (E.M.). Also, the study's authors (M.T. and J.L.) listened to and provided feedback on the first two tapes for all therapists. During the study, the therapists had two supervisory meetings with the clinical psychologist (E.M.). In these meetings, difficult therapeutic situations were discussed to optimize protocol adherence and therapist competency. All sessions were audio taped. Two independent raters evaluated a random selection of 55 (out of 87) tapes on treatment adherence and competence. Together the raters covered all but five audiotapes that were used for training purposes. This selection procedure is comparable to that of other studies (Feeley, DeRubeis, \& Gelfand, 1999; Shaw et al., 1999). Twenty-eight tapes were double coded to examine interrater reliability. The raters were one master-level and one third year bachelor-level clinical psychology students with previous clinical experience. Like the therapists, these students were extensively trained in conducting the treatment protocols. Both raters were blind for condition. To measure treatment integrity, a short version of the Cognitive Therapy Scale (CTS) (Dobson, Shaw, \& Vallis, 1985) and the Collaborative Study Psychotherapy Rating Scale - version 6 (CSPRS-6) (Hollon et al., 1988) was used, supplemented with three items examining the competency of transforming cognitions into mental images (e.g., "To what degree did the therapist direct the client to transform an alternative thought into a helpful mental image?"). Items were scored on a 7-point Likert scale. Higher scores indicate higher treatment integrity.

Overall, tapes were rated as good to excellent in 71\% of I-CR cases, $97 \%$ of CR cases and $75 \%$ of $A C$ cases. As expected, compared to the $C R$ and $A C$ conditions, therapists significantly displayed more I-CR specific behaviors in the I-CR condition, $F(2,79)=1214.77$, $p<.001$. Compared to the I-CR and AC conditions, therapists displayed significantly more CR specific behaviors in the CR condition, $F(2,79)=200.25, p<.001$. Interrater reliability of treatment integrity subscales (i.e., ICC's between .71 and .98) was good to excellent according to Cicchetti (1994) and fair to excellent according to Portney and Watkins (2000). There was no significant difference between therapists in assigned number of treatment conditions $(p=.574)$. Compared to the other therapists, one therapist displayed a significantly reduced overall integrity rating, $F(2,79)=16.82, p<.001$. This difference remained significant after controlling for patient difficulty level (i.e., one CTS item), $F(2,78)$ $=10.82, p<.001$. For this reason, the variable therapist was treated as a random effect within our analyses. 


\section{Procedure}

The Ethical Review Committee Psychology and Neuroscience at Maastricht University provided ethical approval to carry out the study (ERCPN-185_07_11_2017_A1). The study was preregistered at https://osf.io/j9ngp.' Data was gathered from November 2018 to February 2020. Respondents were screened for eligibility by e-mail using the PID-5. Respondents who were eligible for the study were randomly assigned to the conditions (I-CR, CR, AC) using permutated block randomization, stratified by gender. Randomization was carried out by an independent technician from another department at Maastricht University. The participants were blind to the condition. When participants arrived at the lab the study's procedure was explained, and written informed consent was obtained. The study consisted of two sessions one week apart from each other. The first session took approximately 90 minutes, the second session approximately 30 minutes. The first session started with a baseline assessment (M0). Then participants received psycho-education, after which they completed M1. After the imagery transformation/thought diary completion, right before engaging in the allocated intervention, participants received $\mathrm{M} 2$. The intervention continued following protocol and after the intervention, M3 took place. The second session started with a baseline measurement 4 (M4). Then participants briefly recalled their autobiographical memory. After this, all participants engaged in the imagery-interview (i.e., the emotional stressor) which was preceded with M5 and followed by M6. For a graphical overview of the procedure, see Appendix A. At the end of the second session, we conducted an exit-interview in which we asked participants to rate on a VAS from 0 (not at all) to 100 (very much) how exhausting the intervention was, how emotional it was for them, and (if participants were in the I-CR condition) how vividly they could see the mental images and what percentage of the time they saw the mental image when they had their eyes closed. Last, participants were debriefed and received a financial compensation of $€ 15$ or course credits.

\section{Statistical analyses}

SPSS version 24 was used for all analyses. First, means and standard deviations were computed to examine the baseline characteristics of all study variables. Second, independent samples $t$-tests were run to test for baseline differences. Third, multilevel mixed effects regression were run to test the hypotheses that I-CR is more efficacious in reducing hostile beliefs $(\mathrm{H} 1)$, aggressive tendencies $(\mathrm{H} 2)$, anger $(\mathrm{H} 3)$, and hostility traits $(\mathrm{H} 4)$ compared to traditional $\mathrm{CR}$ and the AC conditions. When we analyzed whether both interventions, I-CR and CR, were more efficacious than the AC condition, the AC condition was selected as reference category. To test the difference between I-CR and CR, CR was selected as reference category. Hostile beliefs, aggressive tendencies, anger, and hostility

1 In the pre-registration hostile beliefs are referred to as 'threat appraisals'. Also, the present paper did not include the pre-registered analysis of physiological measures; these were intended to be published elsewhere. 
trait scores were entered as dependent variables. Condition, time and condition by time indicators were entered as independent variables. We differentiated between immediate intervention (T1) and sustained intervention efficacy (T2). Treatment integrity analyses (see Supplemental Material 2) showed that one therapist relatively underperformed compared to the others. For this reason, the variable therapist was treated as a random effect within our analyses. This deviates from pre-registration. Assuming that a 'therapist-effect' was constant across all repeated measures, the therapist variable was entered as a random intercept. To gain two extra degrees of freedom, baseline indicators were removed from the model under the assumption that there are no baseline group differences for the dependent variable. ${ }^{2}$

\section{RESULTS}

Means and standard deviations are shown in Table 2. Four cases were excluded from further analyses, as they were not able to formulate a belief that was related to their autobiographical situation. An examination of group differences of study variables at baseline revealed no significant differences ( $p$ 's > .198), except for the QMI, $H(2)=6.97, p=.031$ (lower at I-CR). Visual inspection of outliers revealed four outliers in the $C R$ and $A C$ conditions with values outside the \pm 1.5 * interquartile range. When these outliers were removed, the QMI group difference was no longer significant, $H(2)=4.72, p=.094$. Nonetheless, analyses were run with and without $Q M I$ scores as covariate 3 . As the pattern of results did not differ in any of the analyses when QMI score was entered as a covariate, results are presented without using QMI scores as covariate.

\section{Immediate intervention efficacy}

\section{Hostile beliefs}

To test the main hypothesis that I-CR reduces hostile belief ratings to a greater extent than $\mathrm{CR}$ and $\mathrm{AC}(\mathrm{HI})$ we ran a mixed regression model. Fixed effects are shown in Table 3. Time and condition variables were reference coded, using AC as reference category. The random effect of therapist was not significant $(p=.594)$. Results showed that I-CR $(b=-0.55, t=-3.96$, $p<.001)$ and $C R(b=-0.28, t=-2.05, p=.044)$ resulted in greater reductions in hostile belief ratings from pre- (M1) to post-intervention (M3) compared to AC (see Table 3 and Figure 2). Also, when the CR condition was selected as reference category, I-CR led to a larger reduction in hostile belief ratings than $C R(b=-0.28, B=-11.03, S E=5.03, t=-2.19, p=.031)$ from pre- $(\mathrm{M} 1)$ to post-intervention (M3).

2 Models were compared to each other using $X^{2}$-tests.

3 In the pre-registration we planned to report results that included QMI as covariate. As the QMI did not influence the pattern of results we decided to exclude it to gain statistical power. 


\section{Table 2}

Study means and standard deviations

\begin{tabular}{|c|c|c|c|c|}
\hline & \multicolumn{3}{|l|}{ Condition } & \multirow{2}{*}{$\begin{array}{l}\text { Baseline Stat. Dif. } \\
F / H(p)\end{array}$} \\
\hline & $\begin{array}{l}\text { I-CR } \\
(n=31)\end{array}$ & $\begin{array}{l}\mathrm{CR} \\
(n=32)\end{array}$ & $\begin{array}{l}\mathrm{AC} \\
(n=20)\end{array}$ & \\
\hline \multicolumn{5}{|l|}{ Hostile belief rating } \\
\hline M1 (S1 pre-intervention) ${ }^{\mathrm{a}}$ & $80.20(22.42)$ & 71.28 (28.11) & 70.56 (23.26) & \\
\hline M3 (S1 post-intervention) & 56.69 (28.93) & 60.80 (28.54) & 72.03 (22.56) & \\
\hline M5 (S2 pre-stressor) & $61.16(26.51)$ & $59.35(25.12)$ & 71.64 (26.93) & \\
\hline M6 (S2 post-stressor) ${ }^{\mathrm{a}}$ & 69.83 (28.28) & $64.36(23.12)$ & 76.55 (24.43) & \\
\hline \multicolumn{5}{|l|}{ Aggressive tendencies } \\
\hline M1 (S1 pre-intervention) a & 33.08 (25.95) & $34.34(19.83)$ & 33.69 (27.45) & \\
\hline M3 (S1 post-intervention) a & 16.78 (17.09) & $20.82(17.75)$ & $28.58(24.35)$ & \\
\hline M5 (S2 pre-stressor) ${ }^{a}$ & $18.41(19.52)$ & $23.12(17.32)$ & $26.71(23.03)$ & \\
\hline M6 (S2 post-stressor) ${ }^{\mathrm{a}}$ & $20.20(21.93)$ & $26.36(19.56)$ & $27.97(21.05)$ & \\
\hline \multicolumn{5}{|l|}{$\underline{\text { State Anger }}$} \\
\hline \multicolumn{5}{|l|}{ POMS } \\
\hline MO (S1 baseline) ${ }^{\mathrm{a}}$ & $2.16(3.36)$ & $1.72(2.17)$ & $3.30(4.71)$ & $0.91(.635)$ \\
\hline M3 (S1 post-intervention) ${ }^{a}$ & $2.81(4.42)$ & $4.41(5.20)$ & $5.20(5.20)$ & \\
\hline M4 (S2 baseline)a & $1.32(2.53)$ & $1.66(2.42)$ & $3.10(5.26)$ & \\
\hline \multicolumn{5}{|l|}{ Anger VAS } \\
\hline MO (S1 baseline) ${ }^{a}$ & $3.14(6.56)$ & $3.04(4.24)$ & $10.22(17.83)$ & $3.24(.198)$ \\
\hline M1 (S1 pre-intervention) & $51.97(26.40)$ & $60.21(20.51)$ & $60.56(20.81)$ & \\
\hline M2 (S1 imagery transformation) & 60.67 (30.86) & $58.16(30.88)$ & $62.46(24.36)$ & \\
\hline M3 (S1 post-intervention) & $23.55(24.67)$ & $34.67(25.14)$ & $59.74(23.57)$ & \\
\hline M4 (S2 baseline) ${ }^{\mathrm{a}}$ & $4.17(8.07)$ & $4.63(5.49)$ & $9.96(19.83)$ & \\
\hline M5 (S2 pre-stressor) ${ }^{\mathrm{a}}$ & 28.37 (26.89) & $26.97(24.70)$ & $34.83(34.83)$ & \\
\hline M6 (S2 post-stressor) & $47.43(32.52)$ & $45.96(29.27)$ & $48.53(23.84)$ & \\
\hline \multicolumn{5}{|l|}{ Hostility Trait measures } \\
\hline QMI MOa & $77.45(18.98)$ & $94.38(35.76)$ & $97.85(33.18)$ & $6.97^{*}(0.031)$ \\
\hline \multicolumn{5}{|l|}{ SIP-AEQ } \\
\hline MO (S1 baseline) & $9.71(6.18)$ & $10.28(5.12)$ & $9.75(5.12)$ & $.10(.909)$ \\
\hline M3 (S1 post-intervention) ${ }^{\mathrm{a}}$ & $7.74(8.95)$ & $7.94(6.21)$ & $9.75(6.32)$ & \\
\hline M4 (S2 baseline) & $7.71(7.44)$ & $8.91(6.37)$ & $7.60(5.20)$ & \\
\hline \multicolumn{5}{|l|}{ VDT } \\
\hline MO (S1 baseline) ${ }^{\mathrm{a}}$ & $4.68(6.36)$ & $4.22(3.94)$ & $8.35(13.89)$ & $1.46(.482)$ \\
\hline M3 (S1 post-intervention) ${ }^{\mathrm{a}}$ & $4.52(5.21)$ & $4.47(4.68)$ & $4.70(4.89)$ & \\
\hline M4 (S2 baseline) ${ }^{a}$ & $6.32(9.62)$ & $5.03(6.67)$ & $3.80(3.38)$ & \\
\hline PID-5H & & & & \\
\hline
\end{tabular}


Table 2

Continued

\begin{tabular}{lllll}
\hline & Condition & & & Baseline Stat. Dif. \\
\hline & I-CR & CR & AC & F/H $(p)$ \\
& $(n=31)$ & $(n=32)$ & $(n=20)$ & \\
\hline M0 (S1 baseline) & $1.11(.51)$ & $.96(.40)$ & $1.02(.39)$ & $.53(.592)$ \\
M4 (S2 baseline) & $.81(.52)$ & $.78(.41)$ & $.75(.41)$ & \\
STAXI-2T & & & & \\
M0 (S1 baseline) & $17.81(4.76)$ & $18.38(2.95)$ & $17.50(3.49)$ & $.35(.703)$ \\
M4 (S2 baseline) & $17.00(4.60)$ & $16.09(3.43)$ & $15.95(2.80)$ & \\
AQ-H & & & & \\
M0 (S1 baseline) & $19.65(7.79)$ & $20.63(5.63)$ & $21.35(7.22)$ & $.39(.677$ \\
M4 (S2 baseline) & $17.16(6.87)$ & $18.25(6.58)$ & $17.80(6.30)$ & \\
FOA & & & & \\
M0 (S1 baseline) & $57.10(11.01)$ & $58.91(8.78)$ & $59.15(11.54)$ & $.33(.718)$ \\
M4 (S2 baseline) & $54.13(10.28)$ & $56.88(9.84)$ & $58.40(14.38)$ & \\
\hline
\end{tabular}

Note. ${ }^{\text {a }}$ non-normally distributed. $\mathrm{S} 1=\operatorname{session} 1$; $\mathrm{S} 2=\operatorname{session} 2$.

\section{Aggressive tendencies and state anger}

To test the hypotheses that the efficacy of I-CR is larger compared to CR and AC in reducing aggressive tendencies ( $\mathrm{H} 2$ ), anger VAS and state anger (POMS) (H3) three separate mixed regression models were run. Fixed effects are shown in Table 3. First, in the model with aggressive tendencies $(\mathrm{H} 2)$ as the dependent variable the random effect of therapist was removed from the model due to non-convergence. Results revealed that $\mathrm{I}-\mathrm{CR}(b=-0.48, t$ $=-3.48, p=.001)$ and $\mathrm{CR}(b=-0.35, t=-2.51, p=.014)$ both effectively reduced aggressive tendencies from pre- (M1) to post-intervention (M3) compared to AC. When the CR condition was selected as reference category, there was no significant difference between I-CR and CR at post-intervention (M3) $(B=-3.23, S E=2.88, t=-1.12, p=.264)$.

Second, in the model with anger VAS as the dependent variable $(\mathrm{H} 3)$, the random effect of therapist was not significant $(p=$.398). Findings demonstrated elevated anger VAS levels at baseline in both intervention conditions compared to AC. This finding deviates from our earlier analysis of baseline anger VAS scores. To correct for baseline differences, anger VAS levels at baseline were entered as a covariate (as opposed to earlier models). Moreover, results revealed that both $\mathrm{I}-\mathrm{CR}(b=-0.57, t=-4.05, p<.001)$ and $\mathrm{CR}(b=-0.35, t=-2.50, p<.014)$ led to a greater reduction in anger VAS levels at post-intervention (M3) compared to AC. When the CR condition was selected as reference category, there was no significant difference between $\mathrm{I}-\mathrm{CR}$ and CR at post-intervention (M3) ( $b=-11.22$, SE $=6.32, t=-1.78, p=.080)$. 
Table 3

Mixed regression on hostile belief rating, aggressive tendencies, and anger

\begin{tabular}{|c|c|c|c|c|}
\hline & $B$ & SE & $t$ & $p$ \\
\hline \multicolumn{5}{|l|}{$\underline{\text { Hostile belief rating }}{ }^{a}$} \\
\hline Intercept S1 pre-intervention (M1) & 73.67 & 4.34 & $16.99^{* *}$ & .008 \\
\hline AC S1 post-intervention (M3) & .50 & 4.51 & .11 & .913 \\
\hline AC S2 pre-stressor (M5) & -.15 & 4.53 & -.03 & .974 \\
\hline AC S2 post-stressor (M6) & 4.73 & 4.36 & 1.09 & .281 \\
\hline I-CR S1 post-intervention (M3) & -22.68 & 5.72 & $-3.96^{* * *}$ & $<.001$ \\
\hline I-CR S2 pre-stressor (M5) & -17.22 & 5.71 & $-3.02^{* *}$ & .003 \\
\hline I-CR S2 post-stressor (M6) & -13.37 & 5.47 & $-2.45^{*}$ & .017 \\
\hline CR S1 post-intervention (M3) & -11.65 & 5.69 & $-2.05^{*}$ & .044 \\
\hline CR S2 pre-stressor (M5) & -12.64 & 5.67 & $-2.23^{*}$ & .029 \\
\hline CR S2 post-stressor (M6) & -12.53 & 5.43 & $-2.31^{*}$ & .024 \\
\hline \multicolumn{5}{|l|}{ Aggressive tendencies $^{\text {a }}$} \\
\hline Intercept S1 pre-intervention (M1) & 33.71 & 2.62 & $12.87^{* * *}$ & $<.001$ \\
\hline M3 S1 post-intervention (M3) & -5.12 & 2.72 & -1.88 & .063 \\
\hline M5 S2 pre-stressor (M5) & -6.99 & 3.29 & $-2.13^{*}$ & .036 \\
\hline M6 S2 post-stressor (M6) & -5.73 & 2.95 & -1.94 & .055 \\
\hline I-CR S1 post-intervention (M3) & -11.40 & 3.27 & $-3.48^{* *}$ & .001 \\
\hline I-CR S2 pre-stressor (M5) & -7.95 & 3.97 & $-2.00^{*}$ & .048 \\
\hline I-CR S2 post-stressor (M6) & -7.35 & 3.63 & $-2.03^{*}$ & .046 \\
\hline CR S1 post-intervention (M3) & -8.17 & 3.25 & $-2.51^{*}$ & .014 \\
\hline CR S2 pre-stressor (M5) & -3.96 & 3.94 & -1.00 & .318 \\
\hline CR S2 post-stressor (M6) & -2.06 & 3.60 & -.57 & .569 \\
\hline \multicolumn{5}{|l|}{ State Anger (VAS) } \\
\hline AC S1 baseline (MO) & $11.35^{b}$ & 3.33 & $3.41^{*}$ & .027 \\
\hline AC S1 pre-intervention (M1) & 50.34 & 5.04 & $9.99^{* * *}$ & $<.001$ \\
\hline AC S1 image transformation (M2) & 52.24 & 6.54 & $7.99^{* * *}$ & $<.001$ \\
\hline AC S1 post-intervention (M3) & 49.53 & 5.61 & $8.83^{* * *}$ & $<.001$ \\
\hline AC S2 baseline (M4) & -.26 & 2.48 & -.10 & .917 \\
\hline AC S2 pre-stressor (M5) & 24.61 & 5.70 & $4.32^{* * *}$ & $<.001$ \\
\hline AC S2 post-stressor (M6) & 38.32 & 6.50 & $5.90^{* * *}$ & $<.001$ \\
\hline I-CR S1 baseline (MO) & -6.61 & 2.68 & $-2.47^{*}$ & .016 \\
\hline I-CR S1 pre-intervention (M1) & -1.52 & 6.47 & -.24 & .814 \\
\hline I-CR S1 image transformation (M2) & 5.29 & 8.39 & .63 & .530 \\
\hline I-CR S1 post-intervention (M3) & -29.12 & 7.19 & $-4.05^{* * *}$ & $<.001$ \\
\hline I-CR S2 baseline (M4) & 1.29 & 3.18 & .40 & .687 \\
\hline
\end{tabular}


Table 3

Continued

\begin{tabular}{lllll}
\hline & $B$ & $S E$ & $t$ & $p$ \\
\hline I-CR S2 pre-stressor (M5) & .61 & 7.31 & .08 & .933 \\
I-CR S2 post-stressor (M6) & 5.97 & 8.33 & .72 & .476 \\
CR S1 baseline (M0) & -7.47 & 2.66 & $-2.81^{* *}$ & .006 \\
CR S1 pre-intervention (M1) & 6.82 & 6.43 & 1.06 & .292 \\
CR S1 image transformation (M2) & 2.88 & 8.34 & .35 & .731 \\
CR S1 post-intervention (M3) & -17.90 & 7.15 & $-2.50^{*}$ & .014 \\
CR S2 baseline (M4) & 1.85 & 3.16 & .58 & .561 \\
CR S2 pre-stressor (M5) & -.69 & 7.26 & -.10 & .925 \\
CR S2 post-stressor (M6) & 4.60 & 8.28 & .56 & .580 \\
\hline
\end{tabular}

Note. In all models the active control condition was chosen as reference category. ${ }^{a}$ To gain additional degrees of freedom we posed the constraint that conditions did not differ at baseline on the independent variable, hence all conditions at baseline share the same intercept; $X^{2}$ tests revealed that models did not significantly differ with and without this constraint ( $p$ 's > .260). ${ }^{\circ}$ Intercept for the anger VAS model. S1 = session 1; S2 = session 2.

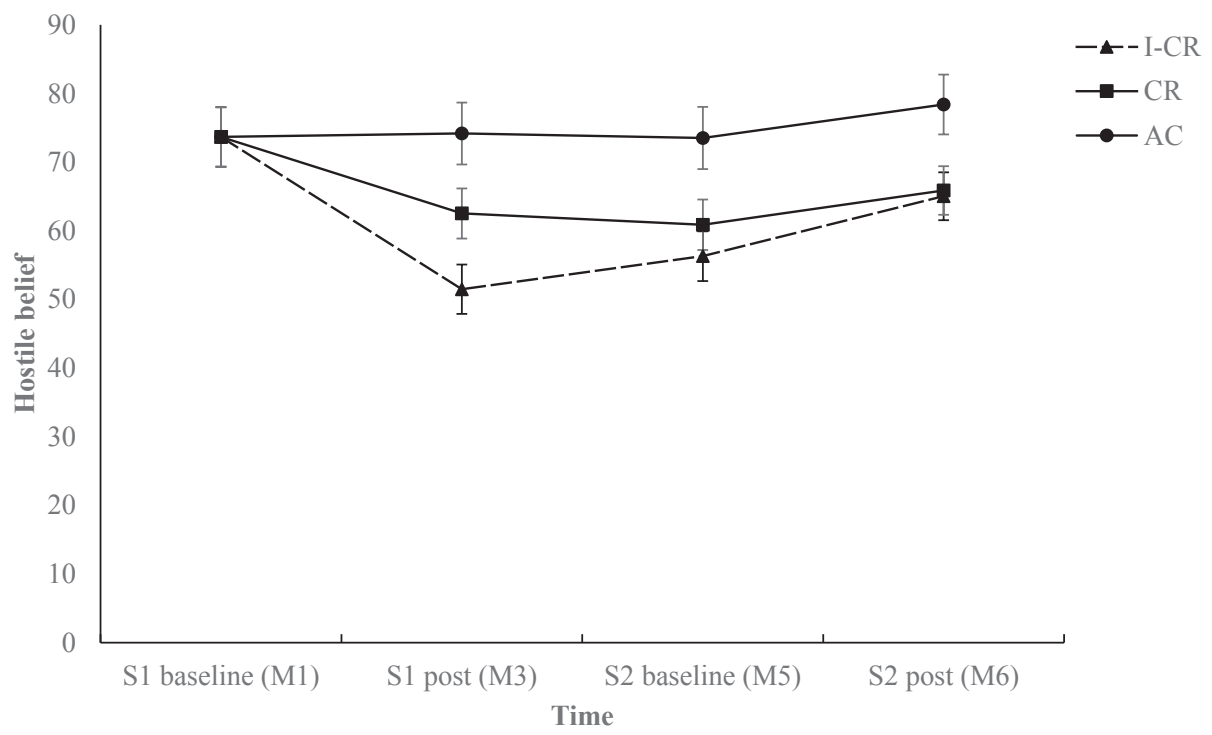

\section{Figure 2}

Estimates of hostile belief rating over time per condition

Note. Error bars represent standard errors of the estimates. S1 = session 1; S2 = session 2. We only present one figure to illustrate the basic pattern of results. 
Third, in the model with state anger (POMS) as the dependent variable (H3) the random effect of therapist on state anger was not significant $(p=.480)$. Findings showed that state anger increased from baseline $(\mathrm{MO})(M=2.51, S E=.65)$ to post-intervention $(\mathrm{M} 3)(M=2.28, S E=.93)$, $(b=0.55, B=2.28, t=2.45, p=.016)$. Interventions did not differ significantly in terms of change in state anger from baseline (M0) to post-intervention (M3) ( $p$ 's > .081).

Taken together, findings on the immediate efficacy of I-CR revealed that from baseline (MO) to post-intervention (M3) I-CR led to larger reductions in hostile beliefs compared to CR and $A C$, while both I-CR and CR resulted in a larger decrease in aggressive tendencies and anger compared to AC. Also, all conditions showed an increase in state anger from baseline (MO) to post-intervention (M3).

\section{Hostility traits}

To test the hypothesis that both I-CR and CR lead to a larger reduction in hostility traits at one-week follow-up compared to $A C(H 4)$, mixed regression models were run with SIP-AEQ, VDT, STAXI-2T, AQ-H and FOA scores as the dependent variables and time, intervention and intervention by time as independent variables. Therapist was entered as a random effect. Results revealed that the random effect of therapist was not significant in any of the models ( $p$ 's $>$.459). The time effect was significant for all dependent variables ( $p$ 's <.018), except for VDT $(p=.880)$. SIP-AEQ $(b=-0.45, B=-1.80, S E=.44, t=-4.12, p<.001), A Q-H(b=-0.67, B=-2.70$, $S E=.44, t=-6.14, p<.001)$ and FOA $(b=-0.30, B=-2.07, S E=.77, t=-2.68, p=.009)$ scores decreased significantly from baseline to follow-up. None of the interaction effects between intervention and time were significant ( $p$ 's > .088). In sum, findings on the intervention efficacy on hostility traits demonstrated that all hostility-trait-variables scores but the VDT decreased in all experimental conditions.

\section{Sustained intervention efficacy at one-week follow-up}

To test the hypothesis that the intervention efficacy sustained over time we analyzed fixed effects on hostile beliefs and aggressive tendencies at one-week follow-up (T2a) and after an emotional stressor (T2b). These fixed effects are presented in Table 3 (M5 and M6). First, results show that at 1-week follow-up (T2a) hostile belief was lower in both the I-CR $(b=-0.42$, $t=-3.02, p=.003)$ and $C R$ conditions $(b=-0.31, t=-2.23, p=.029)$ compared to AC, but the significant post-intervention (M3) difference between I-CR and CR (when CR was used as a reference category) did not sustain ( $B=-4.58, S E=5.02, t=-.91, p=.364)$. Also, findings revealed that at one-week follow-up aggressive tendencies were significantly lower in the I-CR condition ( $b=-0.28, t=-2.00, p=.048$ ), but not in the CR condition, compared to AC. The difference between I-CR and CR (when CR was selected as reference category) was not significant, $(b=-3.99$, SE $=3.49, t=-1.15, p=.256)$. 
Second, we analyzed the fixed effects of intervention on hostile beliefs, aggressive tendencies, and state anger after the emotional stressor at one-week follow-up (T2b). When M4/M5 (preemotional stressor) was selected as reference category, results demonstrated that hostile belief ratings ( $b=0.45, B=6.35, S E=1.56, t=4.08, p<.001)$, aggressive tendencies $(b=0.25$, $B=2.22, S E=.96, t=2.31, p=.024)$ and anger $\operatorname{VAS}(b=1.42, B=41.39, S E=3.20, t=12.93, p$ $<.001)$ significantly increased from pre- (M4/M5) to post-emotional stressor (M6). To test if the emotional stressor fully counteracted the obtained effects of I-CR and CR on hostile beliefs and aggressive tendencies in session 1 , we ran the same model with baseline values of hostile beliefs and aggressive tendencies (M1) as reference category (see Table 3). Hostile belief ( $b$ $=-0.34, t=-2.45, p=.017)$ and aggressive tendencies $(b=-0.28, t=-2.03 p=.046)$ remained significantly reduced compared to $A C$ at one-week follow-up (M5) for participants in the I-CR condition. Also, compared to baseline (M1), hostile belief scores in the CR condition were significantly lower than scores in the AC condition ( $b=-.32, t=-2.31, p=.024)$, but not in terms of aggressive tendency scores.

In sum, observations on the sustainability of the intervention efficacy revealed that the efficacy of I-CR on hostile belief and aggressive tendencies was sustained. Moreover, the efficacy of $\mathrm{CR}$ was sustained in reducing hostile beliefs, but not in reducing aggressive tendencies.

\section{DISCUSSION}

The present research investigated if the efficacy of CR for transdiagnostic hostility would enhance through adding mental imagery. We expected that I-CR would be more sustainably efficacious in reducing the believability of hostile beliefs $(\mathrm{H} 1)$, aggressive tendencies $(\mathrm{H} 2)$, state anger $(\mathrm{H} 3)$ and trait-hostility $(\mathrm{H} 4)$ compared to traditional $\mathrm{CR}$ and an AC condition. The findings revealed that both $\mathrm{I}-\mathrm{CR}$ and $\mathrm{CR}$ were superior to the $\mathrm{AC}$ group in changing hostile beliefs, aggressive tendencies, and state anger. We found that one session of I-CR holds the potential of more efficaciously changing hostile beliefs compared to traditional CR. Although actual hostility traits were not reduced more strongly in $\mathrm{I}-\mathrm{CR}$ and $\mathrm{CR}$ than in our control condition, we observed sustained reductions in hostile beliefs and aggressive tendencies. Our findings provide convergent data with previous work that evidenced the potential of mental imagery to increase treatment efficacy for psychopathologies (Arntz \& Weertman, 1999; Beck, 1985; Edwards, 1990; Ehlers et al., 2005; McEvoy et al., 2015; Smucker et al., 1995).

One explanation for our finding that I-CR was superior to CR in changing hostile beliefs is that $\mathrm{I}-\mathrm{CR}$ results in more elaborate processing and changing of meaning of participants ideographic events. This is in line with the ideas of Beck (1985) on the superiority of changing "hot" (i.e., affectively valenced) cognitions when compared to "cold" (i.e., affectively 
unvalenced) cognitions (Beck, 1985). It also aligns with our clinical impression that participants in the I-CR condition reported increased compassion or sympathy for their original source of frustration, while participants in the CR condition would merely show a quantitative decrease of angry cognitions. This clinical impression is supported by (paradoxical) evidence showing that hostility and compassion are positively related constructs as they both reflect vigilant prevention focused self-regulation (Keller \& Pfattheicher, 2013). Nonetheless, the clinical impression remains to be experimentally tested.

I-CR was not only efficacious in changing hostile beliefs but also in reducing aggressive tendencies $(\mathrm{H} 2)$ and state anger $(\mathrm{H} 3)$. Here I-CR only partially differentiated from CR. That is, one session of I-CR did not significantly differ from CR in reducing aggressive tendencies and state anger. However, for I-CR but not for CR efficacy was retained at 1-week follow-up in terms of aggressive tendencies. An explanation for our finding that I-CR was more efficacious in reducing aggressive tendencies than $\mathrm{CR}$, is that only under mental imagery conditions hostile beliefs were able to mediate the effect of treatment on aggressive tendencies. This fits with previous work showing that a tendency to interpret emotionally ambiguous stimuli in a hostile way increases the likelihood of aggressive behavior (Crick \& Dodge, 1994; Epps \& Kendall, 1995). During mental imagery, all senses are activated. Holmes and Mathews (2010) convincingly showed that memories are stored multi-modally (i.e., including all senses), rather than solely verbally. Therefore, during mental imagery and not so much during a verbal treatment technique like $\mathrm{CR}$, reduction in hostile beliefs could have more strongly reduced aggressive tendencies. An alternative explanation is that the mental imagery condition increased state anger, which made it easier to modulate aggressive tendencies. Indeed, a recent review on depression treatment suggests that in-session affect mediates treatment effects in CBT for depression (Aafjes-van Doorn \& Barber, 2017). Given the strong impact of mental imagery on emotional memory (Holmes \& Mathews, 2010), one might expect that I-CR increases in-session anger, which in turn mediates efficacy. However, this explanation is not supported given that the present results indicated that the difference between I-CR and CR in terms of state anger was marginally non-significant $(p=.08)$.

Findings on the sustained and more 'Iong term' efficacy of I-CR demonstrated that reductions in hostile beliefs and aggressive tendencies were (partially) sustained at oneweek follow-up (T2a) and after an emotional stressor (T2b). However, our intervention conditions were not superior to the $\mathrm{AC}$ condition in terms of change in hostility trait levels. Probably we observed a 'regression to the mean' here, implying that the observed decrease in hostility traits reflects random chance. Alternatively, it may be possible that one session of I-CR or CR is just not potent enough to impact change-resistant hostility traits and we set the expectancy of a one-session intervention too high. Indeed, another study that also used a short cognitive intervention (interpretation bias modification training 
on hostile interpretation bias) observed changes in hostile beliefs, but not in hostility traits (Hawkins \& Cougle, 2013). Given that we investigated the efficacy of one session of CR, we urge future studies to implement mental imagery techniques more broadly in longer or multi-session treatment protocols.

The present study possesses several notable limitations. First, our sample includes participants that scored above average on a hostility measure. Caution should be paid to generalizing these findings as further studies are needed that include participants with higher, more clinical levels of hostility (e.g., persons with hostility scores higher than +1 or +2SD), as many factors (e.g., increased psychosocial stressors and comorbidity) were not controlled for. Second, the majority of the present sample was female (72\%). Given that women may express aggressive behavior more indirectly (e.g., through social exclusion) than men (e.g., physical aggression) (Björkqvist et al., 1992) the present findings may differ from those studies using samples including relatively more men. Third, the present design included one single session of (I-)CR. Results can therefore not be generalized to more extensive CBT programs for hostility. Fourth, our small sample size may explain some non-significant findings. Specifically, the observed effects in this study $(b=-0.55)$ are lower than we expected $(b=0.98)$ when we determined the a-priori sample size.

The finding that one session of I-CR holds the potential of more efficaciously changing hostile beliefs compared to traditional $\mathrm{CR}$ has several clinical or social implications. First, it is likely that the efficacy of I-CR can be further enhanced when it is more broadly integrated in traditional CBT protocols. For example, clinicians can consider adding an imagery component to thought records, or combining imagery exercises as a preparation to behavioral experiments (e.g., McEvoy et al., 2015). Moreover, we selected only one type of CR intervention, namely evidence gathering. One could also think of integrating imagery with other CR techniques such as the 'pie-chart' technique, or multidimensional evaluation (Beck, 2011). Second, parts of the present I-CR intervention may be used to test future hypotheses on the working mechanism of CBT and other clinical interventions. For example, it would be interesting to test whether the efficacy of I-CR is attributable to extinction learning (i.e., imaginary exposure) or stimulus revaluation (i.e., changing the meaning of a stimulus).

In sum, we observed that both I-CR and CR efficaciously reduced hostile beliefs, aggressive inclinations and anger compared to an active control condition. I-CR was more efficacious and sustainable than $\mathrm{CR}$ and $\mathrm{AC}$ in reducing hostile beliefs and aggressive inclinations. Findings suggest that implementing imagery techniques in existing treatment protocols can enhance its' efficacy. 


\section{ACKNOWLEDGMENTS, DECLARATION OF INTEREST, AND FUNDING}

We thank Marjolijn Valkenburg, Pauline van Gils, Nina Aussems, Lissa van Baren, Rien Kleijnen and Brigit Lok for their contribution to this work. We have no conflict of interest to disclose. This research did not receive any specific grant from funding agencies in the public, commercial, or not-for-profit sectors. 


\section{REFERENCES}

Aafjes-van Doorn, K., \& Barber, J. P. (2017). Systematic review of in-session affect experience in cognitive behavioral therapy for depression. Cognitive Therapy and Research, 41(6), 807-828. https://doi. org/10.1007/s10608-017-9865-6

Arntz, A., \& Weertman, A. (1999). Treatment of childhood memories: Theory and practice. Behaviour Research and Therapy, 37(8), 715-740. https://doi.org/10.1016/S0005-7967(98)00173-9

Bach, B., Maples-Keller, J. L., Bo, S., \& Simonsen, E. (2016). The alternative DSM-5 personality disorder traits criterion: A comparative examination of three self-report forms in a Danish population. Personality Disorders: Theory, Research, and Treatment, 7(2), 124-135. https://doi.org/10.1037/per0000162

Beck, A. T. (1985). Cognitive therapy, behavior therapy, psychoanalysis, and pharmacotherapy: A cognitive continuum. In Cognition and psychotherapy (pp. 325-347). Plenum.

Beck, J. S. (2011). Cognitive behavior therapy: Basics and beyond (2nd ed.). Guilford Press.

Björkqvist, K., Lagerspetz, K. M., \& Kaukiainen, A. (1992). Do girls manipulate and boys fight? Developmental trends in regard to direct and indirect aggression. Aggressive Behavior, 18(2), 117-127. https://doi.org/ bz3jgt

Buss, A. H., \& Perry, M. (1992). The aggression questionnaire. Journal of Personality and Social Psychology, 63(3), 452-459. https://doi.org/10.1037/0022-3514.63.3.452

Cassiello-Robbins, C., \& Barlow, D. H. (2016). Anger: The unrecognized emotion in emotional disorders. Clinical Psychology: Science and Practice, 23(1), 66-85. https://doi.org/10.1111/cpsp.12139

Coccaro, E. F., Noblett, K. L., \& McCloskey, M. S. (2009). Attributional and emotional responses to socially ambiguous cues: Validation of a new assessment of social/emotional information processing in healthy adults and impulsive aggressive patients. Journal of Psychiatric Research, 43(10), 915-925. https://doi.org/10.1016/j.jpsychires.2009.01.012

Crick, N. R., \& Dodge, K. A. (1994). A review and reformulation of social information-processing mechanisms in children's social adjustment. Psychological Bulletin, 115(1), 74-101. https://doi.org/10.1037/00332909.115.1.74

DeWall, C. N., Finkel, E. J., Lambert, N. M., Slotter, E. B., Bodenhausen, G. V., Pond, R. S., Jr., Renzetti, C. M., \& Fincham, F. D. (2013). The voodoo doll task: Introducing and validating a novel method for studying aggressive inclinations. Aggressive Behavior, 39(6), 419-439.

DiGiuseppe, R., Eckhardt, C., Tafrate, R., \& Robin, M. (1994). The diagnosis and treatment of anger in a cross-cultural context. Journal of Social Distress and the Homeless, 3(3), 229-261. https://doi. org/10.1007/BF02087759 (Multicultural views on domestic violence: Part II)

DiGiuseppe, R., \& Tafrate, R. C. (2003). Anger treatment for adults: A meta-analytic review. Clinical Psychology: Science and Practice, 10(1), 70-84. https://doi.org/10.1093/clipsy/10.1.70

Edwards, D. J. (1990). Cognitive therapy and the restructuring of early memories through guided imagery. Journal of Cognitive Psychotherapy, 4(1), 33-50.

Ehlers, A., Clark, D. M., Hackmann, A., McManus, F., \& Fennell, M. (2005). Cognitive therapy for posttraumatic stress disorder: development and evaluation. Behaviour Research and Therapy, 43(4), 413-431. https://doi.org/10.1016/j.brat.2004.03.006

Epps, J., \& Kendall, P. C. (1995). Hostile attributional bias in adults. Cognitive Therapy and Research, 19(2), 159-178. https://doi.org/10.1007/BF02229692

Evans, I. M., \& Kamemoto, W. S. (1973). Reliability of the short form of Betts' Questionnaire on Mental Imagery: Replication. Psychological Reports, 33(1), 281-282. https://doi.org/10.2466/pr0.1973.33.1.281 
Hackmann, A., Clark, D. M., \& McManus, F. (2000). Recurrent images and early memories in social phobia. Behaviour Research and Therapy, 38(6), 601-610. https://doi.org/10.1016/S0005-7967(99)00161-8

Hawkins, K. A., \& Cougle, J. R. (2013). Effects of interpretation training on hostile attribution bias and reactivity to interpersonal insult. Behavior Therapy, 44(3), 479-488. https://doi.org/10.1016/j.beth.2013.04.005

Hofmann, S. G., Asnaani, A., Vonk, I. J. J., Sawyer, A. T., \& Fang, A. (2012). The efficacy of cognitive behavioral therapy: A review of meta-analyses. Cognitive Therapy and Research, 36(5), 427-440. https://doi.org/10.1007/s10608-012-9476-1

Holmes, E. A., Grey, N., \& Young, K. A. D. (2005). Intrusive images and "hotspots" of trauma memories in Posttraumatic Stress Disorder: an exploratory investigation of emotions and cognitive themes. Journal of Behavior Therapy and Experimental Psychiatry, 36(1), 3-17. https://doi.org/10.1016/j. jbtep.2004.11.002

Holmes, E. A., \& Mathews, A. (2010). Mental imagery in emotion and emotional disorders. Clinical Psychology Review, 30(3), 349-362. https://doi.org/10.1016/j.cpr.2010.01.001

Hornsveld, R. H. J., Muris, P., Kraaimaat, F. W., \& Meesters, C. (2009). Psychometric properties of the Aggression Questionnaire in Dutch violent forensic psychiatric patients and secondary vocational students. Assessment, 16(2), 181-192. https://doi.org/10.1177/1073191108325894

Keller, J., \& Pfattheicher, S. (2013). The Compassion-Hostility Paradox: The Interplay of Vigilant, PreventionFocused Self-Regulation, Compassion, and Hostility. Personality and Social Psychology Bulletin, 39(11), 1518-1529. https://doi.org/10.1177/0146167213499024

Lievaart, M., Franken, I. H. A., \& Hovens, J. E. (2016). Anger assessment in clinical and nonclinical populations: Further validation of the State-Trait Anger Expression Inventory-2. Journal of Clinical Psychology, 72(3), 263-278. https://doi.org/10.1002/jclp.22253

McEvoy, P. M., Erceg-Hurn, D. M., Saulsman, L. M., \& Thibodeau, M. A. (2015). Imagery enhancements increase the effectiveness of cognitive behavioural group therapy for social anxiety disorder: A benchmarking study. Behaviour Research and Therapy, 65, 42-51. https://doi.org/10.1016/j. brat.2014.12.011

McEvoy, P. M., Hyett, M. P., Bank, S. R., Erceg-Hurn, D. M., Johnson, A. R., Kyron, M. J., Saulsman, L. M., Moulds, M. L., Grisham, J. R., Holmes, E. A., Moscovitch, D. A., Lipp, O. V., Campbell, B. N. C., \& Rapee, R. M. (2020). Imagery-enhanced v. verbally-based group cognitive behavior therapy for social anxiety disorder: a randomized clinical trial. Psychological Medicine, 1-10. https://doi.org/10.1017/ S0033291720003001

McEvoy, P. M., \& Saulsman, L. M. (2014). Imagery-enhanced cognitive behavioural group therapy for social anxiety disorder: A pilot study. Behaviour Research and Therapy, 55, 1-6. https://doi.org/10.1016/j. brat.2014.01.006

McNair, D. M., Lorr, M., \& Droppleman, L. F. (1992). Manual for the Profile of Mood States. Educational and Industrial Testing Service.

Norton, A. R., \& Abbott, M. J. (2016). The efficacy of imagery rescripting compared to cognitive restructuring for social anxiety disorder. Journal of Anxiety Disorders, 40, 18-28. https://doi.org/10.1016/j. janxdis.2016.03.009

Sheehan, P. W. (1967). A shortened form of Betts' questionnaire upon mental imagery. Journal of Clinical Psychology, 23(3), 386-389. https://doi.org/https://doi.org/fcfk5f

Smucker, M. R., Dancu, C., Foa, E. B., \& Niederee, J. L. (1995). Imagery rescripting: A new treatment for survivors of childhood sexual abuse suffering from posttraumatic stress. Journal of Cognitive Psychotherapy, 9(1), 3-17.

Spielberger, C. D. (1999). State-Trait Anger Expression Inventory-2. Psychological Assessment Resources. 
Van der Heijden, P., Ingenhoven, T., Berghuis, H., \& Rossi, G. (2014). Nederlandstalige bewerking van The Personality Inventory for DSM-5 ${ }^{\circledR}(P I D-5)-$ Adult, 2011. Uitgeverij Boom.

Verona, E., Sadeh, N., Case, S. M., Reed, A., 2nd, \& Bhattacharjee, A. (2008). Self-reported use of different forms of aggression in late adolescence and emerging adulthood. Assessment, 15(4), 493-510. https:// doi.org/10.1177/1073191108318250

Wicherts, J. M., \& Vorst, H. C. M. (2004). Modelpassing van de Verkorte Profile of Mood States en meetinvariantie over mannen en vrouwen [journal article]. Nederlands Tijdschrift voor de Psychologie en Haar Grensgebieden, 59(1), 11-20. https://doi.org/10.1007/bf03062320 


\section{APPENDIX A}

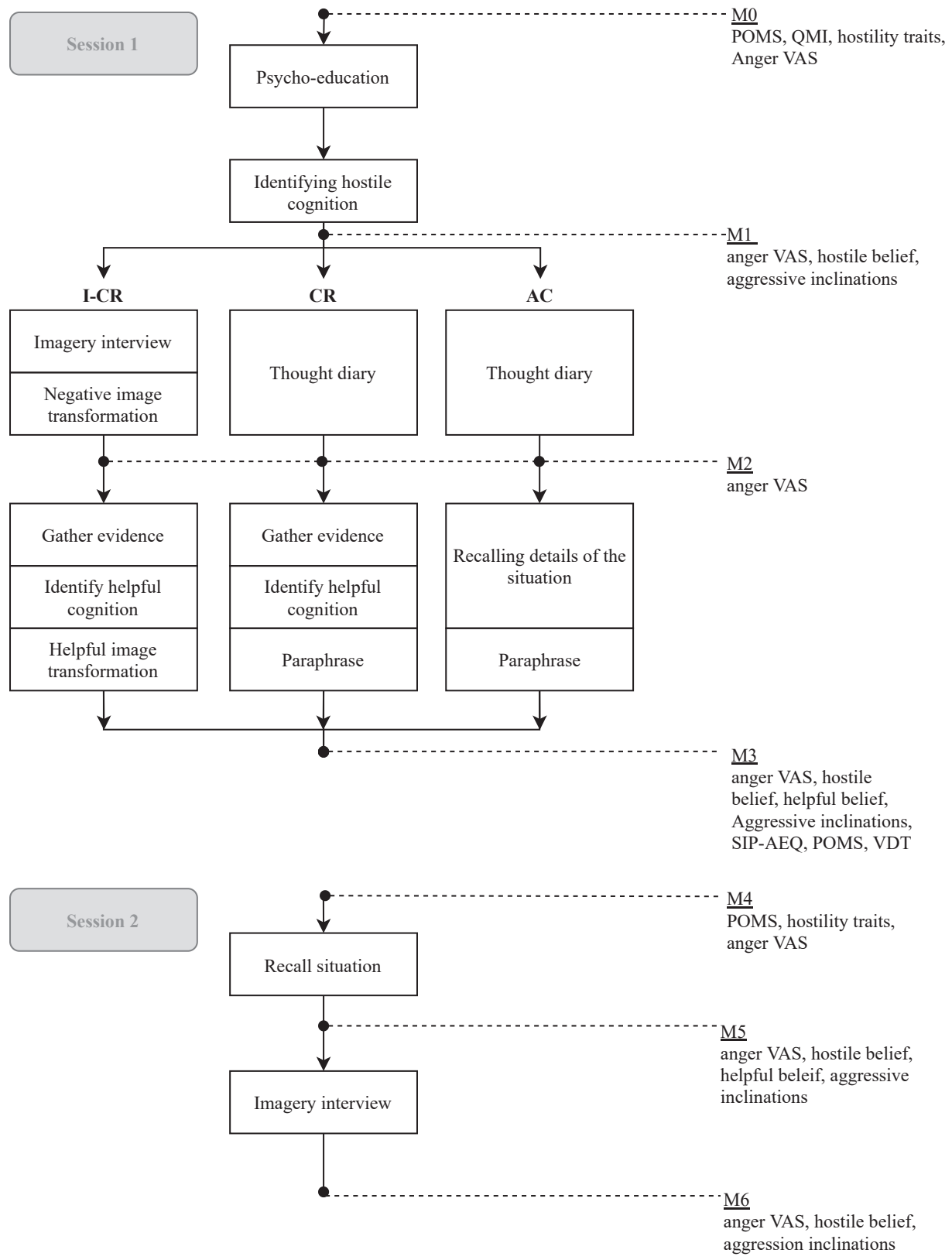

Study procedure

Note. $\mathrm{MO}=$ measurement $0 ; \mathrm{M} 1=$ measurement 1 etc 




\section{CHAPTER 5}

\section{Imagery-Enhanced Cognitive Restructuring of Hostile Beliefs: A Narrative Description}

This chapter is published as: Van Teffelen, M.W., Voncken, M.J., Peeters, F., Mollema, E.D., \& Lobbestael, J. (in press) Imagery-Enhanced Cognitive Restructuring of Hostile Beliefs: A Narrative Description. Cognitive and Behavioral Practice 


\section{ABSTRACT}

Cognitive restructuring (CR) is an efficacious intervention for reducing transdiagnostic hostility. However, evidence suggests that the efficacy of CR can be further improved. A promising candidate for improving the efficacy of $C R$ is mental imagery. Previous work showed that that enriching $\mathrm{CR}$ with mental imagery (I-CR) increased its efficacy in terms of reducing hostile beliefs and aggressive inclinations. In this article, we describe the rationale of the I-CR procedure, how to use it, and illustrate it with case examples. Our clinical experience underlines that imagery seems to capture both the hostile as well as helpful thoughts in a more effective way than verbal formulations. Future studies need to explore whether using this protocol is helpful for patients with clinical levels of hostility. 


\section{INTRODUCTION}

Hostility is a personality constellation that consists of a tendency to experience angry affect, hold hostile cognitions and behave aggressively (American Psychiatric Association, 2013; Barefoot, 1992; Chaplin, 1982). Trait hostility consists of several lower-level dimensions: a cognitive (i.e., hostile intent), affective (i.e., anger) and behavioral (i.e., aggression) dimension. Hostility is associated with profound negative consequences, such as intimate partner violence (Henrichs et al., 2014), increased risk of coronary heart disease (Smith, 1992), and suicidality (Ammerman et al., 2015). One study in $N=3800$ outpatients in the United States demonstrated that 21\% self-reported moderate to severe aggressive behavior in the preceding week (Genovese et al., 2017). Of these 3800 outpatients the majority of patients were classified with major depressive disorder (42\%), anxiety disorder (39\%), and personality disorder (29\%). Hostility rates in the same work were even higher in people with intermittent explosive disorder (67\%), posttraumatic stress disorder (38\%) and cluster B personality disorders (51\%). It may therefore not be surprising that high levels of hostility is often a primary reason to seek treatment in mental healthcare institutions (Lachmund et al., 2005).

The treatment of hostility can be considered challenging for a number of reasons. First, hostility poses a diagnostic problem. Traditional classification instruments such as DSM-5 and ICD11 do not include a 'hostility disorder'. Instead, different aspects of hostility are described as symptoms of other clinical disorders. DSM-5, for example, includes hostility aspects in descriptions of intermittent explosive disorder, posttraumatic stress disorder, borderline personality disorder, paranoid personality disorder, antisocial personality disorder, disruptive mood dysregulation disorder and bipolar disorder. While some authors propose to include a 'hostility disorder' in future editions of classification instruments (DiGiuseppe et al., 2012), others propose to view hostility as a transdiagnostic phenomenon (American Psychiatric Association, 2013; Cassiello-Robbins \& Barlow, 2016; Fernandez \& Johnson, 2016; Vidal-Ribas et al., 2016). Second, hostility is been associated with premature treatment discontinuation (Arntz et al., 2015; Cassiello-Robbins et al., 2015; Putt et al., 2001). Third, hostility is positively associated with psychopathological severity (Cassiello-Robbins \& Barlow, 2016). Last, evidence suggests that hostility may contribute to feelings of inadequacy in therapists (von der Lippe et al., 2008). Irrespective of the conceptual and clinical challenges that currently impact pathological hostility, the prominence of hostility as a clinical problem stresses the need for effective methods of intervention.

Fortunately, cognitive behavioral therapy (CBT) programs have been developed to treat hostility and show favorable outcomes (Hofmann et al., 2012). However, 34\% of patients who received cognitive behavioral treatment packages for hostility did not (or to a less extent) benefit from treatment (Hofmann et al., 2012). It is furthermore speculated that cognitive 
techniques in CBT are more challenging for hostility than, for example, for anxiety disorders (DiGiuseppe et al., 1994). Hostile thoughts are shown to focus more on fairness, blaming, justification and cathartic expression rather than the interpretation of facts (DiGiuseppe et al., 1994), making the identification of hostile interpretation biases that underlie these thoughts more difficult. The challenging nature of hostility treatment moved us to explore how to amplify the effectiveness of cognitive interventions for hostility. In our exploration, it seemed that enrichment with imagery could be a valuable addition in hostility treatment.

The theoretical basis for enriching cognitive treatment with imagery is rooted in mounting evidence that images generate a stronger emotional response than only verbal-linguistic representations of emotions (Holmes \& Mathews, 2010; Pearson et al., 2015).This seems to hold for anger too. That is, a qualitative analysis of emotions and thoughts reported during the recall of intrusive mental images demonstrates that recalling intrusive mental images positively relates to experiencing a variety of affect, including anger (Holmes et al., 2005). In other words, evidence suggests that the underlying mechanism for mental imagery is that of promoting emotional processing. That being said, the idea of integrating imagery in CBT treatment is not new. Edwards (1990) already provided a description of an empirically untested intervention that integrated imagery techniques with cognitive therapy. A decade later, mental imagery was integrated in existing CBT-focused interventions, such as imagery exposure for PTSD (Ehlers et al., 2005), imagery rescripting for negative childhood memories (Arntz \& Weertman, 1999; Smucker et al., 1995), and CBT for social anxiety disorder (e.g., McEvoy et al., 2015; McEvoy \& Saulsman, 2014).

Pioneering work by McEvoy and Saulsman (2014) on imagery enriched CBT included a cognitive restructuring (CR) procedure and seemed a suitable candidate for challenging hostile beliefs. We decided to tailor this procedure to a CR procedure for hostile beliefs and most importantly, to test whether this added effectiveness compared to active control and traditional CR. Indeed, I-CR was more efficacious and sustainable over time in reducing hostile beliefs and aggressive inclinations (Van Teffelen et al., under revision). In the current paper we will share the details of this CR procedure for hostility illustrated with examples of participants of this study and discuss difficulties and further challenges for hostility treatment.

In sum, I-CR seems a promising novel technique for reducing hostile beliefs in transdiagnostic hostility. In the present article, we describe in detail an I-CR procedure for transdiagnostic hostility that aims at adapting hostile beliefs that occur in patients' everyday situations. I-CR is therefore intended for patients who experience hostility on a regular basis. The target population includes patients who hold a general tendency to interpret situations in a hostile way, but also patients who specifically struggle with hostility in specific situations. 


\section{IMAGERY-ENHANCED COGNITIVE RESTRUCTURING}

A brief overview of the I-CR intervention is presented in Figure 1. In short, the procedure includes three phases (i.e., rationale, recall and intervention). The procedure begins with a detailed explanation of the technique using a neutral example during the rationale phase. Then, in the recall phase, participants are asked to describe a recent event that triggered hostility (recall). While recalling the event, the strongest accompanying hostile belief is identified. Following this, participants are guided to relive this event based on the reliving part of the imagery interview described by Hackmann et al. (2000). After that, participants are asked to transform their hostile belief into a mental image. Subsequently, in the intervention phase, participants engage in a regular cognitive restructuring (CR) exercise, which is concluded by formulating a more helpful belief. Although many techniques can be used during cognitive restructuring (e.g., multidimensional evaluation or the pie-chart technique) we followed McEvoy and Saulsman (2014) by using 'evidence gathering' (Beck, 2011). Evidence gathering encourages participants to look for evidence in support of, or against a belief. Last, participants are asked to transform their helpful belief into a helpful (i.e., less hostile) mental image. The full version of the I-CR protocol is provided in Appendix A.

\begin{tabular}{|l|l|l|}
\hline Rationale & \begin{tabular}{l}
\multicolumn{1}{c|}{ Recall phase } \\
1. Identifying hostile belief \\
2. Imagery phase \\
3. Hostile image transformation
\end{tabular} \\
\hline
\end{tabular}

Figure 1

Intervention overview

\section{Rationale phase}

At the beginning of the session, we start with providing an explanation of the intervention. The rationale phase takes approximately 10 minutes. Participants were provided with an interactive example (see below) that is often used in CBT to explain the relationship between thoughts, feelings, and behavior. The I-CR procedure follows this example with the notable difference that it integrates parts of the imagery procedure, allowing participants to practice generating hostile and helpful mental images. Instructions were provided with a calm voice leaving sufficient time after each sentence, allowing participants to generate a clear image of the example. First, participants were asked to image they are lying in bed, waking up to a 
loud noise. Second, participants were guided to generate a hostile image of a burglar. Third, participants were asked to generate and 'install' a helpful image. Below is a transcribed example of John (pseudonym), one of the participants in our experiment. A written release was obtained to use transcript material. John is 40-year old, highly educated, married man with two children, who works full-time.

THERAPIST: "Please close your eyes. Imagine the following. You are in your bed at night. Feel the bed you are lying on. Feel your head on the pillow. Feel the blanket on top of you. Feel the matrass. Hear the nightly sounds in your room. Suddenly, a loud noise wakes you up in the middle of the night. The thought that flashes through your mind is "it's a burglar". Can you see the burglar entering your house? If what you see is a picture, can you describe what you see?

JOHN: "Um okay, so I see a man entering my front door.

THERAPIST: (posing the questions in a slow pace, in interaction with the participant) "What does the burglar look like...? What does the burglar do...? What facial expression does the burglar have...? What posture does the burglar have...?"

JOHN: (in interaction with the questions above) "Well... he is all dressed in black looking shady. He is opening my front door with a lockpick. He looks sneaky with a mean grin on his face. His eyes are dark, I cannot see them. (grimacing)

THERAPIST: "That's great John, you're doing a good job. What do you feel (in your body)? “

JOHN: Well I feel that I am getting angry. I am getting pumped. My heart is starting to pound and my hands are getting sweaty."

THERAPIST: "And what do you do?"

JOHN: "I want to get up and get at him. I have to find something to defend myself or scare him off".

THERAPIST: "Alright John, well done. Now could you imagine that something more harmless generated the sound? Yes? Like what?

JOHN: "Un, well, it could also be my cat crashing into something whilst chasing a fly"

THERAPIST: "Very well John, now how does this look like in an image? What does the cat do? How does it look like? What facial expression does the cat have? What posture?" 
JOHN: "So I have this small table in the middle of the room, and I can see my cat chasing a fly. He gets excited. He's jumping across a chair but then he crashes into the table and a vase falls off and breaks."

THERAPIST: "Very good. Now I want to ask you to rewind 'the tape' and go back to the moment you are sleeping in bed. When you wake up, I want you to clearly imagine seeing the image of your cat crashing into the table whilst chasing a fly. Okay? Now, you are in your bed at night. Feel the bed you are lying on. Feel your head on the pillow. Feel the blanket around you. Feel the matrass. Hear the nightly sounds in your room. Suddenly, a loud noise wakes you up in the middle of the night. Can you see the image of your cat? What do you feel now? How do you respond in the image?

JOHN: "Yea I can see it clearly. I do feel calmer because it happened more often. I turn around and fall asleep again."

THERAPIST: "Alright you can open your eyes again. I would like to discuss the two images you have just generated. What strikes you? What is the difference?

JOHN: "Well, the second time with the cat was a lot less disturbing."

THERAPIST: Indeed, John, the difference shows that it is not the situation itself (the loud noise), but our interpretation of the situation generated in an image (the burglar or the cat) that influences how we feel and behave. In the technique we're using we will question the thoughts from which these images originate."

\section{Recall phase}

\section{Identifying hostile belief}

After explaining the rationale of the intervention, we asked our participants to recall an anger-provoking autobiographical event that still makes them angry at present. Typically, the entire recall phase took about 20 minutes. To determine the hostile belief, we asked participants: "What is the worst thing about the event? What does this say about the intention of the other person involved?" We then encouraged participants to summarize the meaning of the event into one sentence. Based on our clinical experience and experiences in the pilot phase of the study we decided that the following elements had to be included into this hostile belief: an aggressor, a victim, a harmful behavior, and an intention. For example: "My mother (i.e., the aggressor) said something nasty to my friend

1 We asked for events that provoked anger (as opposed to hostile beliefs), as we thought that the concept of 'anger' was easier to grasp for our participants. 
(i.e., the harmful behavior) about me (i.e., the victim) to separate us deliberately (i.e., the intention)". A one-sentence summary of the event (e.g., my friend went on holiday without me) and the hostile belief (e.g., my mother said something nasty to my friend about me to separate us deliberately) were then written on a whiteboard. Examples of events and their related hostile beliefs in three participants (i.e., pseudonyms John, Bastian, and Kim) are presented in Table 1.

\section{Table 1}

Examples of events and related hostile beliefs in three cases

\begin{tabular}{llll}
\hline Participant & Event & Hostile belief & Hostile image \\
\hline John & $\begin{array}{l}\text { My daughter lied by saying } \\
\text { she did not have sex with } \\
\text { her boyfriend }\end{array}$ & $\begin{array}{l}\text { She is doing this on } \\
\text { purpose to hurt me }\end{array}$ & $\begin{array}{l}\text { Scornfully sly little infant } \\
\text { who is ridiculing me }\end{array}$ \\
Bastian & $\begin{array}{lll}\text { My mother told my friend } \\
\text { to go on holiday without }\end{array}$ & $\begin{array}{l}\text { She deliberately says } \\
\text { harmful things to separate }\end{array}$ & A scornfully laughing old \\
& me witch with a wrinkly, mean, \\
& My friend acts nervous on & My friend purposefully & My friend looks at me \\
& my birthday & tries to spoil my birthday & with angry accusing eyes, \\
& & & standing arms crossed \\
\hline
\end{tabular}

\section{Imagery recall}

After the hostile belief is identified, participants recalled the situation in imagery modus. The aim of this phase is to let participants relive the anger-provoking event in imagery, as preparation for the next phase in which the hostile belief was transformed into a hostile image. During the imagery recall participants were asked to describe their anger-provoking event with their eyes closed, as if it is happening here and now, making use of their five senses. We then observed and checked with the participant if (s)he was experiencing an optimal level of hostility (i.e., high enough to sense some hostility, but not to the extent that a participant is overwhelmed). Next, we repeated the hostile belief that was written on the whiteboard. Below is an example of John (see Table 1), who's 15-year old daughter asked for sexual education, because she met a boy at school that she liked. John says that one of the most principal things he tried to teach his daughter while raising her was that lying is not tolerated. While giving his daughter sexual education he finds out that his daughter already had sex the day before.

THERAPIST: "Alright John, now I want to ask you to close your eyes and imagine you're going back to the situation where you found out your daughter lied about having sex. Please go back to the moment you were most angry and describe what happens as if it is happening here and now as vividly as possible." 
JOHN: "Alright, I am in the situation, I am in the living room with my daughter. My wife is sitting nearby, and my daughter tells me that in fact she already had sex with the boy. It is like a black haze comes over me, like my brain is going in overdrive. All reason is drained away from my body, I feel anger, I am so heavily disappointed, and I start splurging curse words.

THERAPIST: "If what you see is a picture, describe what you see."

JOHN: "My wife is behind me hoping I do not do something crazy; we are in the living room; my daughter's face is as white as it can be. If my gaze would have been deadly, then I surely would have killed someone that moment. I am standing there, and I am very tense.

THERAPIST: "Do you hear or smell something?"

JOHN: "No, it's dead silent. I smell nothing."

THERAPIST: "What do you feel (in your body)?"

JOHN: "I feel as if my heart is going to jump out of my body, like l'm under 480 volts. My chest muscles are super tense. As if I am very unstable nitroglycerin in which someone just light a spark. I am furious."

THERAPIST: "Can you feel it right now?"

JOHN: "Yea, but much less as back then."

THERAPIST: "Alright try to make the feeling as strong as possible. Focus on the tension in your chest and on your pounding heart. What now goes through your mind is "She's doing this on purpose to hurt me".

\section{Hostile image transformation}

Arriving at the 'hotspot' of the anger-provoking event, we continued with the transformation of the hostile belief into a hostile image. To transform the hostile belief into an image, we aimed to let participants generate a mental image that is as lively as possible and adequately captures all sensory and affective information. Importantly, we told participants that this image does not have to be realistic, as long as it adequately captures a participant's feelings. Below we continue with a written transcription of John. Other examples of hostile image transformations are provided in Table 1. 
THERAPIST: "Very good John. You can keep your eyes closed. Now I want to ask you to visualize as detailed and vividly as possible what it would look like in a picture that your daughter did this on purpose to hurt you. I am not looking for a realistic image. The picture should adequately capture your feelings, not reality. It might even be a cartoon for example. Use as many details as possible. What does your daughter look like? How is she looking at you? What posture does she have?"

JOHN: "Um, okay. It is like I am very tall, and she is very small. I am looking down on her. I see the picture of a scornful, sly little infant who is ridiculing me. She's laughing like a little devil."

\section{Intervention phase}

\section{Cognitive restructuring}

When we identified a hostile belief and image, we wrote down a belief rating (i.e., the likelihood the thought is true) from $0 \%$ to $100 \%$ and proceeded with the cognitive technique evidencegathering. Typically, this phase lasted another 20 to 30 minutes. During evidence gathering we asked participants to come up with evidence in support of and evidence against their hostile belief. To do so we asked participants: "What shows that your thought is true? Are there possible other events you have experienced that make the evidence stronger? What shows that your thought is possibly maybe not true? Do you have any experiences showing that the thought is not always true? Have you experienced something similar before, and if so, what have you learned from it that could possible help you?". We wrote the evidence on the whiteboard under the headers "evidence for" and "evidence against" the thought. After that, we asked participants: "If you look at the evidence you have put forward, what would you conclude about your original thought? Could you think of an alternative, more helpful thought?" An example is shown in Table 2.

\section{Helpful image transformation}

At the end of the evidence-gathering phase, we asked participants to transform their formulated helpful thought into a helpful image. Similar to hostile image transformation, participants are asked to generate this image themselves. Examples of transforming helpful thoughts into images are shown in Table 3. After participants formulated a helpful image, we asked them to 'install' it. To do so, the therapist repeated the image that was described by the participant at the end of the imagery phase (i.e., the anger 'hotspot') and asked them to replace the old image (in the case of John, a scornful, sly infant), with their newly formulated helpful image (in the case of John, a timid little girl with Bambi-like eyes). It is our clinical impression that most of the helpful images included a degree of pity or empathy with the aggressor or acknowledgment of the unintended shortcomings of the aggressor. Last, we asked the participant what they feel when they look at this helpful image and ask them to open their eyes. We experienced that in many cases, the participants developed some sense of compassion for their 'aggressor'. 
Table 2

Example of evidence gathering

\begin{tabular}{|c|c|c|}
\hline Evidence for belief & Evidence against belief & Helpful thought \\
\hline \multicolumn{3}{|c|}{$\underline{\text { John }}$} \\
\hline \multirow[t]{6}{*}{$\begin{array}{l}\text { She does not say she is wrong } \\
\text { and tries to stand up for her } \\
\text { boyfriend }\end{array}$} & $\begin{array}{l}\text { She was afraid or ashamed of } \\
\text { having to tell me that she had } \\
\text { sex. }\end{array}$ & \multirow[t]{6}{*}{$\begin{array}{l}\text { "She's been foolish and only a } \\
\text { little girl that needs help from } \\
\text { her father" }\end{array}$} \\
\hline & She acted impulsively. & \\
\hline & $\begin{array}{l}\text { Her boyfriend maybe pushed } \\
\text { her }\end{array}$ & \\
\hline & I am conservative and she & \\
\hline & knows it. & \\
\hline & She is just a child, too naive & \\
\hline \multicolumn{3}{|c|}{ Bastian } \\
\hline $\begin{array}{l}\text { I really said the opposite of what } \\
\text { my mother said to my friend }\end{array}$ & $\begin{array}{l}\text { Maybe my friend told } \\
\text { something else }\end{array}$ & $\begin{array}{l}\text { My mother must have been } \\
\text { angry for something else }\end{array}$ \\
\hline \multirow[t]{2}{*}{ She did it behind my back } & $\begin{array}{l}\text { Maybe she interpreted it } \\
\text { differently }\end{array}$ & \\
\hline & $\begin{array}{l}\text { My mother was angry about } \\
\text { some other family business }\end{array}$ & \\
\hline \multicolumn{3}{|c|}{$\underline{\mathrm{Kim}}$} \\
\hline Her tone was angry & $\begin{array}{l}\text { Her parents are divorcing and } \\
\text { had a fight in her presence the } \\
\text { night before }\end{array}$ & My friend has problems at home \\
\hline She acted distant & $\begin{array}{l}\text { Maybe she was reacting things } \\
\text { at me, but did not mean it }\end{array}$ & \\
\hline
\end{tabular}

Table 3

Examples of events and related helpful beliefs in three cases

\begin{tabular}{|c|c|c|c|}
\hline Participant & Event & Helpful belief & Helpful image \\
\hline John & $\begin{array}{l}\text { My daughter lied about } \\
\text { having sex }\end{array}$ & $\begin{array}{l}\text { She has been foolish, but I } \\
\text { want to help her }\end{array}$ & $\begin{array}{l}\text { A timid helpless girl } \\
\text { standing there with Bambi- } \\
\text { like eyes, nervously } \\
\text { playing with her hair }\end{array}$ \\
\hline Bastian & $\begin{array}{l}\text { My mother told my friend } \\
\text { to go on holiday without } \\
\text { me }\end{array}$ & $\begin{array}{l}\text { My mother must have been } \\
\text { angry for something else }\end{array}$ & $\begin{array}{l}\text { Woman at the kitchen } \\
\text { table who is on the phone, } \\
\text { looking like she does not } \\
\text { know what to do }\end{array}$ \\
\hline Kim & $\begin{array}{l}\text { My friend acts nervous on } \\
\text { my birthday }\end{array}$ & $\begin{array}{l}\text { My friend has problems at } \\
\text { home }\end{array}$ & $\begin{array}{l}\text { My friend is arguing with } \\
\text { her parents and looks } \\
\text { tormented }\end{array}$ \\
\hline
\end{tabular}


THERAPIST: "I would now like to ask you to express this alternative, helpful belief (read for the white board) "She's been foolish and only a little girl that needs help from her father" in an image, just like we did during the introduction with 'the cat crashing into something whilst catching a fly'. Now close your eyes... I want to ask you to visualize as detailed and vividly as possible what it would look like in a picture that "She's been foolish and only a little girl that needs help from her father". I am not looking for a realistic image. The picture should adequately capture your feelings, not reality. Like a cartoon for example. Use as many details as possible.

JOHN: "Uh okay, so I see my daughter standing there in the room. I always say to her that she has these deer-like eyes, like Bambi. So, I see this image of her, standing in the room like a timid, helpless little girl with these Bambi-eyes, nervously playing with her hair."

THERAPIST: Very well John. Now we are going to install this new image. You can keep your eyes closed. If we go back to the situation, you just went through sexual education and she tells you that in fact she already had sex with the boy, you see the living room, your wife behind you, your daughters face as white as can be, it is dead silent. What now goes through your mind is "She's been foolish and only a little girl that needs help from her father". You can now change the old image to the new, helpful image of your daughter, standing in the room like a timid, helpless little girl with Bambi-eyes, nervously playing with her hair. Take your time. How does this image affect you when you look at it?

JOHN: "Now that I see her, I really have this urge to help her. I mean, she has been foolish, but she cannot help it, she is so young. She has seen nothing of the world yet. Yeah, I want to talk to her and comfort her.

\section{POTENTIAL PROBLEMS AND SOLUTIONS}

A first potential problem that may occur is that participants stick to a realistic description of what happened when transforming the beliefs into images. When this occurs, a possible solution is to repeat the instruction that the image does not have to be realistic and that it can be caricature- or cartoon-like. It can also help to ask additional questions, such as "What does the other person look like? What is his/her facial expression? What is his/her posture? Is the person little or tall? What does a person look like that is ridiculing/taking advantage someone?". A second problem a therapist might run into is asking too many details, or a participant provides too many details. The goal of the mental imagery phase is to evoke a mental image that is as lively as possible, but still tolerable for participants (Hackmann et al., 2000). Questions such as "What do you see? Who is there with you? Are you standing or 
seated?" can be asked to help a participant relive the situation. When a participant is reliving a mental image, it is helpful to look for signs that reveal a participant is becoming emotional, such as sweating or changes in facial expression. By asking too many questions participants can also get distracted or feel that they need to do well and provide the 'right' answer. Then it is recommended to summarize the mental image and let the participant focus on it. A third problem that can arise is that a participant might start describing a mental image in past tense. Describing an image in past tense will potentially lower the vividness and emotionality of the image. When this occurs, a therapist can help a participant by for example by rephrasing "... So your daughter is looking at you. She is not telling the truth." When a participant continues to describe the image in past tense, a therapist should mention this and encourage a participant to describe the image in present tense. A fourth relevant problem a participant might run into is giving multiple 'scenes', or examples in a situation. For instance, a participant described getting angry multiple times because she did not get a promised taxi ride. The situation described by this participant involved multiple scenes, e.g., being on the phone, waiting on the sidewalk, talking to the hotel clerk. The problem of multiple scenes can be tackled by having the participant select the most prominent scene that triggered the most anger. Fifth, a participant might hold a degree of loyalty to the 'aggressor', especially when close relationships are concerned. Participants might then not dare to express their anger, which in turn might trouble the identification of hostile beliefs. A potential solution to this problem is to 'normalize' anger through empathizing with the elicited anger. For example, when a participant is describing that she was not invited to a party with friends she normally hangs out with during the recall phase, a therapist might respond with: "No way, you have to be kidding me? Did (s) he really does that? Does (s)he not realizes what this means to you? I can imagine this must have really triggered your anger!". A sixth problem that may occur is when a participant is not able to reexperience the momentary angry affect that was once associated to the situation as they already developed some helpful thoughts or due to shame rationalized the anger. In that case, extra attention should be paid to the imagery phase. During the last part of the imagery phase, a therapist could repeat to 'focus on the bodily sensations, angry unjust feeling and all its details' as much as possible and provide the participant enough time to do so. In some cases, participants may actively avoid difficult emotions. When a participant is actively avoiding emotions, potentially multiple sessions are required. Last, therapists sometimes had difficulties streaming the flood of words into a concise sentence and to include some form of 'intention' by the aggressor (e.g., (s)he did it on purpose). Therefore, we designed a format for the hostile beliefs which our therapists regarded as helpful. Last, therapists sometimes had difficulties streaming the flood of participants' words into a concise sentence when formulating the hostile belief and to include some form of 'intention' by the aggressor (e.g., '(s)he did it on purpose'). Therefore, we designed a format for the hostile beliefs (i.e., '[AGGRESSOR] [VICTIM] [ACT] [HOSTILE INTENTION]') that our therapists regarded as helpful. This is underlined by evidence indicating that hostile cognitions focusing on 'blaming' vary as a function of (among 
others) assigned intentionality (Alicke, 2000). For this reason, blame-related cognitions (e.g., "he is responsible for hurting my feelings") may flag the 'hotspot' at which intentionality was attributed. On top of that, evidence indicates that these so-called memory 'hotspots' are related to high, or even 'peak' levels of affect (Holmes et al., 2005). It may therefore also be of value to use emotion ratings (e.g., a subjective units of distress scale) in the imagery recovering process. For example, at the start, and before and after asking participants what they feel during the imagery interview. However, asking for emotion ratings already may counteract the evoked emotional arousal.

Even though a significant number of potential problems can be tackled, the intervention was not successful for all participants. First, some participants were, for instance, not able to generate a mental image, because they felt they did not have the general capacity to do so. Such participants kept on describing a realistic account of what happened and said that 'they could not come up with it'. Second, for some participants it was difficult to identify a belief that was challengeable, because the core of the harmful belief was not so much about intentionality, but more about tolerance, fairness, or blame. For example, a man described that he got angry because the management board at his job let him wait outside a meeting room for three minutes. The best hostile belief he provided was 'they do not keep their appointment'. In this particular case it helped to ask, 'does it help you to think that way?'. Third, as is shown in Table 3, we believe that evidence-gathering on its own is not able to cast enough doubt on the intentionality of 'the aggressor' and that it is the helpful image that in the end provokes a feeling of sympathy or pity with the aggressor.

\section{FUTURE DIRECTIONS}

Until now, only our own study showed that compared to active control and traditional CR, one session of I-CR is more efficacious and sustainable over time in reducing hostile beliefs and aggressive inclinations (Van Teffelen et al., under revision). However, these findings were obtained in mostly females (72\%) with increased, but non-clinical levels of hostility. At this point it is unclear if the intervention also works in clinical samples, or samples that include more men. It is also unclear whether I-CR effects are mediated by (other) personal characteristics as, for example, a person's creativity or imagery ability. Although we ran into some participants that seemed to have difficulties with generating mental images, scientific evidence that supports a positive relationship between general imagery capacity and the efficacy of imagery procedures is mixed (see Dibbets et al. (2012) versus Lee and Kwon (2013)). In addition, several empirical questions currently remain to be investigated. For example, it is unclear what the impact would be of multiple sessions, what would be the optimal number of sessions, if these sessions generalize to novel 'real-life' situations, or if the effect sustains 
over time. Last, some authors have proposed that anger can manifest itself as a primary but also as a secondary emotion (i.e., feeling angry in response to a primary emotion such as feeling hurt) (Pascual-Leone et al., 2013). In the present intervention, we approached anger as a primary affective state. Perhaps, focusing on anger as a secondary emotion or probing for co-existing non-angry affect could lead to other images.

With regard to recommendations for further clinical implementation of this technique, we need to say that in our study therapists received 20 hours of extensive training. The training included feedback on role-playing, pilot-runs, and participant tapes by our research group, including a licensed clinical psychologist (E.M.) and cognitive behavioral therapist (M.V.) who have wide experience using imagery techniques in clinical practice. In day-to-day clinical settings, such training seems difficult to obtain. However, substantial time was spent on fine-tuning the protocol, moreover, our therapist were master-level students that had no experience yet with the CR technique 'evidence-gathering'. A more important issue is that in our experience, the parts in which hostile and helpful beliefs are identified and when beliefs are transformed into images is challenging. That is, formulating clear challengeable beliefs and images that cover the affective load of a belief is essential to the intervention, but at the same time very delicate. Our therapists indicated they found it helpful to look for intentionality in formulating the beliefs, and to caricature-like images. Ultimately, we hope that when the technique is applied to multiple situations in which hostility plays a role, this benefits the generalizability to novel 'real-life situations', as for example is reflected by stable, long-term symptom reductions after CBT for other psychopathologies (Hofmann et al., 2012). For hostility however, this remains to be investigated.

In developing the present intervention, we have employed a transdiagnostic approach to hostility. However, as we put forward in the introduction hostility consists of different dimensions (i.e., cognitive, affect and behavioral). Some people may score high on 'affective' aspects of hostility, whereas others score high on cognitive and behavioral aspects of hostility. In traditional diagnostic terms, hostility aspects are reflected differently across psychiatric diagnostic classifications. For example, Intermittent Explosive Disorder includes behavioral aspects of hostility. Post-traumatic stress disorder and borderline personality disorder include both affective and behavioral aspects of hostility. Paranoid personality disorder mainly includes cognitive aspects of hostility. Although I-CR showed efficacious reductions on all aspects of hostility, I-CR showed increased efficacy on cognitive and behavioral, but not affective aspects of hostility compared to traditional CR. For this reason, I-CR may have no added value over traditional CR for patients who primarily experience affective aspects of hostility. However, for patients with more cognitive and behavioral aspects of hostility (e.g., Intermitted Explosive Disorder, Post-traumatic disorder, and borderline and paranoid personality disorder) I-CR could be more suitable than traditional $\mathrm{CR}$. 
In sum, the present article provided a detailed description of I-CR, a novel technique aiming to reduce hostile beliefs in transdiagnostic hostility. I-CR is intended for participants holding a general tendency to interpret situations in a hostile way, but also participants who specifically struggle with hostility in specific situations. We described in detail the intervention protocol that was used in a randomized controlled trial (Van Teffelen et al., under revision), using case examples. Our clinical experience underlines that imagery seems to capture both the hostile as well as the helpful thoughts in a more effective way than verbal formulations. Future studies need to explore whether using this protocol is helpful for participants with clinical levels of hostility. 


\section{REFERENCES}

Alicke, M. D. (2000). Culpable control and the psychology of blame. Psychological Bulletin, 126(4), 556-574. https://doi.org/10.1037/0033-2909.126.4.556

American Psychiatric Association. (2013). Diagnostic and Statistical Manual of Mental Disorders (5th ed.).

Ammerman, B. A., Kleiman, E. M., Uyeji, L. L., Knorr, A. C., \& McCloskey, M. S. (2015). Suicidal and violent behavior: The role of anger, emotion dysregulation, and impulsivity. Personality and Individual Differences, 79, 5762. https://doi.org/10.1016/j.paid.2015.01.044

Arntz, A., Stupar-Rutenfrans, S., Bloo, J., van Dyck, R., \& Spinhoven, P. (2015). Prediction of treatment discontinuation and recovery from borderline personality disorder: results from an rct comparing schema therapy and transference focused psychotherapy. Behaviour Research and Therapy, 74, 60-71. https:// doi.org/10.1016/j.brat.2015.09.002

Arntz, A., \& Weertman, A. (1999). Treatment of childhood memories: Theory and practice. Behaviour Research and Therapy, 37(8), 715-740. https://doi.org/10.1016/S0005-7967(98)00173-9

Barefoot, J. C. (1992). Developments in the measurement of hostility. In H. S. Friedman (Ed.), Hostility, coping, \& health. (pp. 13-31). American Psychological Association. https://doi.org/10.1037/10105-001

Beck, J. S. (2011). Cognitive behavior therapy: Basics and beyond (2nd ed.). Guilford Press.

Cassiello-Robbins, C., Conklin, L. R., Anakwenze, U., Gorman, J. M., Woods, S. W., Shear, M. K., \& Barlow, D. H. (2015). The effects of aggression on symptom severity and treatment response in a trial of cognitive behavioral therapy for panic disorder. Comprehensive Psychiatry, 60, 1-8. https://doi.org/10.1016/j. comppsych.2015.04.012

Cassiello-Robbins, C., \& Barlow, D. H. (2016). Anger: The unrecognized emotion in emotional disorders. Clinical Psychology: Science and Practice, 23(1), 66-85. https://doi.org/10.1111/cpsp.12139

Chaplin, J. P. (1982). Dictionary of psychology. Laurel.

Dibbets, P., Poort, H., \& Arntz, A. (2012). Adding imagery rescripting during extinction leads to less ABA renewal. Journal of Behavior Therapy and Experimental Psychiatry, 43(1), 614-624. https://doi.org/10.1016/j. jbtep.2011.08.006

DiGiuseppe, R., Eckhardt, C., Tafrate, R., \& Robin, M. (1994). The diagnosis and treatment of anger in a crosscultural context. Journal of Social Distress and the Homeless, 3(3), 229-261. https://doi.org/10.1007/ BF02087759 (Multicultural views on domestic violence: Part II)

DiGiuseppe, R., McDermut, W., Unger, F., Fuller, J. R., Zimmerman, M., \& Chelminski, I. (2012). The comorbidity of anger symptoms with personality disorders in psychiatric outpatients. Journal of Clinical Psychology, 68(1), 67-77. https://doi.org/10.1002/jclp.20835

Edwards, D. J. (1990). Cognitive therapy and the restructuring of early memories through guided imagery. Journal of Cognitive Psychotherapy, 4(1), 33-50.

Ehlers, A., Clark, D. M., Hackmann, A., McManus, F., \& Fennell, M. (2005). Cognitive therapy for post-traumatic stress disorder: development and evaluation. Behaviour Research and Therapy, 43(4), 413-431. https:// doi.org/10.1016/j.brat.2004.03.006

Fernandez, E., \& Johnson, S. L. (2016). Anger in psychological disorders: Prevalence, presentation, etiology and prognostic implications. Clinical Psychology Review, 46, 124-135. https://doi.org/10.1016/j.cpr.2016.04.012

Genovese, T., Dalrymple, K., Chelminski, I., \& Zimmerman, M. (2017). Subjective anger and overt aggression in psychiatric outpatients. Comprehensive Psychiatry, 73, 23-30. https://doi.org/10.1016/j. comppsych.2016.10.008

Hackmann, A., Clark, D. M., \& McManus, F. (2000). Recurrent images and early memories in social phobia. Behaviour Research and Therapy, 38(6), 601-610. https://doi.org/10.1016/S0005-7967(99)00161-8 
Henrichs, J., Bogaerts, S., Sijtsema, J., \& Klerx-van Mierlo, F. (2014). Intimate Partner Violence Perpetrators in a Forensic Psychiatric Outpatient Setting: Criminal History, Psychopathology, and Victimization. J Interpers Violence. https://doi.org/10.1177/0886260514552272

Hofmann, S. G., Asnaani, A., Vonk, I. J. J., Sawyer, A. T., \& Fang, A. (2012). The efficacy of cognitive behavioral therapy: A review of meta-analyses. Cognitive Therapy and Research, 36(5), 427-440. https://doi. org/10.1007/s10608-012-9476-1

Holmes, E. A., Grey, N., \& Young, K. A. D. (2005). Intrusive images and "hotspots" of trauma memories in Posttraumatic Stress Disorder: an exploratory investigation of emotions and cognitive themes. Journal of Behavior Therapy and Experimental Psychiatry, 36(1), 3-17. https://doi.org/10.1016/j.jbtep.2004.11.002

Holmes, E. A., \& Mathews, A. (2010). Mental imagery in emotion and emotional disorders. Clinical Psychology Review, 30(3), 349-362. https://doi.org/10.1016/j.cpr.2010.01.001

Lachmund, E., DiGiuseppe, R., \& Fuller, J. R. (2005). Clinicians' diagnosis of a case with anger problems. Journal of Psychiatric Research, 39(4), 439-447. https://doi.org/10.1016/j.jpsychires.2004.10.009

Lee, S. W., \& Kwon, J.-H. (2013). The efficacy of imagery rescripting (IR) for social phobia: A randomized controlled trial. Journal of Behavior Therapy and Experimental Psychiatry, 44(4), 351-360. https://doi. org/10.1016/j.jbtep.2013.03.001

McEvoy, P. M., Erceg-Hurn, D. M., Saulsman, L. M., \& Thibodeau, M. A. (2015). Imagery enhancements increase the effectiveness of cognitive behavioural group therapy for social anxiety disorder: A benchmarking study. Behaviour Research and Therapy, 65, 42-51. https://doi.org/10.1016/j.brat.2014.12.011

McEvoy, P. M., \& Saulsman, L. M. (2014). Imagery-enhanced cognitive behavioural group therapy for social anxiety disorder: A pilot study. Behaviour Research and Therapy, 55, 1-6. https://doi.org/10.1016/j. brat.2014.01.006

Pascual-Leone, A., Gilles, P., Singh, T., \& Andreescu, C. A. (2013). Problem Anger in Psychotherapy: An Emotion-Focused Perspective on Hate, Rage, and Rejecting Anger. Journal of Contemporary Psychotherapy, 43(2), 83-92. https://doi.org/10.1007/s10879-012-9214-8

Pearson, J., Naselaris, T., Holmes, E. A., \& Kosslyn, S. M. (2015). Mental Imagery: Functional Mechanisms and Clinical Applications. Trends in Cognitive Sciences, 19(10), 590-602. https://doi.org/10.1016/j. tics.2015.08.003

Putt, C. A., Dowd, E. T., \& McCormick, R. A. (2001). Impact of pre-existing levels of hostility and aggression on substance abuse treatment outcome. Counselling Psychology Quarterly, 14(2), 139-147. https://doi. org/10.1080/09515070110058576

Smith, T. W. (1992). Hostility and health: Current status of a psychosomatic hypothesis. Health Psychology, 11(3), 139-150. https://doi.org/10.1037/0278-6133.11.3.139

Smucker, M. R., Dancu, C., Foa, E. B., \& Niederee, J. L. (1995). Imagery rescripting: A new treatment for survivors of childhood sexual abuse suffering from posttraumatic stress. Journal of Cognitive Psychotherapy, 9(1), 3-17.

Van Teffelen, M. W., Voncken, M. J., Peeters, F., Mollema, E. D., \& Lobbestael, J. (under revision). Mental imagery increases the efficacy of cognitive restructuring for hostile beliefs: A randomized controlled trial.

Vidal-Ribas, P., Brotman, M. A., Valdivieso, I., Leibenluft, E., \& Stringaris, A. (2016). The status of irritability in psychiatry: A conceptual and quantitative review. Journal of the American Academy of Child and Adolescent Psychiatry, 55(7), 556-570. https://doi.org/10.1016/j.jaac.2016.04.014

von der Lippe, A. L., Monsen, J. T., Rønnestad, M. H., \& Eilertsen, D. E. (2008). Treatment failure in psychotherapy: The pull of hostility. Psychotherapy Research, 18(4), 420-432. https://doi. org/10.1080/10503300701810793 


\section{APPENDIX A}

Intervention protocol

\section{Phase 1: Rationale}

THERAPIST: "We start by explaining the technique that we are going to use. The technique we are about to apply uses mental images we can generate in our mind. To explain this, I would like you to do the following exercise.

Please close your eyes.

Imagine the following. You are in your bed at night.... Feel the bed you are lying on.... Feel your head on the pillow... Feel the blanket on top of you.... Feel the matrass.... Hear the nightly sounds in your room.... ${ }^{2}$

Suddenly, a loud noise wakes you up in the middle of the night.

The thought that flashes through your mind is "it's a burglar". Can you see the burglar entering your house? If what you see is a picture, can you describe what you see? What does the burglar look like? What does the burglar do? What expression does the burglar have? What posture does the burglar have?"

What do you feel (in your body)?

Wat do you do in the image?

Now could you imagine that something more harmless generated the sound? Yes? Like what? how does this look like in an image? What does the cat do? How does it look like? What expression does the cat have? What posture?"

Now I want to ask you to rewind 'the tape' and go back to the moment you are sleeping in bed. When you wake up, I want you to clearly imagine seeing the image of [REPEAT THE HELPFUL IMAGE OF THE PARTICIPANT]. Okay?

Now, you are in your bed at night.... Feel the bed you are lying on.... Feel your head on the pillow.... Feel the blanket around you.... Feel the matrass.... Hear the nightly sounds in your room....

2 Tip. Allow some time to let people generate the image. 
Suddenly, a loud noise wakes you up in the middle of the night. Can you see the image of [REPEAT THE HELPFUL IMAGE OF THE PARTICIPANT]?

What do you feel now (in your body)?

And what do you do?

You can open your eyes again. You are back again. I would now like to discuss these two images. What do you notice about these images? The difference shows that it is not the situation (the loud noise), but the image we create (the burglar, or something harmless) that determines what you will feel, such as anger, sadness, or fear. In the technique we are about to use we will challenge the thoughts that underly these images.

When you are ready, we can work with the negative event you've experienced."

\section{Phase 2: Recall}

\section{Part 2.1: Identifying the hostile belief}

THERAPIST: "I would like to discuss a negative event you've been through, that triggered anger which still, at this very moment, makes you angry when you think back at to it. ${ }^{3}$ Can you recall an event that made you angry? If you remember multiple situations, please select the one that made you most angry." ${ }^{4,5}$

THERAPIST "What happened?"

WHITEBOARD HEADER: SITUATION

THERAPIST: "What went through your mind? What did you think of it? Is this the thought that made you most angry? "What is the worst thing about the event? What were the consequences? What does this say about the intention of the other person involved?"

\section{WHITEBOARD HEADER: BELIEF}

! Formulate hostile belief in one concise sentence (as aggressive as possible)

! FRAME: [AGGRESSOR] [VICTIM] [ACT] [HOSTILE INTENTION]

! Stick to a participant's words, do not interpret them

3 Extra information. The situation should ideally be emotionally ambiguous. The hostile belief should involve a harmful intention of another person. When the participant does not come up with a hostile intention (e.g., he did it on purpose) by himself, you can suggest it.

4 Tip. When the event concerns harm done to someone else, ask: "how did it influence you?"

5 Tip. Beliefs should not be weakened/rationalized. Beware social desirability. 
THERAPIST: "What did you feel? And what did you do?"

\section{Part 2.2: Imagery interview}

THERAPIST: "Now I want to ask you to close your eyes and imagine you are going back to the situation [MENTION PARTICIPANT'S SITUATION HERE]. Please go back to the moment you were most angry and describe what happens as if it is happening here and now as vividly as possible. Then I will ask several questions.

Now focus on the image and try to make it as vividly as possible. Can you see the image? Describe what happens as if it is happening here and now, so in the present tense.

\section{1. "[SHORTLY SUMMARIZE THE SITUATION] ${ }^{6}$}

2. Where are you?

3. If what you see is a picture, describe what you see.

4. Who is/are with you?

5. What do you hear?

6. What do you smell?

7. What do you sense in your body?

8. What emotion do you feel? Focus on the angry unjust feeling and all its details. Can you feel it in your body? Sense [REPEAT THE PARTICIPANTS BODILY SENSATIONS]?? If not: try to make it more vivid.

9. What now goes through your mind is ... [REPEAT THE HOSTILE BELIEF]

\section{Part 2.3 Hostile image transformation}

THERAPIST: "You can keep your eyes closed. Now I want to ask you to visualize as detailed and vividly as possible what it would look like in a picture that [MENTION HOSTILE BELIEF]. I am not looking for a realistic image. The picture should adequately capture your feelings, not reality. Like a cartoon for example. Use as many details as possible.

! Use as many details as possible: What does the other do? What does the other look like? What is the other's expression? What does the other person's face look like? What was the other person's posture?

6 Tip. Beware not to mention too many details. A participant might 'lose' the image. Try to sense if the participants are still looking at the image by checking if he can see it vividly.

7 Tip. Try to go as far as possible. For example, "What do you sense in your face? What else do you feel in your face?" Other examples of physiological signals are muscle tension, heart pounding, warmth, numb fingers, sweating. 
You can open your eyes again. You are here again. "[TAKE SOME TIME TO LET THE PARTICIPANT ACCOMMODATE]

\section{Phase 3: Intervention}

\section{Part 3.1 Cognitive Restructuring}

THERAPIST: "Now we move on to the next phase, in which we search for evidence in support of and against the belief we've written down."

\section{$\checkmark \quad$ WHITEBOARD HEADER: EVIDENCE}

THERAPIST: "I would now like to brainstorm about the evidence you can think of that supports your belief. What shows that the belief is true? What is it that makes the belief feel true? Are there other things you have been through the make the evidence stronger? What does it say about the person when he/she behaves like that?"

\section{$\checkmark \quad$ WHITEBOARD HEADER: COUNTER-EVIDENCE}

THERAPIST: "What shows that your thought is not true? Are there possible other events you have experienced that make the evidence weaker? What shows that your thought is possibly maybe not true? Do you have any experiences showing that the thought is not always true? Have you experienced something similar before, and if so, what have you learned from it that could possible help you?"

\section{Part 3.2: Identifying the helpful belief}

\section{$\checkmark \quad$ WHITEBOARD HEADER: HELPFUL BELIEF}

THERAPIST: "If you look at the evidence you've put forward, what would you conclude about your original thought? Could you think of an alternative, more helpful thought?"

! Formulate helpful belief in one concise sentence

\section{Part 3.3: Helpful image transformation}

THERAPIST: "I would now like to ask you to express this alternative, helpful belief [MENTION THE BELIEF] in an image, just like we did [MENTION THE PARTICIPANTS ANSWER DURING THE RATIONALE]. Now close your eyes... I want to ask you to visualize as detailed and vividly as possible what it would look like in a picture that [MENTION HELPFUL BELIEF]. I am not looking for a realistic image. The picture should adequately capture your feelings, not reality. Like a cartoon for example. Use as many details as possible. 
Now we are going to install this new image. If we go back to the situation, [REINTRODUCE THE PARTICIPANT TO THE SITUATION], yOu see [MENTION WHAT THE PARTICIPANT SAW DURING THE IMAGERY INTERVIEW], you hear [MENTION WHAT THE PARTICIPANT HEARD DURING THE IMAGERY INTERVIEW], etc. [...CONTINUE UNTILL THE 'HOTSPOT', BUT STOP BEFORE THE PARTICIPANT GETS ANGRY]. What now goes through your mind is [MENTION THE HELPFUL BELIEF]. You can now change the old image to the new, helpful image [MENTION THE IMAGE]. Take your time. How does this image affect you when you look at it? How does it make you feel?

You can now reopen your eyes." 



\section{CHAPTER 6}

Interpretation Bias Modification

Reduces Hostile Bias and Aggression:

A Randomized Clinical Trial

This article is under revision for publication as: Van Teffelen, M.W., Lobbestael, J, Voncken, M.J., Cougle, J.R., \& Peeters, F. Interpretation Bias Modification Reduces Hostile Bias and Aggression: A Randomized Clinical Trial. 


\section{ABSTRACT}

Hostility is a transdiagnostic phenomenon that can have a profound negative impact on interpersonal functioning and psychopathological severity. Evidence suggests that cognitive bias modification for interpretation bias (CBM-I) potentially reduces hostile interpretation bias (HIB), anger, and aggression. However, stringent efficacy trials in people with clinical levels of hostility are currently lacking. The present study investigated the effects of CBM-I in two studies: one randomized sham-controlled feasibility trial (Study 1) in a mixed clinical-community sample of men $(N=20)$, and one randomized sham-controlled clinical trial (Study 2 ) in a mixedgender sample with clinical levels of hostility $(N=135)$, pre-registered at https://osf.io/r46jn. We expected that CBM-I would result in a larger increase in benign bias and larger reductions in hostile bias, hostility symptoms and traits at post-intervention compared to an active control (AC) condition. We also explored beneficial carry-over effects of CBM-I on working alliance in subsequent psychotherapy five weeks after finishing CBM-I $(n=17)$. Results showed that CBM-I increased benign bias in both trials and reduced HIB in Study 2, but not in Study 1. Findings of Study 2 also revealed greater reductions in behavioral aggression and less reductions in general psychological distress in CBM-I relative to control, though no condition differences were found in self-report hostility measures. The results suggest that CBM-I is an efficacious intervention for HIB and aggressive behavior. 


\section{INTRODUCTION}

Hostility is a trait constellation consisting of a tendency to hold a hostile attributional style, experience angry affect, and behave aggressively, and is considered a trans-diagnostic clinical phenomenon (Cassiello-Robbins \& Barlow, 2016). Clear prevalence estimates in clinical samples are currently missing, however one observational study in 3800 outpatients indicated that $43.60 \%$ reported moderate to severe anger and $21.20 \%$ reported moderate to severe aggressive behavior in the preceding week (Genovese et al., 2017). Next to a profound impact on negative interpersonal functioning (Henrichs et al., 2014), hostility is associated with increased psychopathological severity (Cassiello-Robbins \& Barlow, 2016) and suicidality (Ammerman et al., 2015).

Treatment options for hostility exist. However, effects appear less pronounced than those for other psychopathologies (e.g., panic disorder, and body dysmorphic disorder), as 34\% of patients do not profit from treatment (Hofmann et al., 2012). Moreover, premature treatment discontinuation in patients with psychopathology is significant (Arntz et al., 2015; CassielloRobbins et al., 2015; Putt et al., 2001) and few high-quality treatment effects studies on hostility have been conducted (Del Vecchio \& O'Leary, 2004). Furthermore, patients with increased levels of hostility are often described by therapists as 'challenging' (von der Lippe et al., 2008).

One potential promising novel way of reducing hostility is offered by cognitive bias modification for interpretation bias (CBM-I). CBM-I is a computerized procedure that targets an important aspect of hostility, i.e. hostile interpretation bias (HIB), referring to a tendency to interpret emotionally ambiguous scenarios in a hostile way. This is achieved by presenting patients with many (unfamiliar) emotionally ambiguous scenarios on a computer followed by a reinforcement of benign instead of hostile interpretations (Mathews \& Mackintosh, 2000). In the present work, we aim to investigate the effects of CBM-I on HIB in one randomized sham-controlled feasibility trial and one randomized sham-controlled clinical trial.

Initially, meta-analytic evidence supported the efficacy of CBM-I on anxiety- and depressionrelated biases with a pooled effect size of $g=.81$ (Hallion \& Ruscio, 2011). More recently, a metaanalysis on the efficacy of CBM-I on anxiety and depressive symptomatology revealed only small standardized mean differences (SMD) of SMD = -.30 for anxiety symptoms and SMD $=-.26$ for depressive symptoms (Fodor et al., 2020). However, inconsistency of findings (specifically for depression trials), heterogeneity, and risk of bias potentially impede reliable interpretation of these findings. Thus, at present it is unclear whether CBM-I is efficacious at all, and how large the effect is. Moreover, these meta-analytic studies on the effects of CBM-I in anxiety and depression did not include HIB as an outcome. Preliminary evidence supporting the efficacy of CBM-I on HIB is provided by five studies. A first study showed that HIB can be experimentally 
manipulated in both benign and hostile directions in students (Hawkins \& Cougle, 2013). This study also showed that participants experienced less anger when confronted with a provocative insult following benign interpretation training. The second study evidenced that eight sessions of benign interpretation training in a relatively small sample of aggressive boys resulted in greater reductions of HIB, anger and self-reported aggression compared to untrained controls (Vassilopoulos et al., 2014). A third randomized sham-controlled study in non-treatment seeking people with alcohol use disorder and elevated levels of trait anger showed that eight sessions of CBM-I resulted in greater improvements in interpretation bias, trait anger and self-reported anger expression (Cougle et al., 2017). The fourth study compared the effects of benign versus hostile training in students and showed that benign training resulted in an increase in prosocial interpretations and a reduction in anger and self-reported verbal aggression, whereas hostile training did not result in significant changes (AlMoghrabi et al., 2018). A fifth and final study in non-treatment seeking college students with major depressive disorder compared an eightsession CBM-I training to a sham control condition and demonstrated that CBM-I resulted in greater improvement in interpretation bias and anger control. However, no effects were found on depressive interpretation bias, depressive symptoms, or trait anger (Smith et al., 2018). Taken together, preliminary evidence suggests that CBM-I may be moderately efficacious in reducing hostile interpretation bias. To the best of our knowledge, a methodologically stringent randomized sham-controlled clinical trial in (adult) people with clinical levels of hostility is currently lacking.

Besides its potential efficacy as a stand-alone intervention, recent evidence suggests that CBM-I may perhaps additionally augment the efficacy of existing therapy protocols. Two studies showed that offering CBM-I prior to (computerized) cognitive behavior therapy enhanced training effects on anxiety symptoms compared to sham-training prior to cognitive behavior therapy (Beard et al., 2019; Butler et al., 2015). The idea of offering CBM-I prior to existing therapy protocols may be even more attractive for populations with increased levels of hostility. That is, patients with increased hostility levels are at an increased risk to engage in hostile interactions with therapists (von der Lippe et al., 2008), which negatively impacts working alliance (Gülüm et al., 2018). One study showed that working alliance positively mediated the relationship between low levels of hostility and treatment outcome in dialectical behavior therapy for borderline personality disorder (Hirsh et al., 2012). Offering CBM-I prior to psychotherapy may therefore have beneficial effects on psychotherapy on top of its general effects, through increased working alliance levels.

Taken together, preliminary evidence suggests that CBM-I potentially reduces HIB, anger, self-reported aggression, and working alliance. In the present work we developed an eightsession CBM-I intervention and compared its effects to an active control condition in two trials. The first study (Study 1) served as a feasibility trial to establish whether CBM-I alters hostile and benign biases and state anger in the desired direction followed by a randomized sham- 
controlled clinical trial (RCT) (Study 2) in people with clinical levels of hostility in which the efficacy of CBM-l in terms of hostile bias, benign bias and hostility outcomes (i.e., state and trait hostile thoughts, anger and aggression) is assessed. The primary hypothesis was that CBM-I would result in a greater increase in benign interpretations and a greater reduction in $\mathrm{HIB}$ compared to active control training (AC) in both studies. The secondary hypothesis in Study 2 was that CBM-I would lead to greater reductions in hostility and general psychiatric symptoms. We also expected greater reductions in state-anger in both studies. Lastly, we explored the carry-over effects in Study 2 of CBM-I on subsequent psychotherapy and expected increased quality of working alliance with participant's therapists.

\section{STUDY 1}

\section{Methods \\ Participants}

Participants were sampled in two ways. First, we recruited via flyers on a university campus. Second, to ensure sufficient variation at the extreme end of the hostility dimension, we additionally recruited participants with clinically relevant levels of hostility who were on a waiting list for treatment at two mental healthcare facilities in Maastricht, the Netherlands. Only men were included, to reduce sample heterogeneity. Exclusion criteria were a waitlist shorter than four weeks' ${ }^{1}$ age below 18 and above 60 years and illiteracy. Clinically relevant levels of hostility were assessed by clinical judgement of their therapist. Patients were excluded from participation, also based on clinical judgement, if they showed signs of current psychosis or mania, alcohol or drug abuse/dependency, and acute suicide risk. The total sample consisted of $N=29$ participants, of which $n=9$ were lost to follow-up. The final sample consisted of $N$ $=20$ participants, of which $n=9$ were in the CBM-I condition and $n=11$ in the AC condition. Mean age was $M=40.2$ (SD =9.6). The highest completed education level was low for $n=4$, middle for $n=12$, and high for $n=13$ participants. Five participants were on active psychotropic medication. Age, educational level and use of psychotropic medication did not significantly differ between conditions (ps > .071).

\section{Intervention arms}

CВM-I. This intervention condition consisted of eight sessions of benign intervention training, one session every three days. Prior to each session, participants engaged in an imagery task because a previous study reported that this increased the efficacy of CBM-I (Holmes et al., 2006). During this task, participants were instructed to imagine a lemon as

1 Our CBM-I intervention took place over the course of four weeks. To avoid confounding effects of other therapies, people with a waiting time shorter than four weeks were excluded. 
vividly as possible on all sensory modalities with their eyes closed. This exercise prepared participants to imagine scenarios presented in the intervention as lively as possible. Each session consisted of two parts. In the first part, participants were presented with 38 scenarios of the Word-Sentence Association Paradigm (WSAP) (Beard \& Amir, 2008). Here, participants were shown either a hostile (e.g., 'rude') or neutral (e.g., 'unaware') word, followed by an ambiguous sentence (e.g., 'You are trying to concentrate, but someone is talking very loud'). Each ambiguous sentence was presented twice in a random order: once in combination with the hostile word and once in combination with the neutral word. Participants then had to indicate whether the word was related to the sentence by pressing 'yes' or 'no'. Participants received positive feedback when they related neutral words to ambiguous sentences (i.e., a green 'V'-sign accompanied by the text "Correct, the answer is yes/no"). Similarly, participants received negative feedback when they related hostile words to ambiguous sentences (i.e., "Incorrect, the answer should have been yes/no"). An example of the procedure is shown in the Appendix A. In the second part, participants were presented with 33 vignettes of the scenario training (Hawkins \& Cougle, 2013; Mathews \& Mackintosh, 2000). Here, participants were shown ambiguous sentences (e.g., "Someone near you laughs very loudly"). Then, participants had to complete a disambiguating word fragment (e.g., "This person is unaw_re of how loud he is"). After that, participants had to answer a comprehension question (e.g., "Is this person trying to annoy others?") by pressing "yes" or "no." Similar to the WSAP, participants received positive feedback when the comprehension question was answered in a benign way and negative feedback when the comprehension question was answered in a hostile way. For a graphical example, see the Appendix B.

Active control training. The active control condition was similar to the CBM-I condition, except that participants were presented with only neutral words during the WSAP (e.g., "ball" and "concentrate") and neutral scenarios (e.g., "Your friend is walking through the park", "He sees a squi_el" and "Did your friend see a bird?") during the scenario training.

\section{Materials}

Benign and hostile interpretation bias. Interpretation tendencies were measured with the Social Information Processing-Attribution and Emotional Response questionnaire (SIP-AEQ) (Coccaro et al., 2009). Participants were asked to read eight vignettes (e.g., "You tell a friend something personal and ask your friend not to discuss it with anyone else. However, a couple of weeks later, you find out that a lot of people know about it. You ask your friend why she/he told other people and your friend says: "Well, I don't know, it just came up and I didn't think it was a big deal."), followed by four statements (e.g., "My friend wanted me to feel stupid for asking to keep my secret", as an example of a hostile interpretation). Participants were then asked to indicate the likelihood of 
each statement on a 4-point Likert scale ranging from 0 (not likely at all) to 3 (very likely). Internal consistency of the SIP-AEQ is good and convergent and discriminant validity are adequate (Coccaro et al., 2009).

State anger. State anger was measured using the seven items of the anger subscale of the Profile Of Mood States (POMS) (McNair et al., 1992). Participants were asked to indicate the extent to which items (i.e., "bad-tempered", "annoyed", "rebellious", "furious", "grouchy", "angry", and "on edge") reflect their current mood state on a 5-point Likert scale ranging from $\mathrm{O}$ (not at all) to 4 (very much). Internal consistency of the POMS is good and validity is adequate (Wicherts \& Vorst, 2004).

\section{Procedure}

The Ethical Review Committee Psychology and Neuroscience at Maastricht University provided ethical approval to carry out the study (ECP-170_09_11_2014). The study took place between February and July 2016. When participants arrived at the lab, the study's procedure was explained and written informed consent was obtained. In our information letter we explained participants that we were studying how we can reduce feelings of hostility with a computer training. We explained that our training aimed to change the thought processes that are involved in hostility. Next, participants were told that the experiment involved two experimental conditions; an active condition and a placebo condition to which participants were randomly allocated. An independent technician from another department at Maastricht University carried out permutated block (i.e., blocks of 4 and 6) randomization (stratified by gender) using https:// www.randomizer.org/. The participants were blind to the condition. Participants completed bias and anger measures prior to engaging in the first session of their allocated intervention. The next seven sessions and post-intervention assessment were carried out at home. During the last session, bias and anger measures were again completed. The first and last session took approximately one hour, and the other sessions took about 20 minutes. At the end participants were fully debriefed, thanked and reimbursed with $€ 35$ for their participation.

\section{Statistical analyses}

SPSS version 24 was used for all analyses. First, means and standard deviations were computed to examine the baseline characteristics of bias and anger measurements. Second, independent $t$-tests or Man-Whitney $U$-tests were run to examine baseline differences. Third, to test the hypothesis that CBM-I leads to greater reductions in benign and hostile bias and anger three repeated measures ANOVA models were run. In each model, condition, time, and condition by time interaction were entered as predictors. Analytic practices in the current multisession CBM-I literature on how to deal with missing sessions are divergent. That is, some authors choose to exclude cases with missing data (Lang et al., 2012), while others decide to include cases that at least underwent at least $75 \%$ of the intervention (Brettschneider et 
al., 2015). This led us to decide that participants who did not complete more than $75 \%$ (i.e., six out of eight) sessions were excluded from the analysis $(n=9)$. Non-normally distributed variables were square root transformed to obtain normality. Simple effects were analyzed using independent samples $t$-tests.

\section{Results}

Baseline levels of hostile bias, benign bias and state anger revealed no significant differences (ps $>$.139) between the conditions, indicating that random allocation was successful. Means and standard deviations of benign bias, hostile bias, and state anger levels were respectively $M=5.0, S D=1.7, M=4.8, S D=2.8$, and $M=7.9, S D=6.7$ in the CBM-I condition and $M=6.4$, $S D=2.2, M=3.2, S D=2.6$, and $M=6.7, S D=7.0$ in the $A C$ condition.

Next, to test the hypotheses that CBM-I results in a greater increase in benign bias, greater reduction in hostile bias and greater reduction in state anger reactivity, three repeated measures ANOVA models were run. Condition and time were entered as respectively between-subjects and within-subjects factors. First, findings on benign bias revealed that the condition by time interaction $(F(1,18)=5.30, p=.034)$ factor was significant, whereas the time $(F(1,18)=3.82, p=.066)$ and condition $(F(1,18)=0.05, p=.829)$ were not significant. Follow-up t-tests showed that benign bias significantly increased from pre- to post-intervention in the CBM-I condition ( $t=2.93, p=.019)$, but not in the AC condition ( $t=0.26, p=.803$ ) (between subjects $d=0.51$ at post-intervention, $95 \% \mathrm{Cl}=-0.43$ to 1.46$)$. Second, findings on hostile bias showed that the main effect of time was significant $(F(1,18)=9.70, p=.006)$, whereas there was no significant main condition effect, and no condition by time interaction effect ( $p s>$ .319). Third, results on state anger reactivity (i.e., change in anger from pre- to post-session) demonstrated that the time effect was significant $(F(1,18)=10.50, p=.005)$, whereas the condition and the interaction were not significant ( $p s>$.316).

\section{Study 1 - Discussion}

In Study 1, we examined the feasibility of an eight-session CBM-I intervention. In line with our expectations, findings revealed that CBM-I altered benign bias in a positive direction compared to AC. Contrary to our expectations, results revealed a non-differential decrease over time for hostile bias and anger reactivity for both conditions. One explanation for this pattern of findings is that no such effects are present. Other explanations are that the current sample is too small to detect such effects, or that hostility levels were not high enough. In short, Study 1 revealed that CBM-I has moderate to good feasibility, at least in terms of improvement in benign bias. Therefore, we tried to replicate these findings in a larger trial, which was the focus of Study 2. 


\section{STUDY 2}

\section{Methods \\ Participants}

Participants were sampled in two ways. First, we recruited in two outpatient and one inpatient mental healthcare facility in the Netherlands (i.e., METggz, Mondriaan - Radix and U-Center). Participants were screened for eligibility while on the waitlist for treatment. Second, participants were sampled in the local community using an advertisement in local news media asking for 'people with a short fuse.' Inclusion criteria were age between 18 and 60 years, mastery of the Dutch language, basic computer skills and a score above 1.27 on the hostility scale of the Personality Inventory for DSM-5 (PID-5H) (Van der Heijden et al., 2014). This cutoff equals one standard deviation above the mean in both a Danish (a comparable population to the Netherlands) community as well as a clinical sample (Bach et al., 2016). Exclusion criteria were being on a waitlist for treatment shorter than four weeks ${ }^{2}$, IQ estimate below 80 , observed psychotic/manic symptoms during intake, suicidality and not having access to a computer. A participant flow diagram is presented in Figure 1. In the pre-registration we determined sample size in the following way; to detect an effect of $d=0.81$ (Hallion \& Ruscio, 2011) with $a=.05$ and $\beta=.10$, anticipating a 25\% drop-out, $N 1=N 2=10.5 * 2 / 0.81^{2}$ /.75 $\approx 43$ participants are needed per condition. However, if we would have used the obtained effect size in S1 $(d=0.51)^{3}$ to detect an effect with $a=.05$ and $\beta=.20$ we would have needed a minimum of $n=61$ participants per condition. In total, $N=135$ people entered the study, of whom $n=37$ were lost to follow-up. Sample characteristics are shown in Table 1.

\section{Intervention arms}

The intervention arms were similar to Study 1.

\section{Materials}

Interpretation bias. To measure interpretation bias we used the SIP-AEQ, similar to Study 1. In addition, we administered the Word Sentence Association Paradigm-Hostility (WSAP-H) scale (Dillon et al., 2016). In the WSAP-H, participants were presented with sixteen hostile and sixteen neutral word-sentence pairs and are asked to indicated how well each word is related to the sentence on a 6-point Likert scale ranging from 1 (not related at all) to 6 (very related). Mean scores on the hostile and neutral word-sentence pairs are a measure for respectively hostile and benign interpretation bias. In the present study, we split up the WSAP-H in two parts to enable measurement pre- and post-intervention. The instrument shows good internal consistency (in this study a's range from .70 to .72) and adequate discriminant validity (Dillon et al., 2016).

2 Our CBM-I intervention took place over the course of four weeks. To avoid confounding effects of other therapies, people with a waiting time shorter than four weeks were excluded.

3 We thank one of the reviewers of this paper for the valuable suggestion to include this in our manuscript. 


\section{Enrollment}

Assessed for eligibility $(\mathrm{n}=951)$

- Inpatient $(\mathrm{n}=343)$

- Outpatient $(\mathrm{n}=420)$

- Community $(\mathrm{n}=188)$

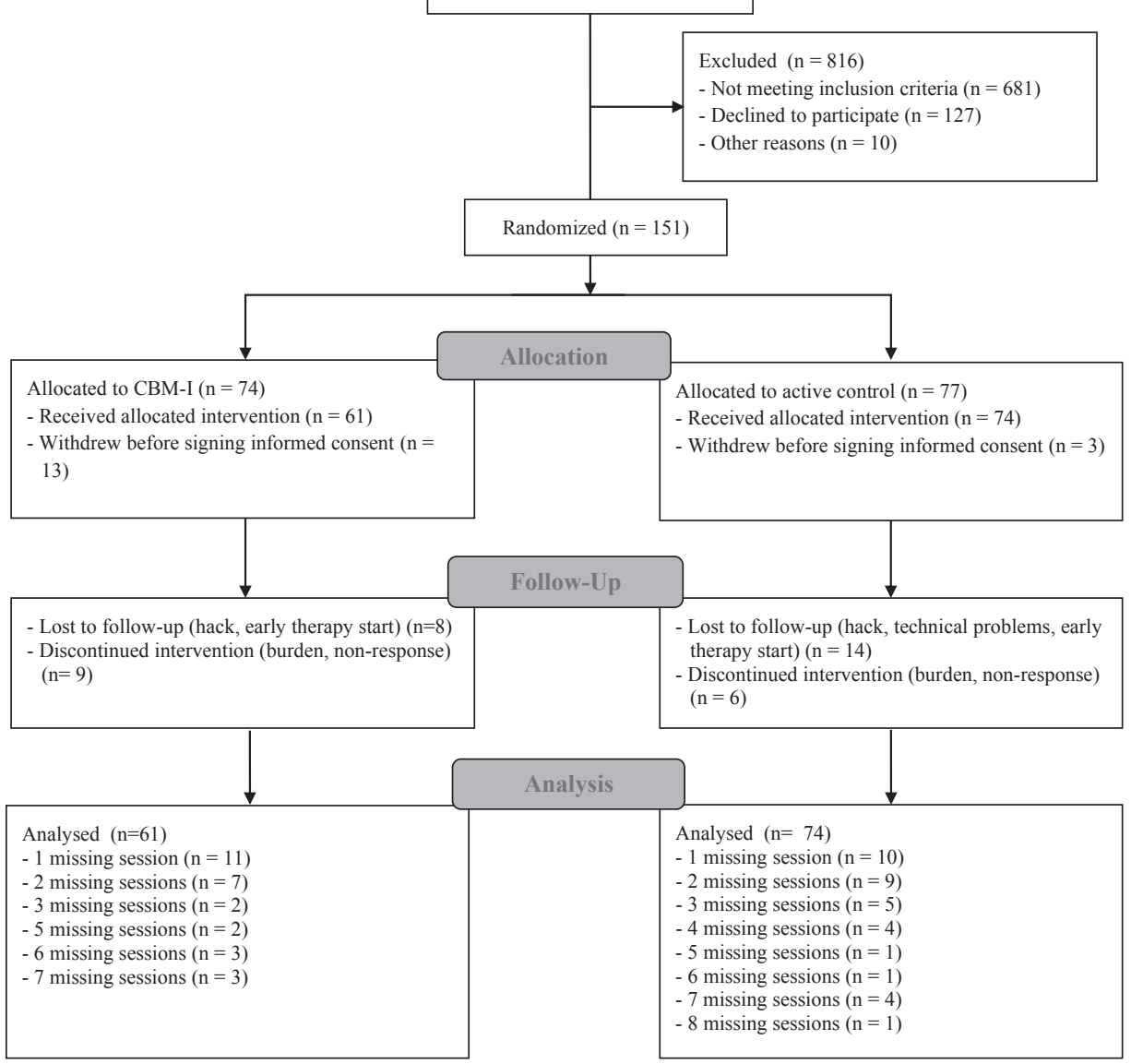

\section{Figure 1}

\section{Study 2 - Participant flow diagram}

Note. Unfortunately, some participants were lost to follow-up due to a successful cyberattack on Maastricht University on 23 December 2019; these participants are labeled as 'hack'.

State measures. To measure different aspects of state hostility and general psychiatric symptoms in the past three days participants completed four measures. First, they were administered an adapted state-version of the eight-item hostility subscale of the Aggression Questionnaire (AQ-HS) (Buss \& Perry, 1992), measuring self-reported hostile thoughts in the past three days, which is scored on a 5-point Likert scale ranging from 1 (totally disagree) to 5 (totally agree). Second, we administered the 15-item State-Trait Anger Expression Inventory-2 
state scale (STAXI-2S) (Spielberger, 1999), measuring self-reported anger in the past three days, which is scored on a 4-point Likert scale ranging from 1 (not at all) to 4 (very much). Third, they completed an adapted state-version of the Forms of Aggression State Questionnaire (FOAS) (Verona et al., 2008), measuring self-reported aggressive behavior in the past three days, which is scored on a 5-point Likert scale ranging from 1 ((almost) never) to 5 ((almost) always). In contrast to the original FOA, participants were asked to indicate how often each behavior occurred in general in the past three days instead of 'when angry.' Moreover, we used an 11-item version that included the highest loading items from the original 40-item FOA in a separate sample of $N=120$ in one of our other studies (van Teffelen et al., under revision). In addition, to measure general psychiatric symptoms in the past three days, we administered the Kessler Psychological Distress Scale (K10) (Kessler et al., 2002). This 10-item K10 is scored on a 5 -point Likert scale ranging from 1 (always) to 5 (never). Finally, active alcohol and drug use was measured with the timeline follow-back questionnaire (Sobell \& Sobell, 1990). All scales have demonstrated good reliability - in the present study a's range from .74 to .95and adequate validity (Buss \& Perry, 1992; Donker et al., 2010; Meesters et al., 1996; Sobell \& Sobell, 1990; Verona et al., 2008).

\section{Table 1}

Study 2 - Sample characteristics

\begin{tabular}{|c|c|c|c|c|}
\hline & \multirow[b]{2}{*}{$\begin{array}{l}\text { Total sample } \\
\qquad(N=135)\end{array}$} & \multicolumn{2}{|c|}{ Condition } & \multirow{2}{*}{$\begin{array}{c}\text { Statistical dif. } \\
X^{2} / F(p)\end{array}$} \\
\hline & & $\begin{array}{l}\text { CBM-I } \\
(n=61)\end{array}$ & $\begin{array}{c}\mathrm{AC} \\
(n=74)\end{array}$ & \\
\hline Population sample, $n(\%)$ & & & & $3.14(.370)$ \\
\hline Inpatient & $21(16)$ & $7(11)$ & $14(19)$ & \\
\hline Outpatient & $30(22)$ & $14(23)$ & $16(22)$ & \\
\hline Community & $84(62)$ & $40(66)$ & $44(59)$ & \\
\hline Primary DSM-5 classification & & & & $11.16(.132)$ \\
\hline Major depressive disorder & $16(12)$ & $6(2)$ & $10(14)$ & \\
\hline Anxiety disorder & $2(1)$ & $0(0)$ & $2(3)$ & \\
\hline Addiction & $8(6)$ & $2(3)$ & $6(8)$ & \\
\hline Post-traumatic stress disorder & $5(4)$ & $1(2)$ & $4(5)$ & \\
\hline Personality disorder & $15(11)$ & $11(18)$ & $4(5)$ & \\
\hline Intermittent explosive disorder & $3(2)$ & $1(2)$ & $2(3)$ & \\
\hline ADHD & 1 (1) & $0(0)$ & $1(1)$ & \\
\hline None & $85(63)$ & $40(66)$ & $45(61)$ & \\
\hline Age in years, $M(S D)$ & $39.24(11.80)$ & $39.74(12.37)$ & $38.82(11.37)$ & $.45(.656)$ \\
\hline Gender, $n(\%)$ & & & & $.14(.710)$ \\
\hline Male & $82(61)$ & $36(59)$ & $46(62)$ & \\
\hline Female & 53 (139) & $25(41)$ & $28(38)$ & \\
\hline
\end{tabular}




\section{Table 1}

Continued

\begin{tabular}{|c|c|c|c|c|}
\hline & \multirow[b]{2}{*}{$\begin{array}{c}\text { Total sample } \\
\qquad(N=135)\end{array}$} & \multicolumn{2}{|c|}{ Condition } & \multirow{2}{*}{$\begin{array}{c}\text { Statistical dif } \\
X^{2} / F(p)\end{array}$} \\
\hline & & $\begin{array}{l}\text { CBM-I } \\
(n=61)\end{array}$ & $\begin{array}{c}\text { AC } \\
(n=74)\end{array}$ & \\
\hline Education, $n(\%)$ & & & & $.31(.855)$ \\
\hline Low & $14(10)$ & 7 (11) & $7(9)$ & \\
\hline Middle & $58(43)$ & $27(44)$ & $31(42)$ & \\
\hline High & $63(47)$ & $27(44)$ & $36(49)$ & \\
\hline Work situation, $n$ (\%) & & & & $.12(.990)$ \\
\hline Employed & $89(66)$ & $41(67)$ & $48(65)$ & \\
\hline Unemployed & $37(27)$ & $16(26)$ & $21(28)$ & \\
\hline Student & $7(5)$ & $3(5)$ & $4(5)$ & \\
\hline Retired & 2 (1) & $1(2)$ & $1(1)$ & \\
\hline \multicolumn{5}{|l|}{ Medication } \\
\hline $\mathrm{AD}, \mathrm{SSRI}, n(\%)$ & $17(13)$ & $6(10)$ & $11(15)$ & $.77(.381)$ \\
\hline AD, SNRI, $n(\%)$ & $4(3)$ & $1(2)$ & $3(4)$ & $.68(.410)$ \\
\hline AD, TCA, $n(\%)$ & $5(4)$ & $3(5)$ & $2(3)$ & $.46(.498)$ \\
\hline Mood stabilizer, $n(\%)$ & $2(1)$ & $1(2)$ & $1(1)$ & $.02(.890)$ \\
\hline Addiction, $n(\%)$ & $1(1)$ & $0(0)$ & $1(1)$ & $.830(.362)$ \\
\hline AP, classic, $n(\%)$ & $3(2)$ & $2(3)$ & $1(1)$ & $.57(.450)$ \\
\hline AP, atypical, $n(\%)$ & $5(4)$ & $0(0)$ & $5(7)$ & $4.28(.039)$ \\
\hline Anxiolytic, $n$ (\%) & $10(7)$ & $3(5)$ & $7(9)$ & $1.41(.494)$ \\
\hline Stimulant, $n(\%)$ & $5(4)$ & $2(3)$ & $3(4)$ & $.06(.812)$ \\
\hline Aggression, $n$ (\%) & $1(1)$ & $0(0)$ & $1(1)$ & $.83(.362)$ \\
\hline Alcohol abuse, $n$ (\%) & & & & $11.14(.347)$ \\
\hline Low & $5(4)$ & $4(7)$ & $1(1)$ & \\
\hline Moderate & $5(4)$ & $3(5)$ & $2(3)$ & \\
\hline High & $9(7)$ & $4(7)$ & $5(7)$ & \\
\hline Cannabis abuse, $n$ (\%) & & & & $4.55(.473)$ \\
\hline Low & $2(1)$ & $2(3)$ & $0(0)$ & \\
\hline Moderate & $3(2)$ & $2(3)$ & $1(1)$ & \\
\hline High & 2 (1) & $1(2)$ & $1(1)$ & \\
\hline
\end{tabular}


Trait measures. To measure different aspects of trait hostility participants completed the hostility scale of the Personality Inventory for DSM-5 (PID-5H), the AQ-H (measuring cognitive aspects of trait hostility), FOA (measuring self-reported trait aggression) and the voodoo doll task (VDT) (DeWall et al., 2013). The 10-item PID-5H measures overall trait hostility and was scored on a 4-point Likert scale ranging from 0 (very false or often false) to 3 (very true or often true). The VDT measures behavioral aggression. During the VDT participants are presented with an ambiguous vignette on a computer (e.g., "You are carrying a heavy load of groceries up to a check-out line at the grocery store and just as you are about to enter in line, someone cuts in front of you. You end up dropping some things on the floor") (Tremblay \& Belchevski, 2004). Participants were then allowed to insert up to 51 pins into a voodoo doll that represents the other person from the vignette. The PID-5H, AQ-H and the VDT have demonstrated good reliability - in the present study a's range from .81 to .93- and adequate validity (DeWall et al., 2013; Krueger et al., 2012).

Working alliance. To measure potential carry-over effects of CBM-I on working alliance in subsequent psychotherapy we administered the Working Alliance Inventory (WAI), client version (Horvath \& Greenberg, 1989), which measures the quality of the therapeutic working alliance between patient and therapist. The 36-item WAI was scored on a 5-point Likert scale ranging from 1 (never) to 5 (always). The WAI shows adequate reliability - in the present study $a=.93-$ and adequate criterion validity (Horvath \& Greenberg, 1989).

\section{Procedure}

The Ethical Review Committee Psychology and Neuroscience at Maastricht University provided ethical approval to carry out the study (ERCPN_170_09_11_2014_A6). This study was preregistered at https://osf.io/r46jn. The study was registered semi-retrospectively, after seven participants were recruited. Recruitment took place from September $3^{\text {rd }}, 2018$ until May $11^{\text {th }}, 2020$. The procedure was similar to Study 1 , except for four notable differences. First, the first session from this study was carried out at home instead of in our lab. Second, Study 2 was conducted as a double-blind trial, instead of a single-blind study, implying that both patients and experimenter were blind for allocated condition. Third, we administered interpretation bias, state, and trait measures instead of solely interpretation bias and state affect measures. All instruments were measured pre- and post-intervention. Fourth, we monitored if participants would enter therapy after our intervention. When this occurred, we offered one additional 'booster' CBM-I or AC intervention session to account for variability in time between the end of the interventions and the start of therapy. The booster sessions consisted of 33 additional scenario training and 38 additional WSAP trials. Five weeks after start of therapy, we administered the WAI once. 


\section{Statistical analyses}

Statistical analyses were similar to Study 1, except for a few notable differences. First, the hypotheses that CBM-I leads to greater increases in benign bias and greater reductions in hostile bias, state hostility, general psychiatric symptoms, and trait hostility were assessed using twelve mixed regression models. Condition, time, and condition by time interaction indicators were entered as predictors. Mixed regression was opted for given its ability to handle missing data and modelling error terms, leading to an increase in statistical power (Baayen et al., 2008). Within each regression model, repeated measures were clustered in participants. AR1 was selected as covariance structure, as -2 log likelihood testing revealed that it was most parsimonious. As VDT scores were highly skewed, we used Poisson regression. ${ }^{4}$ This is in line with analytic practices in de VDT literature (DeWall et al., 2013). VDT post-score was entered as dependent variable. VDT pre-score and condition were entered as independent variables. For this specific analysis, VDT pins were imputed following the multiple imputation method. Specifically, pre-test VDT scores were used to predict post-test VDT scores in five pooled imputations. Moreover, we calculated a reliable change index (RCI) for both HIB measures (WSAP-H and SIP-AEQ) (Jacobson \& Truax, 1991). Second, to examine effects of intervention on working alliance in subsequent psychotherapy the following analyses were run. One independent samples t-test on working alliance was run to test intervention differences. Then, we examined correlations between change scores of the outcome measures and working alliance. As VDT scores were highly skewed, we used Poisson regression to regress working alliance on VDT post-intervention scores, corrected for baseline instead of examining their correlation. Analyses were conducted following the intent-to-treat principle. Moreover, to test confounding influences from active alcohol or drug use during CBM-I sessions, analyses were performed with and without participants who did not complete at least $75 \%$ of sessions while not under the influence of alcohol or drugs.

\section{Results}

Means and standard deviations of study variables are presented in Table 2. Tests of baseline differences revealed that variables did not differ significantly at baseline between conditions, except of atypical antipsychotic use. Overall, this indicates that random allocation was successful. Comparing our baseline values to other studies revealed that hostility levels in this sample are comparable to or larger than other studies using clinical samples (Bach et al., 2016; Coccaro et al., 2017; Dillon et al., 2016; Hornsveld et al., 2009; Lievaart et al., 2016). In total, 14.32\% of values were missing. Missed sessions per conditions are shown in Figure 1. Number of missed sessions did not differ per condition

4 Pre-registration file stated that we would analyze VDT scores using mixed regression. However, VDT-scores were extremely skewed. 
$X^{2}=.03, p=.871$ and Little's MCAR test indicated that they were missing completely at random $X^{2}=.49, p=.975$. Results are presented including participants who did not complete at least $75 \%$ of sessions while not under the influence of alcohol or drugs. The pattern of results did not change when participants who not completed at least $75 \%$ of sessions while not under influence were excluded. We present the results for bias, state hostility, general psychiatric symptoms, trait hostility, and working alliance below.

\section{Table 2}

Study 2 - descriptives

\begin{tabular}{|c|c|c|c|c|}
\hline & \multicolumn{2}{|c|}{$\begin{array}{l}\text { CBM-I } \\
(n=61)\end{array}$} & \multicolumn{2}{|c|}{$\begin{array}{c}\text { AC } \\
(n=74)\end{array}$} \\
\hline & Pre & Post & Pre & Post \\
\hline \multicolumn{5}{|l|}{ Bias } \\
\hline SIP hostile bias & $15.90(9.17)$ & $11.37(8.67)$ & $15.51(8.15)$ & $14.65(8.68)$ \\
\hline SIP benign bias & $11.56(4.42)$ & $14.90(4.46)$ & $11.37(4.07)$ & $11.73(4.46)$ \\
\hline WSAP hostile bias & $3.43(.81)$ & $2.40(1.04)$ & $3.41(.92)$ & $3.15(.88)$ \\
\hline WSAP benign bias & $3.81(.99)$ & $4.36(.84)$ & $3.63(.93)$ & $3.67(.72)$ \\
\hline \multicolumn{5}{|l|}{$\underline{\text { State measures }}$} \\
\hline Hostile thoughts (AQ-HS) & $16.68(8.24)$ & $16.05(9.01)$ & $19.02(8.50)$ & $15.20(8.48)$ \\
\hline Anger (STAXI-2S) ${ }^{a}$ & $29.27(10.87)$ & $24.32(8.82)$ & $28.00(10.45)$ & $23.59(11.67)$ \\
\hline Aggressive behavior (FOAS) & $15.93(3.81)$ & $14.20(3.74)$ & $14.82(3.43)$ & $14.18(4.02)$ \\
\hline General symptoms (K10) ac & $34.95(10.75)$ & $37.56(12.21)$ & $34.78(11.07)$ & $40.67(10.34)$ \\
\hline \multicolumn{5}{|l|}{ Trait hostility } \\
\hline Overall trait hostility (PID-5H) & $1.74(.50)$ & $1.52(.55)$ & $1.71(.58)$ & $1.57(.68)$ \\
\hline Hostile intent $(\mathrm{AQ}-\mathrm{H})$ & $23.24(6.72)$ & $15.66(7.66)$ & $23.76(6.60)$ & $15.51(8.19$ \\
\hline SR Trait aggression $(F O A)^{a}$ & $71.73(19.88)$ & $53.73(13.69)$ & $66.41(13.60)$ & $51.06(13.95)$ \\
\hline Aggressive behavior (VDT) & $10.17(10.93)$ & 7.00 (8.99) & $11.08(12.14)$ & $11.22(13.35)$ \\
\hline WAl $^{\mathrm{b}}$ & - & $157.13(11.10)$ & - & $146.70(20.34)$ \\
\hline
\end{tabular}

Note. ${ }^{a}$ non-normally distributed. ${ }^{b} \mathrm{FU}$ measurement for people who engaged in therapy, $n \mathrm{CBM}-\mathrm{I}=8$, $n \mathrm{AC}=9$. ${ }^{\mathrm{c}}$ Higher scores indicate less psychiatric symptoms. SR = self-reported.

\section{Bias}

To test the main hypothesis that CBM-I results in a larger increase in benign bias and a larger decrease in hostile bias two mixed regression models were run. The overall (i.e., effect- coded) interaction effects were significant ( $p$ 's < .001). Fixed (i.e., reference-coded) effects of benign and hostile bias are presented in Table 3. The effects of WSAP benign and hostile bias are shown in and Figures 2 and 3. In Table 3, time and condition variables were reference coded using the $\mathrm{AC}$ condition as reference. Hence, fixed effects presented in Table 3 are estimated using $A C$ as reference category, $A C$ baseline measurement as intercept. Findings showed that 
CBM-I led to a greater increase in SIP-AEQ $(d=0.29,95 \% \mathrm{Cl}=0.12$ to 0.46$)$ and WSAP $(d=0.26$, $95 \% \mathrm{Cl}=0.09$ to 0.43 ) benign bias from pre- to post-intervention compared to AC. Results also revealed that CBM-I led to a greater decrease in SIP-AEQ ( $d=-0.17,95 \% \mathrm{Cl}=-0.34$ to 0.00$)$ and WSAP ( $d=-0.33,95 \% \mathrm{Cl}=-0.83$ to -0.17 ) hostile bias from pre- to post-intervention compared to AC. On the SIP-AEQ 23.0\% of participants in the CBM-I group and $6.8 \%$ of participants in the AC group showed significant reliable change $\left(X^{2}=7.25, p=.007\right)$. On the WSAP-H $57.4 \%$ of participants in the CBM-I group and $32.4 \%$ of participants in the $\mathrm{AC}$ group showed significant reliable change $\left(X^{2}=8.46, p=.004\right)$.

\section{Table 3}

Study 2 - Mixed regression on bias and aggression

\begin{tabular}{|c|c|c|c|c|}
\hline & $b$ & $S E$ & $t$ & $p$ \\
\hline \multicolumn{5}{|l|}{ Bias } \\
\hline \multicolumn{5}{|c|}{$\underline{\text { SIP-AEQ Benign bias }}$} \\
\hline Intercept & 10.64 & .91 & 11.68 & $<.001^{* * *}$ \\
\hline Time & -.58 & .57 & 1.02 & .311 \\
\hline Condition & -2.87 & 1.37 & -2.09 & .038 \\
\hline Condition by time & 2.87 & .86 & 3.34 & $.001^{* *}$ \\
\hline \multicolumn{5}{|l|}{$\underline{\text { SIP-AEQ Hostile bias }}$} \\
\hline Intercept & 17.47 & 1.65 & 10.60 & $<.001^{* * *}$ \\
\hline Time & -1.56 & .98 & -1.61 & .111 \\
\hline Condition & 2.99 & 2.49 & 1.20 & .231 \\
\hline Condition by time & -2.94 & 1.48 & -1.99 & $.050^{*}$ \\
\hline \multicolumn{5}{|l|}{$\underline{\text { WSAP Benign bias }}$} \\
\hline Intercept & 3.87 & .21 & 18.09 & $<.001^{* * *}$ \\
\hline Time & -.12 & .14 & -.88 & .383 \\
\hline Condition & -.61 & .32 & -1.88 & .062 \\
\hline Condition by time & .64 & .21 & 3.05 & $.003^{* *}$ \\
\hline \multicolumn{5}{|l|}{$\underline{\text { WSAP Hostile bias }}$} \\
\hline Intercept & 3.73 & .20 & 19.07 & $<.001^{* * *}$ \\
\hline Time & -.31 & .12 & -2.53 & $.013^{*}$ \\
\hline Condition & .77 & .29 & 2.60 & $.010^{*}$ \\
\hline Condition by time & -.73 & .19 & -3.95 & $<.001^{* * *}$ \\
\hline \multicolumn{5}{|l|}{ State measures } \\
\hline \multicolumn{5}{|l|}{$\underline{\mathrm{AQ}-\mathrm{HS}}$} \\
\hline Intercept & 23.14 & 1.61 & 14.34 & $<.001^{* * *}$ \\
\hline Time & -3.90 & .99 & -3.95 & $<.001^{* * *}$ \\
\hline Condition & -4.28 & 2.41 & -1.77 & .078 \\
\hline Condition by time & 2.85 & 1.46 & 1.95 & .054 \\
\hline
\end{tabular}


Table 3

Continued

\begin{tabular}{|c|c|c|c|c|}
\hline & $b$ & $S E$ & $t$ & $p$ \\
\hline \multicolumn{5}{|l|}{ STAXI-2S } \\
\hline Intercept & 35.07 & 2.31 & 15.19 & $<.001^{* * *}$ \\
\hline Time & -5.26 & 1.47 & -3.59 & $.001^{* *}$ \\
\hline Condition & .37 & 3.45 & .11 & .914 \\
\hline Condition by time & -.08 & 2.18 & -.04 & .970 \\
\hline \multicolumn{5}{|l|}{ FOAS } \\
\hline Intercept & 16.77 & .80 & 20.91 & $<.001$ \\
\hline Time & -.97 & .49 & -2.00 & $.049^{*}$ \\
\hline Condition & 1.70 & 1.20 & -2.00 & .159 \\
\hline Condition by time & -.97 & .72 & -1.34 & .183 \\
\hline \multicolumn{5}{|l|}{$\underline{\mathrm{K} 10}$} \\
\hline Intercept & 27.28 & 1.89 & 14.42 & $<.001^{* * *}$ \\
\hline Time & 6.20 & 1.07 & 5.81 & $<.001^{* * *}$ \\
\hline Condition & 2.77 & 2.83 & .98 & .329 \\
\hline Condition by time & -3.16 & 1.58 & -1.99 & $.049^{*}$ \\
\hline \multicolumn{5}{|l|}{ Trait hostility } \\
\hline \multicolumn{5}{|l|}{ PID-5H } \\
\hline Intercept & 1.83 & .11 & 16.77 & $<.001^{* * *}$ \\
\hline Time & -.08 & .06 & -1.31 & .191 \\
\hline Condition & .14 & .16 & .83 & .410 \\
\hline Condition by time & -.11 & .09 & -1.17 & .243 \\
\hline \multicolumn{5}{|l|}{$\underline{A Q-H}$} \\
\hline Intercept & 32.81 & 1.37 & 23.96 & $<.001^{* * *}$ \\
\hline Time & -8.37 & .79 & -10.56 & $<.001^{* * *}$ \\
\hline Condition & -.30 & 2.05 & -.15 & .883 \\
\hline Condition by time & .56 & 1.20 & .47 & .641 \\
\hline \multicolumn{5}{|l|}{ FOA } \\
\hline Intercept & 84.51 & 3.24 & 26.05 & $<.001^{* * *}$ \\
\hline Time & -14.94 & 1.90 & -7.85 & $<.001^{* * *}$ \\
\hline Condition & 8.71 & 4.88 & 1.79 & .076 \\
\hline Condition by time & -3.90 & 2.89 & -1.35 & .181 \\
\hline
\end{tabular}

Note. ${ }^{*}$ Significant at $p=.050 ;{ }^{* *}$ significant at $p=.010 ; * * *$ significant at $p<.001$. In all models the active control condition was chosen as reference category. 


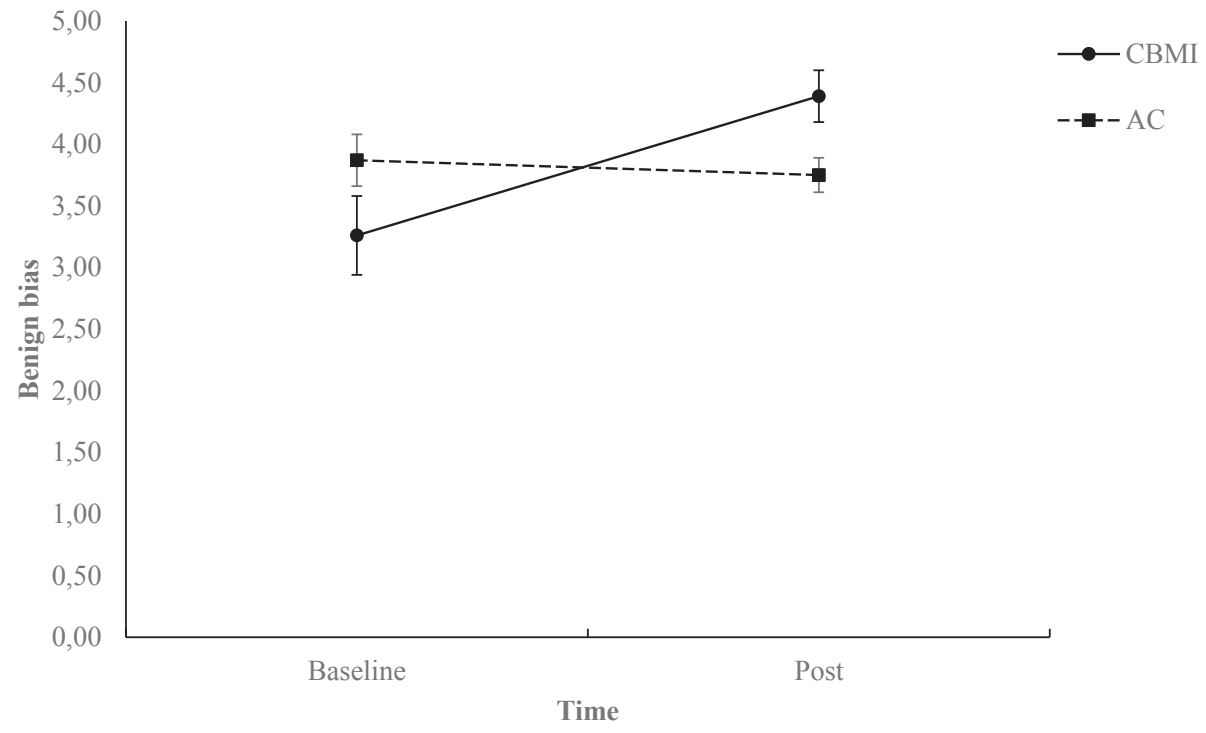

\section{Figure 2}

Study 2 -Estimates of WSAP benign bias over time per condition

Note. Error bars represent standard errors of the estimates. We chose one outcome (WSAP) to depict as this strongly resembles the SIP-AEQ pattern.

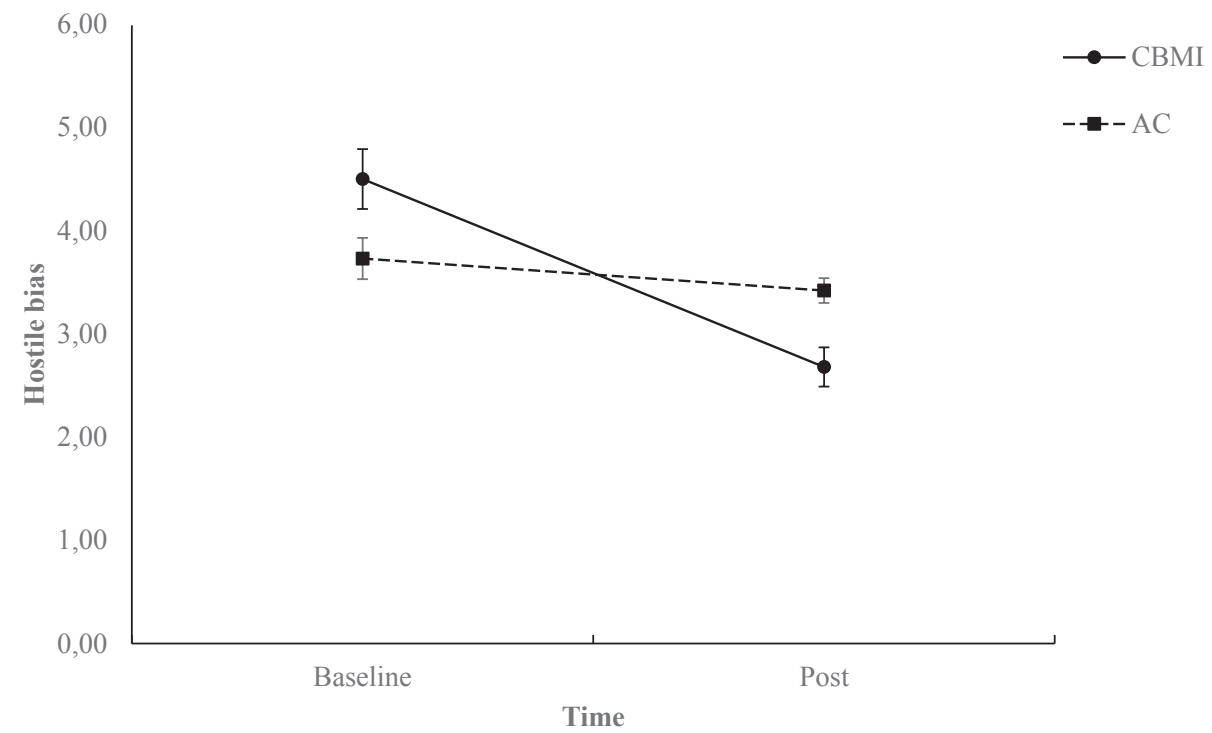

\section{Figure 3}

Study 2 - Estimates of WSAP hostile bias over time per condition

Note. Error bars represent standard errors of the estimates. We chose one outcome (WSAP) to depict as this strongly resembles the SIP-AEQ pattern. 


\section{State hostility and general psychiatric symptom measures}

To test the hypothesis that CBM-I leads to larger reductions in state hostility and general psychiatric symptoms than $A C$, four separate mixed regression models were run with cognitive aspects of hostility (AQ-H), state anger (STAXI-2S), self-reported aggression (FOAS) and general psychiatric symptoms (K10) as dependent variables and time, condition and condition by time as independent variables. Findings are shown in Table 3. Results showed that CBM-I led to a lesser reduction in general psychiatric symptoms $(\mathrm{K} 10)(d=-0.17,95 \% \mathrm{Cl}=-0.34$ to $0.00)$ from pre to post intervention compared to AC. Results on self-reported state aspects of hostility (AQ-H, STAXI-2S, and FOAS) revealed a time effect in which all variables reduced from pre- to post intervention ( $p s<.001)$. None of the interaction effects were significant ( $p s>.054)$.

\section{Trait hostility measures}

To test the prediction that CBM-I results in larger reductions in hostility traits than AC, four separate mixed regression models were run with overall hostility (PID5-H), cognitive aspects of hostility $(\mathrm{AQ}-\mathrm{H})$ and self-reported aggression traits (FOA) as dependent variables and time, condition and condition by time as independent variables. Results are shown in Table 3. For the self-reported hostility measures (PID-5H, AQ-H, and FOA) findings revealed significant time effects ( $p$ 's < .007), but no significant interaction effects ( $p s>$.18). Next, a Poisson regression model was run with behavioral aggression (VDT) at post-intervention as dependent variables and condition and behavioral aggression at baseline as independent variables. Results showed that CBM-I resulted in greater reductions in behavioral aggression from pre- to post intervention $(B=-.28, S E=.08, d=-0.29,95 \% C l=-.47$ to -.10$)$ compared to $A C$ (see Figure 4). Last, given that men express aggression more physically than women (Björkqvist et al., 1992) we explored CBM-I effects on behavioral aggression for men. Results showed that the effect of CBM-I increased $(d=-0.41,95 \% \mathrm{Cl}=-1.10$ to -0.20$)$ compared to $\mathrm{AC}$.

\section{Carry-over effects on working alliance in subsequent psychotherapy}

To test the hypothesis that CBM-I leads to beneficial carry-over effects on working alliance in subsequent psychotherapy we explored the data of $n=17$ ( $n=8$ for CBM-I and $n=9$ for AC) participants who engaged in psychotherapy after the experiment. First, an independent samples $t$-test was run on working alliance as dependent variable. Results demonstrated that the two conditions did not differ significantly in terms of working alliance in psychotherapy, $t=$ $1.45, p=.168$. Then correlations were calculated to examine relations between change scores on the outcome variables and working alliance. Results showed that none of the outcomechange scores significantly related to working alliance (ps > .069). However, when working alliance was regressed on post-test VDT scores, correcting for that the indicated usefulness per condition (i.e., interaction) did not depend on hostility level $(O R=.32, p=.171)$. 


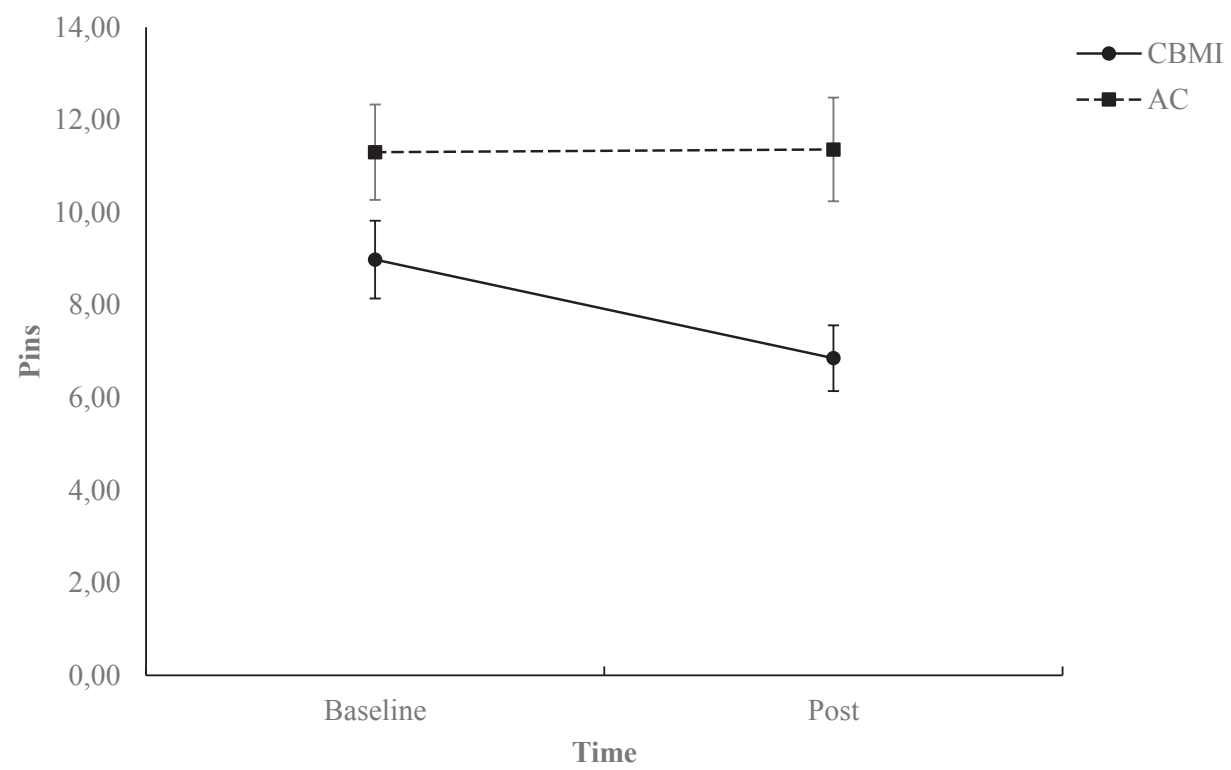

\section{Figure 4}

Study 2 - VDT pins over time per condition

Note. Error bars represent standard errors of the estimates. VDT = Voodoo Doll Task.

\section{Study 2 - Discussion}

In Study 2 we tested the efficacy of CBM-I intervention versus AC in a larger double-blind, sham-controlled clinical trial in people with clinical levels of hostility where the additional impact on hostility outcomes and general psychiatric symptoms was assessed. In line with our expectations, Study 2 revealed that CBM-I altered benign bias in a positive baseline VDT score, results showed a significant negative relationship between VDT score at postintervention and working alliance $\left(\mathrm{B}=-0.04, \mathrm{SE}=0.02, X^{2}=6.32, p=.012, d=0.42,95 \% \mathrm{Cl}\right.$ $=-1.00$ to -0.13$)$. This suggests that less post-test aggressive behavior is related to a higher degree of working alliance.

\section{Perceived usefulness}

To explore if the perceived usefulness per condition was impacted by hostility levels we ran a binary logistic regression model with usefulness as dependent variable and condition, baseline hostility level (PID-5H score) and the condition by hostility interaction as independent variables. Within the CBM-I and AC conditions, respectively $72.5 \%$ and $40.0 \%$ of participants indicated they found the intervention useful. Moreover, results showed that for participants in the CBM-I condition the odds of indicating the intervention as useful are 29 times higher than in the $\mathrm{AC}$ condition $(O R=29.46, p=.027,95 \% \mathrm{Cl}=1.48$ to 585.65), and direction, and hostile bias and aggressive behavior in a negative direction compared to $\mathrm{AC}$. Contrary to our 
expectations, results revealed that CBM-I decreased general psychiatric symptoms to a lesser extent than AC. Also, findings showed only a significant non-differential decrease over time for self-reported state and trait hostility measures. Moreover, explorative findings showed no difference between conditions in working alliance for people who went into psychotherapy after our interventions. Interestingly, across conditions reductions in aggressive behavior (VDT) were related to increased working alliance, whereas changes in other outcome variables were not significantly related to working alliance.

\section{GENERAL DISCUSSION}

The present work investigated the effects of a novel CBM-I intervention for hostility. We first tested its feasibility in a single-blind randomized sham-controlled feasibility trial using a mixed clinical-community male sample $(N=20$, Study 1$)$ and then tested its efficacy in a double-blind, randomized sham-controlled clinical trial in a mix-gender sample of people with clinical levels of hostility ( $N=135$, Study 2 ). Overall, we found that eight sessions of CBM-I across four weeks increased benign bias. Study 1 indicated moderate to good feasibility but showed no significant effects on hostile bias. In Study 2, CBM-I increased benign bias and reduced hostile bias and aggressive behavior with small effect sizes. However, we observed no differential changes in self-reported hostility measures. Surprisingly, results indicated that general psychiatric symptoms decreased to a lesser extent in the CBM-I condition, compared to AC. Results furthermore showed that reductions in aggressive behavior were related to an increased quality of working alliance in subsequent psychotherapy following both interventions, but we did not observe a differential impact of CBM-I on working alliance in subsequent psychotherapy; however, this analysis was very underpowered.

The strength of therapy effects on benign and hostile bias in the present study (i.e., $d=0.29$ and $d=0.26$ for benign bias, and $d=-0.17$ and -0.33 for hostile bias), are smaller than those in a number of previous studies. One study compared one CBM-I session to a sham condition in students and found medium effect sizes ( $d=0.44$ for benign bias and $d=0.66$ for hostile bias) (Hawkins \& Cougle, 2013). Two other studies compared an eight-session CBM-I training to a sham condition and demonstrated medium to large effect sizes ( $d=1.17$ for benign bias and $d=0.65$ for hostile bias) in non-treatment seeking people with alcohol use disorder (Cougle et al., 2017) and major depressive disorder ( $d=1.06$ for benign bias and $d=0.64$ for hostile bias) (Smith et al., 2018). A fourth study compared eight sessions CBM-I to a waitlist condition in aggressive boys and found large effect sizes ( $d=1.40$ for benign bias and $d=2.21$ for hostile bias) (Vassilopoulos et al., 2014). A fifth study compared one session of CBM-I benign training to a negative training condition and revealed a large effect size (approximate $d=0.85$ for benign bias) (AlMoghrabi et al., 2018). However, the effect size on aggression in the current 
study does converge with findings of a recent meta-analysis across 85 studies showing that CBM-I for anxiety $(S M D=-0.30)$ and depression $(S M D=-0.26)$ demonstrates small effects on symptoms compared to a sham condition (Fodor et al., 2020). Importantly, this meta-analysis showed that studies with lower methodological quality and therefore higher risk of bias generally found higher effect sizes. We believe that the present work fits within its conclusions, given that our effect sizes on aggression in Study 2 are small, while this study fulfills criteria for high methodological quality and low risk of bias (e.g., intention to treat analysis, random sequence generation, allocation concealment, blinding). Still, we observed no significant efficacy of CBM-I on hostile bias in Study 1, which most probably can be attributed to low power.

Next to an observed efficacy on bias, Study 2 revealed secondary efficacy of CBM-I on behavioral aggression. The finding that CBM-I reduces behavioral hostility suggests an information processing pathway towards aggressive behavior that operates distinctly from non-behavioral aspects of hostility. This is in line with the Social Information Processing model of aggression (Crick \& Dodge, 1994), which implies that the hostile interpretation of external (i.e., situational) and internal (e.g., emotional) cues results into a narrowing of potential behavioral response patterns. This, in turn, increases the likelihood of aggressive response patterns. CBM-I for hostility thus seems to provide people with an interpretational strategy (Clifton et al., 2016) that 're-opens' previously suppressed but more adaptive behavioral response patterns, while leaving the more temperamental, emotional cue generation processes intact. Importantly, changes in aggressive behavior were observed using a well-validated behavioral measure, but not self-reported measures. On the one hand, this suggests that changes may occur outside of participants' awareness. On the other hand, the self-report/ behavior discrepancy may reflect measurement problems that are related to aggression, such as paradigm flexibility (Elson et al., 2014; Hyatt et al., 2019), social desirability, and construct identity confusion (van Teffelen et al., 2020).

The explorative finding that reductions in aggressive behavior were related to increased working alliance levels, but that working alliance levels in subsequent psychotherapy did not differ significantly between conditions could be explained by a non-differential motivation effect. That is, 'doing something' while waiting for therapy and experiencing a change in one's aggressive behavior may facilitate beliefs about one's ability to change. In line with this, experimental research shows that when people are led to belief that their emotions are highly controllable, this facilitates the regulation of subsequent emotional responses (Bigman et al., 2016). Notwithstanding, statistical power in the present explorative sample is simply too small to conclude that there is no true effect of CBM-I on the perceived quality of the working alliance in subsequent psychotherapy. We cannot rule out that CBM-I may have augmenting effects when provided prior to treatment, but this issue is largely neglected in the field and requires further experimental evidence. 
Several important limitations impact the present findings. First, the samples included participants with clinical levels of hostility that were both treatment- and non-treatmentseeking people. Although most people were screened in a treatment-seeking population (80\%), treatment-seeking people made up (only) $38 \%$ of the final sample. It could be argued that people with clinical levels of hostility are more likely to decline participation, but Figure 1 shows that our sample composition is more likely due to treatment-seeking people that did not meet our inclusion criteria. However, this still implies that our results may not generalize to a treatment-seeking sample that for instance shows increased numbers of experienced psychosocial stressors, comorbidity, tendencies for interpersonal conflict and premature treatment discontinuation. As a related issue, the present sample included more men than women. Given that men express aggression more physically than women (Björkqvist et al., 1992; Genovese et al., 2017) this could have amplified the strength of the present findings. When we explored CBM-I effects on behavioral aggression for men only, its effect slightly increased from $d=0.28$ using the complete sample to $d=0.41$. A second limitation of the present study is that it did not include a follow-up measurement. We therefore do not know whether the results sustain over time. Third, there is currently no consensus in the CBM-I literature in terms of dose-response effects. We opted for eight 20-minute sessions, but we urge future studies to investigate the optimal dose-response effect. A fourth drawback of the study was that we omitted to define interpretation bias as a main outcome prior to the study, while we did base the a priori power analysis on interpretation bias only. Fifth, the present study contained and active and a control condition. Perhaps, the observed findings were impacted by the fact that people who score high on hostility do not like to be manipulated. However, participants were explicitly told they were going to be randomly allocated to an intervention study for hostility with active or control condition. We also asked the participants if they thought whether or not they thought the interventions was beneficial for them. Within the CBM-I and $A C$ conditions, respectively $72.5 \%$ and $40.0 \%$ of participants indicated they found the intervention useful. However, the perceived usefulness per condition did not depend on baseline hostility levels. Last, we originally intended to exclude people who actively used alcohol or drugs. After additional scrutiny of the literature, however, we could not find convincing evidence that supported this criterion. On the contrary, literature showed that bias modification studies are conducted and shown to be efficacious in samples that are on active alcohol use (Wiers et al., 2015). That study showed for example that the alcohol approach bias significantly reduced, but non-differentially from active control training. In the present study, analysis showed that alcohol or drug consumption on the same day prior to CBM-I sessions did not impact the pattern of results. We recommend future studies on CBM-I to further disentangle the influence of alcohol and substance consumption on CBM-I efficacy. 
The present work holds several clinical implications. First, the finding that CBM-I for hostility increased benign bias and reduced hostile bias and aggression implies that people with clinical hostility levels experience small but significant improvements after the repeated stimulation of benign interpretations in random ambiguous scenarios. This shows that CBM-I holds promise as a prevention or intervention strategy for hostility at relatively low cost. In addition, explorative analysis of CBM-I effects on (physical) aggressive behavior suggests that the effect is slightly stronger for men. Evidently, this finding suggestion requires replication. Our findings also suggest that CBM-I could be implemented in both treatment- and nontreatment-seeking settings. However, research is still in its' early stages as a number of important questions remain unanswered at this point: Does efficacy sustain over time? What is the optimal dose-response effect? Can CBM-I serve as an add-on to standard treatment, for example when people are on waitlist? And, is the intervention effective in everyday clinical practice? The questions require further research prior to further implementation.

In sum, we observed that CBM-I increased benign bias, reduced hostile bias, and reduced and behavioral aggression with small effects, which may be of benefit for people with clinical levels of hostility. 


\section{REFERENCES}

AlMoghrabi, N., Huijding, J., \& Franken, I. H. A. (2018). The effects of a novel hostile interpretation bias modification paradigm on hostile interpretations, mood, and aggressive behavior. Journal of Behavior Therapy and Experimental Psychiatry, 58, 36-42. https://doi.org/10.1016/j.jbtep.2017.08.003

Ammerman, B. A., Kleiman, E. M., Uyeji, L. L., Knorr, A. C., \& McCloskey, M. S. (2015). Suicidal and violent behavior: The role of anger, emotion dysregulation, and impulsivity. Personality and Individual Differences, 79, 57-62. https://doi.org/10.1016/j.paid.2015.01.044

Arntz, A., Stupar-Rutenfrans, S., Bloo, J., van Dyck, R., \& Spinhoven, P. (2015). Prediction of treatment discontinuation and recovery from Borderline Personality Disorder: Results from an RCT comparing Schema Therapy and Transference Focused Psychotherapy. Behaviour Research and Therapy, 74, 60-71. https://doi.org/10.1016/j.brat.2015.09.002

Baayen, R. H., Davidson, D. J., \& Bates, D. M. (2008). Mixed-effects modeling with crossed random effects for subjects and items. Journal of Memory and Language, 59(4), 390-412. https://doi.org/10.1016/j. jml.2007.12.005

Bach, B., Maples-Keller, J. L., Bo, S., \& Simonsen, E. (2016). The alternative DSM-5 personality disorder traits criterion: A comparative examination of three self-report forms in a Danish population. Personality Disorders: Theory, Research, and Treatment, 7(2), 124-135. https://doi.org/10.1037/per0000162

Beard, C., \& Amir, N. (2008). A multi-session interpretation modification program: Changes in interpretation and social anxiety symptoms. Behaviour Research and Therapy, 46(10), 1135-1141.

Beard, C., Rifkin, L. S., Silverman, A. L., \& Björgvinsson, T. (2019). Translating CBM-l into real-world settings: Augmenting a CBT-based psychiatric hospital program. Behavior Therapy, 50(3), 515-530. https:// doi.org/10.1016/j.beth.2018.09.002

Bigman, Y. E., Mauss, I. B., Gross, J. J., \& Tamir, M. (2016). Yes I can: Expected success promotes actual success in emotion regulation. Cognition and Emotion, 30(7), 1380-1387. https://doi.org/10.1080/02 699931.2015 .1067188

Björkqvist, K., Lagerspetz, K. M., \& Kaukiainen, A. (1992). Do girls manipulate and boys fight? Developmental trends in regard to direct and indirect aggression. Aggressive Behavior, 18(2), 117-127. https://doi.org/ bz3jgt

Brettschneider, M., Neumann, P., Berger, T., Renneberg, B., \& Boettcher, J. (2015). Internet-based interpretation bias modification for social anxiety: A pilot study. Journal of Behavior Therapy and Experimental Psychiatry, 49(Part A), 21-29. https://doi.org/10.1016/j.jbtep.2015.04.008

Buss, A. H., \& Perry, M. (1992). The aggression questionnaire. Journal of Personality and Social Psychology, 63(3), 452-459. https://doi.org/10.1037/0022-3514.63.3.452

Butler, E., Mobini, S., Rapee, R. M., Mackintosh, B., \& Reynolds, S. A. (2015). Enhanced effects of combined cognitive bias modification and computerised cognitive behaviour therapy on social anxiety. Cogent Psychology, 2(1). https://doi.org/10.1080/23311908.2015.1011905

Cassiello-Robbins, C., Conklin, L. R., Anakwenze, U., Gorman, J. M., Woods, S. W., Shear, M. K., \& Barlow, D. H. (2015). The effects of aggression on symptom severity and treatment response in a trial of cognitive behavioral therapy for panic disorder. Comprehensive Psychiatry, 60, 1-8. https://doi. org/10.1016/j.comppsych.2015.04.012

Cassiello-Robbins, C., \& Barlow, D. H. (2016). Anger: The unrecognized emotion in emotional disorders. Clinical Psychology: Science and Practice, 23(1), 66-85. https://doi.org/10.1111/cpsp.12139 
Clifton, J. L., Hedley, S., Mountier, E., Tiszai, B., \& Grimshaw, G. M. (2016). Practice makes perfect: Training the interpretation of emotional ambiguity. Cognition \& Emotion, 30(4), 654-668. https://doi.org/10.10 80/02699931.2015.1020768

Coccaro, E. F., Fanning, J., \& Lee, R. (2017). Development of a social emotional information processing assessment for adults (SEIP-Q). Aggressive Behavior, 43(1), 47-59. https://doi.org/10.1002/ab.21661

Coccaro, E. F., Noblett, K. L., \& McCloskey, M. S. (2009). Attributional and emotional responses to socially ambiguous cues: Validation of a new assessment of social/emotional information processing in healthy adults and impulsive aggressive patients. Journal of Psychiatric Research, 43(10), 915-925. https://doi.org/10.1016/j.jpsychires.2009.01.012

Cougle, J. R., Summers, B. J., Allan, N. P., Dillon, K. H., Smith, H. L., Okey, S. A., \& Harvey, A. M. (2017). Hostile interpretation training for individuals with alcohol use disorder and elevated trait anger: A controlled trial of a web-based intervention. Behaviour Research and Therapy, 99, 57-66. https:// doi.org/10.1016/j.brat.2017.09.004

Crick, N. R., \& Dodge, K. A. (1994). A review and reformulation of social information-processing mechanisms in children's social adjustment. Psychological Bulletin, 115(1), 74-101. https://doi.org/10.1037/00332909.115.1.74

Del Vecchio, T., \& O'Leary, K. D. (2004). Effectiveness of anger treatments for specific anger problems: A meta-analytic review. Clinical Psychology Review, 24(1), 15-34. https://doi.org/10.1016/j.cpr.2003.09.006

DeWall, C. N., Finkel, E. J., Lambert, N. M., Slotter, E. B., Bodenhausen, G. V., Pond, R. S., Jr., Renzetti, C. M., \& Fincham, F. D. (2013). The voodoo doll task: Introducing and validating a novel method for studying aggressive inclinations. Aggressive Behavior, 39(6), 419-439.

Dillon, K. H., Allan, N. P., Cougle, J. R., \& Fincham, F. D. (2016). Measuring Hostile Interpretation Bias:The WSAP-Hostility Scale. Assessment, 23(6), 707-719. https://doi.org/10.1177/1073191115599052

Donker, T., Comijs, H., Cuijpers, P., Terluin, B., Nolen, W., Zitman, F., \& Penninx, B. (2010). The validity of the Dutch K10 and extended K10 screening scales for depressive and anxiety disorders. Psychiatry Research, 176(1), 45-50. https://doi.org/10.1016/j.psychres.2009.01.012

Elson, M., Mohseni, M. R., Breuer, J., Scharkow, M., \& Quandt, T. (2014). Press CRTT to measure aggressive behavior: The unstandardized use of the competitive reaction time task in aggression research. Psychological Assessment, 26(2), 419-432. https://doi.org/10.1037/a0035569

Fodor, L. A., Georgescu, R., Cuijpers, P., Szamoskozi, Ş., David, D., Furukawa, T. A., \& Cristea, I. A. (2020). Efficacy of cognitive bias modification interventions in anxiety and depressive disorders: a systematic review and network meta-analysis. Lancet Psychiatry, 7(6), 506-514. https://doi.org/10.1016/s22150366(20)30130-9

Genovese, T., Dalrymple, K., Chelminski, I., \& Zimmerman, M. (2017). Subjective anger and overt aggression in psychiatric outpatients. Comprehensive Psychiatry, 73, 23-30. https://doi.org/10.1016/j. comppsych.2016.10.008

Gülüm, I. V., Soygüt, G., \& Safran, J. D. (2018). A comparison of pre-dropout and temporary rupture sessions in psychotherapy. Psychotherapy Research, 28(5), 685-707. https://doi.org/10.1080/10503307.2016 1246765

Hallion, L. S., \& Ruscio, A. M. (2011). A meta-analysis of the effect of cognitive bias modification on anxiety and depression. Psychological Bulletin, 137(6), 940-958. https://doi.org/10.1037/a0024355

Hawkins, K. A., \& Cougle, J. R. (2013). Effects of interpretation training on hostile attribution bias and reactivity to interpersonal insult. Behavior Therapy, 44(3), 479-488. https://doi.org/10.1016/j.beth.2013.04.005

Henrichs, J., Bogaerts, S., Sijtsema, J., \& Klerx-van Mierlo, F. (2014). Intimate Partner Violence Perpetrators in a Forensic Psychiatric Outpatient Setting: Criminal History, Psychopathology, and Victimization. J Interpers Violence. https://doi.org/10.1177/0886260514552272 
Hirsh, J. B., Quilty, L. C., Bagby, R. M., \& McMain, S. F. (2012). The relationship between agreeableness and the development of the working alliance in patients with borderline personality disorder. Journal of Personality Disorders, 26(4), 616-627. https://doi.org/10.1521/pedi.2012.26.4.616

Hofmann, S. G., Asnaani, A., Vonk, I. J. J., Sawyer, A. T., \& Fang, A. (2012). The efficacy of cognitive behavioral therapy: A review of meta-analyses. Cognitive Therapy and Research, 36(5), 427-440. https://doi.org/10.1007/s10608-012-9476-1

Holmes, E. A., Mathews, A., Dalgleish, T., \& Mackintosh, B. (2006). Positive Interpretation Training: Effects of Mental Imagery Versus Verbal Training on Positive Mood. Behavior Therapy, 37(3), 237-247. https:// doi.org/10.1016/j.beth.2006.02.002

Hornsveld, R. H. J., Muris, P., Kraaimaat, F. W., \& Meesters, C. (2009). Psychometric properties of the Aggression Questionnaire in Dutch violent forensic psychiatric patients and secondary vocational students. Assessment, 16(2), 181-192. https://doi.org/10.1177/1073191108325894

Horvath, A. O., \& Greenberg, L. S. (1989). Development and validation of the Working Alliance Inventory. Journal of Counseling Psychology, 36(2), 223-233. https://doi.org/10.1037/0022-0167.36.2.223

Hyatt, C. S., Chester, D. S., Zeichner, A., \& Miller, J. D. (2019). Analytic flexibility in laboratory aggression paradigms: Relations with personality traits vary (slightly) by operationalization of aggression. Aggressive Behavior, 45(4), 377-388. https://doi.org/10.1002/ab.21830

Jacobson, N. S., \& Truax, P. (1991). Clinical significance: A statistical approach to defining meaningful change in psychotherapy research. Journal of Consulting and Clinical Psychology, 59(1), 12-19. https:// doi.org/10.1037/0022-006X.59.1.12

Kessler, R. C., Andrews, G., Colpe, L. J., Hiripi, E., Mroczek, D. K., Normand, S. L. T., Walters, E. E., \& Zaslavsky, A. M. (2002). Short screening scales to monitor population prevalences and trends in non-specific psychological distress. Psychological Medicine, 32(6), 959-976. https://doi.org/10.1017/ S0033291702006074

Krueger, R. F., Derringer, J., Markon, K. E., Watson, D., \& Skodol, A. E. (2012). Initial construction of a maladaptive personality trait model and inventory for DSM-5. Psychological Medicine, 42(9), 18791890. https://doi.org/10.1017/S0033291711002674

Lang, T. J., Blackwell, S. E., Harmer, C. J., Davison, P., \& Holmes, E. A. (2012). Cognitive bias modification using mental imagery for depression: Developing a novel computerized intervention to change negative thinking styles. Eur J Pers, 26(2), 145-157. https://doi.org/10.1002/per.855

Lievaart, M., Franken, I. H. A., \& Hovens, J. E. (2016). Anger assessment in clinical and nonclinical populations: Further validation of the State-Trait Anger Expression Inventory-2. Journal of Clinical Psychology, 72(3), 263-278. https://doi.org/10.1002/jclp.22253

Mathews, A., \& Mackintosh, B. (2000). Induced emotional interpretation bias and anxiety. Journal of Abnormal Psychology, 109(4), 602-615.

McNair, D. M., Lorr, M., \& Droppleman, L. F. (1992). Manual for the Profile of Mood States. Educational and Industrial Testing Service.

Meesters, C., Muris, P., Bosma, H., \& Schouten, E. (1996). Psychometric evaluation of the Dutch version of the Aggression Questionnaire. Behaviour Research and Therapy, 34(10), 839-843. https://doi. org/10.1016/0005-7967(96)00065-4

Putt, C. A., Dowd, E. T., \& McCormick, R. A. (2001). Impact of pre-existing levels of hostility and aggression on substance abuse treatment outcome. Counselling Psychology Quarterly, 14(2), 139-147. https:// doi.org/10.1080/09515070110058576

Smith, H. L., Dillon, K. H., \& Cougle, J. R. (2018). Modification of Hostile Interpretation Bias in Depression: A Randomized Controlled Trial. Behavior Therapy, 49(2), 198-211. https://doi.org/10.1016/j. beth.2017.08.001 
Sobell, L. C., \& Sobell, M. B. (1990). Self-report issues in alcohol abuse: State of the art and future directions. Behavioral Assessment, 12(1), 77-90.

Spielberger, C. D. (1999). State-Trait Anger Expression Inventory-2. Psychological Assessment Resources. Tremblay, P. F., \& Belchevski, M. (2004). Did the Instigator Intend to Provoke? A Key Moderator in the Relation Between Trait Aggression and Aggressive Behavior. Aggressive Behavior, 30(5), 409-424. https://doi.org/10.1002/ab.20027

Van der Heijden, P., Ingenhoven, T., Berghuis, H., \& Rossi, G. (2014). Nederlandstalige bewerking van The Personality Inventory for DSM-5® (PID-5) - Adult, 2011. Uitgeverij Boom.

van Teffelen, M. W., Lobbestael, J., Voncken, M. J., \& Peeters, F. (2020). Uncovering the hierarchical structure of self-reported hostility. PloS One, 15(9), e0239631. https://doi.org/10.1371/journal.pone.0239631

Vassilopoulos, S. P., Brouzos, A., \& Andreou, E. (2014). A multi-session attribution modification program for children with aggressive behaviour: changes in attributions, emotional reaction estimates, and self-reported aggression. Behavioural and cognitive psychotherapy, 1-11. https://doi.org/10.1017/ S1352465814000149

Verona, E., Sadeh, N., Case, S. M., Reed, A., 2nd, \& Bhattacharjee, A. (2008). Self-reported use of different forms of aggression in late adolescence and emerging adulthood. Assessment, 15(4), 493-510. https:// doi.org/10.1177/1073191108318250

von der Lippe, A. L., Monsen, J. T., Rønnestad, M. H., \& Eilertsen, D. E. (2008). Treatment failure in psychotherapy: The pull of hostility. Psychotherapy Research, 18(4), 420-432. https://doi. org/10.1080/10503300701810793

Wicherts, J. M., \& Vorst, H. C. M. (2004). Modelpassing van de Verkorte Profile of Mood States en meetinvariantie over mannen en vrouwen [journal article]. Nederlands Tijdschrift voor de Psychologie en Haar Grensgebieden, 59(1), 11-20. https://doi.org/10.1007/bf03062320

Wiers, R. W., Houben, K., Fadardi, J. S., van Beek, P., Rhemtulla, M., \& Cox, W. M. (2015). Alcohol cognitive bias modification training for problem drinkers over the web. Addictive Behaviors, 40, 21-26. https:// doi.org/10.1016/j.addbeh.2014.08.010 


\section{APPENDIX A}

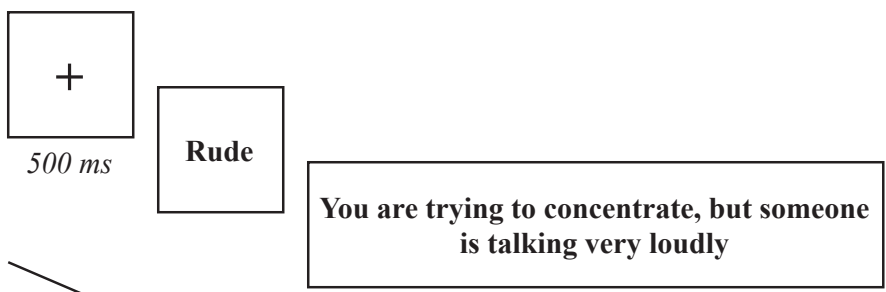

Participant presses space bar

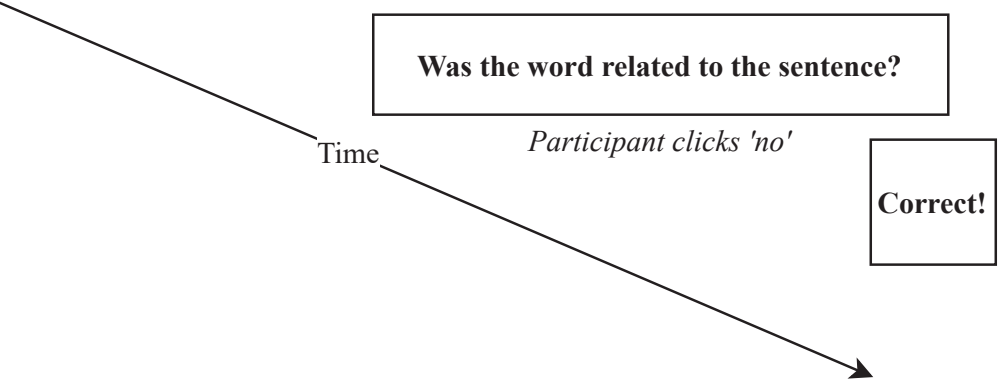

Outline of the word-sentence association paradigm.

\section{APPENDIX B}

\section{Someone near you has a very loud voice}

This person is unaw_re of how loud he is

Participant fills in the missing letter ' $a$ '

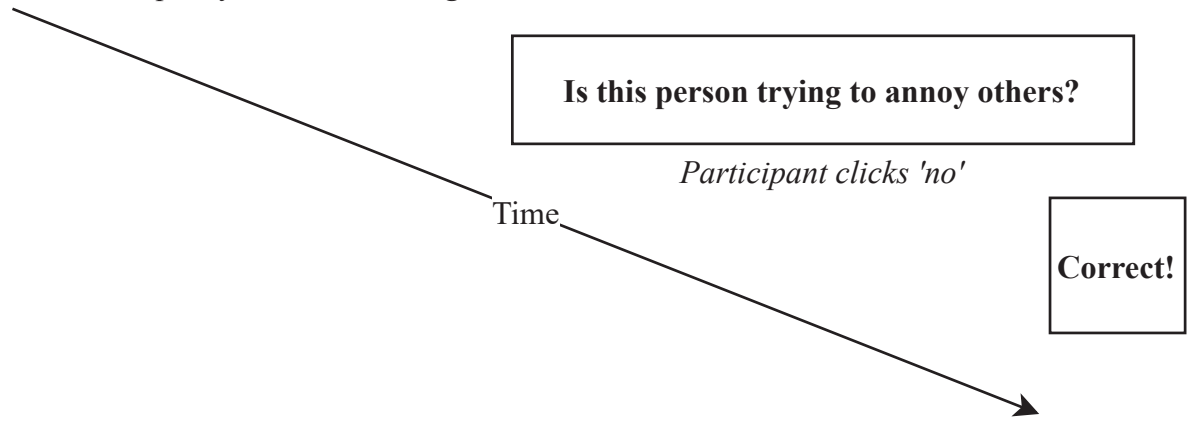

Outline of the scenario training. 



\section{CHAPTER 7}

General Discussion 



\section{GENERAL DISCUSSION}

The present work set out to find a better understanding of hostility and how to influence it. Specifically, this thesis had three main goals: (1) examining the dimensions of hostility (chapter 2); (2) comparing laboratory provocation methods that induce hostility and assess how these interact with psychopathic and narcissistic personality traits (chapter $\mathbf{3}$ ); and (3) developing new ways to advance treatment options for hostility (chapters 4, $\mathbf{5}$ and $\mathbf{6}$ ) by testing the efficacy of imagery-enhanced cognitive restructuring (I-CR) and cognitive bias modification of hostile interpretation bias (CBM-I). In the following, the main findings are summarized and discussed and recommendations for future research will be provided. Last, implications for the clinical field will be outlined.

\section{MAIN FINDINGS}

\section{Dimensions of Hostility}

In hostility research many scholars use the same term for different constructs, or different terms for the same construct. Some refer to anger (Ramirez \& Andreu, 2006; Spielberger, 1999) or irritability (Vidal-Ribas et al., 2016) as the affective dimension of hostility, while others include both cognitive and affective aspects of hostility when referring to anger (Wilkowski \& Robinson, 2008). Along the same lines, there are scholars who coin the term hostility for cognitive aspects of antagonistic phenomena (Chida \& Steptoe, 2009; Smith, 1992; Spielberger et al., 1985). Others define hostility as the sum of affective, behavioral, and cognitive aspects (American Psychiatric Association, 2013; Barefoot, 1992).

There are two potential reasons for the confusion in concept identity of hostility. One reason is the diversity in the number of factors that are reported in psychometric studies. For example, some report two factors aligning with the two-dimensional anger experience/anger expression model (see e.g., Martin et al., 2000), while others report factor solutions in line with the threefactor anger-hostility-aggression (AHA) or affect-behavior-cognition (ABC) model, sometimes even within the same study (Martin et al., 2000). Up to five factors have been reported in the literature (see e.g., Maier et al., 2009). A second, more fundamental reason that provides an explanation for the concept identity confusion in hostility research is that hostility components are simply not accurately measured. Despite the fact that many hostility self-reports hold excellent psychometric properties, closer inspection shows that many self-report items tap into and subsequently load on more than one dimension. That is, an item that intends to measure aggressive behavior may also assess the affective component of anger. As an example, the Buss-Perry Aggression Questionnaire (AQ) (Buss \& Perry, 1992) includes items such as "I have become so mad that I have broken things" (measuring both anger and physical aggression), 
"When people annoy me, I may tell them what I think of them" (measuring both anger and verbal aggression), or "Given enough provocation, I may hit another person" (measuring both hostile intent and physical aggression). A search on Web of Science on 28 August 2020 reveals that the $A Q$ is cited 2995 times since its initial construction. This shows that currently the attitude in the hostility field regarding self-report instrument is too permissive. A premise to the theoretical understanding, prevention and treatment of hostility begins with accurate measurement. When the validity of hostility items is already reduced at face level, we should not be surprised that there is a lack of consensus on the structure of hostility in psychometric studies - reflecting the garbage in, garbage out concept. Consequently, the existence of cross-capturing items in hostility measures reduces their construct and face validity.

In chapter $\mathbf{2}$ we examined whether a hierarchical model structure can account for differences reported by psychometric studies on the number of underlying hostility dimensions. We specifically selected instruments from the literature that included as little cross-capturing items as possible. Similar to constructs such as 'narcissism' and 'agreeableness', we predicted that hostility can be expressed as a construct with a hierarchical structure or, in other words, as a construct that can be interpreted at different levels of specificity. The findings of chapter $\mathbf{2}$ confirmed this hypothesis. Specifically, hierarchical factor analysis revealed five specificity levels of hostility. At the highest specificity level (most abstract), hostility can be expressed as one dimension characterized by a low threshold to experience angry affective states and react harmfully upon them (i.e., physically, and verbally). At the lowest level (most specific), hostility is characterized by one cognitive, one affective and three behavioral dimensions (i.e., social, verbal, and physical aggressive behavior). These dimensions align with the content of the solutions that were reported in previous psychometric studies.

Theoretically our findings are in line with work by Averill (1983), who demonstrated already almost four decades ago that angry affective states and aggressive behavior can occur independently of each other in everyday situations. In other words, a person may experience angry affect, but this does not necessarily result in the expression of aggressive behavior. Vice versa, a person may behave aggressively without experiencing angry affect. The present work adds that the same goes for the cognitive dimension of hostility, and similarly, that a person can be prone to express aggression either socially, verbally, or physically. In other words, interpreting a situation in a hostile way does not necessarily result in angry affect or aggressive behavior. Similarly, being verbally aggressive can exist in isolation, without necessarily resulting in physical aggression. The finding that hostile affect, behavior, and cognition can occur independently from each other implies that these may have different antecedents and consequences. Perhaps, hostile affect (i.e., anger) is influenced more by internal psychophysiological changes (e.g., blood pressure or cardiovascular reactivity) (Zawadzki et al., 2017), whereas hostile behavior (i.e., aggression) is more influenced by 
antecedents that lower inhibition capacity such as increased cognitive load (Vasquez \& Howard-Field, 2016) or the acute presence of physical threat (Blanchard et al., 2001). In turn, hostile interpretation tendencies may be more affected by the (emotional) ambiguity of threats (Blanchard et al., 2011).

Results from other chapters in this dissertation further illustrate the importance of differentiating between different hostility dimensions. First, in chapter $\mathbf{3}$ we differentiated cognitive (i.e., perceived threat), affective (i.e., negative affect), and behavioral (i.e., physical aggressive behavior) factors and found that -generally- these do not differentially alter after experiencing social exclusion or insult. However, our findings showed that psychopathic personality traits are positively related to reduced negative affective change, and in turn to reduced aggressive responding. Results also revealed that narcissistic personality traits are positively related to perceived threat under insult conditions, and in turn to reduced initial aggressive responding. Thus, dimensions of hostility appear to have differential mediating effects on relationships between psychopathology and provoked physical aggression. Second, in chapter $\mathbf{4}$ we differentiated hostile beliefs (i.e., cognitive dimension), anger (i.e., affective dimension), and aggression (i.e., behavioral dimension). We found that compared to an active control condition $(A C)$, traditional cognitive restructuring (CR) and I-CR were more efficacious in reducing hostile beliefs, anger, and aggression. However, I-CR was sustainably more efficacious in reducing hostile beliefs and aggression compared to AC and CR. Therefore, I-CR and CR seem to impact the majority of hostility dimensions compared to AC. Finally, in chapter $\mathbf{6}$ we differentiated hostile interpretation bias (i.e., cognitive dimension), anger and aggression. Results showed that compared to $\mathrm{AC}, \mathrm{CBM}-\mathrm{I}$ was more efficacious in reducing hostile interpretation bias and aggression. Hence, CBM-I seems to impact cognitive and behavioral dimensions, but not affective dimensions of hostility. Moreover, in both chapters 4 and 6 we found no differential impact between the active interventions and $A C$ on a broad 'capture-it-all' hostility measure (i.e., the PID-5H). Thus, our findings illustrate that distinct interventions indeed have differential impact on dimensions of hostility.

Altogether, our work consistently stresses the importance of differentiating hostility components. Hostility components do not only require distinct measurement; they can also help to disentangle the differential impact of personality traits, proactive and reactive aggression, and treatment. In treatment for example, it is vital to understand which 'button' elicits change in which domain. Treatment mechanism studies could provide insight into what intervention impacts which hostility dimension. Similarly, it is important to understand which domains are not affected by therapeutic interventions and would require additional or other forms of therapy. Leaving some hostility dimensions untreated may lead to a suboptimal reduction of hostility as a whole. 


\section{Feeding the Flame: Provoking Hostility}

One way to study hostility is by experimentally provoking it. In light of the conceptual problem hostility currently faces (outlined above), different provocation methods may differentially impact hostility dimensions. Experimental literature offers many different ways to provoke hostility. However, different hostility induction methods were never directly compared to each other. Consequently, it was unclear which method is most effective in a given domain, limiting the generalizability of observed effects.

Because of this gap in the current literature, we in chapter $\mathbf{3}$ directly compared two laboratory provocation methods that induce hostility. To reduce the confounding procedural influence, we selected two procedures with high methodological similarity: social exclusion and insult. We expected that social exclusion and insult would equally impact aggressive behavior, general negative affect, and threat perception. In addition, we added two personality concepts with potentially contrasting effects on hostility, i.e. psychopathic traits that were previously shown to reduce provoked hostility, and narcissistic traits that were previously shown to increase provoked hostility. Thus, relationships between provoked hostility, psychopathic and narcissistic personality traits were explored. Results confirmed our hypothesis that social exclusion and insult equally impact aggressive behavior, negative affect, and threat perception. Findings also revealed that under circumstances of agentic threat (i.e., insult) narcissistic traits are related to increased threat perception. In turn, threat perception was related to reduced initial aggressive responding. Results furthermore demonstrated that psychopathic traits are related to reduced negative affective change after provocation. In turn, reduced negative affective change was negatively related to provoked aggressive behavior. In other words, narcissism predisposes to feeling threatened by an insult, initially withholding aggression, but lashing out when a new threat emerges. In turn, psychopathy predisposes to experiencing less change in negative affect after provocation, leading to reduced aggressive responding.

The fact that -aside from ours- no other studies directly compared the impact of hostility provocation methods is highly problematic. In order to determine if there is a true causal relationship between situational factors and hostility, scholars turn to meta-analytic studies (see e.g., Bettencourt et al., 2006; Hyatt et al., 2019). Meta-analytic studies aim to aggregate all available studies on a topic to determine a pooled effect size and are regarded as evidence with the highest quality and lowest risk of bias (Atkins et al., 2004). One of these systematic reviews across 37 studies reported comparable effect sizes for different provocation types (Bettencourt et al., 2006). However, the main methodological problem with meta-analyses in the provoked hostility field is that they have drawn conclusions on the relative effectiveness of different types of provocations without including studies that directly compare different provocations to each other, because they are absent. In a way, 
one could therefore say that past meta-analyses were comparing apples and oranges. Ignoring the absence of direct comparisons limits the conclusions that can be drawn on what procedure is most provocative for who.

An example of how direct comparisons can provide new hypotheses on the nature of provocations and how they impact outcomes is shown in the present dissertation. In chapter $\mathbf{3}$ explorative findings demonstrated that psychopathic traits are related to reduced affective responding and narcissistic traits are related to increased threat perception in response to provocation. These findings might indicate that psychopathic-related hostility is more affectively based, while narcissistic-related hostility is more cognitively based. As a consequence, hostility interventions may be less effective when they target affective hostility aspects in psychopathic people. Along the same lines, hostility interventions may be attenuated when they target cognitive hostility aspects in narcissistic people. In chapter $\mathbf{4}$ it was demonstrated that both traditional CR and I-CR reduce hostile beliefs, self-reported anger and aggressive inclinations compared to AC. Moreover, chapter $\mathbf{6}$ showed that CBM-I reduced hostile interpretation bias and aggressive behavior, but not self-reported anger.

Perhaps, people with psychopathic traits show increased benefit from interventions that put less emphasis on affective hostility aspects, such as CBM-I or social skills, problem solving skills or behavioral skills training. Along the same lines, people with narcissistic traits may benefit more from interventions that are more cognitively (but not necessarily less affectively) based, such as CR, I-CR or CBM-I. Hopefully, the present work stimulates provocation research to move forward and conduct randomized studies comparing provocation procedures and how they relate to distinct pathological personality traits, in order to provide new insight into tailored treatment strategies.

\section{Extinguishing the Flame: Reducing Hostility}

The most widely empirically investigated psychological treatment for hostility is cognitive behavioral therapy (CBT). Although treatment studies show support for its' effectiveness (Hofmann et al., 2012), evidence suggests that there is room for improvement in the treatability of hostility. A promising target for treatability optimization is hostile interpretation bias. The literature suggests that treatment options for hostile interpretation bias may be advanced in two ways: first, by optimizing the efficacy of therapist-provided CR; and second by implementing computerized CBM-I.

\section{Optimization of therapist-provided CR}

One important intervention that has shown to effectively reduce hostility is CR. Previous work showed that enhancing CR with mental imagery may increase its efficacy. In chapter $\mathbf{4}$ it was investigated whether I-CR outperformed traditional CR. People with high levels of hostility 
were randomly allocated to one session $\mathrm{CR}$, I-CR, or active control $(\mathrm{AC}$ ) interventions. At baseline, post-intervention and at one-week follow-up changes in hostile beliefs, aggressive inclinations, state anger and hostility traits were measured. Moreover, at one-week follow-up participants were exposed to a provocation. We expected that I-CR would be efficacious in reducing hostile beliefs, aggressive inclinations, state anger and hostility traits compared to $\mathrm{CR}$ and $\mathrm{AC}$. Findings showed that hostile beliefs, aggressive inclinations, and state anger were more strongly reduced by I-CR and CR compared to AC. Additionally, I-CR was sustainably more efficacious in reducing hostile beliefs and aggressive inclinations compared to AC. All conditions reduced hostility traits over time. These findings suggest that integrating the use of mental imagery in standard CR for hostility results in more elaborate processing, likely because mental imagery has a stronger cognitive impact.

\section{Implementation of computerized CBM-I}

Another way of advancing treatment options for hostility is by developing and implementing novel interventions. This is important because a significant number of patients do not benefit from treatment as usual. One intervention that holds promise to reduce hostility is CBM-I. Chapter $\mathbf{6}$ describes the development of a novel CBM-I intervention and its ' treatment effect in two experiments. The first experiment tested the feasibility of the CBM-I intervention compared to an active control (AC) condition in a small mixed community-clinical male sample. The second experiment described a randomized controlled trial, comparing CBM-I to AC in a large sample of people with clinical levels of hostility. It was expected that CBM-I would result in a stronger increase in benign bias and stronger reductions of hostile bias and hostility symptoms and traits compared to AC. The second experiment also explored whether CBM-I was related to beneficial carry-over effects in case people engaged in psychotherapy after CBM-I. Findings confirmed that CBM-I efficaciously increased benign bias in both trials. Moreover, the second experiment demonstrated that CBM-I reduced hostile bias, behavioral aggression compared to AC. However, CBM-I did not reduce affective aspects of hostility compared to AC.

Following the evidence presented in chapters $\mathbf{4}$ and $\mathbf{6}$, all interventions (i.e., I-CR, CR and CBM-I) effectively reduced aggressive behavior by targeting hostile interpretations. This evidence is in line with contemporary working models of hostility (Allen et al., 2018; Crick \& Dodge, 1994; Wilkowski \& Robinson, 2008) that predict reductions in aggressive behavior by establishing reappraisal strategies. Our findings indicate that these reappraisal strategies can be installed in different ways. On the one hand, (I-)CR attempts to install a reappraisal strategy through the elaborate personalized evaluation of provoking situations (top-down). On the other hand, CBM-I attempts to install a reappraisal strategy by repeatedly reinforcing benign interpretations in many random emotionally ambiguous scenarios (bottom-up). Perhaps, combining both top-down and bottom-up reappraisal strategies can be complementary in the treatment of hostility. 
Despite the interesting nature of the present findings, it must be stressed that in the present dissertation, effect sizes on aggressive behavior were small. That is, CBM-I had a small effect $(d=-$.) on physical aggression; CR had a small effect of $d=-.35$ on aggressive inclinations (irrespective of the nature of aggression); and I-CR had a small effect of $d=-.48$ on aggressive inclinations. I-CR and CR had no effect on physical aggression, as measured by the voodoo doll task (VDT). One explanation for the physical aggression discrepancy between (I-)CR and CBM-I could be that our (I-)CR study included a sample with more women than men, whereas the CBM-I sample included more men than women. Women tend to express their aggression more socially than physically compared to men (Björkqvist et al., 1992). An alternative explanation could be that the people in the clinical sample of the CBM-I study had higher levels of physical aggression at baseline than people in the sample of the I-CR study and were therefore more susceptible for change. A third explanation could be that one session of (I-)CR is just not potent enough to elicit change in physical aggression.

Although both interventions reduced aggression to a small but significant extent, the current dissertation underlines the importance of separating physical, verbal, and relational dimensions of aggression (chapter 2). Two general limitations are worth mentioning. First, verbal, and relational aggression were not operationalized or analyzed consistently across our studies. That is, chapter $\mathbf{3}$ did not operationalize verbal and relational aggression, and chapters $\mathbf{4}$ and $\mathbf{6}$ did operationalize, but did not separately analyze verbal and relational aggression. Second, hostility dimensions were not measured consistently throughout this dissertation. For example, chapter $\mathbf{2}$ was solely based on self-report, whereas chapter $\mathbf{6}$ measured hostile intent using vignettes and word-sentence associations, anger using self-report and aggression using both self-report and behaviorally using the VDT. In general, we found no differences within studies when multiple measures were used per construct. However, chapters $\mathbf{4}$ and $\mathbf{6}$ showed that both interventions differentially impacted state and trait levels of hostile intent and aggression. Specifically, CBM-I impacted hostility traits, whereas (I-CR impacted hostility states. One explanation for this divergence is a time effect. CBM-I consisted of eight 30-minute training sessions (i.e., four hours), while (I-)CR lasted 90 minutes. Hopefully, the present work stimulates future research to investigate the effects of treatment on aggressive behavior beyond physical aggression.

Next to the importance of precise hostility measurement, the findings in this dissertation indicate that it may be beneficial to personalize interventions. The personalized medicine account holds that a patient's unique characteristics play an important role in tailoring their therapies (Hamburg \& Collins, 2010; Ozomaro et al., 2013). Following this line of reasoning, mapping a patient's characteristics that are relevant to hostility may provide an avenue for tailored, more effective treatment. That is, chapters $\mathbf{2}$ and $\mathbf{3}$ revealed that it is important to differentiate hostility into cognitive, affective, and behavioral dimensions and that these dimensions are differentially impacted by psychopathic and narcissistic personality traits under 
provocation conditions. Specifically, psychopathic traits impact affective, whereas narcissistic traits impact cognitive dimensions. It may therefore be beneficial for people with psychopathic traits to put less emphasis on interventions that target affective dimensions of hostility, such as progressive relaxation. Along the same lines, for people with narcissistic traits it may be beneficial to focus treatment more on interventions that target cognitive aspects of hostility, such as CR and CBM-I. Altogether, offering a combination of interventions that aligns with individual trait-profiles may further increase effectiveness.

\section{CLINICAL IMPLICATIONS}

The results of the present work come with several implications for clinical practice. First, across four different studies, the current work suggests that hostile interpretation bias is a promising intervention target. Specifically, hostile interpretation bias was identified as a separate hostility dimension (chapter $\mathbf{2}$ ) that is differentially impacted by situational factors and personality traits (chapter 3). In addition, three different interventions (I-CR, CR and CBM-I) targeting hostile interpretations showed significant reductions on hostility complaints (chapters $\mathbf{4}$ and $\mathbf{6}$ ). This shows that hostile interpretation bias is a valid, stand-alone concept within hostility that is therapeutically malleable. It also implies that hostile interpretation bias is a dimension that should not be underestimated in patients. Rather, hostile interpretation bias is a construct that should specifically be attended to. For example, even when a patient is not showing overt aggressive behavior it does not mean that these patients or the people in their environment are not burdened by the patient's tendency to interpret situations in a hostile way.

Second, findings in chapter $\mathbf{2}$ suggest that at present the construct and face validity of hostility measures is questionable. This implies that using a hostility instrument in clinical practice can lead to false conclusions. For example, a clinician intends to measure hostility aspects in a patient, in order to determine potential targets for intervention. If the clinician selects a hostility instrument containing cross-capturing items (as e.g., the $A Q$, as outlined above) this will negatively impact the risk of measuring the wrong construct and not detecting the changes (s)he aims to measure. Vice versa, measurement imprecision will inaccurately estimate levels of interpretation bias, affect, and affect potentially resulting in a wrong selection of interventions. Along the same lines, in chapter $\mathbf{6}$ it was shown that CBM-I impacts cognitive and behavioral, but not affective aspects of hostility. Using an instrument that intends to measure hostile behavior, but in reality, partially measures cognitive or affective dimensions of hostility may lead a clinician to falsely conclude that CBM-I is not effective. Thus similarly, using an instrument that intends to measure cognitive dimensions of hostility, but actually underestimates it may lead a clinician to falsely disregard CBM-I or (I-)CR as potential intervention. 
Third, the finding that I-CR outperformed traditional CR in a randomized trial suggests that integrating mental imagery in standard CR procedures not only benefits patients with social anxiety disorder (McEvoy et al., 2015) or patients with post-traumatic stress and personality disorder (Arntz \& Weertman, 1999; Ehlers et al., 2005; Smucker et al., 1995). It also provides clinical hostility research with an exciting new therapeutic avenue. However, research is still in its early stages and important issues need to be addressed before continuing its' implementation.

Chapter $\mathbf{5}$ provided a detailed description of the I-CR procedure, including the discussion of problems a therapist may run into during I-CR and potential solutions. Examples of such problems are participants finding it difficult to generate or hold mental images, or participants actively avoiding re-experiencing angry affect. Nonetheless, a number of questions remain to be answered, for example: What is the impact of patients' level of creativity or general imagery capacity on the efficacy of I-CR? What is the impact of multiple I-CR sessions? Do effects sustain over time? And do results generalize do everyday situations? Moreover, in the present protocol we selected 'evidence-gathering' as intervention procedure. It may be worthwhile investigating if other CR-techniques, such as the so-called 'pie-chart' technique or multidimensional evaluation aligns equally well with the proposed imagery techniques. Hopefully, the present work stimulates further research to facilitate further implementation.

Fourth, it was shown in chapter 6 that CBM-I efficaciously reduced hostile interpretation bias and aggressive behavior in a participant sample with clinical levels of hostility. This suggests that people with clinical levels of hostility show small but significant improvements in aggressive behavior after the repeated stimulation of benign interpretations in random ambiguous scenarios across eight weeks. Consequently, this demonstrates that computerized CBM-I holds the potential of an intervention that can be implemented at relatively low cost. Perhaps, CBM-I can be offered as an add-on when patients are on waitlist for therapistprovided therapy. Also, for some people, the threshold for seeking professional help for hostility problems may be too high. For these people and for non-treatment seeking people, CBM-I as a stand-alone intervention may be valuable. However, CBM-I research in hostility is still in its early stages and a number of questions remain to be unanswered prior to further implementation, such as: What is the optimal dose-response effect? Does efficacy sustain over time? Is the intervention effective in everyday clinical practice? And can CBM-I serve as an add-on to standard treatment, for example when people are on waitlist?

Fifth, for a significant number of patients, hostility problems are a primary reason to seek help. However, hostility is not described as a separate 'disorder' in traditional classification instruments such as the DSM-5. Instead, aspects of hostility are included in other disorders. The transdiagnostic approach in the present work may therefore also have diagnostic implications.

Chapter 2 revealed up to five separate hostility dimensions. When these dimensions are mapped on traditional DSM-5 classifications, it becomes clear that hostility criteria for Intermittent 
Explosive disorder are verbal- and physical. For post-traumatic stress disorder, borderline personality disorder, antisocial personality disorder, and disruptive mood dysregulation disorder, criteria are based on affective and behavioral dimensions of hostility. For paranoid personality disorder, criteria are mostly related to cognitive or affective aspects of hostility. For bipolar disorder, criteria are mostly related to affective aspects of hostility. These DSM- 5 criteria may provide a first quick-and-dirty indication of which intervention to select. For example, a person diagnosed with Intermittent Explosive Disorder may specifically benefit from interventions that are behavioral in nature, such as social skills training, or problem-solving skills training. Likewise, a clinician may opt for social skills training, or problem-solving skills training in combination with progressive relaxation for reducing hostility in a patient suffering from with PTSD. Similarly, a patient with paranoid personality traits may benefit from more cognitively based interventions, such as (I-)CR or CBM-I. Related to this, when hostility is a primary reason to seek help, it may be worthwhile to map a patient's hostility profile and when this does not match the full clinical picture as described by current DSM-5 criteria, clinicians may want diagnose an 'unspecified disruptive, impulse-control, and conduct disorder', and tailor treatment base on a patients personality profile. In sum, hostility is a diagnostically challenging condition. Consequently, the effectiveness of hostility interventions may differ between nomological diagnostic classifications.

Taken together, the clinical implications of the present dissertation suggest that hostility is a challenging construct in terms of measurement and diagnosis. In spite of its' challenging nature, the cognitive dimension of hostility is an intervention target that appears to be sensitive for further efficacy optimization. Specifically, the present dissertation showed that CR procedures can be improved through the integration of mental imagery. Moreover, CBM-I may be a valuable, low-cost addition to current treatment options.

Overall, the present dissertation showed that hostility is an unrecognized, but highly impairing condition that requires better diagnostic understanding and targeted clinical intervention. Findings revealed that hostility consists of multiple dimensions at different specificity levels and that these dimensions are differentially impacted by personality traits and interventions. Specifically, the integration of mental imagery techniques and implementation of cognitive bias modification provides exciting new avenues for advancing the treatability of hostility.

Hopefully, the current work stimulates joint efforts in future research to further unravel the antecedents and consequences of hostility dimensions and how they relate to personality profiles. A better understanding of hostility may increase diagnostic precision and provide valuable insight into new (e.g., I-CR and CBM-I) and more personalized intervention strategies. Ultimately, following Aristotle's words, this may help patients to become angry with the right person, to the right degree, for the right purpose, and in the right way. 


\section{REFERENCES}

Allen, J. J., Anderson, C. A., \& Bushman, B. J. (2018). The General Aggression Model. Current Opinion in Psychology, 19, 75-80. https://doi.org/10.1016/j.copsyc.2017.03.034

American Psychiatric Association. (2013). Diagnostic and Statistical Manual of Mental Disorders (5th ed.).

Arntz, A., \& Weertman, A. (1999). Treatment of childhood memories: theory and practice. Behaviour Research and Therapy, 37(8), 715-740. https://doi.org/10.1016/S0005-7967(98)00173-9

Atkins, D., Best, D., Briss, P. A., Eccles, M., Falck-Ytter, Y., Flottorp, S., Guyatt, G. H., Harbour, R. T., Haugh, M. C., Henry, D., Hill, S., Jaeschke, R., Leng, G., Liberati, A., Magrini, N., Mason, J., Middleton, P., Mrukowicz, J., O'Connell, D., Oxman, A. D., Phillips, B., Schunemann, H. J., Edejer, T., Varonen, H., Vist, G. E., Williams, J. W., Jr., Zaza, S., \& Group, G. W. (2004). Grading quality of evidence and strength of recommendations. BMJ, 328(7454), 1490. https://doi.org/10.1136/bmj.328.7454.1490

Averill, J. R. (1983). Studies on anger and aggression: Implications for theories of emotion. American Psychologist, 38(11), 1145-1160. https://doi.org/10.1037/0003-066X.38.11.1145

Barefoot, J. C. (1992). Developments in the measurement of hostility. In H. S. Friedman (Ed.), Hostility, coping, \& health. (pp. 13-31). American Psychological Association. https://doi.org/10.1037/10105-001

Bettencourt, B., Talley, A., Benjamin, A. J., \& Valentine, J. (2006). Personality and aggressive behavior under provoking and neutral conditions: a meta-analytic review. Psychological Bulletin, 132(5), 751.

Björkqvist, K., Lagerspetz, K. M., \& Kaukiainen, A. (1992). Do girls manipulate and boys fight? Developmental trends in regard to direct and indirect aggression. Aggressive Behavior, 18(2), 117-127. https://doi.org/ bz3jgt

Blanchard, D. C., Griebel, G., Pobbe, R., \& Blanchard, R. J. (2011). Risk assessment as an evolved threat detection and analysis process. Neuroscience and biobehavioral reviews, 35(4), 991-998. https:// doi.org/10.1016/j.neubiorev.2010.10.016

Blanchard, D. C., Hynd, A. L., Minke, K. A., Minemoto, T., \& Blanchard, R. J. (2001). Human defensive behaviors to threat scenarios show parallels to fear- and anxiety-related defense patterns of non-human mammals. Neurosci Biobehav Rev, 25(7-8), 761-770. https://doi.org/10.1016/s01497634(01)00056-2

Buss, A. H., \& Perry, M. (1992). The aggression questionnaire. Journal of Personality and Social Psychology, 63(3), 452-459. https://doi.org/10.1037/0022-3514.63.3.452

Chida, Y., \& Steptoe, A. (2009). The association of anger and hostility with future coronary heart disease: a meta-analytic review of prospective evidence. Journal of the American College of Cardiology, 53(11), 936-946. https://doi.org/10.1016/j.jacc.2008.11.044

Crick, N. R., \& Dodge, K. A. (1994). A review and reformulation of social information-processing mechanisms in children's social adjustment. Psychological Bulletin, 115(1), 74-101. https://doi.org/10.1037/00332909.115.1.74

Ehlers, A., Clark, D. M., Hackmann, A., McManus, F., \& Fennell, M. (2005). Cognitive therapy for posttraumatic stress disorder: development and evaluation. Behaviour Research and Therapy, 43(4), 413-431. https://doi.org/10.1016/j.brat.2004.03.006

Hamburg, M. A., \& Collins, F. S. (2010). The Path to Personalized Medicine. New England Journal of Medicine, 363(4), 301-304. https://doi.org/10.1056/NEJMp1006304

Hofmann, S. G., Asnaani, A., Vonk, I. J. J., Sawyer, A. T., \& Fang, A. (2012). The efficacy of cognitive behavioral therapy: A review of meta-analyses. Cognitive Therapy and Research, 36(5), 427-440. https://doi.org/10.1007/s10608-012-9476-1 
Hyatt, C., Zeichner, A., \& Miller, J. (2019). Laboratory aggression and personality traits: A meta-analytic review. Psychology of Violence, 9(6), 675-689.

Maier, K. J., Goble, L. A., Neumann, S. A., Giggey, P. P., Suarez, E. C., \& Waldstein, S. R. (2009). Dimensions across measures of dispositional hostility, expressive style, and depression show some variation by race/ethnicity and gender in young adults. Journal of Social and Clinical Psychology, 28(10), 11991225. https://doi.org/10.1521/jscp.2009.28.10.1199

Martin, R., Watson, D., \& Wan, C. K. (2000). A three-factor model of trait anger: Dimensions of affect, behavior, and cognition. Journal of Personality, 68(5), 869-897. https://doi.org/10.1111/1467-6494.00119

McEvoy, P. M., Erceg-Hurn, D. M., Saulsman, L. M., \& Thibodeau, M. A. (2015). Imagery enhancements increase the effectiveness of cognitive behavioural group therapy for social anxiety disorder: A benchmarking study. Behaviour Research and Therapy, 65, 42-51. https://doi.org/10.1016/j. brat.2014.12.011

Ozomaro, U., Wahlestedt, C., \& Nemeroff, C. B. (2013). Personalized medicine in psychiatry: problems and promises. BMC medicine, 11(1), 132. https://doi.org/10.1186/1741-7015-11-132

Ramirez, J. M., \& Andreu, J. M. (2006). Aggression, and some related psychological constructs (anger, hostility, and impulsivity); some comments from a research project. Neuroscience and biobehavioral reviews, 30(3), 276-291. https://doi.org/10.1016/j.neubiorev.2005.04.015

Smith, T. W. (1992). Hostility and health: Current status of a psychosomatic hypothesis. Health Psychology, 11(3), 139-150. https://doi.org/10.1037/0278-6133.11.3.139

Smucker, M. R., Dancu, C., Foa, E. B., \& Niederee, J. L. (1995). Imagery rescripting: A new treatment for survivors of childhood sexual abuse suffering from posttraumatic stress. Journal of Cognitive Psychotherapy, 9(1), 3-17.

Spielberger, C. D. (1999). State-Trait Anger Expression Inventory-2. Psychological Assessment Resources.

Spielberger, C. D., Johnson, E., Russell, S., Crane, R., Jacobs, G., \& Worden, T. (1985). The experience and expression of anger: Construction and validation of an anger and hostility in cardiovascular and behavioral disorders. In M. A. Chesney \& R. H. Rosenman (Eds.), Anger and hostility in cardiovascular and behavioral disorders (pp. 5-30). Hemisphere.

Vasquez, E. A., \& Howard-Field, J. (2016). Too (mentally) busy to chill: Cognitive load and inhibitory cues interact to moderate triggered displaced aggression. Aggressive Behavior, 42(6), 598-604. https:// doi.org/10.1002/ab.21654

Vidal-Ribas, P., Brotman, M. A., Valdivieso, I., Leibenluft, E., \& Stringaris, A. (2016). The status of irritability in psychiatry: A conceptual and quantitative review. Journal of the American Academy of Child and Adolescent Psychiatry, 55(7), 556-570. https://doi.org/10.1016/j.jaac.2016.04.014

Wilkowski, B. M., \& Robinson, M. D. (2008). The cognitive basis of trait anger and reactive aggression: An integrative analysis. Personality and Social Psychology Review, 12(1), 3-21. https://doi. org/10.1177/1088868307309874

Zawadzki, M. J., Smyth, J. M., Sliwinski, M. J., Ruiz, J. M., \& Gerin, W. (2017). Revisiting the lack of association between affect and physiology: Contrasting between-person and within-person analyses. Health Psychology, 36(8), 811-818. https://doi.org/10.1037/hea0000466 




\section{CHAPTER 8}

Summary

Samenvatting 



\section{SUMMARY}

Hostility is a trait consisting of a tendency to experience hostile thoughts and anger and to express aggressive behavior. Profound negative consequences of hostility are an increased risk of interpersonal violence, heart disease and suicidality. Within current mental health care hostility is a major mental health problem. Hostility appears to be just as common as depression or anxiety and is often a primary reason for patients to seek help. Moreover, it significantly increases the severity of other forms of mental illness and the chance of treatment discontinuation. However, traditional psychiatric classification instruments do not include a formal hostility 'diagnosis'. Instead, hostility is considered a phenomenon that transcends diagnosis, i.e., a transdiagnostic phenomenon.

The current dissertation aims (1) to gain a better understanding of the nature of hostility, (2) to understand how it can be provoked and (3) to explore ways to improve its treatment. This resulted in three main goals: to investigate the dimensional structure of hostility (chapter 2); to compare methods that provoke hostility in the lab and how they interact with psychopathic and narcissistic personality traits (chapter 3); and to develop new ways to advance the treatability of hostility (chapters 4, 5 and $\mathbf{6}$ ). The following section explains and summarizes the main findings.

One problem in hostility research is that researchers often use the same term for different phenomena, or different terms for the same phenomenon. This is at least partly due to a lack of consensus in the findings of studies that investigate the dimensional structure of hostility (i.e., factor analytic studies). For example, studies report that the number of factors underlying hostility ranges between two (e.g., experience and expression) and four (e.g., hostile thoughts, angry feelings, verbal aggression, and physical aggression) dimensions. In chapter $\mathbf{2}$ we investigated whether a hierarchical model structure can explain these differences. Similar to constructs such as "narcissism" and "agreeableness", we predicted that hostility is characterized by a hierarchical structure, i.e., a construct that can be interpreted at different levels of specificity. The findings of chapter $\mathbf{2}$ confirmed this hypothesis. Specifically, hierarchical factor analysis showed five levels of specificity within hostility. At the highest, most abstract level, hostility can be expressed as one dimension, characterized by a low threshold for experiencing anger and responding aggressively, physically, or verbally. At the lowest, most specific level, hostility is characterized by one cognitive, one affective, and three behavioral dimensions (i.e., social, verbal, and physical aggressive behavior). This structure seems to explain the diversity in results of previous psychometric studies.

Using the best possible operationalization of hostility, several ways of inducing hostility have been reported in the literature. However, these methods have never been directly compared. In chapter $\mathbf{3}$ we therefore compared two provocation methods that induce hostility in the 
lab (i.e., social exclusion and insult) and examined how they interact with psychopathic and narcissistic personality traits. We selected two procedures based on methodological similarity and expected them to have an equal impact on aggressive behavior, negative affect, and perceived threat. The results confirmed the hypothesis that social exclusion and insult had a similar impact on hostility. Findings also revealed a negative relationship between perceived threat and initial aggressive responding in people with elevated levels of narcissism after an insult. The results further showed a negative relationship between change in negative affect and aggressive behavior in people with psychopathic traits. Hopefully, identifying how hostility relates to pathological personality traits provides novel insight into what intervention works for who.

An important intervention that has proven to be effective in reducing hostility is cognitive restructuring (CR). In chapters $\mathbf{4}$ and $\mathbf{5}$, it was investigated whether enriching CR with "mental imagery" increases its efficacy. People with increased hostility levels were randomly assigned to one session of $\mathrm{CR}$, imagery-enhanced $\mathrm{CR}(\mathrm{I}-\mathrm{CR})$ or an active control intervention (AC). Changes in hostile thoughts, aggressive inclinations, state anger, and hostility traits were measured at baseline, post-intervention and one week after the intervention (follow-up). Subjects were also confronted with an emotional stressor (i.e., reimagining an autobiographical anger-evoking event) one week after the intervention. We expected I-CR to be more efficacious in reducing hostile beliefs, aggressive inclinations, state anger, and hostility traits, compared to CR and AC. Results showed that hostile thoughts, aggressive inclinations, and state anger indeed decreased more strongly after I-CR and CR compared to AC. In addition, I-CR was sustainably more efficacious in reducing hostile thoughts and aggressive inclinations compared to $A C$ and CR. All interventions reduced hostility traits over time.

Another way to advance the treatability of hostility is to develop and implement novel interventions. One intervention that could be potentially efficacious in reducing hostility is cognitive bias modification for hostile interpretation bias (CBM-I). Chapter $\mathbf{6}$ describes the development of a new CBM-I intervention and how it was tested in two experiments. The first experiment tested the feasibility of CBM-I compared to an active control (AC) condition in a small male mixed patient-community sample. The second experiment described a randomized, controlled experiment in a large group of people with clinical hostility levels. It was hypothesized that in the first experiment, CBM-I would lead to a stronger increase in benign bias and a stronger decrease in hostile bias. In the second experiment, in addition to an improvement in interpretation bias, a stronger decrease in state and trait hostility was expected compared to AC. The second experiment also explored whether CBM-I had beneficial carry-over effects on working alliance, when participants underwent psychotherapy after the experiment. Results confirmed that CBM-I increased benign bias in both experiments. In addition, the second, larger experiment showed that CBM-I led to a greater decrease in 
hostile bias and aggressive behavior, but not in non-behavioral aspects of hostility compared to AC. No evidence was found for beneficial carry-over effects to psychotherapy after CBM-I in a small subgroup.

Hopefully, the present dissertation stimulates future research to further disentangle the antecedents and consequences of hostility dimensions and how they relate to pathological personality traits. Improved understanding of hostility can increase diagnostic precision and may guide personalized intervention strategies. 



\section{SAMENVATTING}

Hostiliteit is een karaktertrek. Mensen met deze karaktertrek voelen zich vaak boos, hebben last van vijandige gedachtes en kunnen zich agressief gedragen. Hostiliteit kan leiden tot interpersoonlijk geweld, hartziekten en suïcidaliteit. Hostiliteit vormt een probleem binnen de huidige geestelijke gezondheidszorg (GGZ). Hostiliteit lijkt namelijk net zo veel voor te komen als depressiviteit of angst en is vaak een belangrijke reden voor patiënten om hulp te zoeken. Gek genoeg kent hostiliteit geen 'diagnose', terwijl het wel de ernst van psychische aandoeningen en de kans op het vroegtijdig stoppen van een behandeling verhoogd. Om deze reden kan hostiliteit gezien worden als een fenomeen dat diagnoses overstijgt, oftewel een transdiagnostisch fenomeen.

Het huidige proefschrift is geschreven om een beter begrip te krijgen van de aard van hostiliteit en hoe het opgewekt en verminderd kan worden. Dit werd verdeeld in drie hoofddoelen: het onderzoeken van de dimensionele structuur van hostiliteit (hoofdstuk 2); het vergelijken van methoden die hostiliteit opwekken in het laboratorium, en hoe psychopathische en narcistische persoonlijkheidstrekken deze relatie beïnvloeden (hoofdstuk 3); en het ontwikkelen van nieuwe manieren om het behandelaanbod voor hostiliteit te bevorderen (hoofdstukken 4, 5 en 6). In het volgende deel worden de belangrijkste bevindingen uitgelegd en samengevat.

Een probleem binnen hostiliteitsonderzoek is dat onderzoekers vaak dezelfde term voor verschillende fenomenen, of verschillende termen voor hetzelfde gebruiken. Dit reflecteert mogelijk een gebrek aan consensus in de bevindingen van studies die onderzoek doen naar de dimensionele structuur van hostiliteit. Zo rapporteren studies factorstructuren bestaande uit ergens tussen de twee (bijvoorbeeld, ervaring en expressie) en vier (bijvoorbeeld, vijandige gedachtes, boze gevoelens, verbale agressie en fysieke agressie) dimensies. In hoofdstuk 2 onderzochten we of een hiërarchische modelstructuur deze verschillen kan verklaren. Gelijk aan fenomenen, of constructen als 'narcisme' en 'vriendelijkheid' voorspelden wij dat hostiliteit uitgedrukt kan worden als een construct met een hiërarchische opbouw of, met andere woorden, een construct dat geïnterpreteerd kan worden op verschillende niveaus van specificiteit. De bevindingen van hoofdstuk $\mathbf{2}$ bevestigden deze hypothese. Specifiek toonde hiërarchische factor analyse aan dat er sprake is van vijf specificiteitsniveaus binnen hostiliteit. Op het hoogste, meest abstracte niveau kan hostiliteit uitgedrukt worden als één dimensie, gekarakteriseerd door een lage drempel om boosheid te ervaren en er fysiek of verbaal agressief op te reageren. Op het laagste, meest specifieke niveau is hostiliteit gekarakteriseerd door één cognitieve, één affectieve en drie gedragsmatige dimensies (i.e., sociaal, verbaal en fysiek agressief gedrag). Deze structuur lijkt de verscheidenheid in resultaten van voorgaande psychometrische studies te verklaren. 
Met het best mogelijke begrip van hostiliteit tot dusver, zijn er in de literatuur verschillende manieren gerapporteerd waarmee hostiliteit opgewekt kan worden. Echter, deze methodes zijn tot dusver nooit direct met elkaar vergeleken. We vergeleken daarom in hoofdstuk $\mathbf{3}$ twee provocatiemethodes in het lab die hostiliteit opwekken (i.e., sociale exclusie en belediging) en bekeken hoe ze werden beïnvloed door psychopathische en narcistische persoonlijkheidstrekken. We selecteerden twee procedures gebaseerd op methodologische gelijkenis en verwachtten dat ze een gelijke impact zouden hebben op agressief gedrag, negatief affect en waargenomen dreiging. Ook verkenden we de relaties tussen geprovoceerde hostiliteit en psychopathische en narcistische persoonlijkheidstrekken. De resultaten bevestigde de hypothese dat sociale exclusie en belediging een vergelijkbare impact hadden op hostiliteit. Bevindingen lieten ook een negatieve relatie zien tussen waargenomen dreiging en initiële agressieve respons in mensen met verhoogde niveaus van narcisme na een belediging. De resultaten lieten verder een negatieve relatie zien tussen verandering in negatief affect en agressief gedrag in mensen met psychopathische trekken.

Een belangrijke interventie die effectief is gebleken in het verminderen van hostiliteit is cognitieve herstructurering. In hoofdstukken $\mathbf{4}$ en $\mathbf{5}$ werd onderzocht en beschreven of het verrijken van CR met 'mental imagery' zijn werkzaamheid verhoogd. Mensen met een verhoogde hostiliteit werden willekeurig toegewezen aan één sessie CR, 'imagery'-verrijkte CR (I-CR) of een actieve controle interventie (AC). Bij baseline, post-interventie en één week na de interventie (follow-up) werden veranderingen in vijandige gedachtes, agressieve neigingen, momentane boosheid en hostiliteitstrekken gemeten. Ook werden proefpersonen één week na de interventie blootgesteld aan een provocatie. We verwachtten dat I-CR werkzamer zou zijn in het verminderen van vijandige overtuigingen, agressieve neigingen, momentane boosheid en hostiliteitstrekken, vergeleken met CR en AC. Resultaten lieten zien dat vijandige gedachtes, agressieve neigingen en momentane boosheid sterker verminderden na I-CR en CR vergeleken met AC. I-CR was bovendien duurzaam werkzamer in het verminderen van vijandige gedachtes en agressieve neigingen vergeleken met $A C$ en $C R$. Alle interventies verminderden hostiliteitstrekken over tijd.

Een andere manier om behandelopties voor hostiliteit te bevorderen is door het ontwikkelen en implementeren van nieuwe interventies. Eén interventie die mogelijke effectief zou kunnen zijn in het verminderen van hostiliteit is 'cognitive bias modification for hostile interpretation bias' (CBM-I). Hoofdstuk 6 beschrijft de ontwikkeling van een nieuwe CBM-I interventie en hoe het werd getest in twee experimenten. Het eerste experiment testte de haalbaarheid van CBM-I vergeleken met een actieve controle $(A C)$ conditie in een kleine gemengde steekproef van mannen uit de algemene bevolking en mannelijke patiënten. Het tweede experiment beschreef een gerandomiseerd, gecontroleerd experiment in een grote groep mensen met klinische hostiliteitsniveaus. De hypothese was dat CBM-I in het eerste experiment 
zou leiden tot een sterkere toename van goedaardige bias en een sterkere afname van vijandige bias. In het tweede experiment werd naast een verbetering in interpretatie bias, een sterkere afname in momentane hostiliteit en hostiliteitstrekken verwacht vergeleken met AC. In het tweede experiment werd ook verkend of CBM-I gunstig overdragen effect had op werkalliantie, wanneer participanten psychotherapie ondergingen na het experiment. Resultaten bevestigden dat CBM-I goedaardige bias verhoogde in beide experimenten. Bovendien liet het tweede, grotere experiment zien dat CBM-I leidde tot een grotere daling in vijandige bias en agressief gedrag, maar niet in niet-gedragsmatige aspecten van hostiliteit vergeleken met $A C$. Er werd geen bewijs gevonden voor gunstige overdragende effecten naar psychotherapie na CBM-I in een kleine subgroep. 



\section{CHAPTER 9}

Scientific and Societal Impact 



\section{SCIENTIFIC AND SOCIETAL IMPACT}

The present dissertation aimed to investigate the nature of hostility and how to manipulate it. In a sequence of studies, we examined the validity of hostility, how it can be provoked in laboratory settings, and how increased levels of hostility can be reduced. First, findings revealed that hostility can be structurally divided in cognitive, affective, and behavioral factors. Second, results demonstrated that social exclusion and insult are comparable in terms of impact on hostility, but the personality traits of psychopathy and narcissism differentially impact on this relationship. Third, findings revealed that hostile interpretations and aggressive behavior can efficaciously be reduced with therapist provided imagery-enhanced cognitive restructuring (I-CR) and computerized cognitive bias modification for interpretation bias (CBM-I). The present findings have scientific and clinical impact in several ways. First, the result that hostility can be hierarchically structured may in short term provide hostility scholars with more precisely defined dimensions of hostility. Hopefully, this stimulates efforts to develop and test more standardized and precise assessment options for hostility. In the long term, this finding may contribute to a reduction of conceptual identity confusion that clouds the validity of the hostility construct and provide more precise intervention targets. Second, the finding that social exclusion and insult have equal impact on hostility in the short terms provides first evidence that researchers may interchangeably use social exclusion or insult procedures to experimentally induce hostility. Moreover, the finding that psychopathic and narcissistic traits differentially impact this relation may in the long run provide clinicians with new insights on how to tailor treatment plans for people with clinical levels of hostility. Third, the finding that integrating mental imagery in existing therapist-provided CR enhances its efficacy, in the short term provides scholars and clinicians with a novel procedure that can be used and further tested in scientific and clinical settings. In order to stimulate further efforts of researchers and clinicians in testing and using I-CR, we developed a detailed narrative procedure. This is important, because the technique needs further proof of its' effectiveness in different samples and independent laboratories. For example, the impact of multiple, or the optimal number of I-CR sessions is unclear. Also, it is not clear whether the technique generalizes to novel everyday situations, or what its efficacy is in people with more extreme levels of hostility. Hopefully, in the long run, I-CR offers a new option for patients (and their social relations) that suffer from the profound negative consequences of hostility. Last, the finding that CBM-I efficaciously reduces hostile interpretations and aggressive behavior in the short term provides the clinical field with a new technique that can be implemented at relative low-cost. Compared to the fields of anxiety and mood disorders, the hostility field lags behind in terms of CBM-I research. With the present study we hope to stimulate research efforts to answer more detailed questions concerning the effects of CBM-I. This includes, for example, investigating the optimal 'dose' of CBM-I, or examining the effects of CBM-I when it is offered as an add-on prior to traditional therapist-provided therapy. Taken together, the present findings impact patients, clinicians, and scientists by providing new insights in the nature of hostility, how it can experimentally be provoked and how it can be efficaciously reduced. 



\section{APPENDIX}

Curriculum Vitae 



\section{CURRICULUM VITAE}

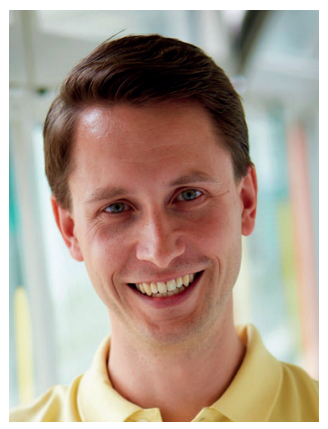

Martijn van Teffelen was born in Nijmegen, the Netherlands, on January $30^{\text {th }}$, 1989. He completed his secondary education at Dominicus College Nijmegen. He started his study psychology at Maastricht University and obtained his bachelor's degree in 2013. In 2015 he completed his research-master's degree in Cognitive and Clinical Neuroscience (psychopathology specialization) with distinction (cum laude). After finishing his master's degree, he started working as a psychologist at Virenze-RIAGG Maastricht, and as a research assistant at Maastricht University. He then received a joint grant from Virenze-RIAGG Maastricht and Maastricht University to start his doctorate research in 2016 under the supervision of dr. Jill Lobbestael, prof. dr. Frenk Peeters, and dr. Marisol at the department of Clinical Psychological Science. This involved a joint clinical research project in which doctorate research was combined with clinical work at Virenze-RIAGG Maastricht, and later MET-GGZ. In 2019 he completed his BKO (Basis Kwalificatie Onderwijs) certificate. As of September 1 ${ }^{\text {st. }} 2020$ Martijn, continues his work as a healthcare (GZ) psychologist in training at MET-GGZ. 



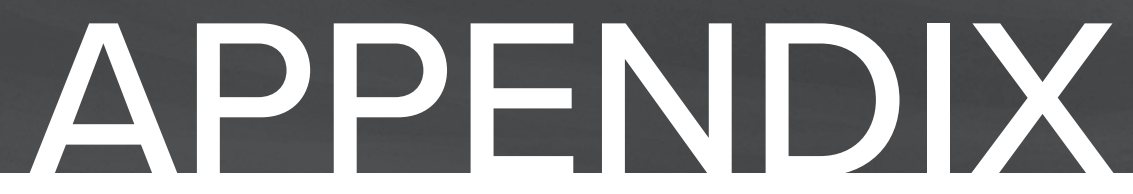

List of Publications and Presentations 



\section{PUBLICATIONS}

Van Teffelen, M.W., Peeters, F., Voncken, M., Lobbestael, J. (under revision). Interpretation Bias Modification Reduces Hostile Bias and Aggression: A Randomized Clinical Trial.

Van Teffelen, M.W., Voncken, M., Peeters, F., Mollema, E., \& Lobbestael, J. (Under Revision). The efficacy of incorporating mental imagery in cognitive restructuring techniques on reducing hostility: A randomized controlled trial.

Van Teffelen, M.W., Voncken, M., Peeters, F., Mollema, E., \& Lobbestael, J. (in press). Imageryenhanced cognitive restructuring of hostile beliefs: A narrative description, Cognitive and Behavioral Practice.

Geschwind, N., Van Teffelen, M.W., Hammarberg, E., Arntz, A., Huibers, M.J.H., \& Renner, F. (Submitted). Impact of measurement frequency on self-reported depressive symptoms: An experimental study in a clinical setting. PsyArXiv. https://doi.org/10.31234/osf.io/9v38z

Van Teffelen, M.W., Lobbestael, J., Voncken, M., \& Peeters, F. (2020). Uncovering the hierarchical structure of self-reported hostility. PLOS ONE, 15(9), e0239631. https://doi. org/10.1371/journal.pone.0239631

Van Teffelen, M.W., Vancleef, L., \& Lobbestael, J. (2020). Provoked aggression, psychopathy and narcissism: Comparing the impact of social exclusion and insult. Psychology of Violence. https://doi.org/10.1037/vio0000340

Lobbestael, J., Van Teffelen, M.W., Baumeister, R. (2019). Psychopathy subfactors distinctively predispose to dispositional and behavioral sadistic pleasure. Journal of Behavior Therapy and Experimental Psychiatry, 67. https://doi.org/10.1016/j.jbtep.2019.02.003

Lobbestael, J., \& Van Teffelen, M.W. (2015). Persoonlijkheidsstoornissen. In H. van der Molen, E. Simon, \& J. van Lankveld (Eds.), Klinische psychologie: theorieën en psychopathologie. Groningen: Wolters-Noordhoff.

Van Teffelen, M.W. (2013). Fear to get near: personal space in individuals with psychopathic traits. Maastricht Student Journal of Psychology and Neuroscience, 2, 70-83. 


\section{PRESENTATIONS}

Broadcast L1 News. Maastricht, 2019. "Kort lontje".

Broadcast RTV Maastricht. Maastricht, 2019. "UM conducting research on short tempers".

VGCt najaarscongres. Veldhoven, 2019. "Treat the treatment: cognitieve herstructurering van vijandige gedachtes met imagery”. Oral presentation.

MET ggz kennisdelingsdag. Roermond, 2019. Cognitive bias modification for hostile interpretation: A pilot study in personality disorder patients and non-patients. Oral presentation.

Congres European Association for Behavioral and Cognitive Therapy. Sofia, 2018. Cognitive bias modification for hostile interpretation: A pilot study in personality disorder patients and non patients. Poster presentation.

Congres International Society of Research on Aggression. Parijs, 2018. Provoked aggression in the lab: Do psychopathic and narcissistic traits play a differential role? Poster presentation.

FPN Research dag. Gronsveld, 2018. Provoked aggression in the lab: Do psychopathic and narcissistic traits play a differential role? Poster presentation.

Lunchreferaat PsyQ/Mondriaan. Maastricht, 2017. Verminderen van woede met e-health. Oral presentation.

Medewerkersnascholing Sensoor. Heerlen, 2017. Emotie en hulpverlening: Een GGZ perspectief. Oral presentation.

VGCt najaarscongres. Veldhoven, 2016. Verminderen van woede met e-health. Oral presentation.

Broadcast L1 avondgasten. Maastricht, 2016. “Meppen in het bos”. TV-debate.

Research master graduation symposium. Maastricht, 2015. The impact of narcissistic and psychopathic traits on aggression after social exclusion or insult. Poster presentation.

Psychology Student Conference. Maastricht, 2013. Fear to get near: personal space in individuals with psychopathic traits. Poster presentation. 




\section{APPENDIX}

Dankwoord 



\section{DANKWOORD}

Sociologen Latour \& Woolgar concludeerden in 1979 dat wetenschappelijke feiten niet 'hard', maar eerder het resultaat zijn van de sociale interactie tussen wetenschappers. Wetenschap is niet mogelijk zonder intermenselijke relaties. Zo ook heeft dit proefschrift niet tot stand kunnen komen zonder de bijdrage van velen: wetenschap verbindt! In tijden van een wereldwijde COVID-19 pandemie is dit voelbaarder dan ooit. Een aantal mensen in het bijzonder verdienen dan ook een woord van dank.

Allereerst is wetenschap is niet mogelijk zonder proefpersonen en patiënten, die hun 'nek uitsteken' en het wagen deel te nemen aan wetenschappelijke studies, zoals die in dit proefschrift. Zeker voor patiënten is dit absoluut geen sinecure.

Jill, Frenk en Marisol: Woedegroep; Trident ensemble; Nathan-DeWall-Fanclub; mijn promotieteam. Wij vonden elkaar in dit promotietraject in onze gezamenlijke bruggenbouwers mentaliteit: een passie voor het overbruggen van de kloof tussen wetenschap en klinische praktijk. Jullie diversiteit aan kennis binnen persoonlijkheids-, stemmings- en angststoornissen gaven de transdiagnostische aard van dit proefschrift echt body. Ik ga onze etentjes missen.

Jill, wij leerden elkaar 10 jaar geleden kennen na een college dat je gaf over persoonlijkheidsstoornissen. Wat ben ik blij dat jij sinds die tijd mijn mentor bent! Je bent kritisch, niet alleen op anderen, maar ook op jezelf. Dát maakt je echt goed in wat je doet. Ik heb enorm veel bewondering voor de scherpte waarmee jij in je vak staat. Je weet als geen ander het overzicht te houden en structuur te scheppen in chaos. De drive waarmee je dat doet is aanstekelijk! Wat veel mensen niet weten is dat je overigens ook een indrukwekkende performance weet neer te zetten samen met Nicole: 'Gemist' van De Jeugd van Tegenwoordig, zoals tijdens het schrijfweekend in Holset. Dit én het agressie congres in Parijs (inclusief oesters eten in het Quatier Latin) zijn voor mij absoluut twee hoogtepunten in de afgelopen 10 jaar!

Frenk, wat ben ik blij dat jij ben aangesloten bij mijn promotieteam. Je aarzelde eerst wat, want "wat wist jij nou van hostiliteit?". Maar, je indrukwekkende ervaring als psychiater, én in het uitvoeren van klinisch wetenschappelijk onderzoek bleken van onschatbare waarde. Ik heb enorme bewondering voor je vermogen uit te zoomen, de zin van de onzin te scheiden en pragmatische beslissingen te nemen, om over je gitaarcollectie nog maar te zwijgen. Mijn eerste kennismaking met jou was tijdens een van je colleges over stemmingsstoornissen in de research master: languit-liggend op een tafel, aan het eind van de dag in één van de collegezalen op het Debyeplein: “...en wat doen mannen als 
ze depressief zijn? Juist ja, drinken." Ook het sparren over één van de toen toekomstige studies (jij al rokend) in de parkeergarage van (toen nog) RIAGG Maastricht zal ik niet snel vergeten. Eén belangrijke les zal ik nooit vergeten: "delen = vermenigvuldigen".

Marisol, ook jij bent een onmisbaar lid geweest van 'de woedegroep'. Ik weet dat je meer bij onze meetings aanwezig had willen zijn dan dat je gezondheid toe stond. Weet dat je er wat mij betreft er altijd was op de momenten die er voor mij toe deden. Ik kan met recht zeggen dat zonder jouw bijdrage de kwaliteit van dit proefschrift niet het huidige niveau had gehaald. Vooral jouw vermogen om de wereld door de ogen van patiënten te kunnen bekijken, en daarin aan te voelen wat qua interventies werkt en wat niet is echt van onschatbare waarde.

Beste leden van de beoordelingscommissie, prof. dr. Muris, prof. dr. Rijkeboer, prof. dr. Otgaar, prof. dr. Bushman, en dr. Salemink, bedankt voor het lezen van het manuscript en voor alle tijd die u in de beoordeling van dit proefschrift gestoken heeft. Dear prof. dr. Bushman, thank you for reviewing this manuscript and for participating in the evaluation committee of this dissertation. Ik waardeer uw komst naar mijn verdediging om te opponeren. Ook de overige leden van de corona wil ik hier voor bedanken.

Eline, wat heb ik een geluk gehad dat jij me in 2010 hebt aangenomen voor de basispsycholoog/ promovendus functie bij Virenze-RIAGG Maastricht en Universiteit Maastricht. Wij wisten op dat moment nog niet dat jij een onmisbare rol zou gaan spelen binnen dit proefschrift! Ook heb ik het geluk gehad om klinische vlieguren te mogen maken met jou als regiebehandelaar. Wat is jouw klinische ervaring indrukwekkend! Ik ben blij dat die 'blik' heeft meegedacht en geschreven aan het 'imagery-CR' project! Jesse, we were lucky to have you on board for our CBM-I trial! Your experience was of great value in launching our two studies. I want to thank you for your quick guidance and feedback. Even hurricanes, pandemics and cyber-attacks could not keep us from bringing this project to a great success! Linda, ook jij enorm bedankt voor je begeleiding bij de provocatie studie. Het volgen van een masterstage bij jou was super leerzaam. Nicole en Fritz, bedankt dat ik na het afronden van mijn master betrokken mocht blijven bij de 'wachtlijst BDl'-studie.

Mijn dank is groot aan de organisaties die mij de kans hebben gegeven mijn onderzoeken uit te voeren: METggz, U-Center, Mondriaan zorggroep, en Academisering. In het speciaal wil ik Frans Kochen en Hannie van Genderen bedanken voor het tot stand komen van mijn positie.

Mijn baan zou een stuk lastiger zijn geweest als ik niet de hulp had gehad van een aantal topmensen! Allereerst, de OZA's! Nina, zonder jou was de administratie van de CT+ studie een puinhoop geworden! Brigit, dank voor je geduld in het screenen van mensen met een kort lontje, het verbaast me dat je er zelf geen kort lontje van hebt gekregen. Astrid, 
je vloog later in bij de CBM-I studie. Zonder jou was de plotselinge media-aandacht die deze studie te 'verduren' kreeg in stilte gestorven. En dan Lisette, het fundament van de CBM-I studie! Wat ben ik blij dat jij er bent geweest om de inclusie van zo'n 100 mensen met een kort lontje in goede banen te leiden. Soms bleek al een eerste telefoontje genoeg om iemand te laten 'ontploffen'. Maar gelukkig, jouw stevigheid, standvastigheid en betrouwbaarheid is iets waar ik op heb kunnen terugvallen. En dan, alle studenten die hebben geholpen bij het verzamelen van data: Lisanne, Renée, ex-RIAGG gangster en warme collega Dieuwertje, Marjolijn, Pauline, Rien en Lissa. Het zoeken en screenen van proefpersonen, provoceren van narcistische en psychopathische mannen, afnemen van interviews, uitvoeren van interventies en beluisteren van opgenomen therapiesessies is een hels karwei dat jullie geweldig hebben uitgevoerd! Anne, ook al hebben we elkaar nooit in persoon ontmoet, jij was de rots in de branding bij $U$-Center! Eric en Tom, zonder jullie technische ondersteuning en eeuwige geduld in het aanleveren van data was de dataverzameling binnen U-Center niet gelukt. Ronald, ook jij enorm bedankt voor het screenen van en 'achterna' zitten van patiënten bij Radix. Het motiveren van forensische patiënten is absoluut geen lachertje! Ingrid, Ira, Ina, Rosy, Kitty, Roger en Miriam, bedankt voor jullie organisatorische kracht in het draaiende krijgen en houden van mijn project bij U-Center, METggz en Mondriaan. Lindy, Caroline, Marionne, Paula, Daniëlle en Jessie, bedankt voor de gezellige praatjes, en al die keren dat ik op jullie terug kon vallen met één of ander formuliertje dat ik weer eens niet goed begreep of niet goed heb ingevuld. Jullie zijn onmisbaar.

En dan mijn kamergenoten. Wat ben ik blij dat jullie er waren! Suzanne, Linda, Franca, Ramon, Rachelle, Sanne, Leo en Yu. Bedankt voor alle gezelligheid; jullie zorgden voor een goede balans! Muffin-o-clock was hét moment van de dag om naar toe te leven. Leo, half-Italian, half-German, half Dutch! Thanks for being our Sicilian tour-guide and for sharing your nonna's family recipes. Truly, the lasagna is something out of this world. I already miss our food discussions.

CPS-collega's, bedankt voor alle waardevolle discussies de afgelopen jaren. Het was een voorrecht te mogen samenwerken met jullie 'great minds'. Lorraine, Ramon, Linda, Pim, Marjolijn, Thomas, bedankt voor de gezellig lunches! Conny en Maartje, collega's van de Heuvelland-fietsclub, onze fietstochtjes waren én zijn voor mij dé manier om op te laden of stoom af te blazen van het werk. Hopelijk kunnen we dit nog lang voortzetten! Lotte en Ghislaine, jullie morele en spirituele steun vanuit het astrologisch lijntje voegde een bijzondere dimensie toe aan mijn PhD-tijd. Lotte, ook bedankt voor de gezellige en steunende koffiewandelingen! Nicole, Maarten, Marleen, Jill en Dalena, leden van de 'Imagery focusgroep', dank voor de interessante discussies over 'ons' onderwerp! 
Collega's van METggz Zuid, zonder jullie was een belangrijk deel van dit proefschrift niet mogelijk geweest. Niet alleen de huidige enthousiaste club collega's van teams stemming, angst, psychotrauma, persoonlijkheid en TPO, maar ook de collega's die in de afgelopen jaren zijn vertrokken. Wat een hobbelige rit was het de afgelopen 5 jaar. Een fusie, faillissement, cyber-aanval op de universiteit en een overname - ik kan oprecht zeggen dat ik blij ben dat we weer Wc-papier hebben. In het bijzonder wil ik stafvoorzitters Maya, Ellen, Linda en Ramona bedanken. Jullie hebben ervoor gezorgd dat 'het agressie onderzoek' bij iedereen onder de aandacht bleef gedurende de anderhalve jaar. Wisten jullie dat we met zijn allen de 'thermometer' hebben gevuld door tijdens de MDO's in totaal 245 formuliertjes in te vullen? Omdat mijn klinisch werk onderdeel was van mijn promotietraject wil ik ook graag mijn werkbegeleiders Andrea, Elisa, Patrick, Linda, Pauline en supervisors Peter en Cees bedanken voor jullie wijsheid, aanmoediging en stevigheid om op te mogen 'leunen' de afgelopen jaren. Tamara, bedankt voor het bieden van de kans om in opleiding te komen. Mede-GZ-opleidingen, ondanks alle beperkingen van het online onderwijs ben ik blij dat ik bij jullie in de groep ben gekomen. Hopelijk kunnen we elkaar snel weer face-to-face zien! Iris, sinds het begin van dit traject en nog ver daarvoor ben je al mijn buddy. Bedankt dat ik altijd ad-hoc met stoom-uit-de-oren bij je terecht kan! En natuurlijk Clint, volgens mij ben jij de enige van METggz Zuid die de afgelopen jaren de fysieke klappen heeft opgevangen van onze cliënten met een kort lontje - dit geldt in ieder geval voor al mijn cliënten.

Lieve paranimfen Sanne en Anke. Bedankt voor alle momenten dat jullie me gesteund hebben de afgelopen jaren. Sanne, je bent echt een duizendpoot die altijd wel ergens tijd weet te vinden voor een praatje. Anke, de rust die je weet uit te stralen is bewonderenswaardig. Jullie deur stond altijd open voor een praatje, om even stoom af te blazen, om te klagen over wat dan ook. Jullie zijn echt TOP collega's! Fijn om te weten dat jullie tijdens mijn verdediging naast me zullen staan!

Lieve vrienden, we hebben elkaar in het afgelopen jaar door alle maatregelen vaker moeten missen. Reinier en Sanne, Sjoerd en Romy, en Bas en Pien, wat mis ik in deze tijd onze gezamenlijke avondjes 'tafelen'. Reinier, Sjoerd en Bas: manolo's. Al minstens 18 jaar onbezonnenheid, gebral, goede gesprekken, bankjes op de dijk, billige boshits, avontuur, toeren, toepen, kortom: vriendschap. Jullie zijn een grote steun voor me geweest in tijden waarin ik de drive heb ontwikkeld om te doen wat ik nu doe. Monica, Michel, Gonny en Patrick, ik mis onze hikes - hopelijk kunnen we snel weer in het buitenland een mooie tocht maken, wie weet met tent? Krista, Nard, Constant en Marre, bedankt voor de gezellige wine-dines, en gezellige middagen met de kids. Onze weekendjes weg zijn voor herhaling vatbaar! Nard en Constant, nu ik wat meer tijd heb stel ik voor dat we een eerste optreden met '0-kwel \& the Haldolnians' gaan plannen. Birte, Marius, Sarah en Tom, ik geniet altijd van onze spelletjesavonden. Marius, das braucht noch eine Flasche Molly Dooker. Lidka en Paul, 
bedankt voor alle gezellige middagjes/avondjes in Delft, Maastricht en Eys. Paul, de volgende keer meten we onze kracht op de Eyserbosweg? Rob, Roos, Leo en Eleana, ik vergeet nooit onze eerste ontmoeting in ons Eindhovens studentenhuis 'de lamme tak' - Rob gooiend met medische termen en Eleana hierop reagerend met de snelheid van het licht. Dit vind ik nog altijd onveranderd gezellig!

Lieve familie. Zonder jullie support had ik dit proefschrift misschien wel nooit afgerond. Pa, Frouk, ma en Fred, dank dat jullie er voor me zijn. Pa en ma, jullie hebben me gevormd. Door jullie heb ik de kans gehad me te ontwikkelen in wat ik het liefst doe: mensen helpen. Pa, van jou heb ik geleerd me in dingen vast te bijten en door te zetten als het tegenzit: een mens lijdt het meest aan het lijden dat hij vreest. Ma, ik bewonder je vermogen om in het moment te leven en te genieten van de kleine dingen. Casper, kleine grote broer, we hebben al veel mee gemaakt samen. Wat ben ik geschrokken toen je "de auto tegen een boom parkeerde". Wat een geluk hebben we dat je weer helemaal de oude bent. Je bent slim en grappig, ik kijk naar je op en ben blij dat je de peetoom van Noor bent; ik put veel kracht uit onze gesprekken. Nanette, voel je welkom in onze familie - het doet me goed je samen met Noor te zien. Vic en Tinny, wat een geluk om jullie om me heen te hebben. Niets is jullie te veel gevraagd; jullie staan altijd voor ons klaar, soms ook ten koste van jullie zelf. Jullie steun is voor mij van onschatbare waarde. Lieve ooms, tantes, neven en nichten - ja ook de Limburgse tak! Ik ben blij met zoveel lieve mensen om ons heen, bedankt dat jullie er zijn.

Janneke en Noor, waar was ik zonder jullie steun en liefde? Jullie waren er op de momenten dat ik dit agressie-proefschrift het liefst het raam uit wilde smijten. Janneke, lieve vrouw, je houdt me scherp en vult (de afwezigheid van) mijn organisatorische talent aan. Onze wandelingen, gesprekken, en andere kleine geluksmomentjes geven me veel kracht en warmte. Ik kijk nu al uit naar ons leven na dit proefschrift. Noor, mijn lieve, kleine meisje. Naast jou lopen met je hand om mijn vinger en jou zien groeien zet de betekenis van dit proefschrift in perspectief. 
